Portland State University

PDXScholar

\title{
A Market Diffusion Potential (MDP) Assessment Model for Residential Energy Efficient (EE) Technologies in the U.S.
}

Momtaj Khanam

Portland State University

Follow this and additional works at: https://pdxscholar.library.pdx.edu/open_access_etds

Part of the Engineering Commons, and the Technology and Innovation Commons Let us know how access to this document benefits you.

\section{Recommended Citation}

Khanam, Momtaj, "A Market Diffusion Potential (MDP) Assessment Model for Residential Energy Efficient (EE) Technologies in the U.S." (2020). Dissertations and Theses. Paper 5512.

https://doi.org/10.15760/etd.7386

This Dissertation is brought to you for free and open access. It has been accepted for inclusion in Dissertations and Theses by an authorized administrator of PDXScholar. Please contact us if we can make this document more accessible: pdxscholar@pdx.edu. 
A Market Diffusion Potential (MDP) Assessment Model for Residential

Energy Efficient (EE) Technologies in the U.S.

by

Momtaj Khanam

A dissertation submitted in partial fulfillment of the requirements for the degree of

\author{
Doctor of Philosophy \\ in \\ Technology Management
}

Dissertation Committee:

Tugrul U. Daim, Chair

Leong Chan

Judith Estep

Robert Fountain

Portland State University

2020 


\section{Abstract}

The Diffusion of Residential Energy Efficient (EE) Technologies has been studied for many years. Finding ways to bridge the energy efficiency gap and increase the diffusion of these technologies have been of much interest to researchers and practitioners alike. However, in most studies, diffusion is equated to adoption of EE technologies by consumers. The present study tries to break this mindset and develops a model to assess the diffusion of residential EE technologies from the market's perspective. The model assesses diffusion of an EE technology based on the market's ability to provide benefits to customers that are identified to be most important. A Hierarchical Decision Model (HDM) has been developed with market attributes as the criteria, and sub criteria being the key components or product/service values that help to develop market attributes. The model has been validated by experts from different parts of the country with a background in clean energy, sustainability, energy conservation and energy efficiency. The relative weights of market attributes and key components are derived from experts' judgment quantification. The Economic Market attribute is found to be the most important aspect for increasing diffusion of residential EE technologies followed by Consumers' Benefit and Legal \& Institutional Market attributes. Codes and Standards are identified as the most significant key component that contributes to the development of Legal and Institutional Market attribute. The model is applied to compare the Market Diffusion Potential (MDP) of three competitive water heating technology cases with diverse fuel source, namely, Ductless Heat Pump (DHP) Water Heater, Solar Water Heater (SWH) and Tankless Gas Water 
Heater (TGWH). DHP shows the highest MDP followed by SWH and TGWH. Low rating key elements in the model for each of the technology cases are recognized and ways to improve the rating by probable interventions has been identified for better MDP. With appropriate measures it is possible to improve the MDP of DHP by $9 \%$ while that of SWH and TGWH can be improved by $20 \%$ and $11 \%$ respectively. A scenario analysis provides an analysis of the effect of hypothetical market approach that helps to elicit nonconsequential market approach, focus on specific market approach to increase MDP of a candidate technology as well as formulate appropriate actions to improve MDP of EE technologies.

The research contributes in several ways to the existing knowledge bank of residential EE technology diffusion. It provides an elaborate literature review on market attributes with associated components that help to develop the market attributes. The model allows to identify low rating attributes and helps to improve MDP by taking appropriate actions. Also, scenario analysis provides a snapshot of hypothetical situations that help decision makers to realize what to expect in case of extreme market situations and improve MDP of residential EE technologies by selecting appropriate business inclination strategy for excelling. The model can have several practical applications. The results of MDP assessment would aid in market transformation, utility program selection, as well as feed in information for $\mathrm{R} \& \mathrm{D}$ on prospective $\mathrm{EE}$ technologies and a wide array of other organizations with diversified interests in energy savings, climate change and sustainability. 


\section{Dedication}

To my mother and children - my two lifelines 


\section{Acknowledgements}

He who "Teacheth man that which he knew not".

It has been an amazing academic journey and my report will be incomplete without recognizing the people who have helped me in different capacities in this ride.

My heart is filled with lavish gratitude for my academic supervisor, and Ph.D. dissertation committee chairman, Dr. Tugrul U. Daim, who is an internationally acclaimed professor of technology management. I am deeply indebted for his support, guidance, sage advice, and empathy which have been extraordinary and instrumental in completing my Ph.D. program at ETM. I feel truly blessed to have him as my professor, mentor and advisor.

I am also extremely grateful to my committee members, Dr. Judith Estep, Dr. Leong Chan, and Dr. Robert Fountain for their invaluable feedbacks and suggestions throughout the research process. They spent precious time to edit, and correct my report, provide helpful advice and guide me forward.

The research would not have been possible without all-out participation and contribution from experts at BPA, ETO, NEEA, NWPCC, Vertue Lab and about more than twenty other private and public organizations in different parts of the U.S. I would like to thank profusely all these remarkable experts who were involved in different phases of the research and shared their knowledge and thoughts.

I would also like to extend my heartfelt thanks to all the amazing colleagues at ETM, Dr. Edwin Garces, Dr. Rafaa Khalifa, Dr. Joao Lavoie, Dr. Husam Barham, Chih- Jen Yu, Amir Shaygan, Pei Zhang, and many others. Getting to know these intellectually bright 
people, learning from their experience and knowledge and feeling the warmth of their friendship have been an exhilarating experience.

Finally, there are other people whose names might have been left out in this note but I would like to take this opportunity to extend my profound appreciation and thanks to all those individuals who have encouraged me, stood by me during rain and sunshine, touched my heart through their kindness, and prayed for me. 


\section{TABLE OF CONTENTS}

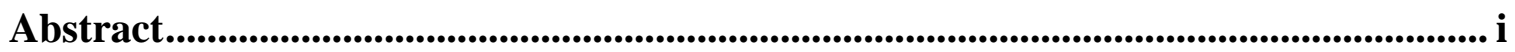

Dedication ....................................................................................................................................ii

Acknowledgements .......................................................................................................... iv

LIST OF TABLES ....................................................................................................

LIST OF FIGURES ...........................................................................................

LIST OF ABBREVIATIONS .................................................................................................. $\mathrm{xv}$

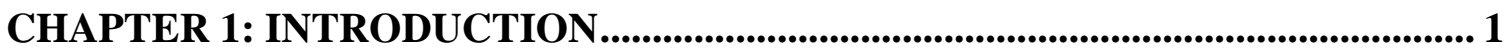

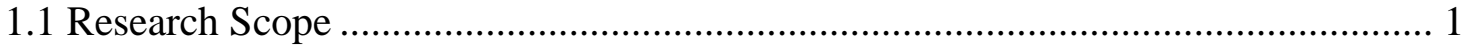

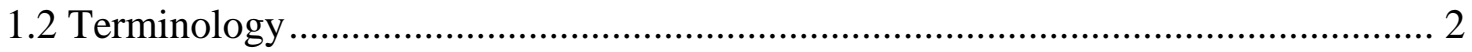

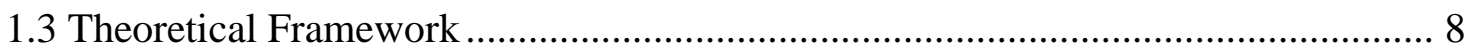

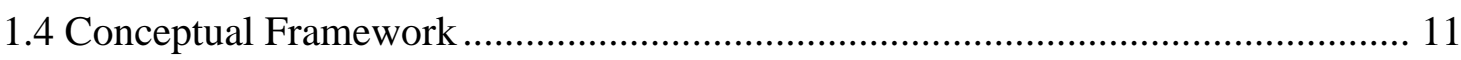

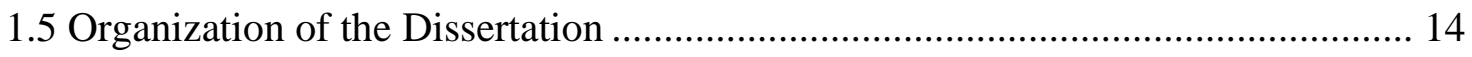

CHAPTER 2: RESEARCH MOTIVATION AND RESEARCH PROBLEMS ....... 16

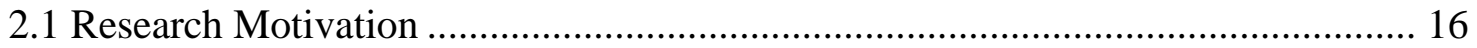

2.1.1 Energy Efficient Technology is Unique ....................................................... 16

2.1.2 Overarching Impact of EE Technology ........................................................... 19

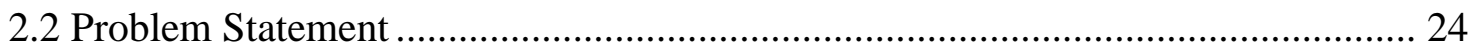

2.2.1 Gap Between Predicted and Actual Potential of EE Technologies .................. 25

2.2.2 Lack of Appropriate 'Measures' for Improving Diffusion................................. 26

2.2.3 Contrasting Factors Impact Diffusion ........................................................... 27

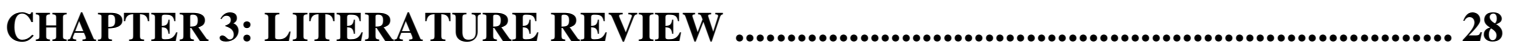

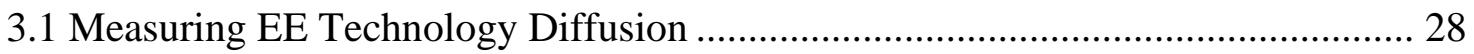

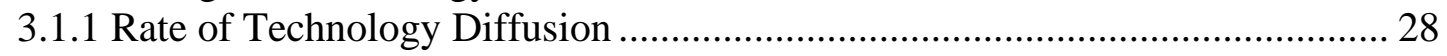

3.1.2 Models for Measuring Diffusion ................................................................ 30

3.2 Actions to Increase EE Technology Diffusion........................................................... 31

3.2.1 Remove Barriers and Reinforce Drivers ........................................................ 31

3.2.2 Energy Efficiency Activities ..................................................................... 35

3.3 Determinants of Residential EE Technology Diffusion......................................... 40

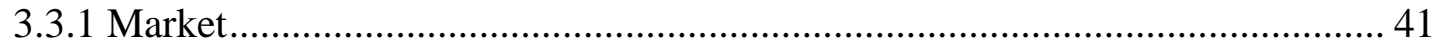

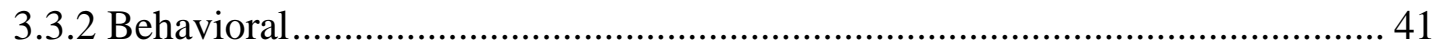

3.3.3 Knowledge and Learning.......................................................................... 42 
3.3.3 Knowledge and Learning............................................................................ 43

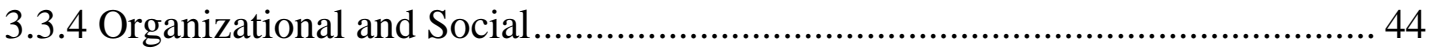

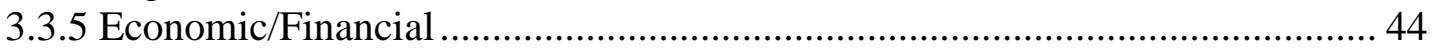

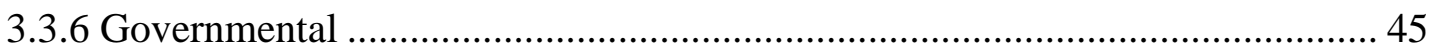

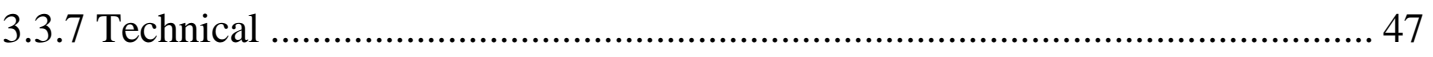

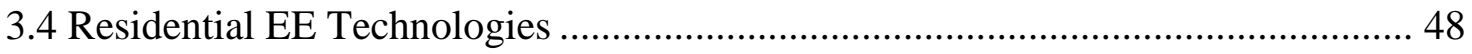

3.5 Cases of Energy Efficient (EE) Technology Diffusion in Different States ............ 55

CHAPTER 4: RESEARCH OBJECTIVES, QUESTIONS, AND METHODOLOGY

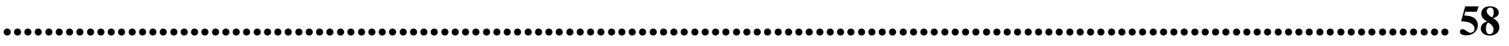

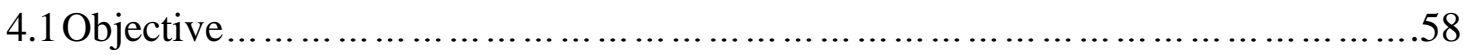

4.2 Review of Multicriteria Decision Models (MCDM)............................................. 59

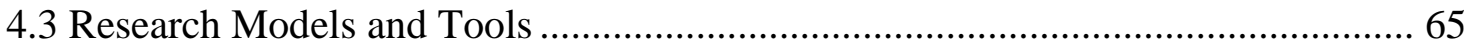

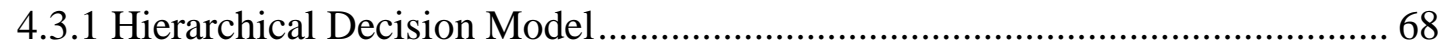

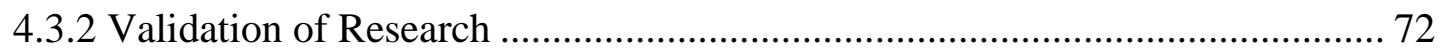

4.3.3 Reliability of Research .......................................................................... 74

4.3.4 Bias in Research ..................................................................................... 75

4.3.5 Inconsistency and Disagreement of Expert Judgment.................................... 75

4.3.5.1 Inconsistency in Expert Judgment ........................................................ 75

4.3.5.2 Disagreement in Expert Judgment ......................................................... 78

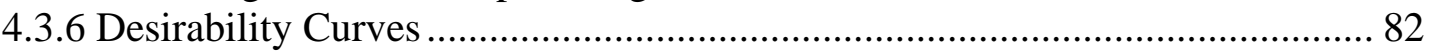

4.3.7 Evaluating Market Diffusion Potential (MDP) ............................................... 84

CHAPTER 5: DEVELOPMENT OF RESEARCH MODEL ........................................ 85

5.1 Expert Panel Formulation................................................................................... 85

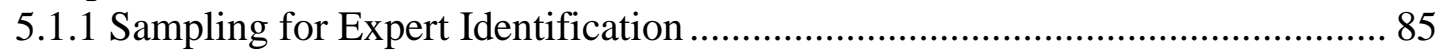

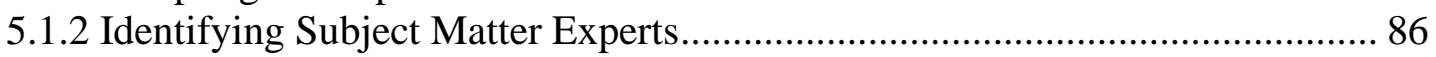

5.1.3 Bibliometrics and Social Networking Analysis................................................ 87

5.1.4 Steps and Issues in Expert Panel Formation.................................................... 89

5.2 Construction of Hierarchical Decision Model (HDM) ……………………........... 93

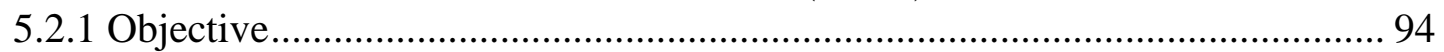

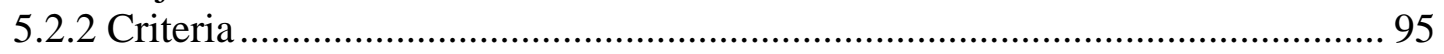

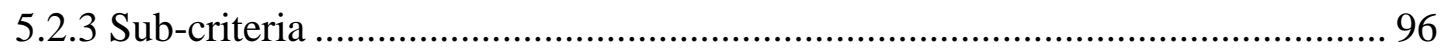

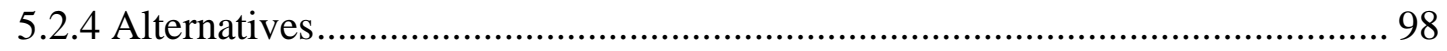

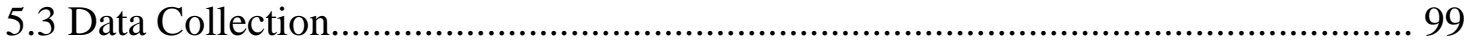

5.3.1 Steps in Panel Formation .......................................................................... 99

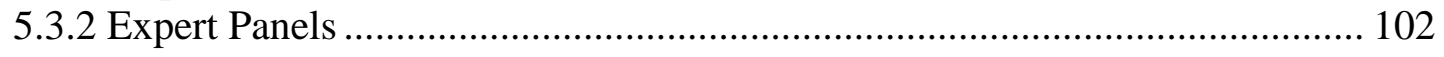

CHAPTER 6: RESULTS OF MODEL VALIDATION AND QUANTIFICATION 105

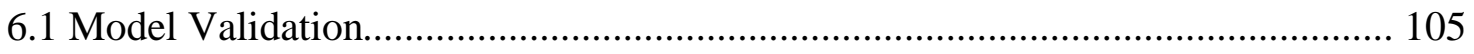


6.1.1 Criteria: Validation of Market Attributes .......................................................... 105

6.1.2 Sub criteria: Validation of Key Components of Market Attributes................. 106 6.1.2.1 Validation of Key Components in Consumers' Benefit Market Attribute..............................................................106

6.1.2.2 Validation of Key Components in Technological Market Attribute ...... 107 6.1.2.3 Validation of Key Components in Economic Market Attribute ............. 108 6.1.2.4 Validation of Key Components in Delivery and Infrastructure Market Attribute 109

6.1.2.5 Validation of Key Components in Legal and Institutional Market Attribute................................................................ 110

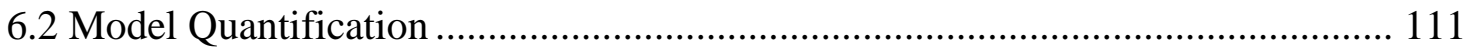

6.2.1 Pairwise Comparison of Market Attributes ...................................................... 111

6.2.2 Pairwise Comparison of Key Components of Market Attributes .................... 112

6.2.2.1 Pairwise Comparison of Key Components in Consumers' Benefit Market Attribute 112

6.2.2.2 Pairwise Comparison of Key Components in Technological Market

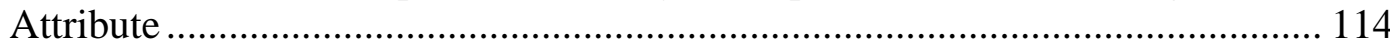

6.2.2.3 Pairwise Comparison of Key Components in Economic Market Attribute............................................................ 115

6.2.2.4 Pairwise Comparison of Key Components in Delivery and Infrastructure Market Attribute. 116 6.2.2.5 Pairwise Comparison of Key Components in Legal and Institutional Market Attribute 118

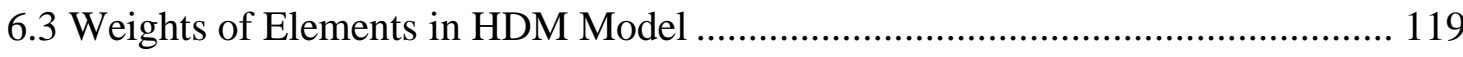

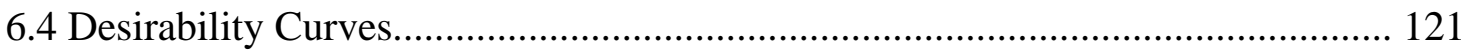

6.4.1 Desirability Curves for Key Components of Consumers' Benefit Market

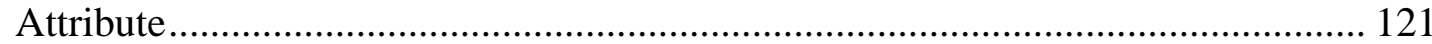

6.4.1.1 Desirability Curve for Comfort.......................................................... 121

6.4.1.2 Desirability Curve for Safety ................................................................. 123

6.4.1.3 Desirability Curve for Non-energy Benefits (NEBs)............................... 124

6.4.1.4 Desirability Curve for Awareness .......................................................... 125

6.4.2 Desirability Curves for Key Components of Technological Market Attribute

6.4.2.1 Desirability Curve for Energy Saving Potential (ESP)........................... 126

6.4.2.2 Desirability Curve for Ease of Installation ............................................. 127

6.4.2.3 Desirability Curve for Ease of Use ......................................................... 128

6.4.2.4 Desirability Curve for Compatibility ...................................................... 130

6.4.3 Desirability Curves for Key Components of Economic Market Attribute..... 131

6.4.3.1 Desirability Curve for Profitability Index (PI)....................................... 131

6.4.3.2 Desirability Curve for Levelized Cost of Electricity (LCOE) .................. 132

6.4.3.3 Desirability Curve for Payback Period .................................................... 133

6.4.3.4 Desirability Curve for Substitutes.......................................................... 134 
6.4.4 Desirability Curves for Key Components of Delivery and Infrastructure Market

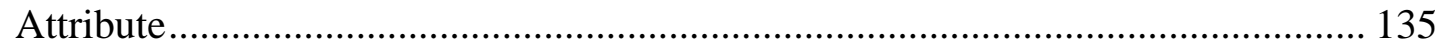

6.4.4.1 Desirability Curve for Competition .................................................... 135

6.4.4.3 Desirability Curve for Trade Allies ...................................................... 136

6.4.4.3 Desirability Curve for Accessibility ....................................................... 138

6.4.4.4 Desirability Curve for Supply Chain ....................................................... 139

6.4.5 Desirability Curves for Key Components of Legal and Institutional Market

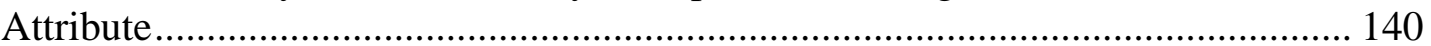

6.4.5.1 Desirability Curve for Standards and Codes.......................................... 140

6.4.5.2 Desirability Curve for Energy Price ..................................................... 141

6.4.5.3 Desirability Curve for Incentives.......................................................... 142

6.4.5.4 Desirability Curve for Labelling .......................................................... 143

CHAPTER 7: MARKET DIFFUSION POTENTIAL OF TECHNOLOGY CASES

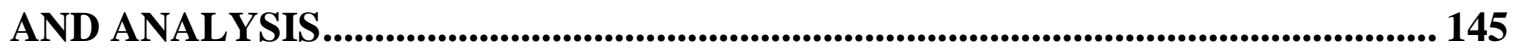

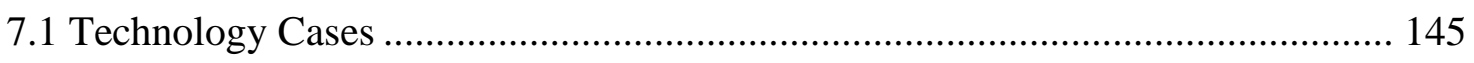

7.2 Application of the MDP Assessment Model to Technology Cases ....................... 147

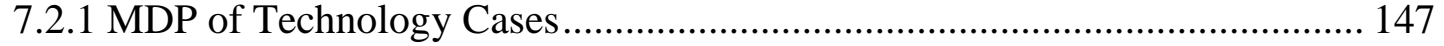

7.2.2 Improving MDP of Technology Cases........................................................ 149

7.2.2.1 Improving MDP of Ductless Heat Pump (DHP) Water Heater ................ 150

7.2.2.2 Improving MDP of Solar Water Heater with Electricity Backup............. 152

7.2.2.3 Improving MDP of Tankless Gas Water Heater (TGWH) ...................... 154

7.2.3 Scenario Analysis ..................................................................................... 158

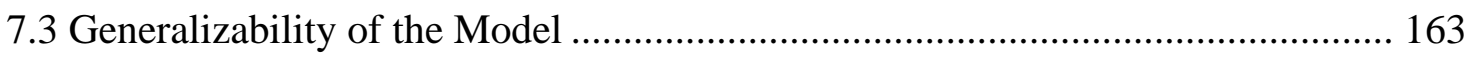

CHAPTER 8: CONCUSION AND CONTRIBUTION.............................................. 165

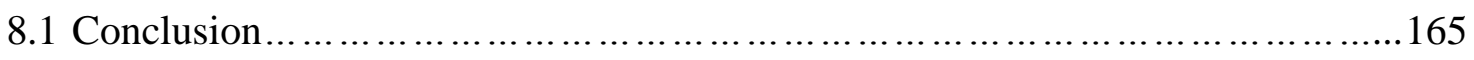

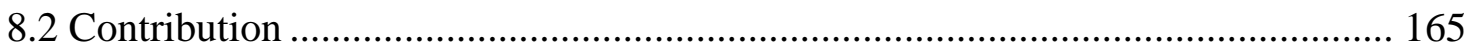

8.2.1 Theoretical Contribution............................................................................ 166

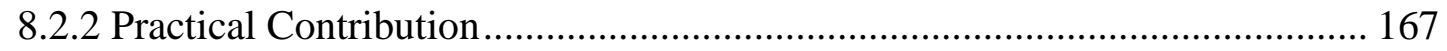

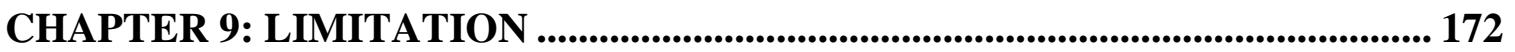

CHAPTER 10: FUTURE RESEARCH......................................................................... 175

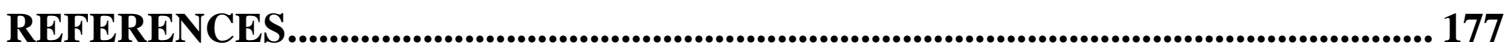

APPENDIX........................................................................................................................ 196

APPENDIX A: Electricity Consumption by End-Use Sector (Quadrillion Btu) ....... 196

APPENDIX B: The Proportion of All Electric Homes is Rising in the U.S.............. 197

APPENDIX C: State Scores in the 2019 State Scorecard........................................... 198 
APPENDIX D: Number of Experts in Expert Panels from different Ph.D

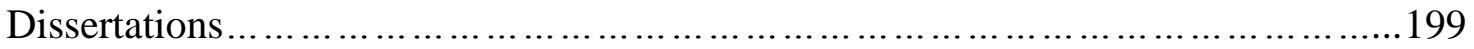

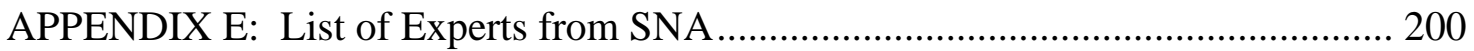

APPENDIX F: HDM Generated by Software .................................................... 202

APPENDIX G: Technical Energy Saving Potential............................................ 203

APPENDIX H: ProfitabilityIndex (PI) of EE projects ....................................... 204

APPENDIX I: Levelized Cost of Electricity Resources ...................................... 205

APPENDIX J: Payback Period of EE Technologies............................................... 206 


\section{LIST OF TABLES}

Table 1: Stakeholders Activity, Objective and Instrument .......................................................... 40

Table 2: Energy Efficient HVAC Cost and Performance ..........................................................52

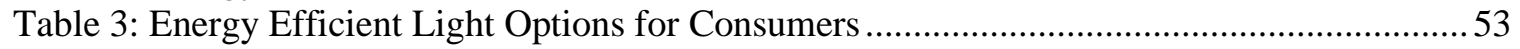

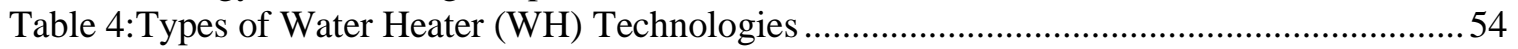

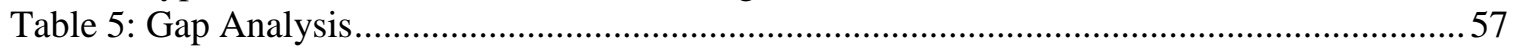

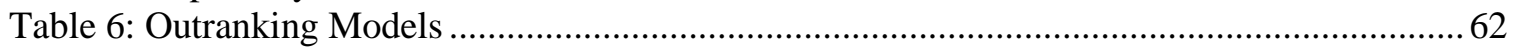

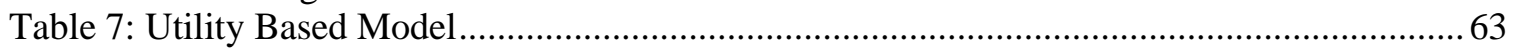

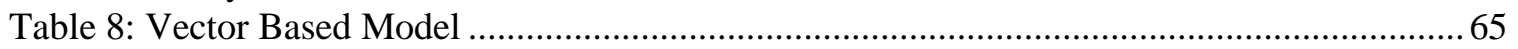

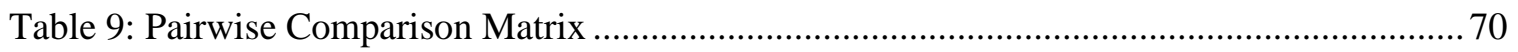

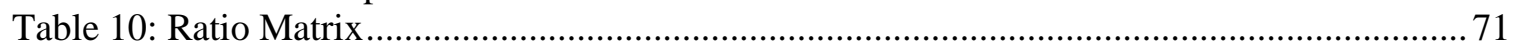

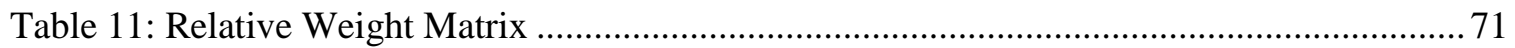

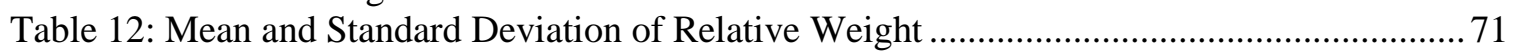

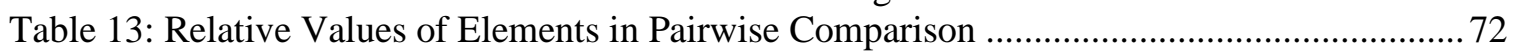

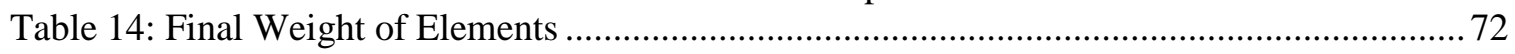

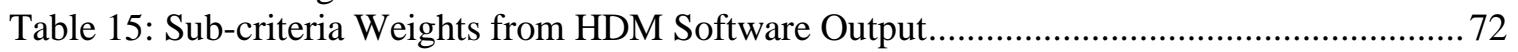

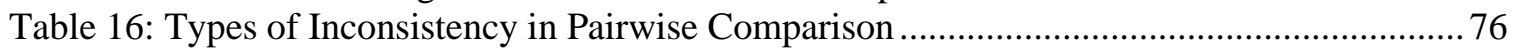

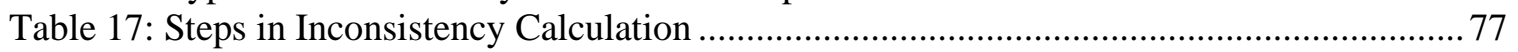

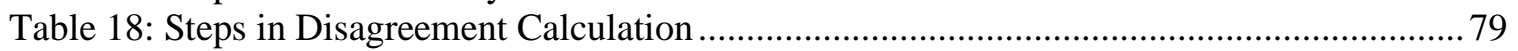

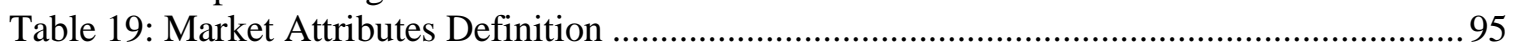

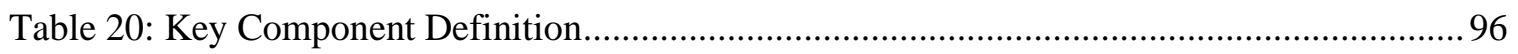

Table 21: Expert Panels for Different Tasks............................................................................ 102

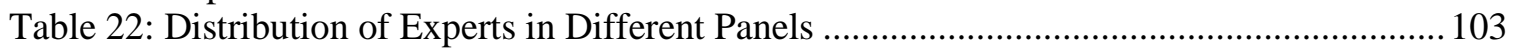

Table 23: Pairwise Comparison of Market Attributes ............................................................... 111

Table 24: Pairwise Comparison of Key Components in Consumers' Benefit Market Attribute. 112

Table 25: Pairwise Comparison of Key Components in Technological Market Attribute ........... 114

Table 26: Pairwise Comparison of Key Components in Economic Market Attribute.................. 115

Table 27: Pairwise Comparison of Key Components in Delivery \& Infrastructure Market

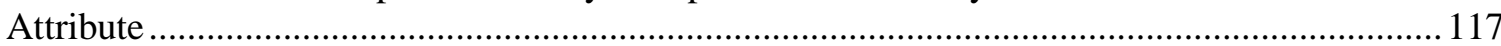

Table 28: Pairwise Comparison of Key Components in Legal \& Institutional Market Attribute 118

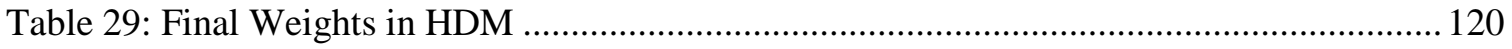

Table 30: A Tentative Guideline on Metrics for Measuring Level of Comfort ............................ 122

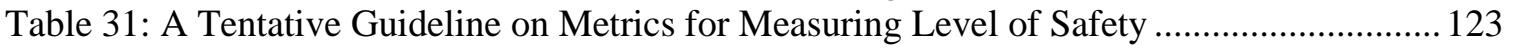

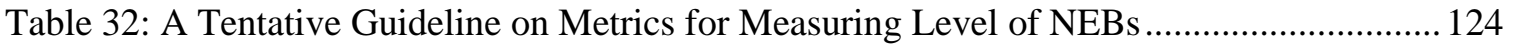

Table 33: A Tentative Guideline on Metrics for Measuring Level of Awareness ........................ 125

Table 34: A Tentative Guideline on Metrics for Measuring Level of Energy Saving Potential.. 127

Table 35: A Tentative Guideline on Metrics for Measuring Level of Ease of Installation.......... 128

Table 36: A Tentative Guideline on Metrics for Measuring Level of Ease of Use ..................... 129

Table 37: A Tentative Guideline on Metrics for Measuring Level of Compatibility ................... 130

Table 38: A Tentative Guideline on Metrics for Measuring Level of Profitability Index (PI).... 131

Table 39: A Tentative Guideline on Metrics for Measuring Level of LCOE ............................... 132

Table 40: A Tentative Guideline on Metrics for Measuring Level of Payback Period ................ 133

Table 41: A Tentative Guideline on Metrics for Measuring Level of Impact of Substitutes....... 134

Table 42: A Tentative Guideline on Metrics for Measuring Level of Competition ..................... 136

Table 43: A Tentative Guideline on Metrics for Measuring Level of Impact of Trade Allies .... 137

Table 44: A Tentative Guideline on Metrics for Measuring Level of Accessibility.................... 138 
Table 45: A Tentative Guideline on Metrics for Measuring Level of Supply Chain Effectiveness

Table 46: A Tentative Guideline on Metrics for Measuring Level of Impact of Codes and

Standards

Table 47: A Tentative Guideline on Metrics for Measuring Level of Impact of Energy Price ... 142

Table 48: A Tentative Guideline on Metrics for Measuring Level of Impact of Incentives........ 143

Table 49: A Tentative Guideline on Metrics for Measuring Level of Impact of Labelling......... 144

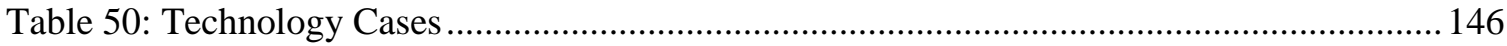

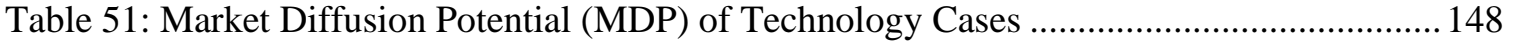

Table 52: Highest and Lowest Rating Key Components for Technology Cases .......................... 150

Table 53: Increased MDP of Technology Cases with Change in Desirability Values .................157

Table 54:Ranking of Technology Cases in Different Scenarios ................................................ 162

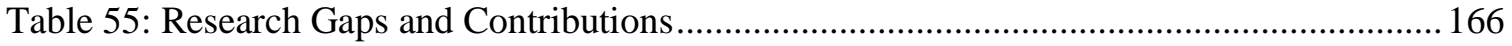




\section{LIST OF FIGURES}

Figure 1: Energy Consumption by Sector in the U.S. in 2018...................................................

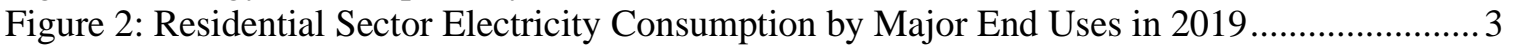

Figure 3: Energy Efficiency Scenario in the U.S. Residential in 2050 ..................................... 4

Figure 4: Market System for Energy Efficient Technology ........................................................ 7

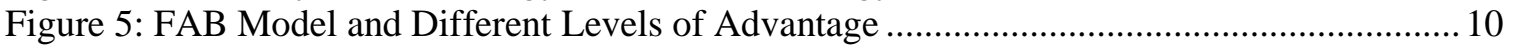

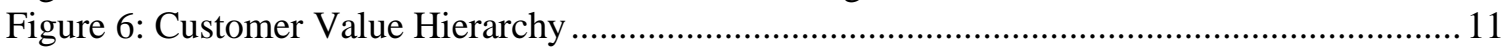

Figure 7: Schematic of Research Concept (Fishbone Cogwheel Diagram).................................. 12

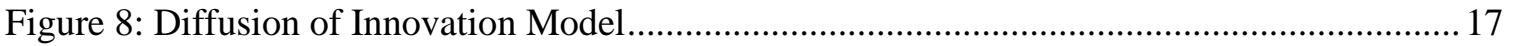

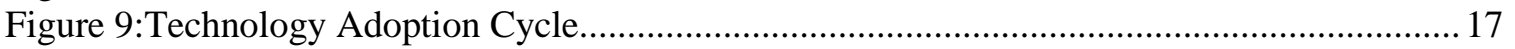

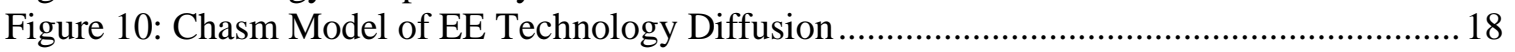

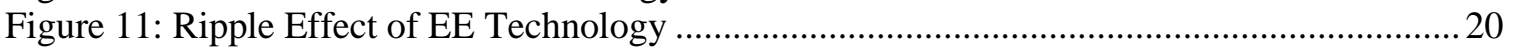

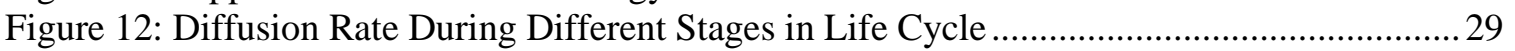

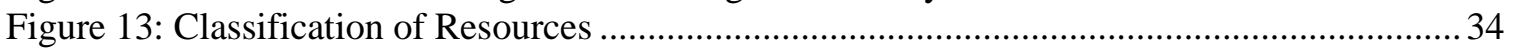

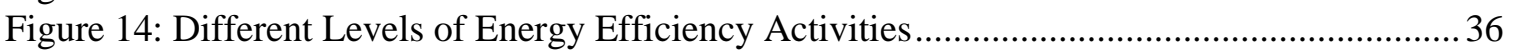

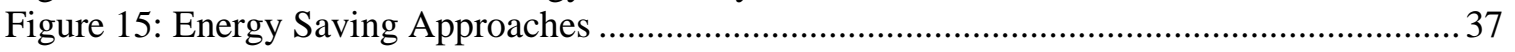

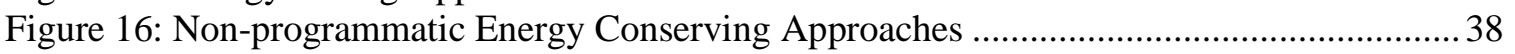

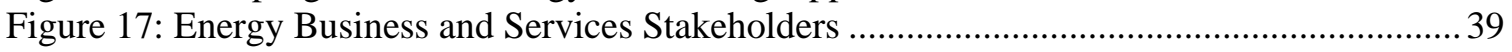

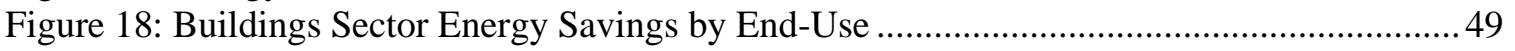

Figure 19: Different Ways to Improve the HVAC Efficiency ....................................................51

Figure 20: Classification of Multicriteria Decision Making (MCDM) .......................................60

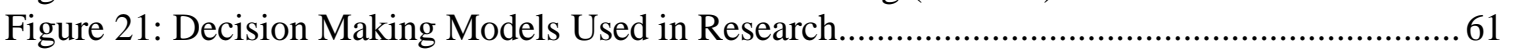

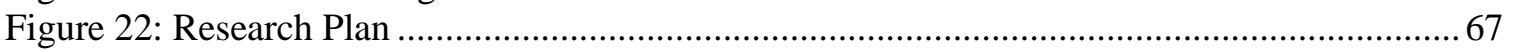

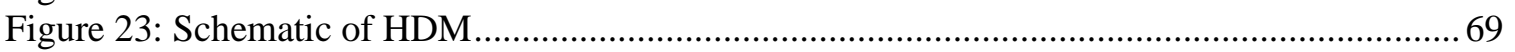

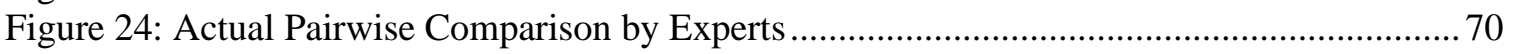

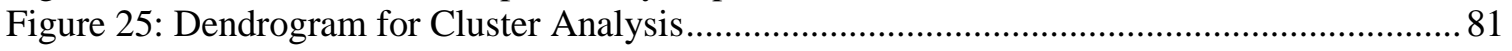

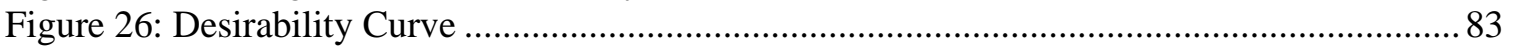

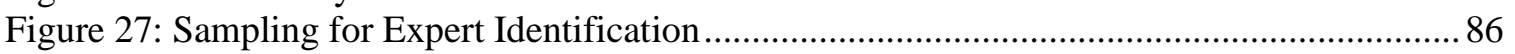

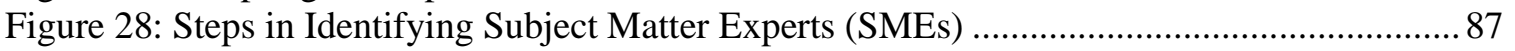

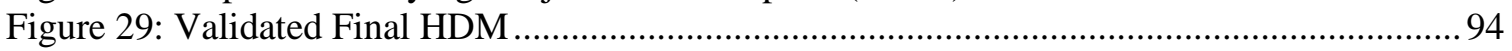

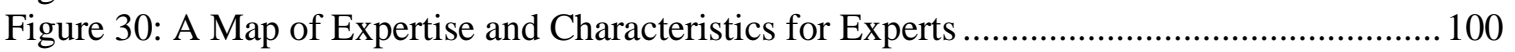

Figure 31: Venn Diagram showing Participation of Experts in Different Tasks .......................... 104

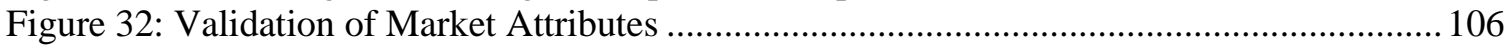

Figure 33: Validation of Key Components of Market Attributes: Consumer's Benefit .............. 107

Figure 34: Validation of Key Components of Market Attributes: Technological ....................... 108

Figure 35: Validation of Key Components of Market Attributes: Economic ............................... 109

Figure 36: Validation of Key Components of Market Attributes: Delivery and Infrastructure ... 110

Figure 37: Validation of Key Components of Market Attributes: Legal and Institutional .......... 111

Figure 38: Dendrogram for Consumers' Benefit Market Attribute ........................................... 113

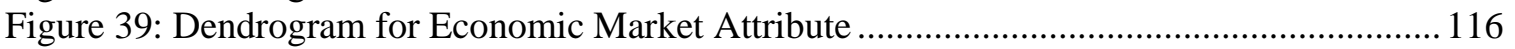

Figure 40: Dendrogram for Delivery \& Infrastructure Market Attribute .................................. 117

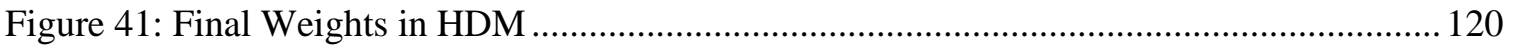

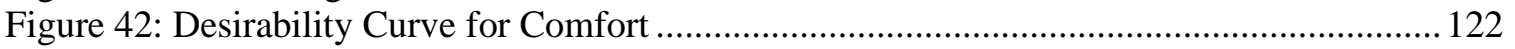

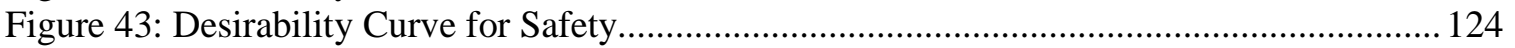

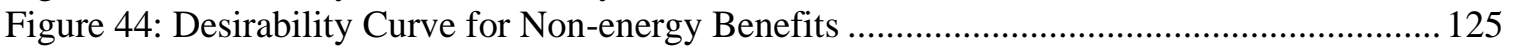

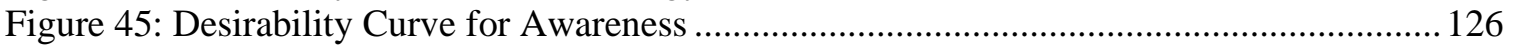

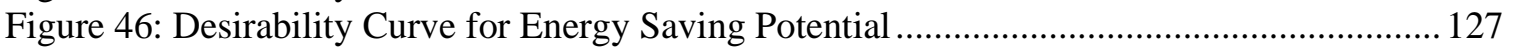

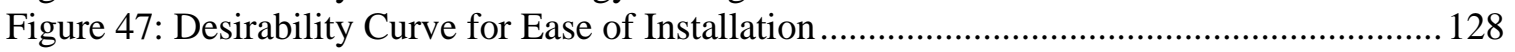

xiii 
Figure 48: Desirability Curve for Ease of Use.

Figure 49: Desirability Curve for Compatibility.....

Figure 50: Desirability Curve for Profitability Index (PI)

Figure 51: Desirability Curve for Levelized Cost of Electricity (LCOE).

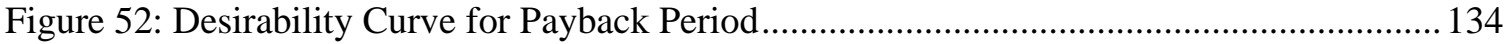

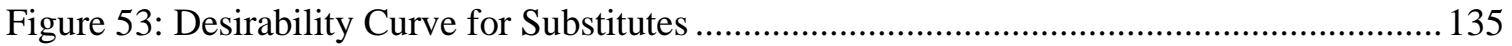

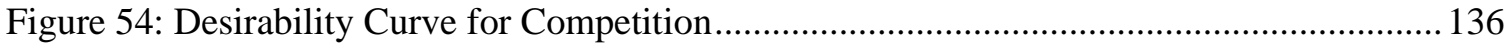

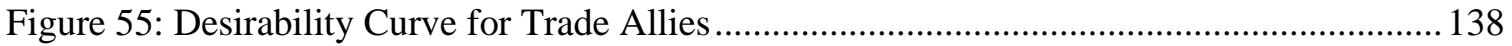

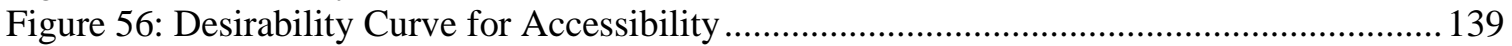

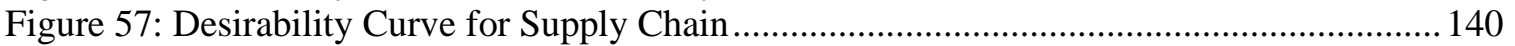

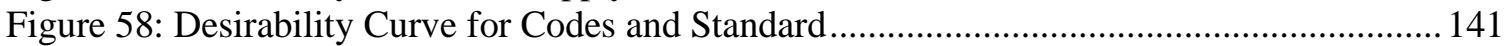

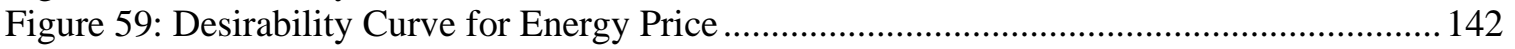

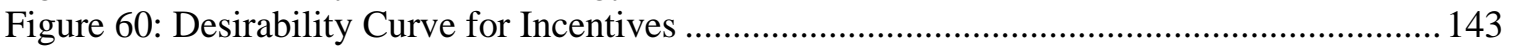

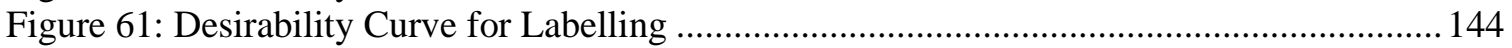

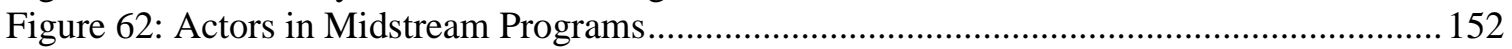

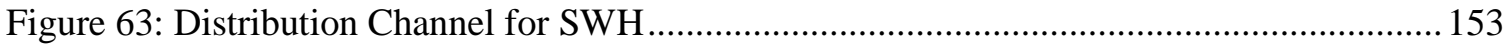

Figure 64: Ranking of Technology Cases with the Base Weights of Market Attributes ............. 158

Figure 65: Ranking of Technology Cases with the Consumers' Benefit Centric Market Approach

Figure 66: Ranking of Technology Cases with Technological Excellence Centric Market Approach

Figure 67: Ranking of Technology Cases with Economic Advantage Centric Market Approach

Figure 68: Ranking of Technology Cases with Delivery \& Infrastructure Superiority Centric Market Approach .

Figure 69: Ranking of Technology Cases with Legal \& Institutional Strength Centric Market Approach

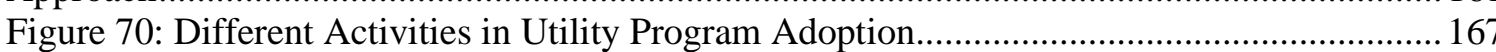

Figure 71: Market Transformation Cycle 


\section{LIST OF ABBREVIATIONS}

\begin{tabular}{|c|c|}
\hline ACEEE & American Council for Energy Efficient Economy \\
\hline AHP & Analytical Hierarchical Process \\
\hline ARRA & American Recovery and Reinvestment Act \\
\hline ASHRAE & American Society of Heating, Refrigerating and Air-Conditioning Engineers \\
\hline BPA & Bonneville Power Administration \\
\hline BWM & Best Worst Method \\
\hline CHP & Combined Heat and Power \\
\hline COP & Coefficient of Performance \\
\hline DEA & Data Envelop Analysis \\
\hline DHP & Ductless Heat Pump \\
\hline $\mathrm{EE}$ & Energy Efficient \\
\hline EIA & Energy Information Administration \\
\hline EPDB & Energy Performance of Building Directives \\
\hline EPRI & Electric Power Research Institute \\
\hline ESP & Energy Saving Potential \\
\hline ETO & Energy Trust of Oregon \\
\hline FAB & Feature Advantage Benefit \\
\hline GHG & Greenhouse Gas \\
\hline GTI & Gas Technology Institute \\
\hline HDM & Hierarchical Decision Model \\
\hline HERS & Home Energy Rating System \\
\hline HMCDM & Hybrid Multicriteria Decision Making \\
\hline HPWH & Heat Pump Water Heater \\
\hline HVAC & Heating, Ventilation and Air Conditioning \\
\hline $\mathrm{HX}$ & Heat Exchangers \\
\hline $\mathrm{ICCC}$ & Intra-class Correlation Coefficient \\
\hline IECC & Institute of Electrical Efficiency \\
\hline IID & Intermittent Ignition Device \\
\hline ISEC & Isolated System Energy Charging \\
\hline KPI & Key Performance Indicators \\
\hline LCOE & Levelized Cost of Electricity \\
\hline LED & Light Emitting Diodes \\
\hline LEED & Leadership in Energy and Environmental Design \\
\hline MCDA & Multicriteria Decision Analysis \\
\hline MCDM & Multicriteria Decision Making \\
\hline MADM & Multi-Attribute Decision Making \\
\hline MDP & Market Diffusion Potential \\
\hline MODM & Multi-Objective Decision Making \\
\hline MOGSA & Mission, Objective, Goal, Strategy, Actions \\
\hline Mtoe & Millions of Tonnes of Oil Equivalent \\
\hline NDCs & Nationally Determined Contributions \\
\hline NEBs & Non-energy Benefits \\
\hline NEEA & Northwest Energy Efficiency Alliance \\
\hline NGHPWH & Natural Gas Heat Pump Water Heater \\
\hline NWPCC & Northwest Power and Conservation Council \\
\hline NYSERDA & New York State's Energy Research and Development Authority \\
\hline
\end{tabular}


OECD Organization for Economic Co-operation and Development

PGE Pacific Gas and Electricity

PI Profitability Index

R \& D Research and Development

RESNET Residential Energy Services Network

SME $\quad$ Subject Matter Expert

SNA Social Network Analysis

STEEPLE Socio-cultural, Technological, Environmental (or Ecological), Economic,

Political, Legal, Ethica

SWH Solar Water Heater

TGWH Tankless Water Heater

WAP Weatherization Assistance Program

WH Water Heater 


\section{CHAPTER 1: INTRODUCTION}

The introductory chapter of the dissertation presents the research and provides impetus to subsequent chapters. The research scope discusses the importance of the research effort, sheds light on the terminologies in the research title, outlines the length and breadth of the study as well as describes the theoretical and conceptual framework of the research. A Market Diffusion Potential (MDP) Assessment Model has been developed with a view to help make decisions and take apposite actions for increasing the diffusion of residential energy efficient technologies.

Chapter 1 concludes with a brief summary of contents in the following chapters and provides a sketch of the research design, research methodology and how the outcome of this research helps in practice.

\subsection{Research Scope}

Background and Definition of Energy efficiency: The concept of 'Energy Efficiency' stemmed from the energy crisis of the 1970's [1][2][3]. However, the term waxed and waned along with other energy terminologies like "conservation" and "renewable energy" through the years. But at the beginning of the 1980s, global warming issues became prominent with many states passing 'least cost planning' regulations, and energy efficiency programs were recharged anew to combat climate change [4][5][6]. 'Conservation' advocates the use of less energy and tries to tame consumers' energy consumption habit while the variability of 'Renewable Energy' impacts the power system. But energy efficiency allows us to save energy without compromising the habitual comfort and splurge that we relish [7]. Energy efficiency allows to achieve the same, or better, level of service 
with less energy expenditure [8]. The technical definition of 'Energy Efficiency' is the ratio of energy output to input and is stated as a percentage [9]. An operational definition of "Energy Efficiency" is achieving the same or better output at optimal cost. According to the EPDB (Energy Performance of Building Directives), optimal cost can be defined as the minimum cost at a certain performance level of an energy efficient device within the timespan of economic lifecycle [10]. However, each new efficient device outperforms its predecessor in efficiency standards and paves the path for greater savings in electricity in the long run [11]. Energy efficient technologies have unveiled new hope to the powerhungry modern civilization. Energy efficiency rescues us from being energy stricken even without building new power plants and helps to manage climate calamity, lower energy bills, cut carbon emissions, lower wear-and-tear of the energy grid and mostly, makes us less dependent on the higher-cost power plants [12][13]. However, despite the enormous potential of energy efficient technologies in tackling energy crisis, adoption of these

technologies is yet to become widespread due to the "Energy Efficiency Gap" or slow diffusion of energy efficient technologies [14] [15].

\subsection{Terminology}

This part of the report tries to clarify the terms used in the title of the dissertation with relevant explanations.

Residential Energy Efficient Technologies: Buildings account for about $40 \%$ of the total energy consumption in the U.S. Residential homes are responsible for more than half of the total energy consumption in buildings (Appendix A), which is equivalent to about 21.5 
quadrillion BTU. The percentage of energy consumed by different sectors in the U.S. is shown in Figure 1[16].

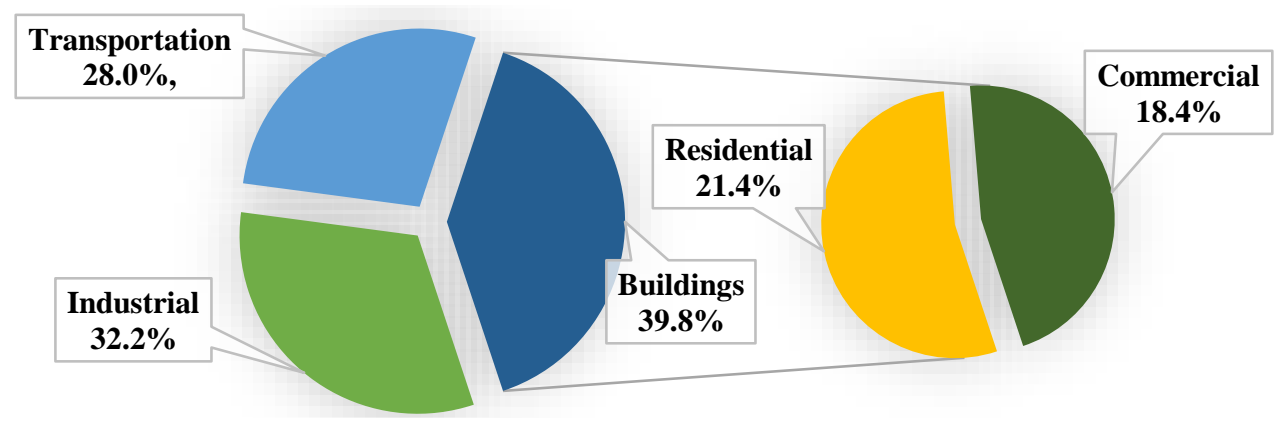

Figure 1: Energy Consumption by Sector in the U.S. in 2018

The most common energy consuming appliances in a residential building are space heating, water heating, air conditioning, lighting, refrigeration, cooking, and other appliances. Figure 2 shows the electricity consumption by major end-use. Heating, ventilation, and air conditioning (HVAC) and water heating are responsible for about $45 \%$ of the total energy use in residential buildings [17].

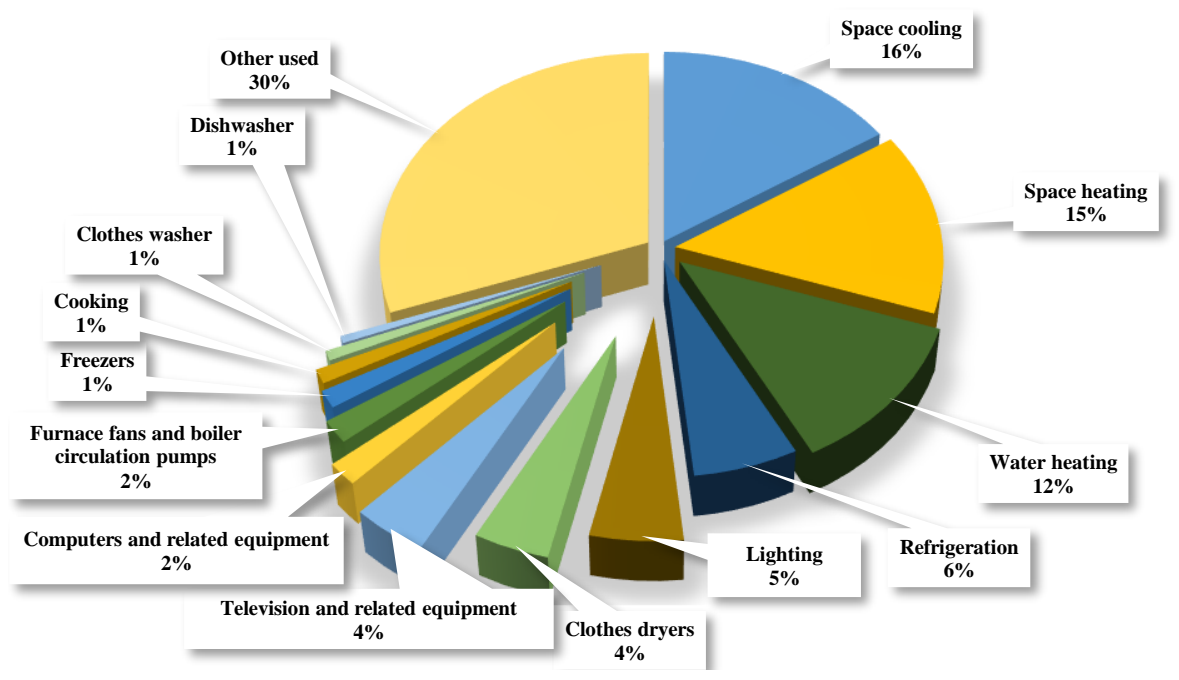

Figure 2: Residential Sector Electricity Consumption by Major End Uses in 2019 
A study was carried out by Laitner et al. to analyze the prospect of energy savings by EE technologies. Laitner et al. compared two probable economic scenarios, Advanced and Phoenix, to the business-as-usual, or reference, to clarify the scope for energy savings by 2050. Advanced scenario assumes diffusion of advanced technologies, while Phoenix scenario predicts better infrastructure, greater demand of EE equipment when inefficient technologies are displaced, better man-made environment with least energy need for movement, along with diffusion of cutting-edge technologies. The findings from the study is captured in Figure 3.

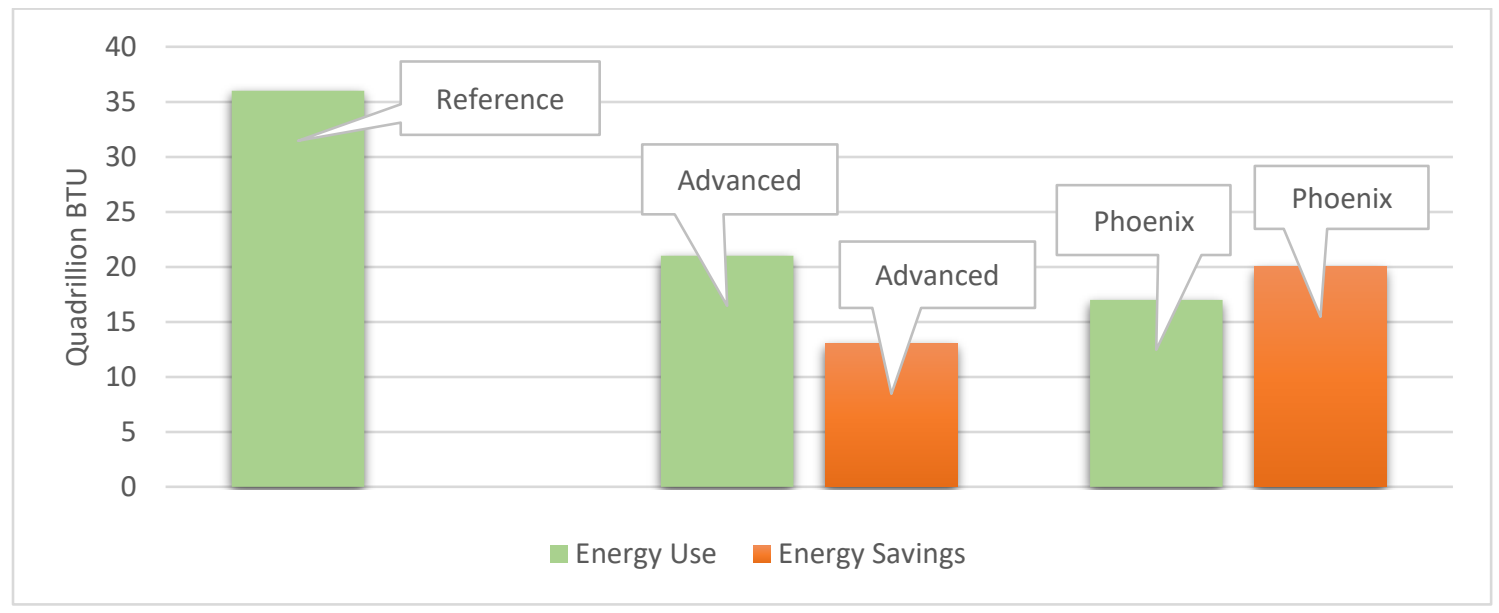

Figure 3: Energy Efficiency Scenario in the U.S. Residential in 2050

The study predicts that it is possible to reduce residential energy use by about $42 \%$ in Advanced case and almost over 50\% in case of Phoenix case scenario [18][19]. Hence, diffusion of residential EE technologies is important for saving energy in buildings.

As reported by ACEEE (American Council for Energy Efficient Economy), the energy intensity declined 50\% during the period of 1980 - 2014. Energy Intensity is, energy use divided by real dollar of GDP. Based on data, energy efficiency is found to be the major 
means for about $60 \%$ of the improvement in energy intensity during this period. Besides energy intensity, carbon dioxide gas emissions in the year 2014 reduced by $10 \%$ from 2005 level. Energy efficiency is recognized as a crucial weapon in reducing harmful greenhouse gas emission in the coming years [19].

Residential sector $\mathrm{CO} 2$ emission was $7.4 \%$ higher in the year 2018 compared to the previous year [20]. While the overall greenhouse gas emission has decreased by $2.1 \%$ in the year 2019, contribution from residential sector shows an upward trend by an increase in direct emission of $2.2 \%$ from 2018 as the electricity use has increased (Appendix B). To meet the Paris Agreement target, the annual Greenhouse gas emission needs to be decreased at a rate of $2.8-3.2 \%$ [21].

The average cost for energy savings made a downslide in 2018 from the previous year as reported by EIA (Energy Information Administration). However, the cost of energy savings for residential sector was higher, keeping the trend of increase since 2013. The average cost of energy savings was 3.4 cents per kilowatt hour in 2018. The incremental annual electricity savings from energy efficiency decreased by 5\% from the year 2017 [11].

Many studies have recognized the fact that diffusion of EE technologies can reduce energy use up to $40-60 \%$ by the year 2050 [22][19][23]. Taking advantage of the market attributes, and ensuring a change in the way the market functions by adoption of appropriate interventions have proved to be effective measures for increasing the diffusion of EE technologies [24] [25] [19] (Nelson and Smith 2018).

Adoption vs. Diffusion: In most literatures, "Market Adoption" "Market Diffusion", "Technology Diffusion" or "Technology Adoption" have been used with similar 
connotation [27] [28][29][30] [31]. However, there are different dynamics behind the process of adoption when compared to diffusion. Adoption studies take the stand of adopters while diffusion studies see through the lens of market and society. Adoption relies on individual or collective decision on accepting or rejecting an innovation while diffusion is the propagation of an innovation through different avenues to adopters [32].

"Technology Diffusion" is a process which starts with individual use or adoption and ends with reach of the technology to potential users in the social system [33][34][35]. Several energy efficient technologies at different stages of maturity have proven to follow the S-curve as different categories of consumers adopt technology until the market saturates [33][36][37].

Energy Efficient Technology Market: 'Marketplace' is a physical location where products or services are bought and sold. However, 'Market' is a system that consists of different actors who are involved not only in production, delivery and trade of tangible goods and services but also engage in facilitation of the adoption of the product or service through rules, regulations, institutions and structures [38]. The different actors in the EE technology market system is shown in Figure 4 [39][38].

An energy efficient technology market is composed of supply side actors represented by manufacturers, supplier of components, enabling technology and technical assistance, EE standards, incentive programs, training and necessary services to successfully deliver the product to the adopters. The demand side actors are consumers who could be individuals, businesses or government [40] [41]. Besides, there are other market participants whose actions are catalytic in diffusion of EE technology [42]. The ultimate 
diffusion is contingent upon and preceded by the market's ability to provide physical and abstract benefits to satisfy the expectations and experiences of the different players in the market. For this research, 'Market Attributes' are broad categories of product and service benefits that the market should be able to deliver in order to increase the diffusion of residential EE technologies [43] .

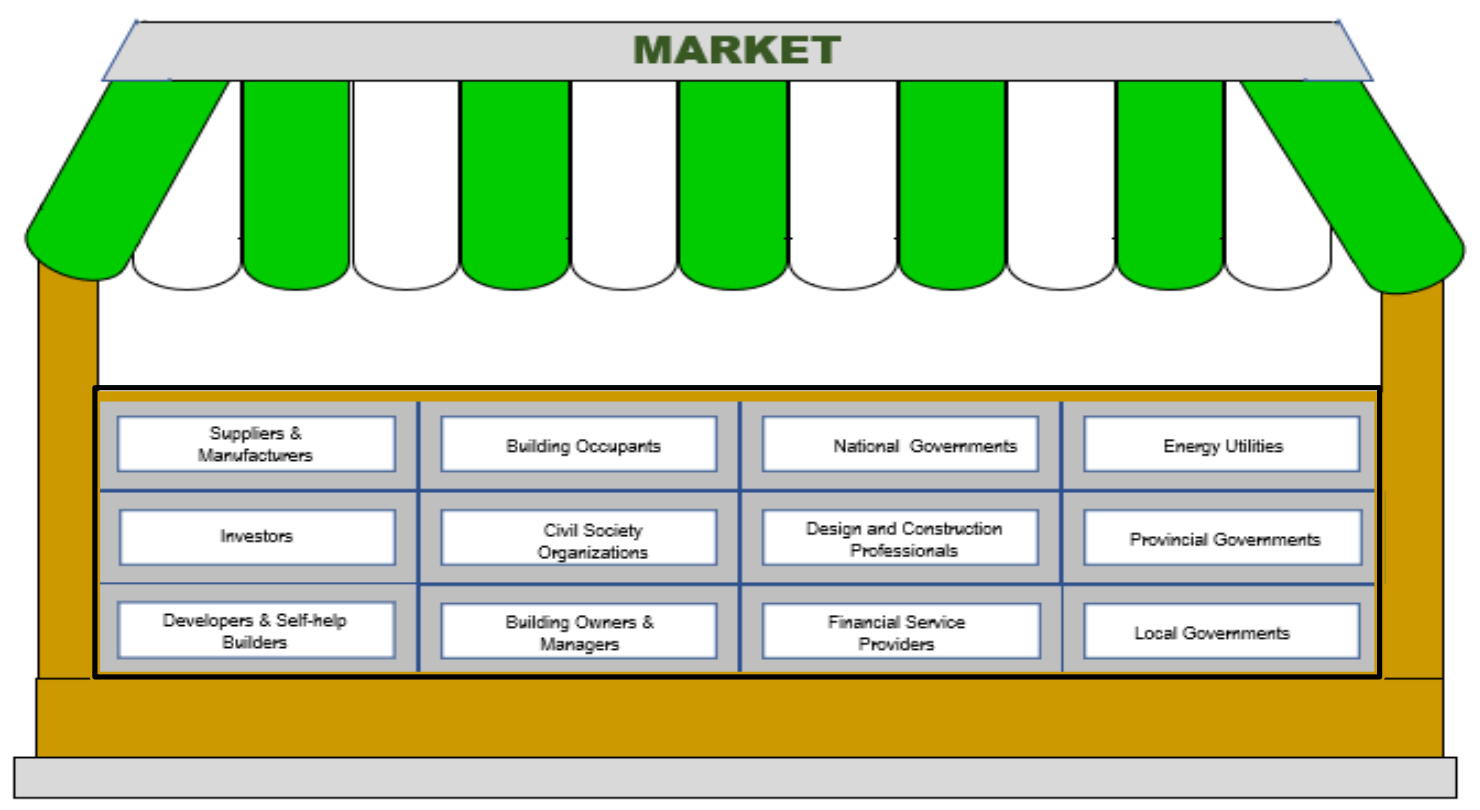

Figure 4: Market System for Energy Efficient Technology

Assessment vs. Other Data Collection Methods: There are many ways of finding the actual data. Assessment, measurement, research, and evaluation are some of the processes used for identifying reality. Assessment is used to get a better insight into a problem. 'Assessment' is the evaluation or estimation of objects that cannot be enumerated. Appraisal of interdisciplinary and interfacing knowledge pertaining to science and society helps decision makers to identify options and take appropriate actions. Expert judgment is a widely used tool for assessment [44]. Measurement is enumerating the data gathered by 
evaluation. Research allows the use of data for comprehending a situation to conclude. 'Evaluation' establishes the value of data by comparing it to a recognized standard [45]. Primary data collected through surveys, interviews, focus groups, direct observation, fieldtesting and any other method is chosen when it is necessary to understand the human attitude, values, and behavior. The information is used for making decisions regarding new or existing technology products [46]. A survey is carried out when it is needed to collect data from a representative sample to understand the nature of the population [47]. The objective of the research is not to find out customers' views but to assess the market's capability in offering a technology product to adopters. The adopters would embrace the product based on the advantages offered and derive benefits in using that product and thereby help to accelerate the diffusion.

Definition of Market Diffusion Potential: 'Market Diffusion Potential' can be defined as a metric that identifies the status quo of a technology in terms of its diffusion proclivity compared to one or more technologies based on the relative strengths of market attributes and relevant key components that constitute market attributes.

\subsection{Theoretical Framework}

The research is built upon existing theories and concepts in literature. The relevant principles and constructs clarify the boundary of this research, origin of the terminologies as well as the logical path for solving the problem of diffusion of energy efficient technologies. 
Benefit is the Most Important Determinant: The time and rate of diffusion of different technologies vary. Among the many different factors that affect adoption decision, benefit is the most important aspect in making buying decision by adopters [48]. Many times, technologies that apparently seemed to be more superior than others took longer time to diffuse than others. Factors that affect diffusion, for example, product features, government incentives, experience, to mention a few, should be decoded as valuable by consumers, and the perceived value is what drives diffusion [49].

Benefit and Customer Value: Feature Advantage Benefit (FAB) is a widely used rubric to understand what an innovation renders, how it works and what makes the user want it. Interestingly, 'Feature' is what innovators design, 'Advantage' is what marketers offer and 'Benefit' is what consumers feel while using the technology [50][51][52]. Figure 5 shows the different elements of the FAB model that corresponds to different levels of advantage perceived by different actors as we move from producers, suppliers and entities who affects business environment to deliver the product to ultimate adopters [50] [53]. The FAB model helped to identify the market attributes for the this research. 


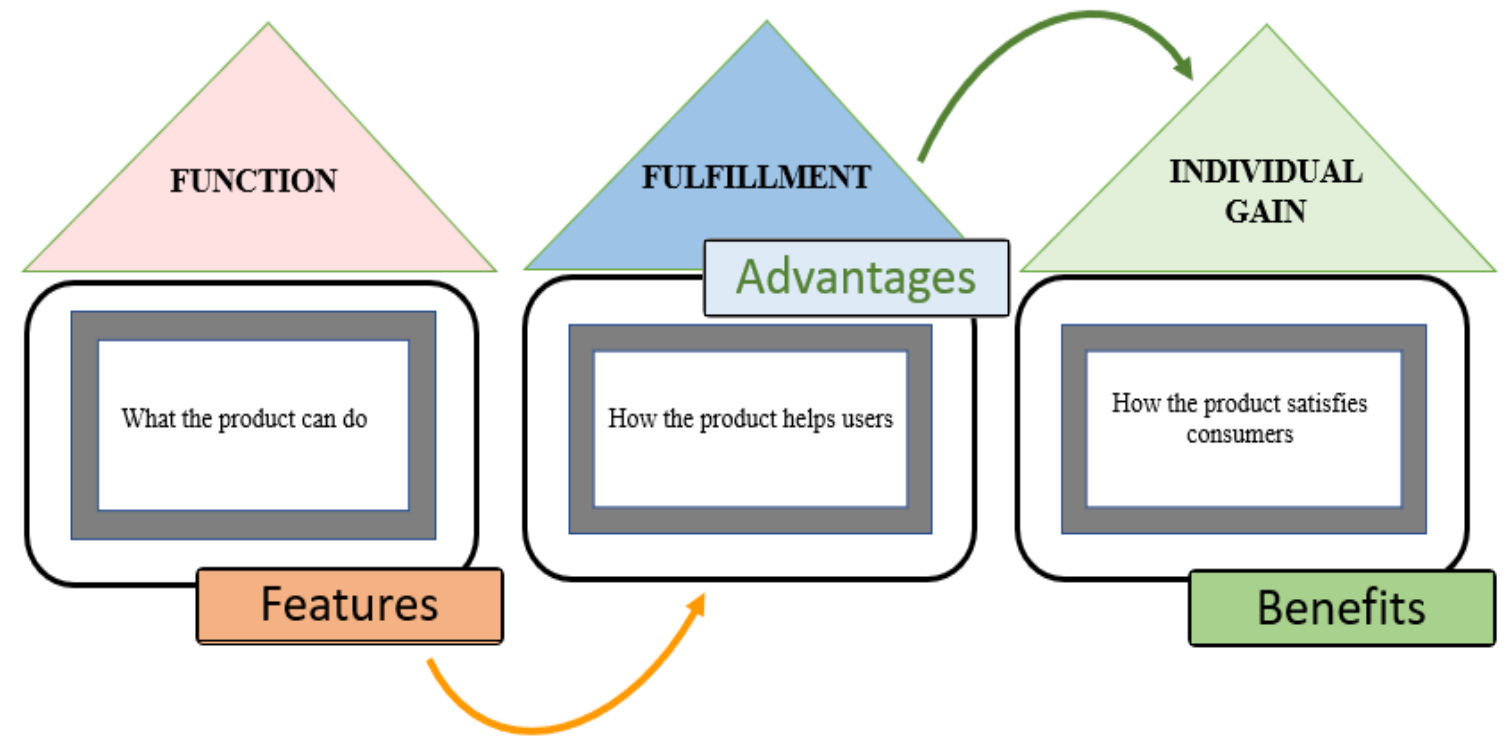

Figure 5: FAB Model and Different Levels of Advantage

Kotler et al. suggests five levels of product benefits. Each level provides increased value. The five levels together are known as customer- value hierarchy. 'Value' is the difference between perceived benefit and sustained cost. Monetary as well as nonmonetary investments could be considered as incurred cost [54][55]. A core product performs the intended functions by a product. The second level of benefit is basic product or generic product benefit that associates attributes that are absolutely crucial for functioning. Expected product benefits are those that are expected from a product and completes the product offering. Augmented features differentiate the product from its competitors. Advantages are derived from the product's performance due to specific elements [56]. For example, a water heater can be connected to mobile devices for remote adjustments and alerts. Core products provide the advantage of solving a particular consumer problem and motivates adopters to buy. However, actual product holds a lot more attributes than just the functionality. Goods and service mix, distribution mix, and 
communication mix are some of the offerings that support the core product. Augmented features of the product provide additional options that exceed customer's expectations in the form of delivery and installation, credit and discount, after-sales service, warranty, spare parts availability, lend alternate device while actual equipment is being revamped or other value-added services. Potential product includes any combination of augmented benefits or bundled product and service offerings [57][58][59][60][55] [43]. The different levels of product benefits are shown in Figure 6 .

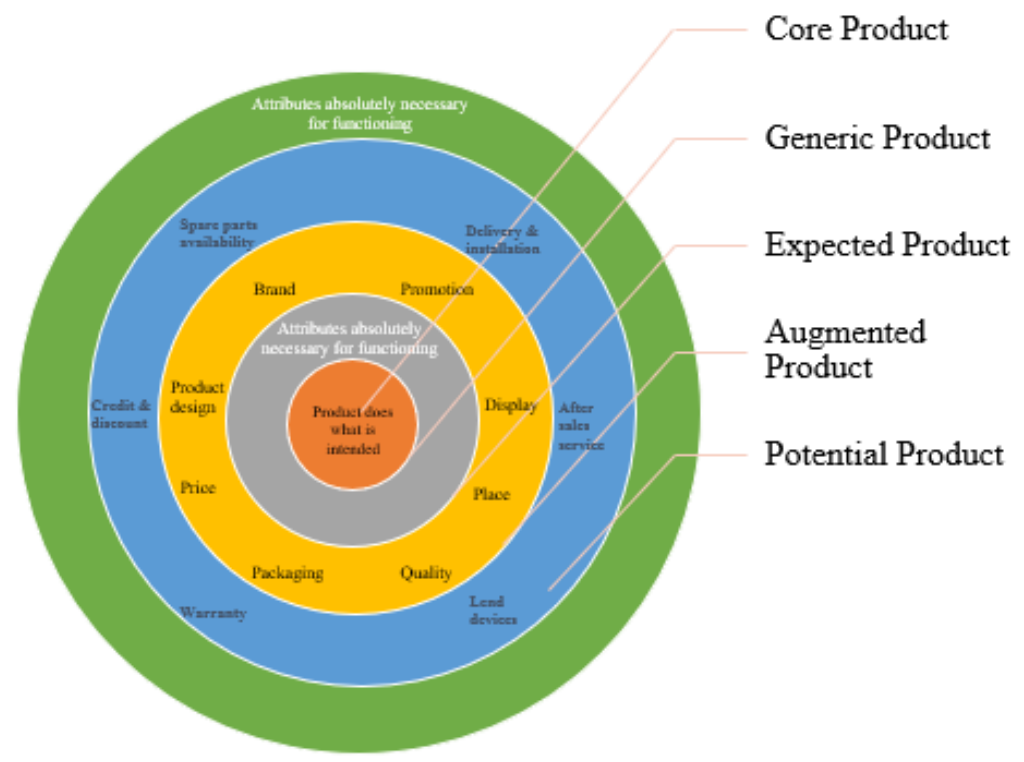

Figure 6: Customer Value Hierarchy

\subsection{Conceptual Framework}

The conceptual framework is the researcher's own understanding of the relations among different components in the study. It shows how the researcher views the problem and intends to solve it [61]. Figure 7 captures the research concept schematically using a 'fishbone' diagram, and 'cogwheel gear concept. The cause and effect diagram show what 
impacts the rate of diffusion. Also, the cogwheel symbolizes how the different causes are interlocked and lead to the end effect of the diffusion rate.

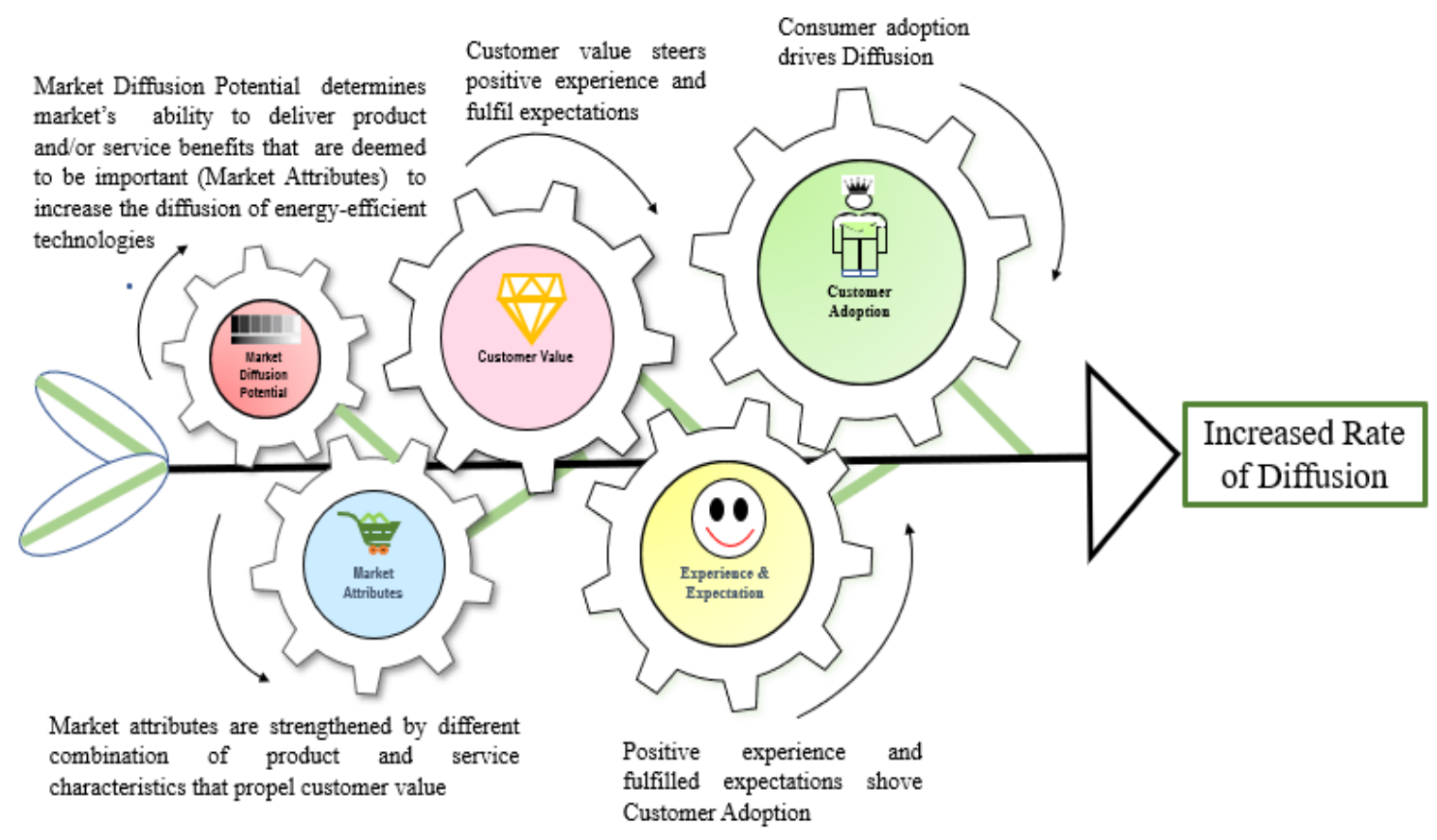

Figure 7: Schematic of Research Concept (Fishbone Cogwheel Diagram)

Consumer adoption impacts the rate of diffusion: A tunnel vision to diffusion considers consumers to be the ultimate decision-maker in adopting an EE technology. Diffusion rate depends on how fast people with different levels of inclination towards the new technology accept it. Market offers features, advantages, and benefits in products and/or services and influences the decisions of consumers in acquiring the product [62][63][64] .

Experience and expectation in use of the EE technologies impact adoption: Accelerating the rate of diffusion at any stage of technology life cycle till saturation depends on to what extent consumers are delighted [65]. Numerous studies have been carried out to understand how to increase the interest of consumers towards energy efficient 
technologies to drive diffusion of the technology. Adoption is triggered with positive experience and fulfilled expectations when consumers' needs, wants and desires are not only met but delivered prodigiously [66].

Customer value from EE technology products/services affect expectation and experience: 'Utility' is a measure of consumer satisfaction derived from product/service usage. It is the perceived value from the use of a technology product and associated services. Fulfillment from an EE technology product varies with perceived utility [67]. Perception of the consumer concerning the 'Utility' of a product/service depends on the worth of it. It is the difference between perceived benefits and perceived cost [68]. Benefits offered by a product/service provides customer value when it saves time and money, helps to earn more money, become happier, healthier, more relaxed, or more productive [69][63][70].

Creating customer value from market attributes: Combination of product and/or service characteristics or bundle of attributes provide utility. Customers derive intrinsic and extrinsic prompts from the product and/or service package and process the information to evaluate value of the product [54]

Market Diffusion Potential: MDP is the market's ability to deliver those product/ service attributes or benefits that are deemed to be important for the diffusion of the energyefficient technologies.

In the present research, 'Market Diffusion Potential' clarifies if the market has the potential to meet and exceed consumers' expectations and experience by creating customer value and thereby accelerate diffusion. 


\subsection{Organization of the Dissertation}

The introductory chapter sets the stage of the research with background and objective of the research. The synopsis of the subsequent chapters are as follows:

Chapter 2 elaborates on the reason behind choosing the research and how one single step of adopting EE technology in a residence can help to take a giant leap in mitigating greenhouse gas emission and global climate change. Also, the chapter recognizes the issues in increasing diffusion of EE technologies in residential buildings.

Chapter 3 paraphrases the excerpts from literature relevant to the problems identified in chapter 2. This chapter also discusses the different EE technologies. The specific EE technology diffusion issues in different states with high scorecard, and identifies the gaps in literature that are addressed later in the study.

Chapter 4 describes the research objective, subobjectives and research questions. It also illustrates the research methodology, models and the tools that are used in the research. This chapter also clarifies how the validity, reliability, bias, inconsistency and disagreement can affect the quality of the research and how to mitigate.

Chapter 5 elaborates the steps for identifying and selecting experts for the study. It consists of a brief description of the different components in the Hierarchical Decision Model. The tasks of panels and allocation of experts in different panels are listed in this chapter.

Chapter 6 discusses the validation of the elements in the model. The major part of this chapter is the desirability curves and pairwise comparison results. For each desirability curve a tentative guideline of metrics is included for measuring the key components in the model. 
Chapter 7 shows the application of the model to three technology cases. The chapter starts with a brief description of the water heaters. The MDP for the three technology cases are calculated. The high and low rating attributes are listed. Appropriate actions are described to improve the low rating attributes and increase MDP. The percentage increase in MDP after improving low rating MDP are calculated. Scenario analysis shows the ranking of technology cases in different scenarios.

Chapter 8 explains how the research gap is bridged through the research. It describes the theoretical and practical contribution of the research by explaining how the research has added knowledge to the assessment of diffusion potential for EE technologies as well as the application of the model in practice.

Chapter 9 identifies the different issues that were not considered as part of this research effort. These topics can be developed in future research activities.

Chapter 10 concludes the dissertation report with direction for future research 


\section{CHAPTER 2: RESEARCH MOTIVATION AND RESEARCH PROBLEMS}

The chapter answers the seemingly succinct but leading question of motivation and, what major issues encompass the diffusion of residential energy-efficient technologies. The genesis of the research idea is from the unique diffusion pattern of energy efficient technologies compared to other technologies. This led to the natural curiosity of identifying problems and adopting a systematic approach to search for solutions through the research.

\subsection{Research Motivation}

\subsubsection{Energy Efficient Technology is Unique}

Technology diffusion is the eventual outcome of adoption by probable users in the society [62]. The success of innovation lies in how the technology spreads to different categories of the adopter. While initial penetration of technology is encouraging, the spread of technology to different segments in the community is compelling and repeat purchases by customers is an overwhelming manifestation of a growing technology [71][72]. A sigmoidal curve is the natural path of diffusion for most innovations. The pace of technology adoption changes with time during its life cycle until it plunges into oblivion and makes way for new technology innovation to take off [73]. The members in a system who adopt the technology has been categorized as innovators, early adopters, early majority, late majority and laggards based on chronological acceptance of the innovation and percentage of the total potential customers. A bell-shaped curve captures the frequency of adoption by each genre of adopters while the S-curve traces the cumulative data (Figure 
8). Each technology has its unique S-curve as the slope of the curve at different time periods are modulated by stimulants and environmental aspects [33].

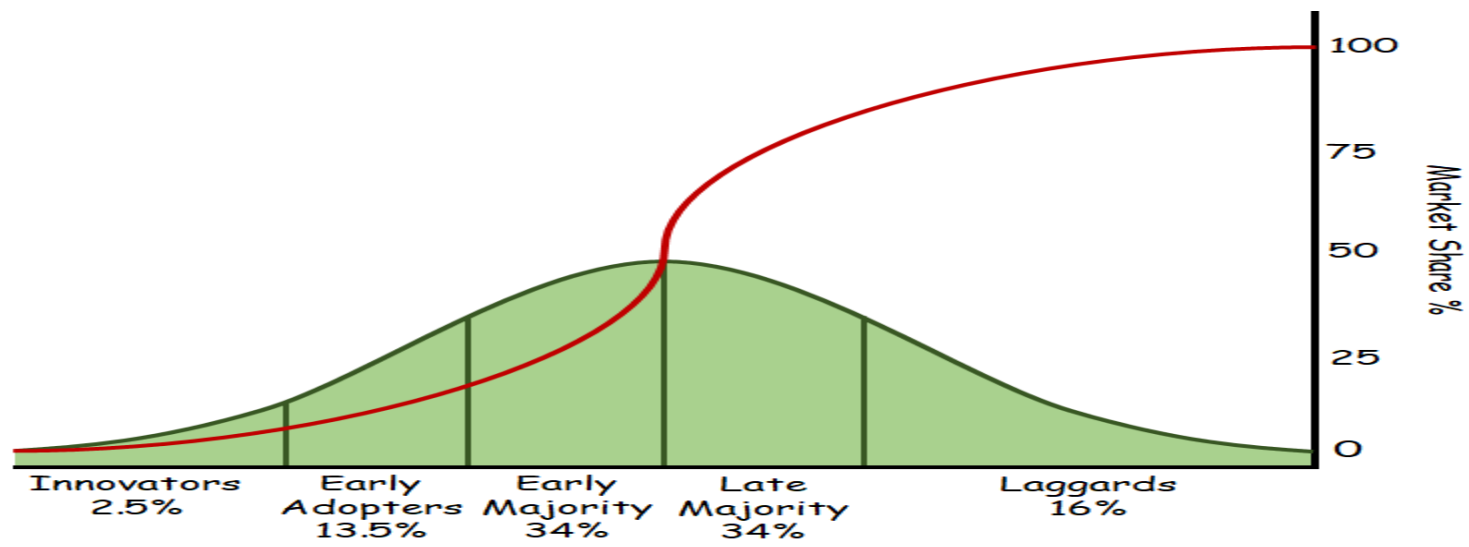

Figure 8: Diffusion of Innovation Model

However, Geoffrey Moore identified cracks in the bell-shaped diffusion curve in the late 20th century, taking the distinctive psychographic characteristics of the customers in consideration at different stages of the bell curve. The most apparent crack known as "Chasm" (Figure 9) is in between early adopters and the early majority as it needs considerable effort in driving the innovation from chosen few to mass buyers [74].

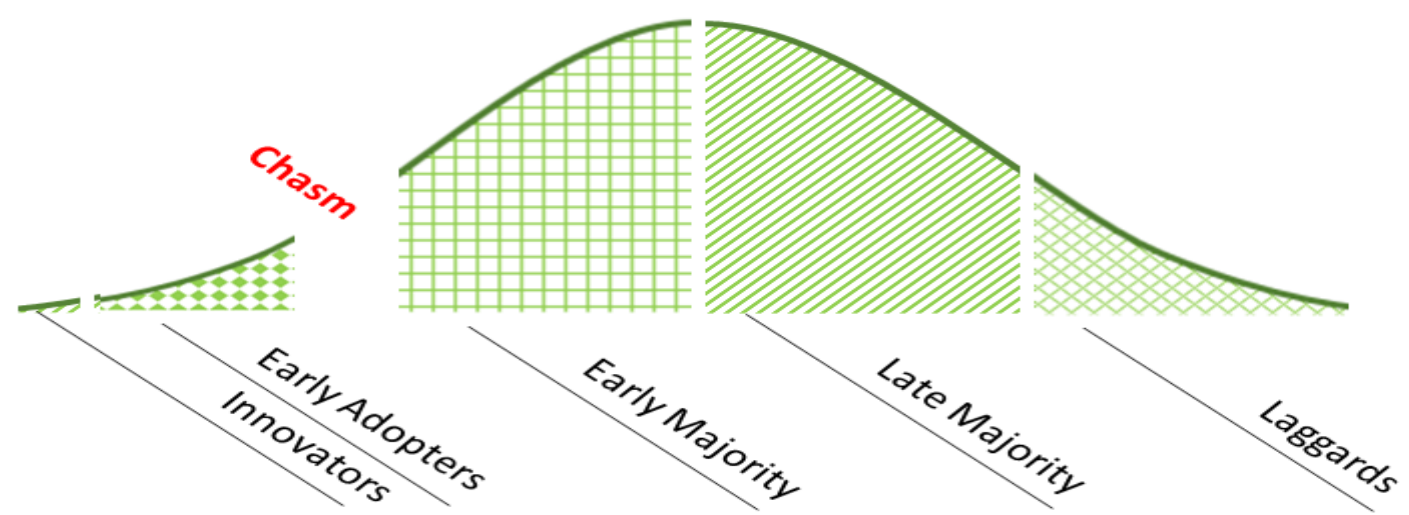

Figure 9:Technology Adoption Cycle 
Energy Efficient (EE) technology is a unique technology product as it needs to surmount two 'chasms' in its technology life cycle (Figure 10). Unlike other technologies, besides having to cross the initial 'chasm' for the transition from characterization to deployment phase, EE technologies need to bridge the gap between its commercial introduction and large-scale utility program adoption [75].

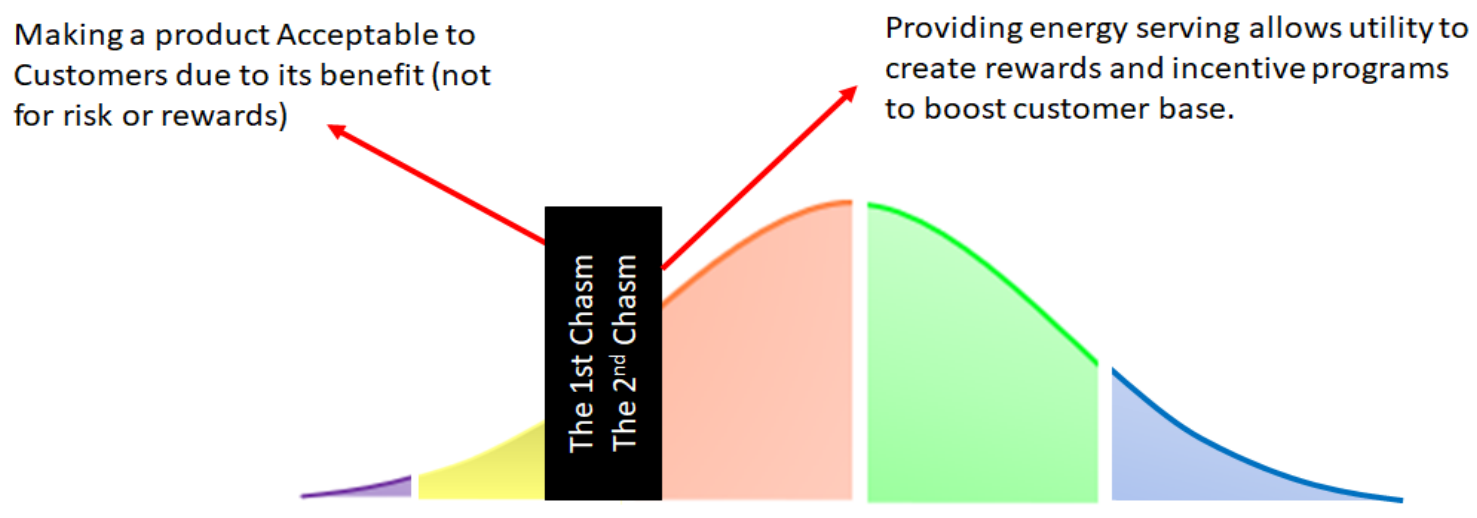

Figure 10: Chasm Model of EE Technology Diffusion

Utility companies have changed their business model in the wake of stringent environmental regulation and technological advancement [76]. Investment in energy efficiency programs cost a third than building new generation, transmission and distribution plants. It also saves time and cost of infrastructure renovation [77]. Based on predicted energy saving potential by EE technologies, utility companies optimize their investments. Due to higher upfront or overall cost of EE technologies, consumers are reluctant to adopt efficient devices in residences. Hence, an intervention by incentives at the early stage of technology life cycle helps to cross the chasm created by perceived risk or lack of rewards and thereby, creates a win-win situation for both utility and its customers $[78]$. 
The diffusion of adopted, as well as forecasted EE technologies, have proven to trace S-curve [71] [72] [79]. Energy efficient lighting fixtures, heating-ventilating-airconditioning (HVAC), windows, insulation, building controls, appliances, building design, and construction offer an enormous prospect of energy saving in residential buildings [80]. Nevertheless, most residential EE technologies are still in the early adoption phase of their life cycles [1]. For buildings, some of the factors for successful diffusion of a residential EE technology are, perceived cost, ease in installation and operation, compatibility with codes and practices, and an opportunity to try out the product without considerable expenditure [81].

\subsubsection{Overarching Impact of EE Technology}

Diffusion of EE technologies at micro-level ( at the lowest or individual level) has a far-reaching impact on meso - economy (at the intermediate or sectoral or organizational level), and macroeconomy (at the highest or market and society level) [82] (Figure 11). 


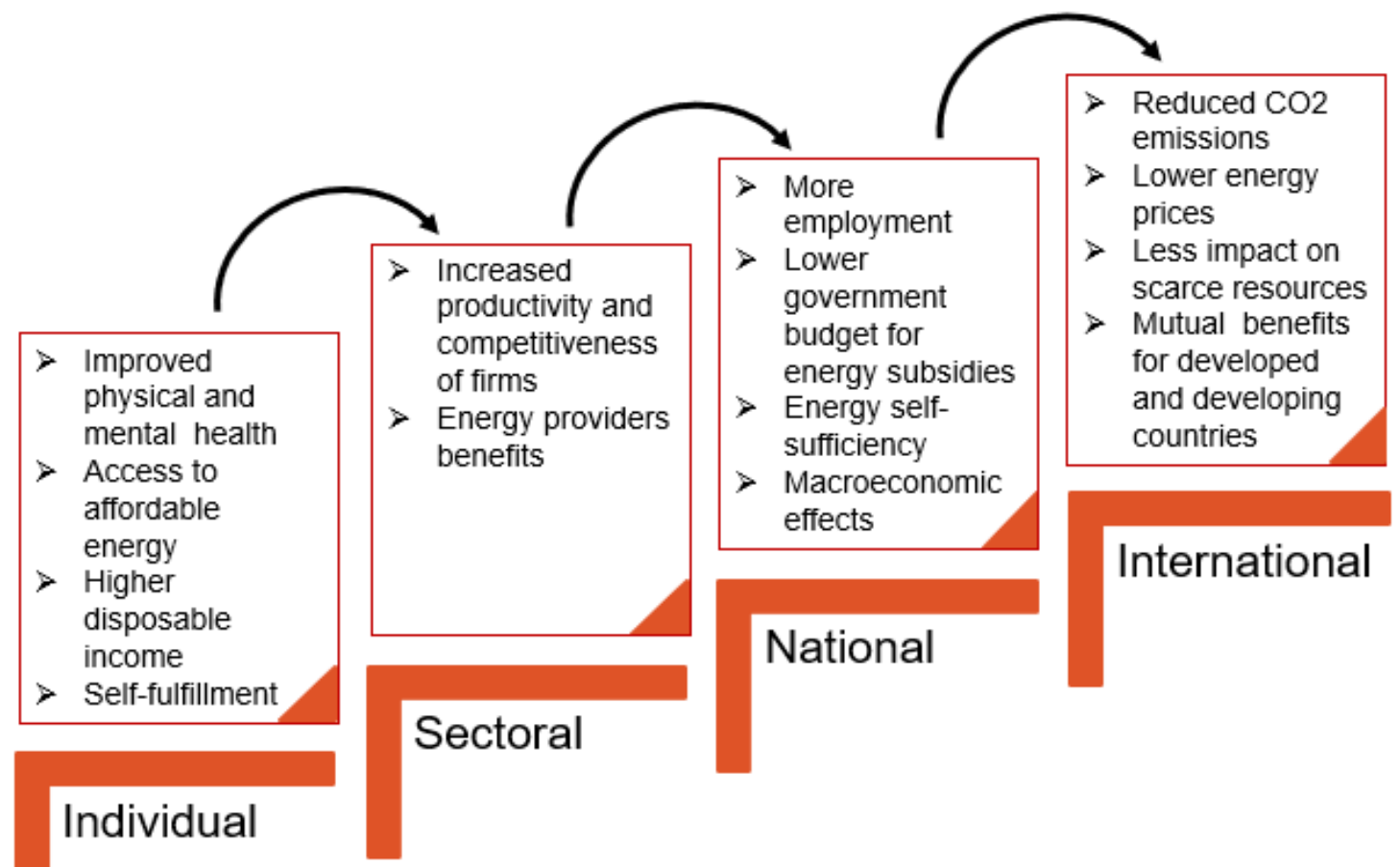

Figure 11: Ripple Effect of EE Technology

Individual Comforts

Individuals, households, and firms enjoy benefit from the adoption of EE technologies. Improved physical and mental health: Building EE technologies have long been proven to reduce the mortality rate by reducing $\mathrm{CO} 2$ emission [83]. Integrated daylighting and energy efficiency in the building is considered to affect the psychological health of residents [84]. Reduction of electricity consumption by using EE heating, cooling, refrigeration, insulation or light bulbs leads to less coal to be fired for electricity generation or less probability of creating heat islands. Improved air quality and less heat ensure a better indoor environment in buildings. The by-product of such an arrangement is improved respiratory, heart and mental health. Also, it reduces health hazards due to heat [85]. 
Access to affordable modern energy: Energy-related expenses consumed almost 15\% of the total income in low-income families in 1998 while during the year 2016, energy related expenses were recorded as $22 \%$ by the households in the very lowest income quintile. Energy efficient technologies can cut $40 \%$ of the energy cost, i.e., helps to reduce the burden on income to $9 \%$. The savings can be used to pay for more basic needs [86][87]. Moreover, saving energy would enable the utility to serve more people in different buildings [88].

Higher disposable income: As EE eases the burden of the utility bill, disposable income increases [89][90][91]. Research has found that almost $25 \%$ of the income from saved energy is spent on more goods and services [92].

Self-fulfillment: A study was conducted in 2009 by Yale Project on Climate Change and the George Mason University Center for Climate Change Communication. The research found more than third of the respondents to be motivated in saving energy in an attempt to protect the environment for greater wellbeing of humanity and enjoy self-satisfaction[93]. Sectoral Profits

EE technology adoption helps business prosperity of economic, industrial, transport, residential, commercial sectors, and the like.

Increased productivity and competitiveness of firms: Firms gain a competitive advantage by adopting EE through labor and capital as well as multifactor productivity. For example, in green buildings, improved ventilation and lighting boost labor productivity that equates to increased productivity of organizations. The increased asset value of green buildings through greater price premiums ensures capital yield. Water and energy usage are less in 
these buildings. In energy efficient hospitals, patients' recovery rate is found to be higher due to natural lighting, ventilation, indoor air quality and panoramic views of nature [94]. Energy provider benefits: Energy service providers can tap both direct and indirect benefits by embracing EE technologies. EE allows the reduced capacity of generation and transmission which in turn reduces maintenance cost and line losses. Less usage of fuels and water, financial risk, maintenance cost, credit and collection cost and greater readiness to comply with environmental regulations are some of the associated benefits of lesser energy production by energy providers. Apart from monetary gains, EE also creates an improved corporate image for utility service firms [89].

National Advantage

Macro-economy of the country gets lifted by EE technology. More employment: EE investment creates direct, indirect and induced jobs [89]. Investment in EE technologies need people of relevant skills and generate immediate employment opportunities. Workers use EE products and services and thus creating indirect jobs in supplier firms. Employees in both direct and indirect employment may use their disposable income to buy products and services in their respective state or countries and thereby, help induced jobs [95][96].

The lower government budget for energy subsidies: The public budgetary position can be improved through lower expenditures on energy in the public sector (government agencies on energy consumption and state-owned utilities on fuel purchases). In countries where fuels are imported, there is a positive impact on currency reserves. Similarly, in energyexporting countries, domestic energy efficiency can free up more fuels for export. Besides, 
for countries with energy consumption subsidies, reduced consumption means lower government budgetary outlays to finance these subsidies [96].

Energy self-sufficiency: EE helps countries who export, import as well as countries that subsidize energy consumption. EE allows energy exporting countries to attain greater supply stock. Energy-importing countries can minimize their use of fossil fuels and save currency reserves. The government needs to spend less on subsidizing energy consumption while EE technologies are in place and thus, eases stress on the federal budget. Moreover, EE prepares for the short-term and long-term energy crisis. The daily energy need during peak demand can be handled by EE whereas, investment in $\mathrm{EE}$, in the long run, derails climate change, tackles energy demand in case of rapid urbanization and ensures green building future [96][97].

Macroeconomic effects: EE is instrumental in increasing the total value of goods and services produced in a country, i.e., GDP. Investment in EE creates more avenues for manufacturing products and services. The output of related industries increases. There is more chance that savings in individual and government expenditure would be spent on domestic products [98][96].

International Benefits

Reduced CO2 emissions: EE is the cheapest way to comply with 'The Paris Agreement' adopted at COP21 in December 2015. The global problem of climate change due to Green House Gas (GHG) emission could be reduced by EE measures as laid out in Nationally Determined Contributions (NDCs) by participating countries in Paris Agreement. The cost 
of reducing GHG emission by the year 2030 has been proved to be at least $\$ 2.3$ trillion less compared to other mitigation alternatives [99].

Lower energy prices: Individual energy saving by EE options could create a commendable impact when it becomes to be a norm of the users in the market. The lower demand for energy pushes the demand curve downward that eventually reduces the wholesale price of electricity[100].

Less impact on scarce resources: EE initiatives have helped many countries to reduce dependence on non-renewable resources. Japan, Germany and the United Kingdom have been able to lower oil and gas imports by adopting EE [97].

Benefits for developed and developing countries: A large percentage of the population in the developing countries do not have access to energy. Countries experiencing rapid urbanization find it hard to cope with the higher demand for energy. EE allows providing energy facility to more people. Developed and developing countries need to collaborate in attaining climate goal. Financial and technical assistance from developed countries would enable developing countries to minimize GHG hazards and energy sustenance [101]. Developed and developing countries may tap social and economic benefits from collaborative research in energy efficiency [102].

\subsection{Problem Statement}

This section highlights some of the widely pronounced issues in diffusion of residential EE technologies. 


\subsubsection{Gap Between Predicted and Actual Potential of EE Technologies}

The adoption of EE technology is not yet widespread. 'How to accelerate the diffusion of EE technologies in the residential sector' is the genesis of many research projects that try to solve the problem of "Energy Efficiency Gap" or "Energy Paradox" or "Rebound Effect."

Due to "Energy Efficiency Gap" or "Energy Paradox" or "Rebound Effect," it is not possible to tap the full potential of energy efficient technologies [103] [104]. Authors have coined a plethora of definitions and explanations for a clear understanding of these phenomena. In simple terms, adoption of energy efficient technologies has been proven to be beneficial to adopters, but in many cases, these technologies are not preferred by users. The term Paradox" appropriately brands this event as it is contrary to a logical decision regarding EE technology choices. Moreover, the number of adopters is less than what is predicted or expected. Therefore, there is a "Gap" between projected and actual EE technology users [103]. "Energy Efficiency Gap" has also been clarified as the difference between the current and anticipated rate of diffusion. Adopters of EE technology in residential buildings are motivated only if their investment ensures profound benefit. An estimate found that $70 \%$ of the total EE technology potential projected by engineers has been realized in OECD (Organization for Economic Co-operation and Development) countries. There is an EE gap of 30\% [105]. The prospect of an energy efficient technology depends on different sets of barriers and drivers [106].

The expectation of saving energy by using energy efficient technologies could be a mirage in many instances as people may tend to spend more energy [107]. Air conditioners 
were identified as a significant electricity consuming unit in Arizona during peak demand times. However, energy efficient AC units were not considered as an option to deal with the odd as consumers may change their behavior and use AC for more hours - a natural outcome of rebound effect [108].

\subsubsection{Lack of Appropriate 'Measures' for Improving Diffusion}

'Measures' are deliberate actions that are quantifiable and is intended to improve diffusion of energy efficient technologies in residences [109]. As stated by William Thompson, also known as Lord Kelvin, "If you cannot measure it, you cannot improve it"[110]. Successful diffusion of EE technology needs identifying the relative impacts of market ability that would bolster the spread of these technologies in buildings [111]. Without assessing the status quo of EE technology diffusion regarding market capability, solutions and actions to accelerate EE diffusion may end in fiasco [112]. Measuring market diffusion potential would enable to identify market abilities that have the most significant impact on diffusion, which capability needs to be enhanced, and a subjective metric to measure how different actions would impact capability [113]. The federal Weatherization Assistance Program (WAP) in the state of Michigan failed to attain the desired outcome. Despite in-person communication with potential users regarding the process and benefits of the program, only $6 \%$ participated in the program. Experts opined that EE programs could not be generalized; implementation depends on the nature of customers and state of diffusion [114]. 


\subsubsection{Contrasting Factors Impact Diffusion}

Two different sets of elements impact the diffusion of EE technologies. Barriers are factors that obstruct the adoption of EE technology while factors that facilitate the dissemination of the technology are drivers. Barriers dissuade whereas, drivers initiate investment in energy-saving technologies [82][115]. The impact of barriers and/or drivers on feasibility and profitability of an energy efficient technology depends on relevant characteristics of technology, social, economic, sectoral (commercial, residential, manufacturing or service enterprises) [116], category (single, multifamily, new home, retrofit, etc.) [104] as well as geospatial (country, state etc.) [117][118][119] features. Perceptual-behavioral, financial-economic, institutional-structural and market-oriented barriers can be broadly classified as micro, meso, and macro while drivers are activated through financial, policy, institutional, regulation, and information manipulation [82]. 


\section{CHAPTER 3: LITERATURE REVIEW}

The chapter reviews literatures from published sources relevant to the issues identified in the problem statement. Three broad categories of literature are studied, for example, measuring diffusion, actions adopted for increasing diffusion and impact of different factors on diffusion of residential EE technologies.

\subsection{Measuring EE Technology Diffusion}

\subsubsection{Rate of Technology Diffusion}

Diffusion or market penetration rate of EE technologies could be slow, moderate or fast (Figure 12). Diffusion rate of a technology is considered to be slow or gradual irrespective of whether the product is in Traction (time from consumer availability to $10 \%$ penetration), Maturity (10\% to $40 \%$ penetration) or Saturation (40\% to $75 \%$ penetration) stage, if the time for reaching the targeted consumers is more than 15 years. Similarly, market penetration is accounted as moderate if the time needed for the technology to spread out is more than five years but less than 15 years. However, for specific technologies, it is found that a moderate rate of diffusion takes more time during traction and saturation compared to the maturity stage of the life cycle. For most technologies, faster rate of diffusion occurs when the targeted customers are reached within five years or less [120][121]. 


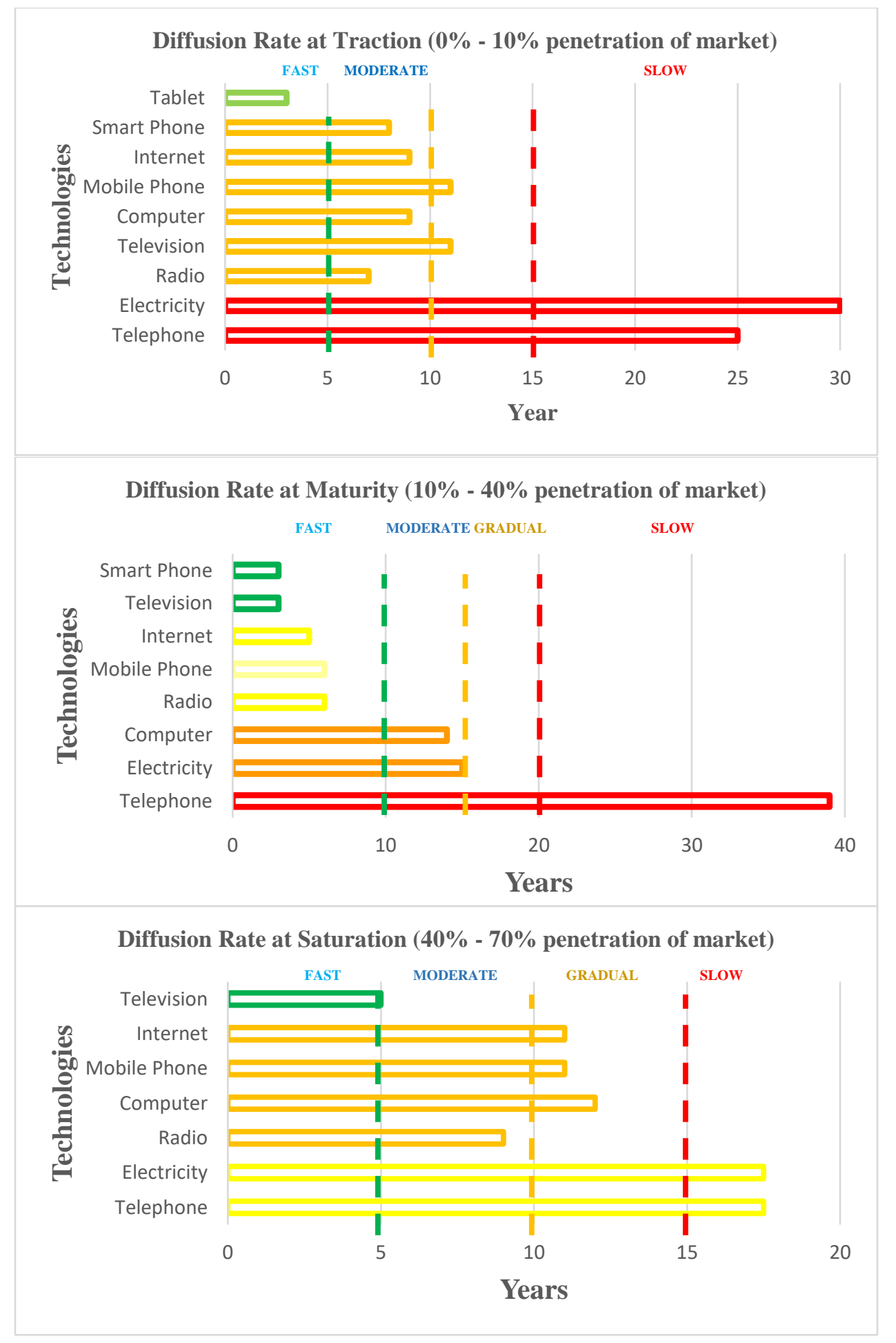

Figure 12: Diffusion Rate During Different Stages in Life Cycle 


\subsubsection{Models for Measuring Diffusion}

Many studies have been carried out to measure the diffusion of EE technologies not only in residential sectors but also in other industries. Traditionally, technology diffusion is measured by the number of actual adopters out of the total potential consumers and is expressed in percentage. The extensive unit-level data needed to quantify the extent of diffusion is not always easy to gather for many impactive technologies [122]. Label (e.g., Energy Star and LEED certification) and patents are two other indirect approaches to measure diffusion. However, there is always the chance of efficient buildings being left out of labeling or innovations getting strayed without being patented [123].

Different models have been used to understand the adoption of residential energy efficient technologies. Agent-Based Model $(\mathrm{ABM})$ is used to capture the adoption of $\mathrm{EE}$ technologies by households based on users' behavior and preference. Mostly, survey and empirical data are used to understand the process of adoption [124]. The diffusion has also been explained by an analogous equation to Darcy's Law of hydraulic flow and considers drivers and barriers in the diffusion of EE technologies [125]. A Micro-level household data from Pacific Gas and Electric (PG\&E) Company in California has been used to find consumers fuel choice for the short-term period and selection of EE technology in the long run to determine the adoption pattern of users [6]. Hence, the diffusion of EE technologies is mostly analyzed from the users' perspective.

Among Multi-criteria Decision Models (MCDM), Analytical Hierarchical Process (AHP) has been the most widely used model to rank barriers of energy efficiency technology in different sectors [126] [127]. Focus group discussion forum has been 
employed to identify managerial- organizational barriers to energy efficiency improvement [128]. Best worst method is also an MCDM tool that has been invented lately and used to rank barriers in energy efficiency technology for buildings [129]. Survey method has been used to prioritize barriers, incentives and benefits of energy technology diffusion by managers and employees of buildings [130] [131][132][104]. Positive and negative criteria (barrier and driver) are synthesized by pairwise comparison with respect to benefit, cost, opportunities and risks [133] [134]. Different categories of qualitative methods are used to rank barriers [135].Cross country case study analysis with field survey of decision makers and stakeholders are carried out to identify barriers and drivers to increase diffusion of EE technologies for retrofit [136]. Attitudinal research is adopted by combining qualitative and quantitative tool to understand attitudes of different actors in building sector to increase diffusion by appropriate actions[130]. The HERS (Home Energy Rating System) index is a metric developed by the Residential Energy Services Network (RESNET) to check the energy efficiency status of a house [137].

\subsection{Actions to Increase EE Technology Diffusion}

\subsubsection{Remove Barriers and Reinforce Drivers}

This section describes the different actions that are suggested in different literatures to reduce barriers and leverage drivers to increase the diffusion of residential EE technologies.

In most cases, policy, planning design, and development are formulated based on expert suggestions to overcome barriers and facilitate diffusion [129][138]. Financial reward, administrative orders and political rewards, improvement of the work environment 
and intrinsic reward are some of the options proposed to overcome barriers to energy efficiency. EE policies are suggested to remove perceived risk for adoption [139][140][141][142]. Fund creation, employing professionals, implementation of the law, encouragement from public institution and transparency are some proactive approaches to accelerate energy efficient technology adoption [143]. Cost benefit analysis is performed to analyze the impact of actions to improve energy savings by diffusion of EE technologies. The policies and programs need to be country and sector specific for removing barriers to energy efficiency. Micro and macro policy interventions are not only need to be in harmony to systematically address barriers but also ensure that they are cost-effective $[144][145][82][31][146][147][148]$. Energy consumption labeling scheme increases energy efficient technology adoption [31][30][149][150]. The adoption of EE technologies also depends on the strictness of policy [151].

Consumers' expectations and experience alter as the product moves along its product lifecycle. There are many studies which focus on clarifying consumers' interaction with EE technologies and what they expect from such appliances. Experience is formed by using an EE technology in a way that enables to accumulate knowledge about the product. When positive experiences are created through various stimuli, it extends the product value to customers. Several studies found the ambiance of a service center, quality level, the way of service delivery, reliable brands and supportive relationship to be strong inducements that enunciate positive experience [152].

Residential and commercial consumers are attracted to EE technologies when they have access to information, get personalized service, contribute to reducing environmental 
hazard and can avail rebates in buying the appliances[153]. However, energy labels and performance-based standards have more positive impact on consumers' buying preferences than financial incentives in the form of income tax credits or rebates. Increase in real electricity and gas prices have been found to impact users' inclination towards searching for energy efficient products [154][6]. Small sized appliances that are easy to operate and are reasonably priced are sure to capture consumers' preference. Besides, contractors play an important part by stepping up their knowledge and skill in making EE technologies available for new or retrofit applications as well as providing accessories and enabling technologies with installation flexibility and ease [155].

People having a positive experience with EE technology in the past is found to be more inclined to acquire EE appliances in the future. In some instances, imposing a tax on nonefficient technologies are thought to be an option to dissuade users from buying non-energy efficient products with favorable experience [156]. Study on automation with technical energy saving potential identified several potential benefits that have significance for consumers. Improved control, usability, thermal comfort, convenience, security and safety, precise room-level thermal control, visual comfort, privacy and ease of operation are some of the examples of individual gain that users prefer [157].

If consumers believe that they are gaining more value in comfort than the cost of the device, they are expected to prefer EE equipment. 'Utility' is the level of satisfaction perceived by a consumer [158]. Studies have proved that the variables that control thermal comfort in a house rely on climate, type of residence and personal relationship of occupants. The extent of satisfaction from an EE device installed indoor is contingent on 
the difference between consumer's perceived and actual benefit that they derive and is mostly dependent on individual characteristics [159]. Thirty percent of the LEED-certified buildings are found to perform beyond expectation while $25 \%$ are considered to underperform. Excess anticipation, faulty technicalities or inapt maneuvering, maintenance and use are responsible for such diversified outcomes [160]. In many cases, users need to have the knowledge or learn how to operate EE equipment. But user-friendly control and proper assistance and feedback can eliminate most of these odds [161]. Consumers' perceptual constancy regarding benefit from a particular EE technology product could be enhanced by building codes, mandatory disclosure regulations and green rating labels [162].

Adoption of EE technologies needs the diffusion of associated physical and intangible resources. Classification of resources for a firm's profitability and market performance by Kamasak is shown in Figure 13 [163].

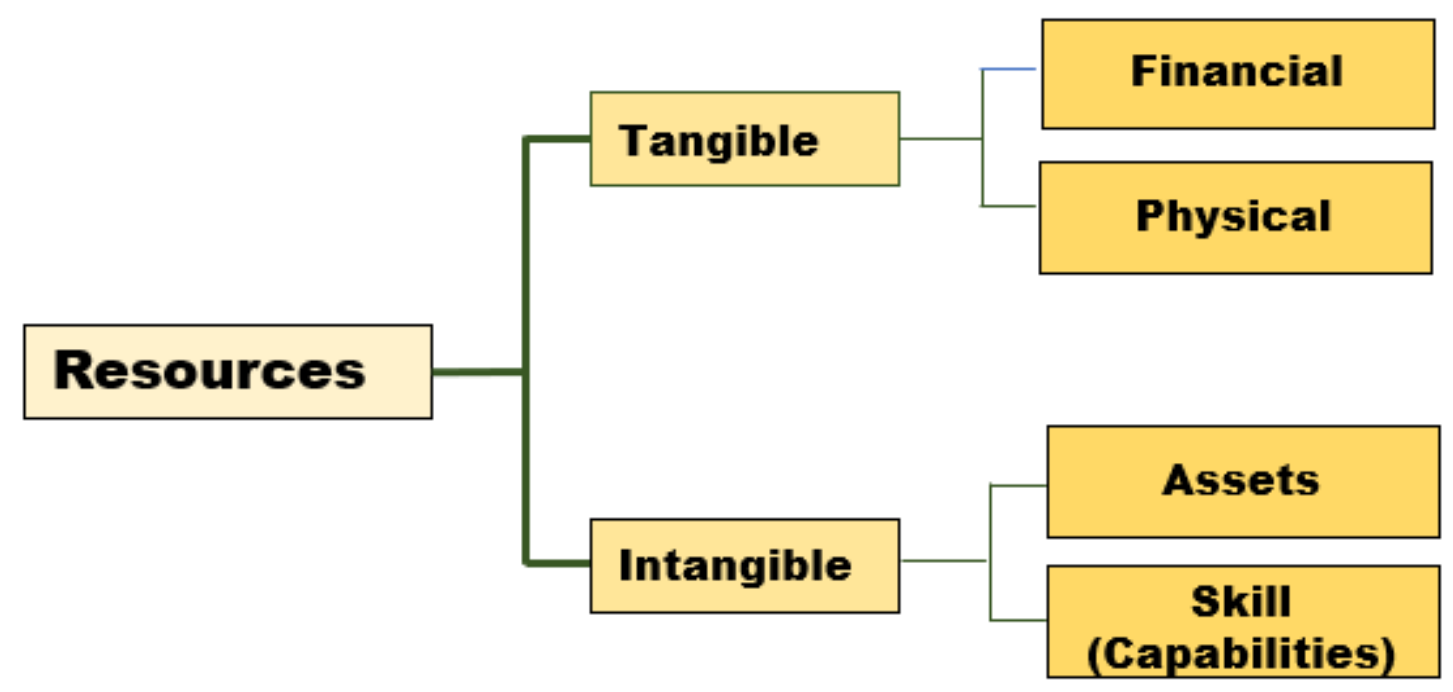

Figure 13: Classification of Resources 
Financial resources and physical goods are categories of tangible resources. Examples of physical assets are land, buildings, machines and tools, equipment, labor, and raw materials. Intangible resources are abstract. Intangible resources could be an employee's knowledge, creativity, organizational culture, brand, design, experiences, and skills [163][164]. Diffusion of technology needs dissemination of processes, knowledge, skilled human resource, availability and transfer of complementary technologies and a highperforming supply chain system. Enabling the adoption of technology requires training installers, maintenance personnel, constructors, troubleshooters by suppliers. Knowledge disseminates through the successive level of organizations and staffs. Funds are channelized from the government, local or industrial entities [165].

Different actors play their parts in the diffusion of technology to ultimate adopters. Innovators are responsible for developing new technology for the market. Opinion leader, facilitator, champion, linking and change agents are intermediate actors who contribute to various capacity for innovation diffusion. Opinion leaders act as catalysts which do not actively participate in the transfer of the innovation but aid in distribution across different firms[166].

\subsubsection{Energy Efficiency Activities}

Energy efficiency initiatives could be in small or large scale. Energy efficiency activities are deliberate endeavors to increase the adoption of EE technologies. However, market potential in the dissemination of an EE technology is essential irrespective of the proportion of activity or the way (deliberate or spontaneous) the product is installed for residential use. Figure 14 shows the different levels of energy efficiency activities based 
on scope and extent. EE measures are confined to improving EE performance by installing an EE equipment or system or adopting an alternative practice that saves energy. EE projects are a collection of initiatives in an individual establishment or location. A program is an assortment of projects with standard features and applications. A program must consider technology and its specific use [167]. A program could be implemented by a single entity or a group of organizations; Program needs careful detail on measures, approach and market segments. A portfolio is a set of similar programs serving one market segment and sometimes supervised by a single organization, e.g., utility [168].

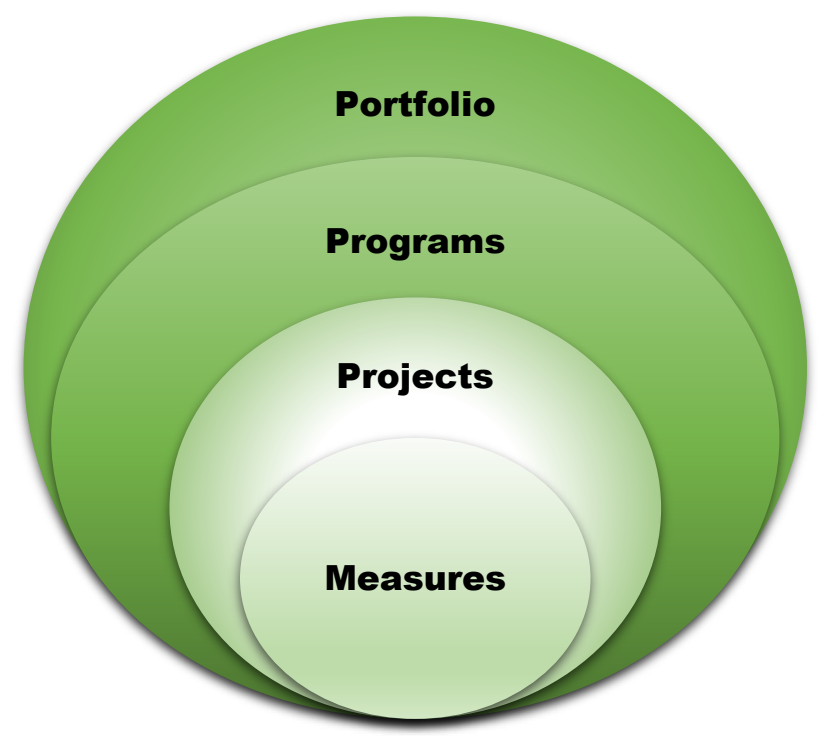

Figure 14: Different Levels of Energy Efficiency Activities

The total savings from EE technology adoption can be extracted either by programmatic savings, market transformation or non-programmatic savings (Figure 15). 


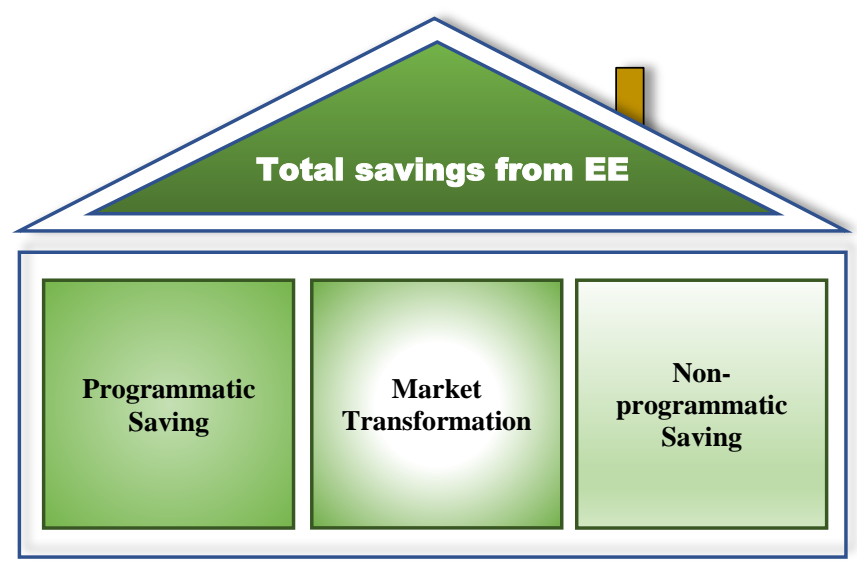

Figure 15: Energy Saving Approaches

Capital funding is employed for Programmatic savings, whereas expense funding is used for Market Transformation and Non-Programmatic savings [169].

Programmatic savings are achieved by programs funded by utilities, regional organizations or the collaboration of different organizations [170]. Market transformation addresses barriers and leverage drivers to achieve the sustained adoption of EE technologies [171]. Non-programmatic savings depend on the actions not supervised by utility or Northwest Energy efficiency Alliance (NEEA). Three ways to realize nonprogrammatic savings are shown in Figure 16. 


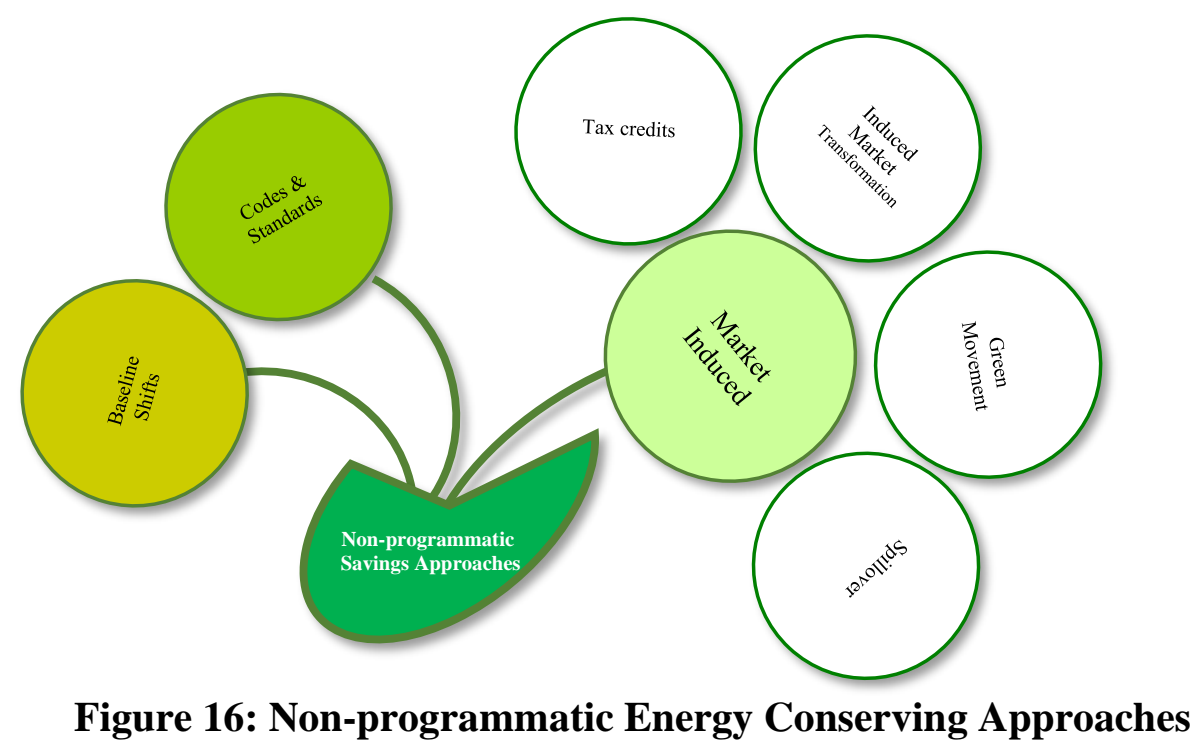

Baseline Shifts affect the energy saving calculation due to energy efficiency initiatives. A baseline is the reference point for comparing energy savings. The baseline metric could be frequently used or consumed state, "business-as-usual" or non-energy measure [172]. Codes and Standards are the legal requirements of percentage saving for buildings or specific appliance. Market-induced savings are achieved when efficient technologies are adopted by consumers not part of the utility-initiated energy efficiency programs [173]. Consumers may get reimbursement for expenditure on energy efficient devices through tax credits or government spending or spending from the American Recovery and Reinvestment Act (ARRA). Induced market transformation is other than the market transformation implemented by NEEA. Due to utility programs, there could be a positive change in the market that is conducive to energy efficiency adoption. Environmental consciousness of users drives the onslaught of the green movement that saves energy. Energy savings can also happen due to the influence of an energy efficiency program. A participant could continue to adopt EE even after the end of the program; Non-participants 
could become interested in saving energy once being exposed or acquainted to such programs without being an actual participant of the program [174] [175].

Different stakeholders are involved in the diffusion of EE technologies by developing codes, standards, incentives, roadmaps, build capability, enhance consumers awareness as well as making information available at all levels of the supply chain (K.-H. Lee 2015) (IEADSM 2018). The classification of stakeholders in promoting residential EE technology is captured in Figure 17.

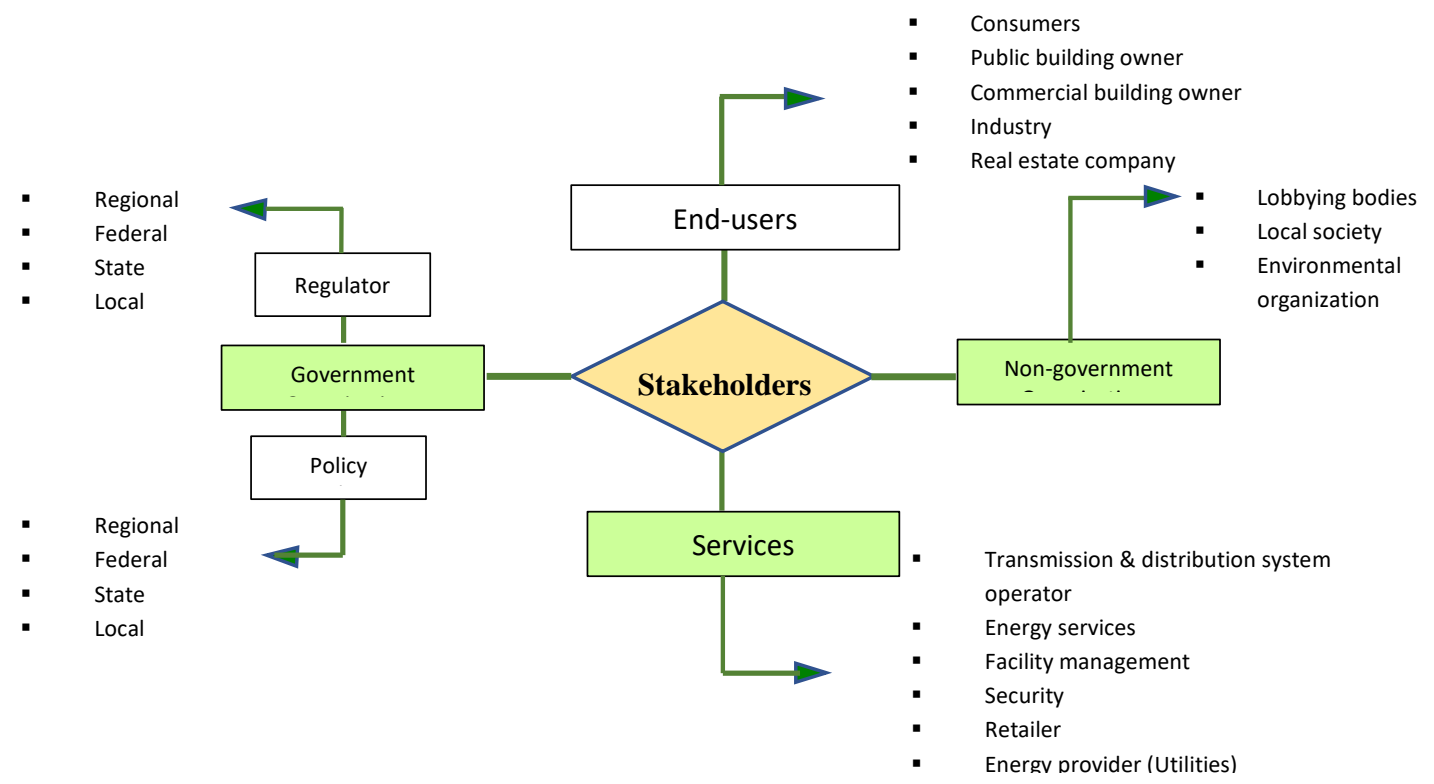

Figure 17: Energy Business and Services Stakeholders

The different objective and roles of Stakeholders in EE technology initiatives are listed in Table 1. 
Table 1: Stakeholders Activity, Objective and Instrument

\begin{tabular}{|c|c|c|c|}
\hline Stakeholders & Activity & Objective & Instrument \\
\hline $\begin{array}{l}\text { Government } \\
\text { authorities }\end{array}$ & $\begin{array}{l}\text { Owner/investor, facilitator, } \\
\text { regulator. }\end{array}$ & $\begin{array}{l}\text { Public } \\
\text { welfare }\end{array}$ & $\begin{array}{l}\text { Owns structure to demonstrate value } \\
\text { of EE by leading example; Helps and } \\
\text { facilitates EE initiatives by private } \\
\text { sectors; Formulates regulations and } \\
\text { policies through directives and } \\
\text { incentives. }\end{array}$ \\
\hline $\begin{array}{c}\text { Non- } \\
\text { government } \\
\text { organizations }\end{array}$ & $\begin{array}{l}\text { Implement policies, helps } \\
\text { building capacity, awareness } \\
\text { and knowledge diffusion } \\
\text { projects. }\end{array}$ & $\begin{array}{l}\text { Public } \\
\text { welfare }\end{array}$ & $\begin{array}{l}\text { Plans activities within the } \\
\text { confinement of jurisdiction. }\end{array}$ \\
\hline Services & $\begin{array}{l}\text { Provides primary energy, } \\
\text { ancillary services. }\end{array}$ & $\begin{array}{l}\text { Business } \\
\text { (profit) }\end{array}$ & Providing energy, goods and services. \\
\hline Users & $\begin{array}{l}\text { Consumes energy and uses } \\
\text { other associated services. }\end{array}$ & $\begin{array}{l}\text { Get better } \\
\text { service }\end{array}$ & Change in perception and behavior. \\
\hline
\end{tabular}

\subsection{Determinants of Residential EE Technology Diffusion}

Determinants are factors that impact the diffusion of EE technologies and affect the potential of diffusion. Barriers hinder optimal adoption while drivers accelerate the spread of EE technologies [82][129][176]. Different factors are categorized under a few broad legends. Depending on the positive or negative impact on diffusion, the same element could be a barrier or driver. In most instances, a factor could either facilitate or impede spread 
based on planning, decision making, implementation and adoption for EE technologies [106]. The following section discusses the different determinant factors in literature:

\subsubsection{Market}

Market structure: There are different interest groups in the market. Diffusion depends on the extent of conflict and consensus [104][1].

Split incentives: Different stakeholders need to be incentivized to drive an EE project [104]. Lack of incentives may divest while appropriate motivation flourish EE projects.

Project time: Building design and construction need less time when compared to EE building plan and projects [104].

Cost of conventional products: Cost of traditional products impacts EE products penetration in the market [129].

Perception about the market: Adoption of the EE technology depends on insight about market demand, size, energy pricing and image [129] [1].

The certainty of Demand: EE projects become compelling when demand for EE products can be predicted with confidence [129][144].

\subsubsection{Behavioral}

Sharing objectives: Successful adoption of EE technology needs compliance with goals and energy measures [104].

Other priorities: Energy saving is not the only consideration; adoption of EE technology also leads to the decision on initial cost and payback period [104].

Inertia: Extent of resistance to change by those involved in the building eco-system affects adoption [104] [139][140] [1]. 
Aggregation bias: Cost-effectiveness of an EE technology depends on a particular segment of consumers usage pattern [1].

Bounded rationality: In most instances, decisions are made based on limited or imperfect information and out of instinct or listening to heart rather than logically using rational deductions [104].

Perceived risk: Adoption of EE technologies entails certain uncertainties. Energy price, consumption pattern and useful life of the technology are unpredictable. People have different perception towards these probable outcomes. Adoption of the technologies, therefore, depends on intensity on perceived risk [140].

\subsubsection{Knowledge and Learning}

Sharing objectives: Successful adoption of EE technology needs compliance with goals and energy measures [104].

Other priorities: Energy saving is not the only consideration; adoption of EE technology also leads to the decision on initial cost and payback period [104].

Inertia: Extent of resistance to change by those involved in the building eco-system affects adoption [104] [139][140] [1].

Aggregation bias: Cost-effectiveness of an EE technology depends on a particular segment of consumers usage pattern [1].

Bounded rationality: In most instances, decisions are made based on limited or imperfect information and out of instinct or listening to heart rather than logically using rational deductions [104]. 
Perceived risk: Adoption of EE technologies entails certain uncertainties. Energy price, consumption pattern and useful life of the technology are unpredictable. People have different perception towards these probable outcomes. Adoption of the technologies, therefore, depends on intensity on perceived risk [140].

\subsubsection{Knowledge and Learning}

Awareness: Education and promotion help to reduce communication gap and enlighten adopters about cost and benefits of EE technologies [129] [149] [140].

Experts \& professionals: Promotion, installation, maintenance, repair or replacement of EE technology needs skilled and trained people. Proper training and knowledge are required to facilitate the adoption of the technology [129] [139] [149][143].

Information: The quality of knowledge about EE technology benefits and opportunities (Palm and Reindl 2017) affects its use. Users are manipulated by information which guides EE technology use [129] [139] [144][149] [1]. 


\subsubsection{Organizational and Social}

Decision-making approach: EE decisions in an organization hinges on intrapreneurship, convergence in managerial opinions and decision- making process [129] [1].

Authority: EE technology initiatives need legitimate power and decision- making authority [129].

Vision: EE technology diffusion needs future-oriented and clear stance from top level management. In the absence of a far-sighted approach, managements' time and effort, policy implementation and convergence of interests become disarrayed [129].

Slow working process: Work structure in implementing EE projects should be simple and faster [129].

\subsubsection{Economic/Financial}

Perceived benefits of investment: In building design and construction, the short-term view regarding initial investment overshadows long-term energy saving [104][177]. EE technologies are considered expensive due to substantial initial investment and also unreliable profitability calculation. In most cases widely accepted models like LCC, Payback Period: Payback Period or NPV or profitability Index (PI) are ignored. Incorrect calculation of costs of planning, implementation, and certification of EE technologies sometimes leads to a higher expense in actual use than perceived [129][1].

High initial investment and of Life Cycle Cost consideration: Benefits are calculated based on initial investment. Life cycle cost or incentives is a part of EE adoption decision [104]. 
External risk: Energy price is unpredictable and affects energy saving EE technologies [104]. Proper assessment of the risk of financial investment in EE projects leads to appropriate investment [129] [149] [1] [139].

High initial investment and long payback period: EE technology needs high initial investment but the time to get a return is very long which discourages allocating fund for the project [140] [149][139].

Lack of finances: EE projects need investment for planning and execution. The absence of fund impedes EE technology diffusion [129][149] [1][143].

Financial planning: Many a time financial decision regarding EE technology programs are short-term and short-sighted [129].

Selector, purchaser, user, and bill payer dilemma: Not all members of the building chain and construction earn benefit from EE equipment. A person who pays the bill gets the profit from energy efficient technology. Hence, other members are more enthusiastic about installing low-cost standard equipment to save investment. Moreover, even if the investor is the user, for massive buildings savings due to the replacement of conventional equipment by $\mathrm{EE}$ or installation of $\mathrm{EE}$ technology is insignificant compared to the overall cost of maintenance and operation. Therefore, EE technology adoption is of less importance. [1][140] [139].

\subsubsection{Governmental}

Planned incentives: Proper planning for disbursing incentives in EE technology promotion is required; otherwise the success of the initiative fades [129]. It is hard for developers to get a subsidy when government funding becomes scarce [139] [149] [1]. Financial 
incentives traditionally in the form of investment subsidies (grants) are among the most common policy instruments to promote EE [178].

Regulated time-invariant electricity price: Electricity rate set months or years ahead in regulated electricity (instead of time-of-use pricing) market and fails to make customers use energy efficiently[149][1].

Politics: Interest and support from leaders at different levels in EE project initiatives, bureaucracy, the interest of various organizations and streamlined structure are some political issues in EE technology adoption [129][179]. Nevertheless, political ideology leads to the different attitude towards energy issues [180][181].

Different perspectives towards energy and environment: Energy efficiency and environment should be considered as two sides of the coin. Integration of these two entwined issues in policy invention, implementation, and future planning are critical to $\mathrm{EE}$ technology penetration [129].

Priority of EE initiatives: While allocating government resources and finances among different projects, EE programs get less priority due to lack of interest from the government and derails EE endeavors [129] [149][143].

Federal and State standards: Energy standards are the technical basis for developing energy codes or how a building should perform as enforced by state or local government. Federal EE standard compels and promotes usage of EE technology. However, in the absence of Federal or State Standards for EE products there is less enthusiasm from manufacturers [129] [139][144][149] [143][182]. 
Implementation of codes and standards: Federal and State standards may not encourage EE if the codes and standards are not implemented, checked and evaluated. Lack of strong leadership at different levels of hierarchy acts as a barrier to EE adoption [129] [149].

Initiatives to promote EE: Creating awareness of EE technology benefits through effective communication boosts adoption [139].

\subsubsection{Technical}

Appeal: Resonating with Rogers diffusion theory, visual appeal of EE technology products due to design and aesthetics influence diffusion [82][30].

Energy saving potential (ESP): The reduction of residential energy consumption depends on the energy saving potential of EE technologies [183]. Also, investment decision on EE technologies is based on lifetime cost and savings [76]. Besides, certified buildings, as well as federal standards, consistently aspire more significant energy savings by EE amenities [71].

Useful Life: The time span during which the EE product performs reliably affects lifecycle cost as well as the contribution towards environmental protection. The hassle of frequent replacement of a device can be avoided with an EE technology that has greater longevity [30].

Technology compatibility: New EE technologies are sometimes not usable in existing building setups due to different standards, size or shape as well as in specific climate zone [129] [139][184].

Development of associated EE components: Development of EE products depend on the development of cost-effective EE equipment, components, and materials. The pace of 
innovation of related products or enabling technology help to accelerate EE technology diffusion [129] [139] [149].

Measure development and field study: Appropriate measure development and field research make documentation of energy saving potential of EE technologies possible and aid in the adoption of these technologies [129] [149].

Replacement of old technology: Adoption of EE technology is contingent on the rate of replacement of conventional technology [129][140].

Safety and reliability of EE technology: Without complete testing, new technology always run the risk of being unsafe for operation and maintenance [139][149].

Model of EE Technology installation: Many projects with EE technology and proven energy saving installations create cases that convince potential users [139].

Others: Human behavior could positively or negatively affect the uptake of EE technology in residences. In many instances, fund availability and political awareness propel technical capability of EE technology [143]. Barriers and drivers are country and sector-specific [145][117][151]. The advent and relative importance of barriers and drivers to energy efficiency vary with context and consumer perception [82] [141][30][146][135][185].

\subsection{Residential EE Technologies}

Energy Efficiency in buildings can offer the most significant energy savings in the U.S [186]. Energy efficiency of buildings depends on the positioning and shape of the house, shade and trees, building materials, walls, windows, lighting, insulation, ventilation, and air conditioning as well as heating and cooling system [187][188] [189]. International 
Energy Agency (IEA) foresees a substantial reduction in carbon emission in Blue Map Scenario. Blue Map Scenario enforces strict policy initiatives in contrast to Base Line Scenario which is business-as-usual. In the event of a Blue Map Scenario, the building sector has the prospect of saving one-third of the energy by the year 2050 compared to Base Line Scenario. Residential HVAC, water heating, and lighting would provide the opportunity to save 50\% energy in the whole building sector (residential and commercial). Figure 18 shows the energy savings by sector and end-use considering a total energy savings of 1509 Millions of tonnes of oil equivalent (Mtoe) in residential and commercial buildings combined. Residential sector is expected to save $2 / 3^{\text {rd }}$ of the total energy savings in buildings [190]. The pareto chart shows the energy savings by sectors in descending order of frequency with a cumulative line on a secondary axis as a percentage of the total energy savings.

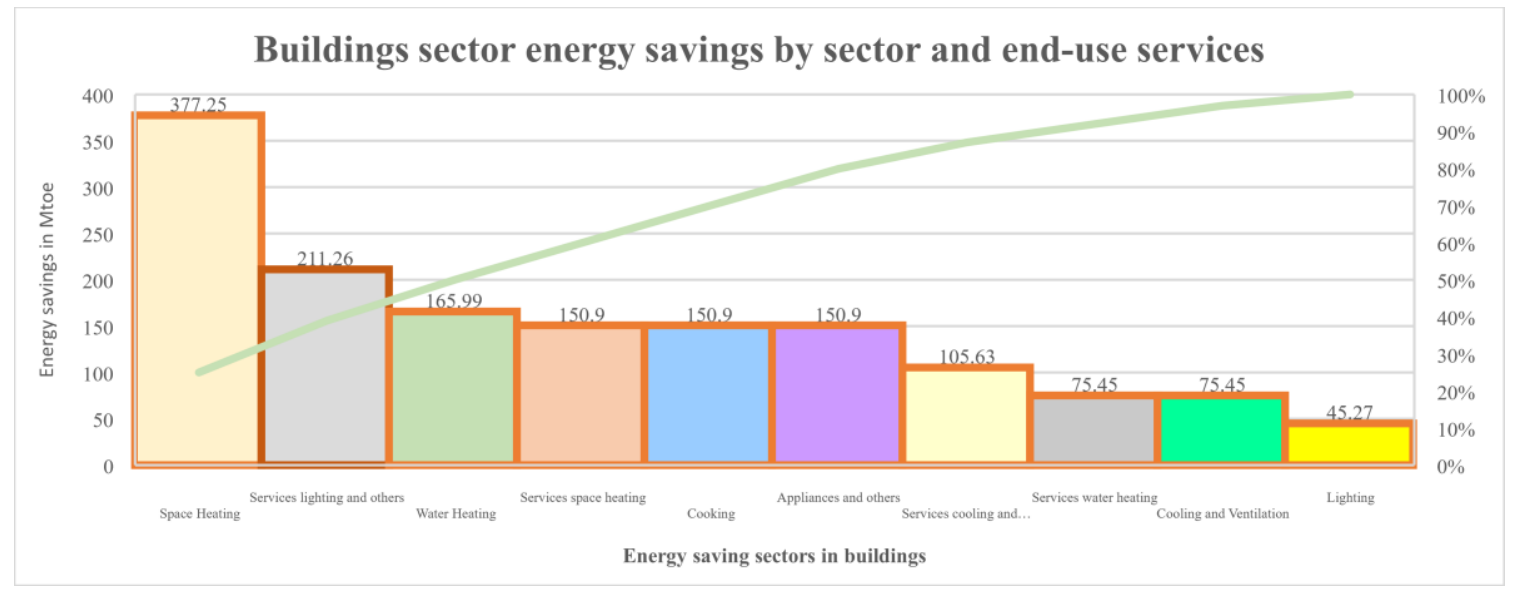

Figure 18: Buildings Sector Energy Savings by End-Use 
Heating, Ventilation, and Air Conditioning (HVAC) Technologies

HVAC systems provide comfort to dwellers in residential buildings by heating, cooling, ventilation, and humidity control in harmony with seasonality and weather condition [191]. Ventilation ensures the building gets required outside air, purification of recirculated air, driving out unwanted polluted air from a toilet, kitchen, etc., and circulation of air inside the dwellings. Pressure control monitors access of air and also, compensating the air exhausted from the house. Airconditioning equipment can be classified based on refrigerant and intricacy in the process of operation of the device [192][193].

Refrigerant based air-conditioning: Refrigeration cycle transfers heat from indoors to outdoors or vice versa.

Non-refrigerant based air-conditioning: Cooling involves evaporation.

Simple system: The refrigerant is used directly to heat or cool. Usually, the simple system is used for one zone.

Complex system: A secondary unit is used for heating and cooling. A complex system is used for heating or cooling more than one zone[194] [195].

The energy efficiency of an HVAC system improves with energy efficient components as classified in Figure 19 [196]. 


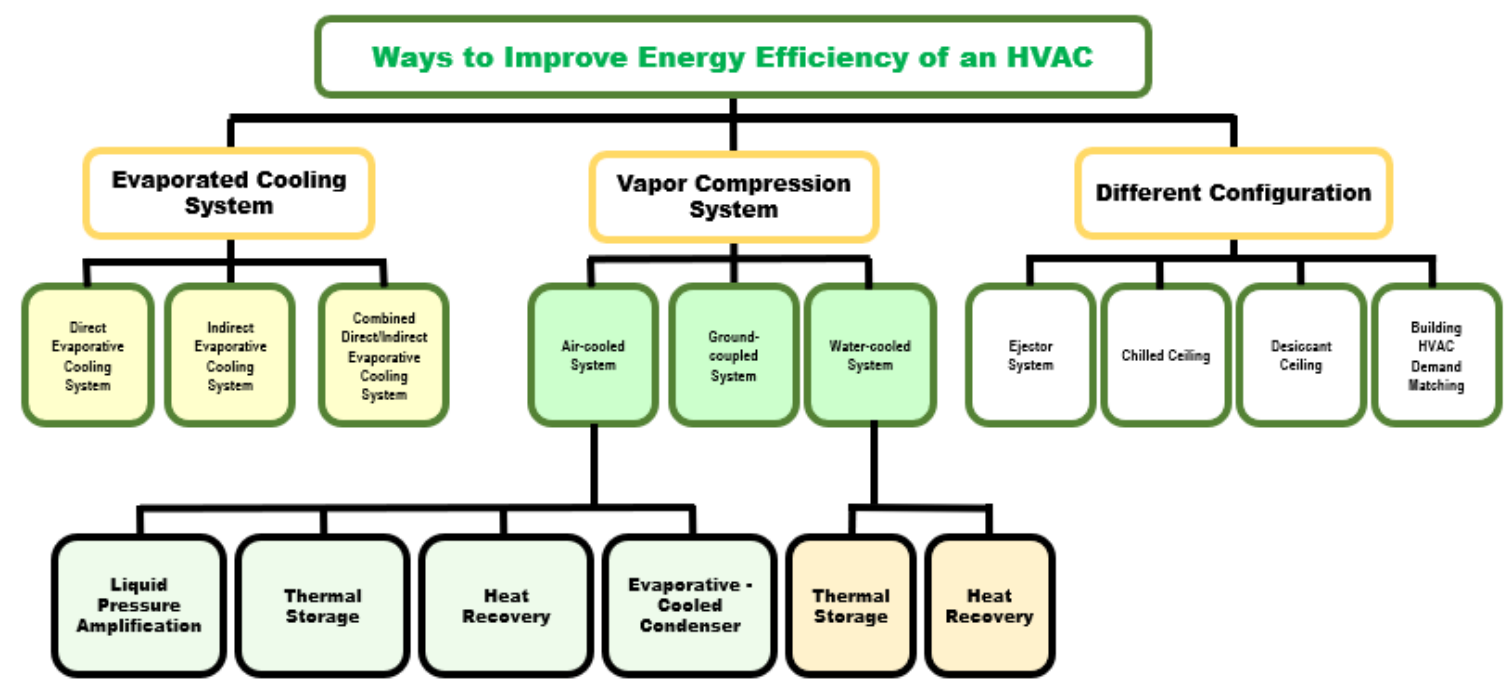

Figure 19: Different Ways to Improve the HVAC Efficiency

Some of the emerging HVAC appliances have a commendable energy conserving capability.

Ducted Heat Pumps: These categories of heat pumps are almost $50 \%$ to $200 \%$ more efficient than conventional electric energy devices [197]. Ducted heat Pumps consist of all components in a single unit. A duct channels the hot air from the condenser to the outside environment [198]. Ducted heat pumps are used when a single ductless heat pump is not sufficient to serve a multifamily home or for aesthetic consideration of the owner or installer [195].

Ductless Heat Pumps (DHP): This type of heat pump consists of an interior unit with a fan, and evaporator while the outside unit comprises condenser and the compressor. A pipe connects the units [198]. Ductless heat pumps are $25 \%$ to $60 \%$ more efficient than conventional devices that use fossil fuel [199]. 
Geothermal Heat Pump (GHP): This kind of heat pump uses heat from the ground. The temperature at a certain depth in the ground is constant, and that is why Geothermal heat pumps are more efficient than air heat pumps that extract heat from the environment where temperature variates [198].

Radiant Heating Ceiling Panels: Radiant Ceiling System is an efficient heating and cooling option for different abodes. It uses a hydronic system for comfortable temperature as well as optimal ventilation and humidity inside the living space [200]. Table 2 shows the relative savings by different HVAC devices.

Table 2: Energy Efficient HVAC Cost and Performance

\begin{tabular}{|l|c|c|c|}
\hline \multicolumn{1}{|c|}{ HVAC } & $\begin{array}{c}\text { Net COP (Energy } \\
\text { output to input } \\
\text { after losses) }\end{array}$ & $\begin{array}{c}\text { Installation } \\
\text { Cost (\$) }\end{array}$ & $\begin{array}{c}\text { Expected } \\
\text { Lifetime (yrs.) }\end{array}$ \\
\hline Geothermal Heat Pump (GHP) & 1.81 & 33,000 & 16 \\
\hline Ductless Mini Split Heat Pump (DMSHP) & 1.89 & 9,000 & 16 \\
\hline Heat Pump Ducted & 1.26 & 18,000 & 16 \\
\hline Radiant Heating Ceiling Panels & 1.20 & 8.000 & 40 \\
\hline
\end{tabular}

\section{Lighting}

An energy efficient light has the least life-cycle cost compared to other energy efficient appliances in the residential buildings. Light Emitting Diodes (LEDs) are the highly efficient lightings. Compared to conventional incandescent and fluorescent lights, they have many advantages regarding cost, longevity, reliability, and flexibility. LED is considered to be a disruptive technology [201]. It has the potential to save almost five billion dollars each year if every home in the U.S replaces their five mostly used light bulbs 
by Energy Star certified LED bulbs [202]. Three major lighting options in the year 2017 are listed in Table 3.

Table 3: Energy Efficient Light Options for Consumers

\begin{tabular}{|c|c|c|c|c|}
\hline Light Bulbs & Efficiency & Energy Use & Energy Cost & Typical Life \\
\hline Incandescent Halogen & $\begin{array}{c}30 \% \text { more than traditional } \\
\text { incandescent bulbs }\end{array}$ & 43 Watt & $\$ 5.18 /$ year & $1-3$ years \\
\hline Compact Fluorescent & $\begin{array}{c}75 \% \text { more efficient than } \\
\text { traditional light bulbs }\end{array}$ & 13 Watt & $\$ 1.57 /$ year & $6-10$ years \\
\hline LED & $90 \%$ more efficient than & & & \\
& traditional light bulbs & & $\$ 1.08 /$ year & $16-20$ years \\
\hline
\end{tabular}

\section{Water Heating Technologies}

Chapter 7 consists of a brief outline on the three different water heating technologies as technology cases. Table 4 describes in brief the different types of water heaters available. 


\section{Table 4:Types of Water Heater (WH) Technologies}

\begin{tabular}{|c|c|c|}
\hline Type of WH & Description & Characteristics \\
\hline $\begin{array}{l}\text { Conventional gas } \\
\text { storage }\end{array}$ & $\begin{array}{l}\text { This type of water heater has a storage } \\
\text { Tank. The temperature is controlled by a } \\
\text { burner or electric element fire [203]. }\end{array}$ & $\begin{array}{l}\text { Storage water heaters are by far the } \\
\text { easiest for consumers to obtain, } \\
\text { particularly when an immediate } \\
\text { replacement is needed [203]. }\end{array}$ \\
\hline $\begin{array}{l}\text { Oil-fired free- } \\
\text { standing }\end{array}$ & $\begin{array}{l}\text { This type of water heaters use burner } \\
\text { operated by oil and some part of fuel } \\
\text { consumption is from electricity [204]. }\end{array}$ & $\begin{array}{l}\text { This type of WH need considerable } \\
\text { maintenance for safety, efficiency } \\
\text { and cost effectiveness [205]. }\end{array}$ \\
\hline $\begin{array}{l}\text { Conventional } \\
\text { electric storage }\end{array}$ & $\begin{array}{l}\text { It consists of a tank with insulation. A } \\
\text { thermostat controls electrical element that } \\
\text { heats the water [206]. }\end{array}$ & $\begin{array}{l}\text { This type of heater is more flexible } \\
\text { than other type of water heaters. } \\
\text { They do not need fuel line, exhaust } \\
\text { flue or pilot lights [206]. }\end{array}$ \\
\hline $\begin{array}{l}\text { Demand Water } \\
\text { Heaters }\end{array}$ & $\begin{array}{l}\text { These are also known as tankless water } \\
\text { heaters, A heating element or igniter heats } \\
\text { water when water is drawn through a } \\
\text { faucet [207]. }\end{array}$ & $\begin{array}{l}\text { The advantage of this type of } \mathrm{WH} \text { is } \\
\text { that it does not need a storage tank. } \\
\text { Different types of fuels) Gas, } \\
\text { electric, propane) can be used [207]. }\end{array}$ \\
\hline Electric Heat Pump & $\begin{array}{l}\text { Use electricity as the fuel. It draws heat } \\
\text { from ambient environment and transfers it } \\
\text { to alter in a storage tank [208]. }\end{array}$ & $\begin{array}{l}\text { Highly efficient water heater } \\
{[208][209] .}\end{array}$ \\
\hline $\begin{array}{l}\text { Indirect water heater } \\
\text { with efficient gas or } \\
\text { oil boiler }\end{array}$ & $\begin{array}{l}\text { Consists of heat exchangers. Two separate } \\
\text { components, for example one inside coil } \\
\text { and one outside HX plate [208]. }\end{array}$ & $\begin{array}{l}\text { The efficiency of this type of water } \\
\text { heater depends on the design and } \\
\text { features [208]. }\end{array}$ \\
\hline $\begin{array}{l}\text { Solar with electric } \\
\text { back-up }\end{array}$ & $\begin{array}{l}\text { Water is heated by heat from sunlight } \\
\text { gathered by collectors [208]. }\end{array}$ & $\begin{array}{l}\text { These are the most energy efficient } \\
\text { water heaters, They cause less } \\
\text { pollution but is dependent on sun } \\
\text { light [208]. }\end{array}$ \\
\hline
\end{tabular}




\subsection{Cases of Energy Efficient (EE) Technology Diffusion in Different States}

Energy efficiency programs have gained momentum in many states in 2019. Massachusetts, California, and New York led the energy efficiency initiatives. A new group of states joined the crowd with aspiring energy efficiency targets. Nevada, New Mexico, Washington, Maine, Virginia, New Jersey, Colorado, Washington, and Hawaii each has set their own efficiency target and strategy for achieving greater energy savings. State Scorecards show the position of different states in terms of six policy areas: Utility and public benefits programs and policies, Transportation policies, Building energy efficiency policies, Combined heat and power (CHP) policies, State government-led initiatives around energy efficiency, and Appliance and equipment standards (Appendix C)[210]. The next section describes the success and failure of initiatives adopted in different states.

Massachusetts is leading the EE drive with the highest score in State Scorecard. However, due to barriers in securing credit, and also, 'split incentive problem', residents are yet to enjoy the full benefit of energy efficiency. Home heating causes a large financial burden for residents in buildings. Codes and standards have effects on new building constructions but for residents, it is a voluntary choice to adopt EE appliances and it has impacted the states ambition in embracing EE technologies in residential and commercial buildings [211].

California has been in the forefront in implementing energy efficiency projects. Energy efficiency projects in Southern California are aided by investor owned utilities. The Energy Network Public Agency Program was intended for better energy management since 2013. 
The program identified many energy efficiency opportunities but funding and experience of project members have been identified as major obstacles in energy efficiency projects [212].

NEEA (Northwest Energy efficiency Alliance) initiated a pilot project in 2008 to replace electric water heaters by Ductless Heat Pump (DHP) water heaters in the Northwest and made commendable progress in diffusion of the technology. However, a report prepared by Cadmus in 2019 identified areas where actions need to be taken to continue diffusion of the technology when direct support from NEEA recedes. Some of the key issues identified in the report are, lack of awareness by suppliers about cold climate water heaters, high initial cost, lack of trained installers, and unwillingness from the part of distributors to promote the technology [213].

According to New York State's Energy Research and Development Authority (NYSERDA), lack of consumers' confidence in new technologies has led to low diffusion of energy efficient space heating technology in the region. Also, the diffusion depends on the location of the states in different climatic zones. Heat pumps have not been very popular in colder climates but have proved to be appropriate for southern climates due to fewer heating degree days [214].

Based on the literature review, the following gaps are identified in the literature as shown in Table 5. 


\section{Table 5: Gap Analysis}

\begin{tabular}{|l|l|}
\hline \multicolumn{1}{|c|}{ GAPS } & \multicolumn{1}{|c|}{ Description } \\
\hline GAP 1: Residential EE technology adoption has & What are the different market attributes and key \\
the perspective of market that affects the potential of & that affect the Market Diffusion Potential (MDP) \\
diffusion. & of EE technologies in the residential buildings? \\
\hline $\begin{array}{l}\text { GAP 2: Different models analyze the effect of } \\
\text { drivers and barriers on adoption but do not quantify }\end{array}$ & What is the relative impact of market attributes and \\
the impact in the diffusion of residential EE & Potential (MDP) of an EE technology in the \\
technologies. & residential buildings? \\
\hline $\begin{array}{l}\text { GAP 3: Possible incentives, policy interventions, } \\
\text { and behavioral modifications are mostly based on the }\end{array}$ & How different actions to improve diffusion impact \\
subjective judgment of existing barriers and drivers & residential EE technologies? \\
actions on increasing diffusion. &
\end{tabular}




\section{CHAPTER 4: RESEARCH OBJECTIVES, QUESTIONS, AND METHODOLOGY}

This section of the report sets out the objective or the goal that the research has accomplished. The research questions elaborate how the gaps are addressed through this research effort. The methodology describes the methods, procedure and techniques in different phases of the research as well as justifies the model to best quantify Market Diffusion Potential [215][216].

\subsection{Objective}

Consumer needs are more specific than before, and demands are hinged on gaining personal benefits rather than only performance or what the product or service is intended for [53]. Market Diffusion Potential (MDP) is a tool that is able to measure how capable the market is in delivering the privileges to the customers through marketing mix and quality dimensions for diffusion of technology at any point in time during its life cycle. EE technologies at different stages in their life cycle may struggle in diffusing to probable adopters. Market Diffusion Potential would be able to identify the status quo of the market concerning the prospect of offering social, economic, legal, technological and industrial advantages to consumers that drive adoption and lead to diffusion.

Based on the issues identified in the problem statement, the following objective, subobjectives and research questions are generated.

Main Objective

To develop a Market Diffusion Potential (MDP) Assessment Model for Residential Energy Efficient (EE) Technologies in the U.S. 


\section{Subobjectives:}

- To determine the market attributes that drive diffusion of EE technologies

- To find out the components or product and service characteristics that constitute market attributes

- To find the relative strength of the attributes and components towards MDP

- To use the model to find the MDP of competing residential EE technology cases

Through the rigor of the research design and methodology and the case study application, the study answers the following questions:

- What are the most important market attributes needed for diffusion of EE technologies?

- What are the key components that are needed to attain specific market attribute?

- What are the relative strengths of the market attributes and key components that impact the MDP?

- What data collection method is appropriate for the study?

- How to find the relative MDP for competing case technologies and what do they mean?

- $\quad$ How the model can help in practice?

\subsection{Review of Multicriteria Decision Models (MCDM)}

Multicriteria Decision Making (MCDM) is a useful tool in making a decision when there are many objectives, players, and issues that need to be considered simultaneously and is dependent on the experts' judgment [217][218]. Hence, MCDM is an appropriate 
tool for the present study as it allows making a practical, efficient, flexible, adaptable and acceptable decision that is backed up by collective opinion of experts. Three broad classifications of MCDM are Multi-Attribute Decision Making (MADM), Multi-Objective Decision Making (MODM) and Hybrid Multicriteria Decision Making (HMCDM). HMCDM has four different options based on the objective of research [217] [219] as shown in Figure 20.

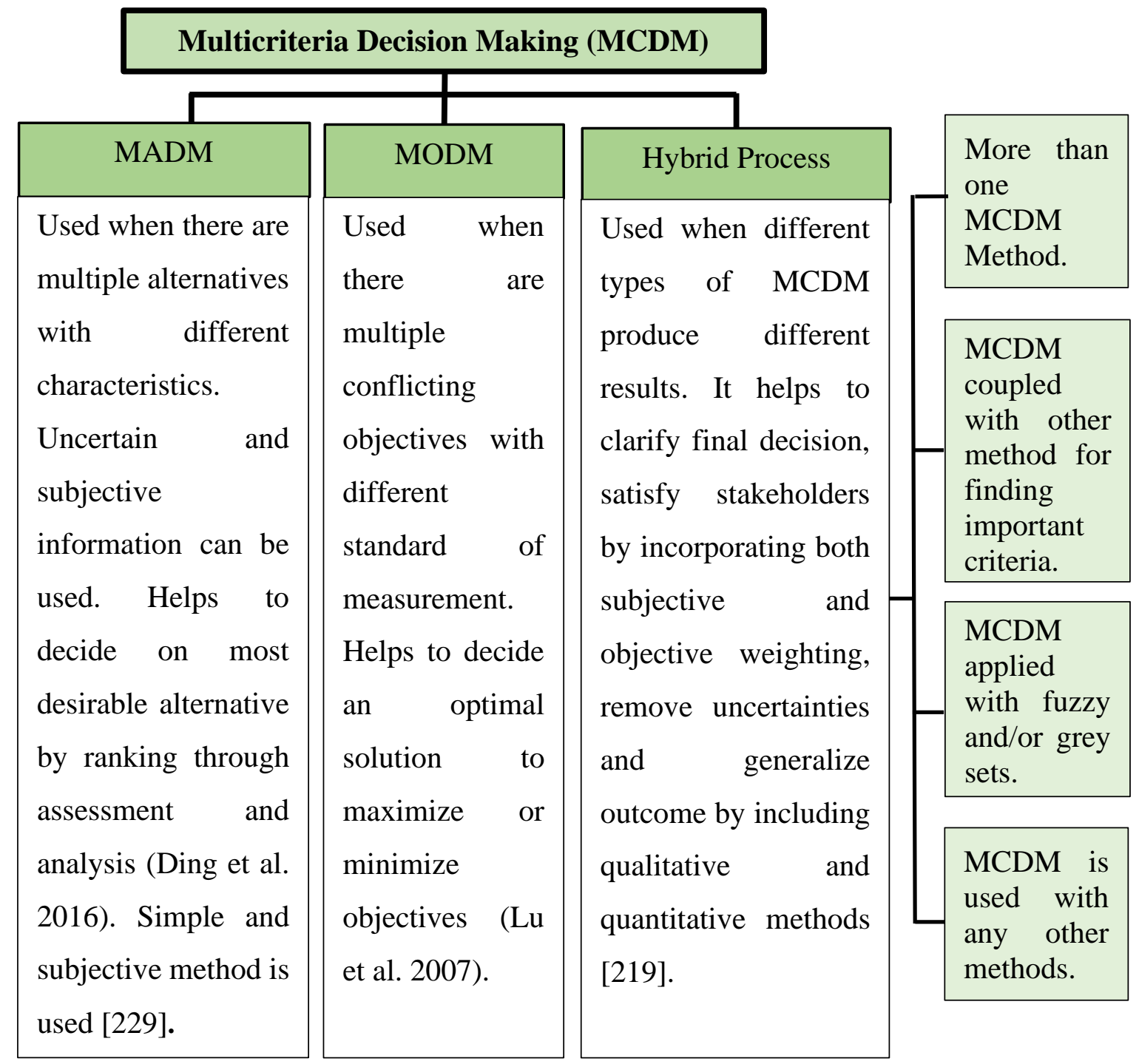

Figure 20: Classification of Multicriteria Decision Making (MCDM) 
MCDM can be carried out by choosing various methods as outlined above. However, there are different models under each of these methods. Models are meant to understand a problem area applying different ways [220]. Based on the research carried out by Mardani et al., Figure 21 shows the widely used MCDM from the year $2000-2014$ in percentage. However, a new vector based MCDM model known as Best Worst Method (BWM) which is developed by Dr. Jafar Rezai in the year 2015 has gained wide acceptance in the research community.

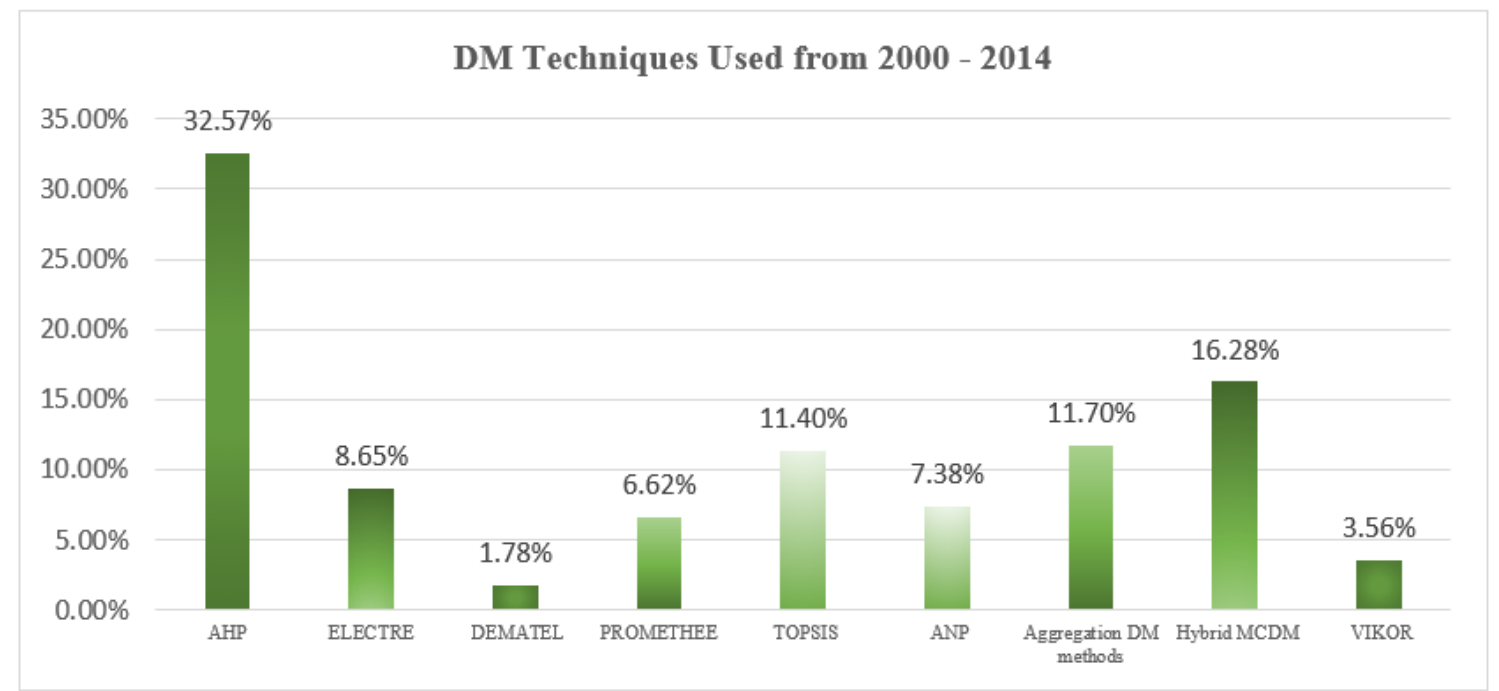

Figure 21: Decision Making Models Used in Research

Table 6, Table 7, and Table 8 show the different widely used models with associated pros and cons in their application [217][221][222][223][224][225][226] [227][228][229][230][231] [232][233][234][235] [236][237][238]. 
Table 6: Outranking Models

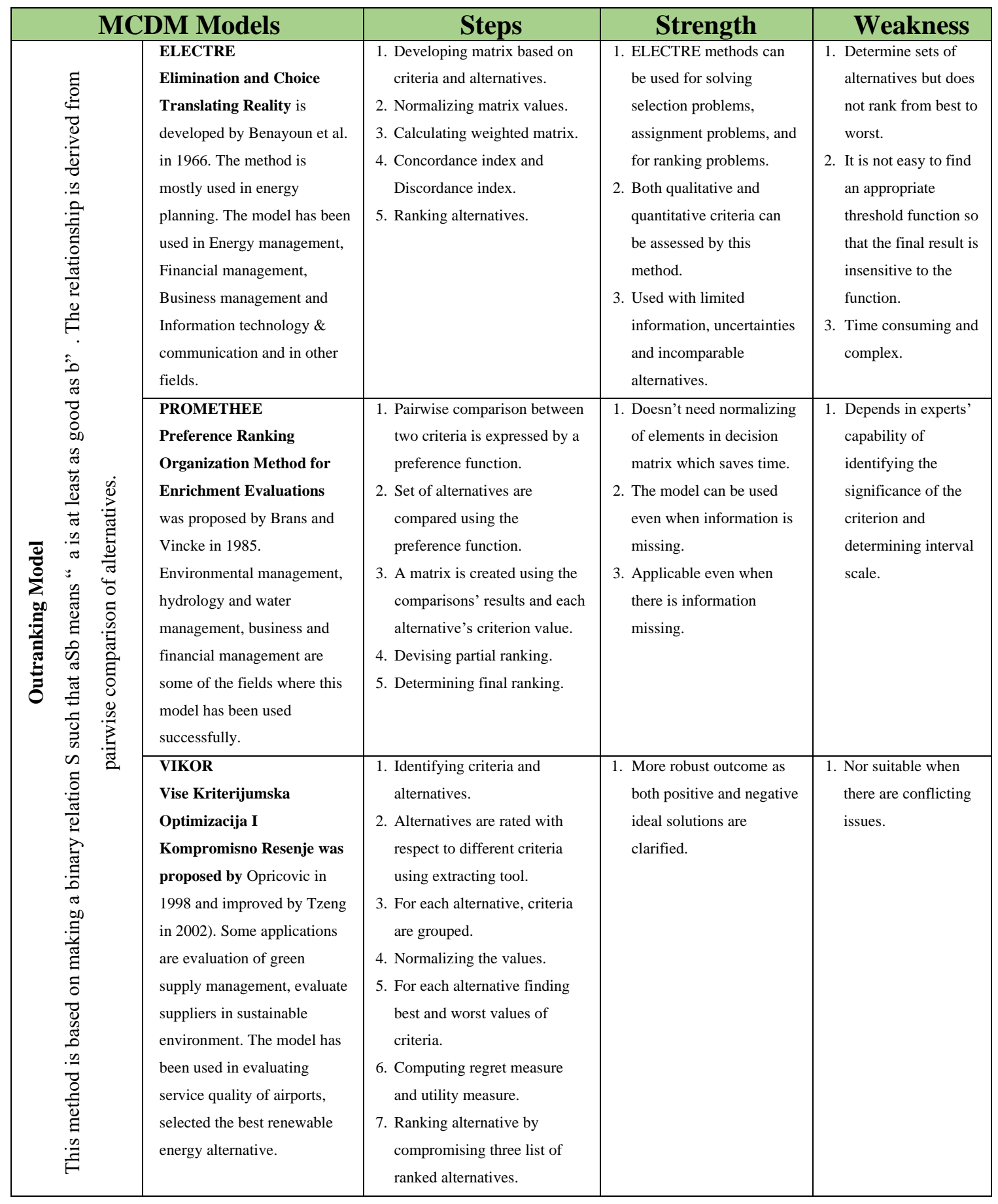


Table 7: Utility Based Model

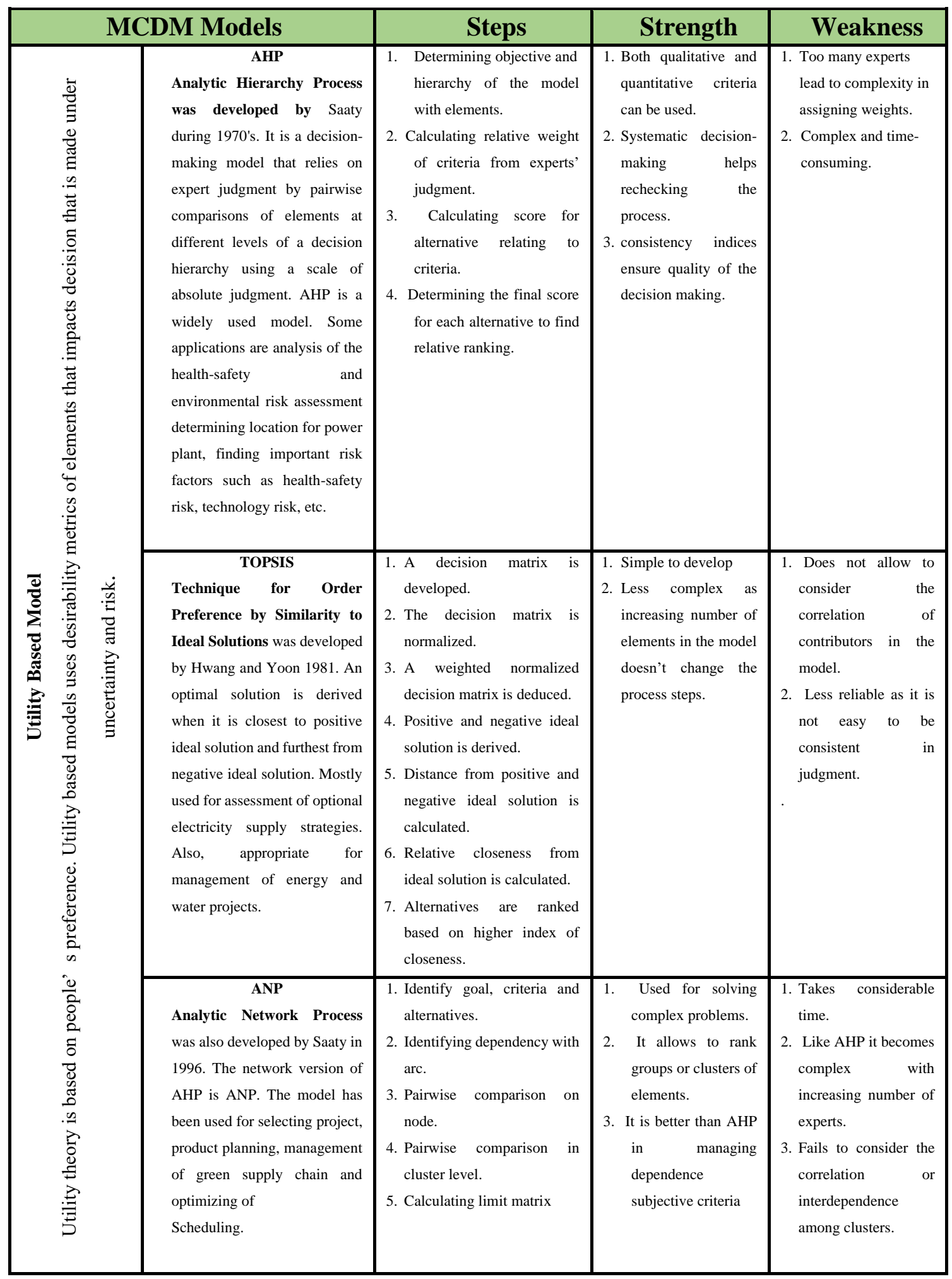


Table 7: Utility Based Model (Continued)

\begin{tabular}{|c|c|c|c|c|c|c|}
\hline \multicolumn{4}{|c|}{ MCDM Models } & Steps & Strength & Weakness \\
\hline 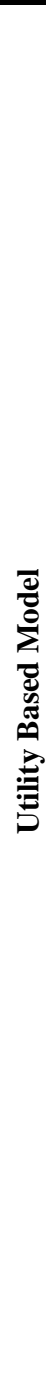 & 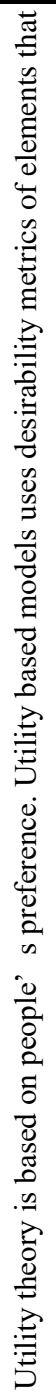 & 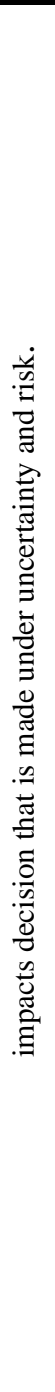 & $\begin{array}{l}\text { DEMATEL } \\
\text { Decision Making Trial } \\
\text { and Evaluation } \\
\text { Laboratory was initiated } \\
\text { by Science and Human } \\
\text { Affairs Program of the } \\
\text { Battelle Memorial Institute } \\
\text { of Geneva between } 1972 \\
\text { and 1976. The model has } \\
\text { been used for assessing } \\
\text { performance of supplier } \\
\text { quality, criteria for design } \\
\text { of restaurant space, } \\
\text { business process } \\
\text { management and in many } \\
\text { other problems. }\end{array}$ & $\begin{array}{l}\text { 1. Identifying decision, goals } \\
\text { and objectives. } \\
\text { 2. Clarifying elements and } \\
\text { alternatives related to the } \\
\text { objective. } \\
\text { 3. Determine utility for each } \\
\text { individual element as well } \\
\text { as comparing each set of } \\
\text { elements. Normalizing the } \\
\text { values } \\
\text { 4. Considering the preference } \\
\text { of different elements and } \\
\text { weighting with respect to } \\
\text { each alternative, the } \\
\text { alternatives are ranked in } \\
\text { order of preference. }\end{array}$ & $\begin{array}{l}\text { 1. The process of ranking } \\
\text { is simple. } \\
\text { 2. Eliminates impact of } \\
\text { experts' subjectivity. } \\
\text { 3. Clarifies relation and } \\
\text { dependence } \\
\text { attributes. } \\
\text { 4. Visual representation } \\
\text { helps decision making. }\end{array}$ & $\begin{array}{l}\text { 1. Alternatives are ranked on } \\
\text { relationships and hence, } \\
\text { those criteria which do not } \\
\text { have relationship do not } \\
\text { contribute in final decision. } \\
\text { 2. Individual assessment by } \\
\text { experts are not used for } \\
\text { group judgment. } \\
\text { DEMATEL is more } \\
\text { effective when applied with } \\
\text { other MCDMs than alone. }\end{array}$ \\
\hline
\end{tabular}


Table 8: Vector Based Model

\begin{tabular}{|c|c|c|c|c|}
\hline \multicolumn{2}{|c|}{ MCDM Models } & Steps & Strength & Weakness \\
\hline 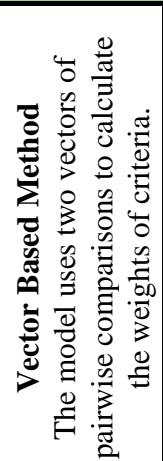 & \begin{tabular}{l}
\multicolumn{1}{c}{ BMW } \\
Best Worst method was \\
developed by Dr. Rezai in \\
2015. Since its inception it has \\
been implemented in many \\
different fields for robust \\
decision making.
\end{tabular} & $\begin{array}{l}\text { 1. Identify criteria } \\
\text { 2. Identify best and worst criteria } \\
\text { 3. Comparing the best driver with } \\
\text { respect to other drivers } \\
\text { 4. Comparing all other drivers } \\
\text { with respect to worst driver } \\
\text { 5. Calculating the optimal } \\
\text { weights }\end{array}$ & $\begin{array}{l}\text { 1. Less comparisons } \\
\text { 2. More reliable } \\
\text { 3. Only integers are used for } \\
\text { comparison }\end{array}$ & $\begin{array}{l}\text { 1. Use of } \\
\text { discontinuous scale } \\
\text { fails to capture the } \\
\text { granularity in } \\
\text { priorities. }\end{array}$ \\
\hline
\end{tabular}

\subsection{Research Models and Tools}

The purpose of the study is to develop an "Assessment Model for Market Diffusion Potential for Residential EE Technology" at a certain point in time. Hence, the problem involves:

- An objective of determining MDP of residential EE technology

- The goal is dependent on several criteria

- Factors can be structured into several hierarchies

- The decision depends on a group of experts' preferences

- There is no unique optimal solution as the criteria, and experts' opinion cannot be universal

A multi-criteria decision model (MCDM) is appropriate for dealing with complex problems with many criteria and sub-criteria and decision problems that can be classified into several hierarchies. MCDM is a generic term which includes all the models and methods that helps to take a decision when the final decision depends on criteria, many of 
which could be at odds [239]. The tools that are used at different phases of the research are explained below:

STEEPLE: STEEPLE (socio-cultural, technological, environmental (or ecological), economic, political, legal, ethical) analysis is used as a guide as it helps to analyze technology from different perspectives [240].

Weighting: Ranking the criteria and identifying the relative impact of sub-criteria towards criteria by HDM proposed by Dr. Kocaoglu has been used for pairwise comparison[241]. Desirability Curve: Desirability functions is used to determine how different factors associated with each criterion affects percent diffusion [242][243][167][244][245].

Amalgamation: The total score for each alternative (three EE technologies are used as case alternatives) is calculated to find out the relative diffusion status concerning all the elements in the model [246].

Developing Measures: The low rating attributes in the model for each alternative are identified and appropriate actions are formulated. The corresponding impact of action is measured and analyzed [247].

Scenario analysis: Scenario analysis is carried out to identify how the diffusion potential changes as the scores or weights of factors that affect the level of diffusion of alternatives change [246][247].

The research plans to address research questions and achieve the objective of the research as captured in Figure 22. 


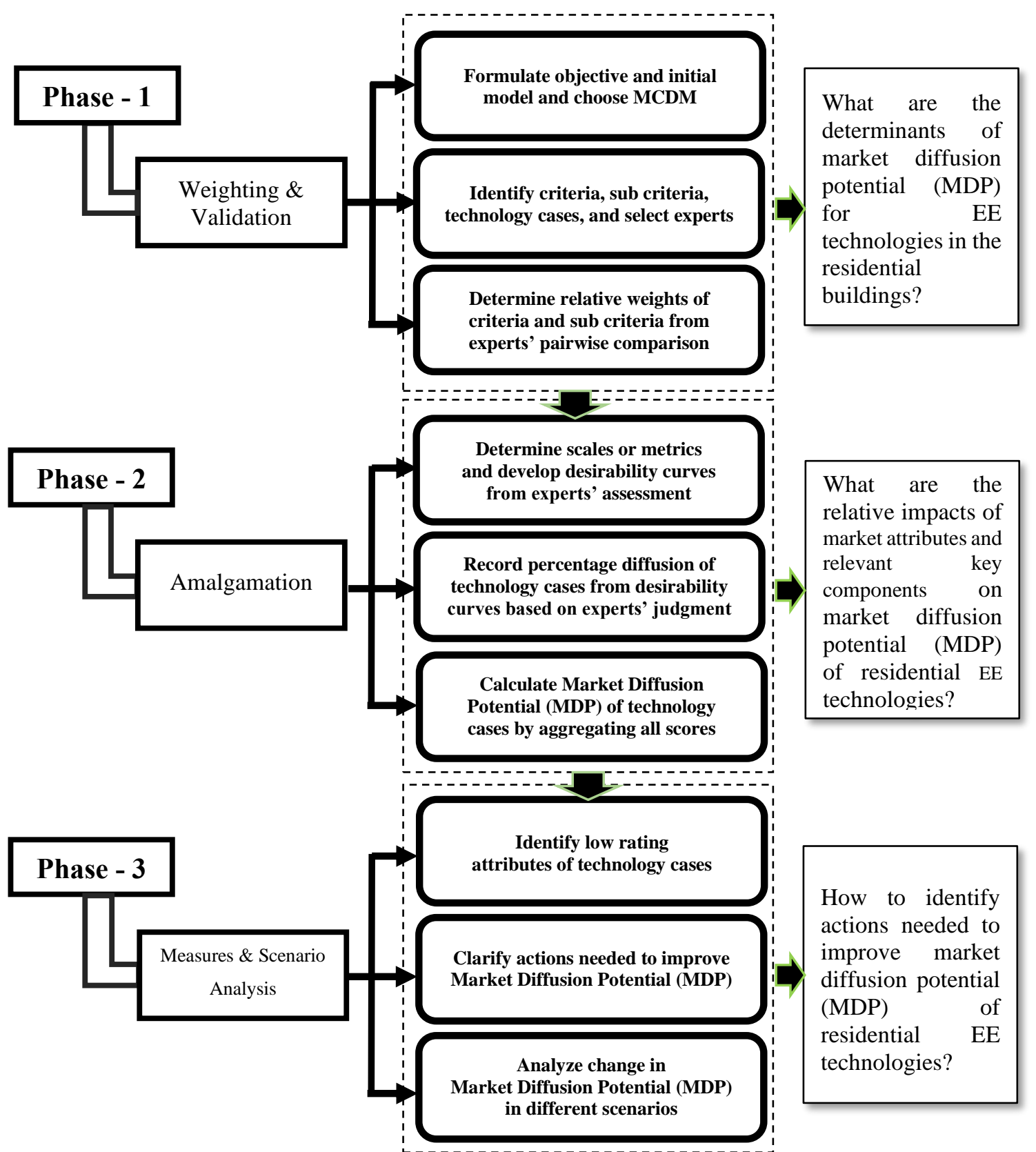

Figure 22: Research Plan 


\subsubsection{Hierarchical Decision Model}

The Hierarchical Decision Model (HDM) is used for the research and it was developed by Dr. Kocaoglu as a PhD dissertation and has since been applied to numerous decision problems. The software for the model was developed by Dr. J. Abara [241]. Hierarchical Decision Model (HDM) is similar to Analytical Hierarchical Process (AHP) developed by Thomas L Saaty as they both help to simplify complex relationship among elements by allowing them to be partitioned into different levels or hierarchy. However, these two methods adopt different mathematical algorithm. Saaty uses the 'Eigen Value' method while Dr. Kocaoglu's HDM adopts Constant Sum Method [248]. The different levels of the HDM are categorized by the acronym MOGSA (Mission, Objective, Goal, Strategy, Actions). Each successive level from top towards bottom dissociates into more detail

elements that defines the contents linked to the elements above [249]. Figure 23 shows a schematic of the Hierarchical Decision Model. 


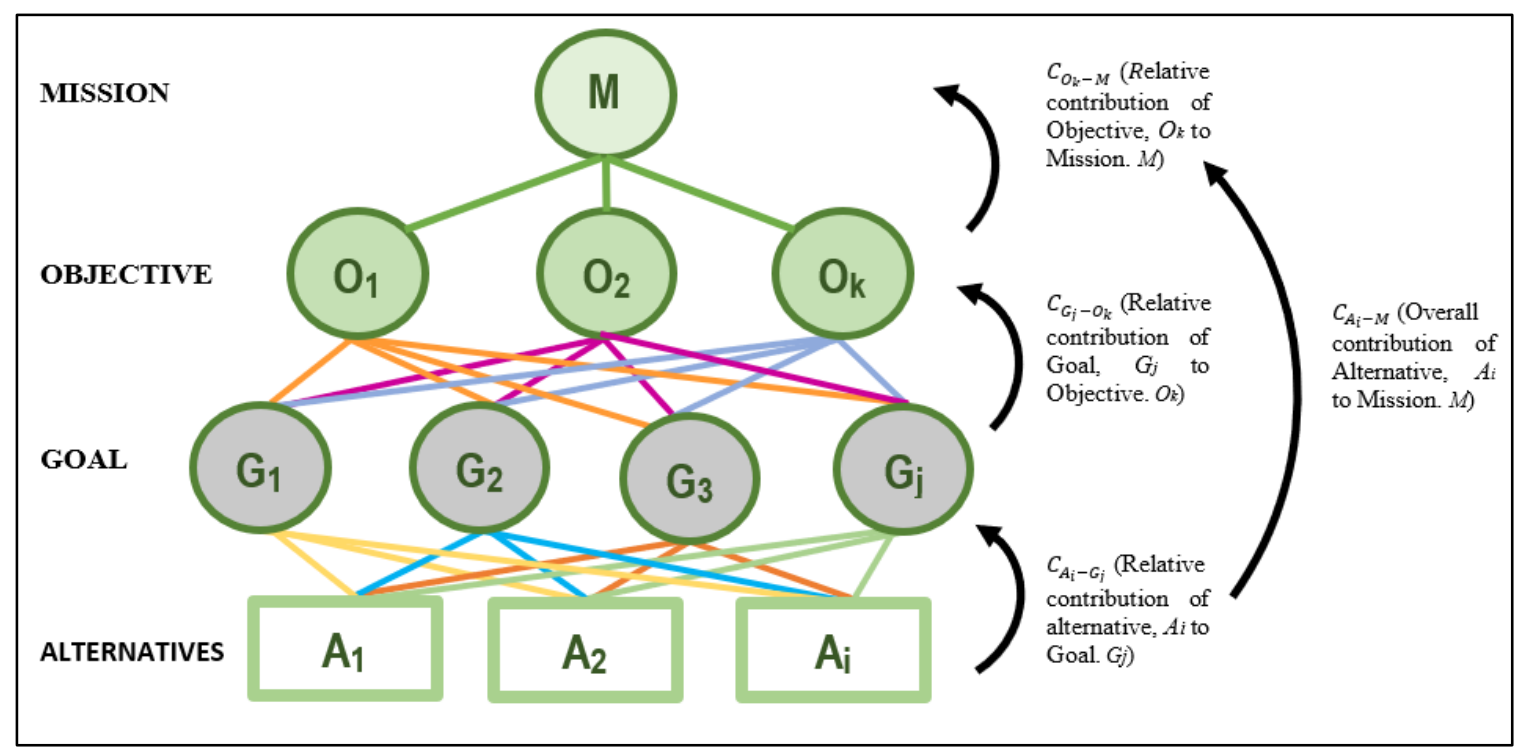

Figure 23: Schematic of HDM

The following section illustrates the 'Constant Sum Method' by an example.

Step 1: The first step is to develop a hierarchical decision model and record pairwise comparison values from experts. Experts distribute 100 points between a pair of comparing elements in the HDM. A matrix table is created based on the pairwise comparison. The number of pairwise comparison depends on number of elements, $n$. The number of elements to compare in pairs is $n(n-1) / 2$. The Pairwise Comparison Matrix (Table 9) is based on the following actual pairwise comparison by expert for the research (Figure 24). 


\begin{tabular}{|c|c|}
\hline Standard & Energy Price \\
\hline 85 & 15 \\
\hline
\end{tabular}

\begin{tabular}{|c|c|}
\hline Standard & Incentives \\
\hline 60 & 40 \\
\hline
\end{tabular}

\begin{tabular}{|c|c|}
\hline Standard & Labelling \\
\hline 90 & 10 \\
\hline
\end{tabular}

\begin{tabular}{|c|c|}
\hline Energy Price & Incentive \\
\hline 25 & 75 \\
\hline
\end{tabular}

\begin{tabular}{|c|c|}
\hline Energy Price & Labelling \\
\hline 60 & 40 \\
\hline
\end{tabular}

\begin{tabular}{|c|c|}
\hline Incentive & Labelling \\
\hline 85 & 15 \\
\hline
\end{tabular}

Figure 24: Actual Pairwise Comparison by Experts

Table 9: Pairwise Comparison Matrix

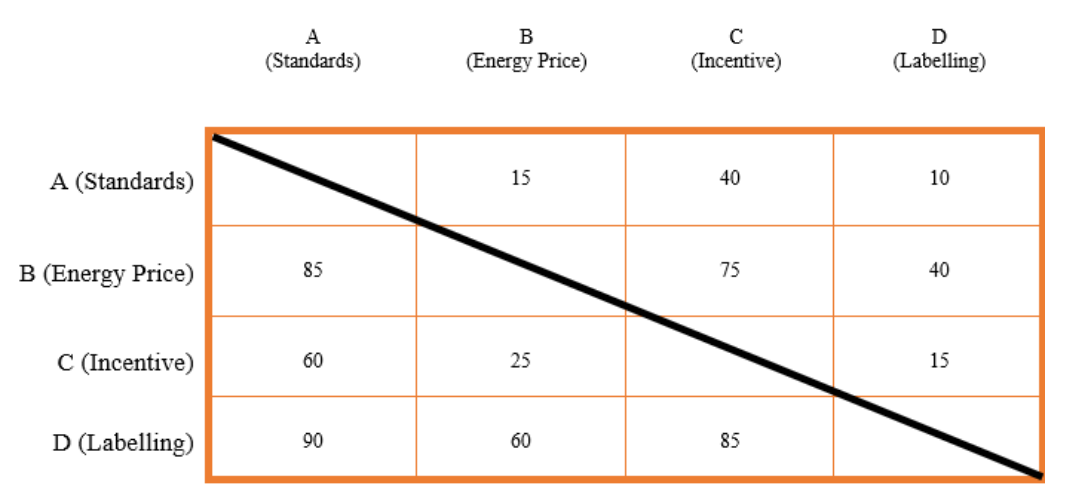

Step 2: The second step is to develop the Ratio Matrix Table (Table 10) by dividing comparisons of two elements. For $\mathrm{R}_{1} \mathrm{C}_{2}$ (first row second column), B/A would be 15/85 while for $\mathrm{R}_{2} \mathrm{C}_{1}$ (second row first column), $\mathrm{A} / \mathrm{B}$ would be 85/15. 
Table 10: Ratio Matrix

\begin{tabular}{|c|c|c|c|c|}
\hline & $\begin{array}{c}\mathrm{A} \\
\text { (Standards) }\end{array}$ & $\begin{array}{c}\mathrm{B} \\
\text { (Energy Price) }\end{array}$ & $\begin{array}{c}\mathrm{C} \\
\text { (Incentive) }\end{array}$ & $\begin{array}{c}\mathrm{D} \\
\text { (Labelling) }\end{array}$ \\
\hline A (Standards) & 1 & $\begin{array}{c}0.17 \\
(15 / 85)\end{array}$ & $\begin{array}{c}0.67 \\
(40 / 60)\end{array}$ & $\begin{array}{c}0.11 \\
(10 / 90)\end{array}$ \\
\hline B (Energy Price) & $\begin{array}{c}5.67 \\
(85 / 15)\end{array}$ & 1 & $\begin{array}{c}3.00 \\
(75 / 25)\end{array}$ & $\begin{array}{c}0.67 \\
(40 / 60)\end{array}$ \\
\hline C (Incentive) & $\begin{array}{l}1.50 \\
(60: 40)\end{array}$ & $\begin{array}{c}0.33 \\
(25 / 75)\end{array}$ & 1 & $\begin{array}{c}0.17 \\
(15 / 85)\end{array}$ \\
\hline D (Labelling) & $\begin{array}{l}9.00 \\
(90 / 10)\end{array}$ & $\begin{array}{c}1.5 \\
(60 / 40)\end{array}$ & $\begin{array}{c}5.67 \\
(85 / 15)\end{array}$ & 1 \\
\hline
\end{tabular}

Step 3: In this step, the value of elements in each column is divided by the value of elements in the next column. For example, the value 1.00 in $\mathrm{R}_{1} \mathrm{C}_{1}$ (first row first column) would be divided by 0.17 which is in $\mathrm{R}_{1} \mathrm{C}_{2}$ (row 1 column 2). Relative Weight Matrix Table is shown in Table 11.

\section{Table 11: Relative Weight Matrix}

\begin{tabular}{|c|c|c|c|}
\hline & $\begin{array}{c}\mathrm{A} / \mathrm{B} \\
\text { (Standards/Energy Price) }\end{array}$ & $\begin{array}{c}\mathrm{B} / \mathrm{C} \\
\text { (Energy Price/Incentives) }\end{array}$ & $\begin{array}{c}\mathrm{C} / \mathrm{D} \\
\text { (Incentives/Labelling) }\end{array}$ \\
\hline A (Standards) & $\begin{array}{c}5.88 \\
(1 / 0.17)\end{array}$ & $\begin{array}{l}0.25 \\
(0.17 / 0.67)\end{array}$ & $\begin{array}{l}6.09 \\
(0.67 / 0.11)\end{array}$ \\
\hline B (Energy Price) & $\begin{array}{c}5.67 \\
(5.67 / 1)\end{array}$ & $\begin{array}{c}0.33 \\
(1 / 3.0)\end{array}$ & $\begin{array}{l}4.47 \\
(3 / 0.67)\end{array}$ \\
\hline C (Incentive) & $\begin{array}{c}4.54 \\
(1.5 / 0.33)\end{array}$ & $\begin{array}{c}0.33 \\
(0.33 / 1)\end{array}$ & $\begin{array}{c}5.88 \\
(1 / 0.17)\end{array}$ \\
\hline D (Labelling) & $\begin{array}{l}6.00 \\
(9.0 / 1.50)\end{array}$ & $\begin{array}{c}0.26 \\
(1.5 / 5.67)\end{array}$ & $\begin{array}{l}5.67 \\
(5.67 / 1)\end{array}$ \\
\hline
\end{tabular}

Step 4: In this step, the mean and standard deviation of data in each column is calculated (Table 12).

Table 12: Mean and Standard Deviation of Relative Weight

\begin{tabular}{|c|c|c|}
\hline A/B (Standards/ Energy Price & B/C (Energy Price/ Incentives) & C/D (Incentives/ Labelling) \\
\hline 5.52 & 0.29 & 5.53 \\
\hline 0.67 & 0.043 & 0.72 \\
\hline
\end{tabular}


Step 5: The value of $\mathrm{D}$ is considered 1 and the corresponding values of $\mathrm{A}, \mathrm{B}$, and $\mathrm{C}$ are calculated (Table 13).

Table 13: Relative Values of Elements in Pairwise Comparison

\begin{tabular}{|c|c|c|c|}
\hline \multicolumn{4}{|c|}{$\mathbf{D}=\mathbf{1}$} \\
\hline$C / D=5.53$ & & $\mathrm{~B} / \mathrm{C}=0.29$ & $\mathrm{~A} / \mathrm{B}=5.52$ \\
\hline $\mathrm{D}=1 \quad \mathrm{C}=5.53$ & $C=5.53$ & $\mathrm{~B}=5.53 * 0.29=1.60$ & $\mathrm{~B}=1.60 \mathrm{~A}=5.52 * 1.60=8.83$ \\
\hline
\end{tabular}

Step 6: The values from Table 11 are normalized to get the final weight of each element (Table 14).

\section{Table 14: Final Weight of Elements}

\begin{tabular}{|c|c|c|c|c|c|}
\hline Elements & A & B & C & D & Total \\
\hline Values & 8.83 & 1.60 & 5.53 & 1 & 16.96 \\
\hline $\begin{array}{c}\text { Normalized } \\
\text { Value } \\
\text { (Weights) }\end{array}$ & 0.52 & 0.10 & 0.32 & 0.06 & 1.00 \\
\end{tabular}

The actual output from the HDM software confirms the process of calculation in Constant Sum Method as shown in Table 15.

Table 15: Sub-criteria Weights from HDM Software Output

\begin{tabular}{|l|c|}
\hline \multicolumn{1}{|c|}{ Level-2 } & Legal \& Institutional \\
\hline Standard & 0.52 \\
\hline Incentives & 0.32 \\
\hline Energy Price & 0.10 \\
\hline Labelling & 0.06 \\
\hline Inconsistency & 0.00 \\
\hline
\end{tabular}

\subsubsection{Validation of Research}

Validity is the accuracy of measurement. The objective of the present study is to measure the market's potential in facilitating the diffusion of residential EE technologies. 
The research is valid if it gauges the market potential [250]. Validity also confirms that the data collected is appropriate to measure the intended element in perspective [251]. The different validity measures with reference to the present study is elaborated below.

Construct Validity: The research instrument used in the study needs to be appropriate for measuring what is intended [250][252]. A hierarchical decision model has been developed with objective, criteria, sub-criteria and alternatives. The initial model is based on extensive literature review. Different technology assessment and strategic planning tools are used to filter large numbers of market attributes and key components (product and service benefits) that help to create market attributes.

A small-scale Delphi survey is conducted with known experts to gather feedback on the model. Based on their advice and feedback the initial model is edited and improved. Content Validity: The elements in the model are appropriate for assessment. For example, the Market Attributes and Key Elements are relevant for measuring MDP. Experts familiar with the subject matter validates the elements to be included in the research [253]. Twentyfour experts from different organizations with diverse background, expertise and experience participated in validating the different components of the model. The consensus of $2 / 3^{\text {rd }}$ majority of the experts on a certain construct is considered as the acceptance criterion. Any comments provided by the experts are carefully decoded and incorporated in the model. The initial improved model is finalized based on experts' validation. Criteria Validity: The elements in a model or the model itself can be verified from existing literatures. Research findings are cross checked with other available instruments [254]. To ensure criteria validity for the relative MDP of technology alternatives, published papers 
and articles on technology alternatives and their performance are reviewed to reinforce the findings from the research [253]. Also, experts are collaborated with the ranking of the alternatives and the related weights of comparative factors for analyzing the diffusion potential of the technology cases. Experts in the relevant field confirms the result to be representation of reality.

Face Validity: This is a method of checking validity by cursory glance by experts at the scales, contents or instruments used in a research. This does not involve any statistical analysis. It is a subjective judgment that helps throughout the research study, but it is not always accepted as a reliable validity check option [252]. For the present research, experts are collaborated at different stages of the process by email, in-person, over the phone as well through zoom and skype.

\subsubsection{Reliability of Research}

Reliability is a measure of getting the same output each time an experiment is carried out in different conditions by different individuals. The reliability aspect of a research study depends on stability, dependability, and repeatability [254] [251]. Consistency is a measure of data reliability when estimates are obtained from consensus of experts [255]. For the research, both consistency of individual expert as well as among experts are calculated to test the reliability of the study. Moreover, reliability depends on selected experts as in judgment quantification method, expert's perception decides the relative weights of elements in the model. A systematic expert selection process has been adopted to ensure experts with the relevant credential are participating in the study [256]. 


\subsubsection{Bias in Research}

Multicriteria Decision Analysis (MCDA) is susceptible to bias at different stages of the process. Bias is an intentional or unintentional manipulation of data. Bias can negatively impact the creditability and reliability of a research [257]. The three stages in MCDA that are vulnerable to bias are, selecting or validating alternatives and objectives, attributes, developing desirability curves and allocating weights to attributes [258]. The different sources of bias are, selection bias (research methodology), investigator bias (researcher's perspective), reactive bias (response from experts or participants), response bias (data collection technique) and confirmation bias (analysis, conclusion, inference)[257] . As human cognitive skill is not perfect, bias is an inevitable consequence of research study involving human judgment. Debiasing is an attempt to reduce the impact of bias. The different remedies for minimizing biases can be trichotomized into prevention (making sure sources of bias are lessened by adopting the correct instrument, data collection tool, and selecting the right experts), cure (when bias is detected during the process of data collection in spite of careful prevention strategies, vacillation and consensus can help identify and reduce bias), and observation (careful analysis, interpretation and elimination of bias where possible to impact of creditability in the final output of the study)[258].

\subsubsection{Inconsistency and Disagreement of Expert Judgment}

\subsubsection{Inconsistency in Expert Judgment}

What is Inconsistency: Inconsistency occurs in the event of the ranking set of alternatives by pair-wise comparison. Inconsistency surfaces when experts' judgment lacks logical reasoning or conflicting views on the preference of other options. Inconsistency may occur 
due to the intricacy of the decision problem or the constraints on the part of the experts due to lack of skill, ability, time, intention or preference [259].

There are two different types of inconsistency, Triad Inconsistency, 'Cyclic Inconsistency' and 'Ordinal Inconsistency' [260]. Table 16 explains the different categories of inconsistency with example.

\section{Table 16: Types of Inconsistency in Pairwise Comparison}

\begin{tabular}{|c|c|}
\hline Inconsistency & Example \\
\hline Triad Inconsistency & $\begin{array}{l}\text { Three letters A, B and C have different values such that, } \\
\text { A > B; } \quad \text { B }>\text { C and } \quad \text { C }>\text { A } \\
\text { A logical deduction would be, A > C. A disparity to this logic }(\mathrm{C} \\
>\text { A) leads to inconsistency or illogical decision and conclusion. }\end{array}$ \\
\hline Cyclic Inconsistency & $\begin{array}{l}\text { In a game of four groups } \mathrm{A}, \mathrm{B}, \mathrm{C} \text { and } \mathrm{D} \\
\text { A, wins against } \mathrm{B} \text { and } \mathrm{C} ; \mathrm{B} \text {, wins against } \mathrm{C} \text { and } \mathrm{D} ; \\
\mathrm{D} \text {, wins against } \mathrm{A} \\
\text { This event is contrary to the logical reasoning that A would win } \\
\text { against D and would lead to ordinally inconsistent comparison. }\end{array}$ \\
\hline $\begin{array}{l}\text { Cardinal } \\
\text { Inconsistency }\end{array}$ & $\begin{array}{l}\text { This type of inconsistency occurs when decision maker fails to } \\
\text { consider the strength of alternatives in pairwise comparison. } \\
\text { If } \mathrm{A}=2 \mathrm{~B} \text { and } \mathrm{B}=2 \mathrm{C} \text { then, } \mathrm{A}=4 \mathrm{C}\left(\mathrm{a}_{\mathrm{ij}}=\mathrm{a}_{\mathrm{ik}} \cdot \mathrm{a}_{\mathrm{kj}} \text { for all } \mathrm{i}, \mathrm{j} \text { and } \mathrm{k}\right. \\
\text { would lead to cardinally consistent comparison) [259]. Contrary } \\
\text { to this fact is when } \mathrm{A} \neq 4 \mathrm{C} \text { and leads to cardinal inconsistency. }\end{array}$ \\
\hline
\end{tabular}


How to measure Inconsistency: Inconsistency is measured by mean standard deviation.

The steps in calculation for finding inconsistency is shown in Table 17.

Table 17: Steps in Inconsistency Calculation

\begin{tabular}{|c|c|c|}
\hline Steps & Description & Equation \\
\hline Step 1 & $\begin{array}{l}\text { Mean of the normalized relative } \\
\text { value of the variable } i \text { for the } n ! \\
\text { orientation. }\end{array}$ & $\begin{array}{c}\overline{r_{l j}}=\frac{1}{n !} \sum_{j=1}^{n !} r_{i j}\left[r_{i j}=\text { relative value of } i_{\text {th }}\right. \\
\left.\text { variable at } j_{\text {th }} \text { orientation }\right]\end{array}$ \\
\hline Step 2 & $\begin{array}{l}\text { Variance of the normalized } \\
\text { relative value of } i_{\text {th }} \text { decision } \\
\text { element. }\end{array}$ & $\sigma_{\mathrm{i}}^{2}=\frac{1}{n !} \sum_{j=1}^{n !}\left(r_{i j-} \overline{r_{l j}}\right)^{2}$ \\
\hline Step 3 & $\begin{array}{l}\text { Standard Deviation of the } \\
\text { normalized relative value of } i_{\text {th }} \\
\text { decision element. }\end{array}$ & $\sigma_{i}=\sqrt{\frac{1}{n !} \sum_{j=1}^{n !}\left(r_{i j}-\overline{r_{l j}}\right)^{2}}$ \\
\hline Step 4 & $\begin{array}{l}\text { Mean standard deviation of all } \\
\text { the elements in the study gives } \\
\text { the inconsistency measure. }\end{array}$ & $\sigma=\frac{1}{n} \sum_{i=1}^{n} \sqrt{\frac{1}{n !} \sum_{j=1}^{n !}\left(r_{i j-} \overline{r_{l j}}\right)^{2}}$ \\
\hline
\end{tabular}

What is the effect of Inconsistency: The quality of the research is affected by inconsistency. Inconsistent judgment would produce different weights of the decision variables by different ranking methods. This leads to wrong decision and concern about the credibility of the research method [261] [262]. 
What is the acceptable limit of Inconsistency: According to Dr. Kocaoglu, the acceptable value of inconsistency should be 0.10 or less irrespective of the number of elements in the study [263]. Moreover, an inconsistency threshold limit developed by Dr. Abbas, allows to check the quality of expert judgment when the number of decision variables vary from $3-12$ within a certain alpha $(\alpha)$ level.

How to manage Inconsistency: In case of inconsistency beyond the acceptable limit, there are three probable options to manage.

- Expert is approached to rework on the pairwise comparison to make it more consistent [264].

- Facilitate consistent judgment by identifying the inconsistent element and asking the expert to provide best estimate.

- Repeated inconsistency may lead to excluding data provided by an individual expert [259].

\subsubsection{Disagreement in Expert Judgment}

What is Disagreement: Inconsistency is a discrepancy in logical judgment by an individual expert, while disagreement is disparity of judgment among experts. Disagreement is inevitable whenever an expert panel is formed with people from different backgrounds and skill sets. Disagreement measures the level of consensus and similarity of expert judgment [265].

How to measure Disagreement: Disagreement Index [263] is a measure to identify agreement among different experts. Table 18 describes the different steps in calculation of 'Disagreement'. 


\section{Table 18: Steps in Disagreement Calculation}

\begin{tabular}{|c|c|c|}
\hline Steps & Description & Equation \\
\hline Step 1 & $\begin{array}{l}\text { Mean relative value of the } i_{t h} \\
\text { element for the } k t h \text { expert }\end{array}$ & $\begin{array}{c}\overline{r_{l k}}=\frac{1}{n !} \sum_{j=1}^{n !} r_{i j}[\mathrm{i}(\text { no. of elements })= \\
1, \ldots \ldots, \mathrm{n}] \\
{\left[r_{i j}=\text { relative value of } \mathrm{i}_{\text {th }} \text { variable at } \mathrm{j}_{\mathrm{th}}\right.} \\
\text { orientation }]\end{array}$ \\
\hline Step 2 & $\begin{array}{l}\text { Mean of the mean relative value of } \\
\text { the } i_{t h} \text { variable for ' } \mathrm{m} \text { ' experts }\end{array}$ & $\begin{array}{c}\mathrm{R}_{\mathrm{i}}=\frac{1}{m} \sum_{k=1}^{m} \overline{r_{l k}} \quad[\mathrm{k}(\text { no of experts })=1, \\
\ldots . ., \mathrm{m}]\end{array}$ \\
\hline Step 3 & $\begin{array}{l}\text { Variance of the mean value for ' } m \text { ' } \\
\text { experts }\end{array}$ & $\sigma^{2}=\frac{1}{m} \sum_{k=1}^{m}\left(R_{i-} \overline{r_{l k}}\right)^{2}$ \\
\hline Step 4 & $\begin{array}{l}\text { Standard Deviation of the mean of } \\
\text { the } i_{\text {th }} \text { decision variable for ' } m \text { ' } \\
\text { experts }\end{array}$ & $\sigma=\sqrt{\frac{1}{m} \sum_{k=1}^{m}\left(R_{i-} \overline{r_{l k}}\right)^{2}}$ \\
\hline Step 5 & $\begin{array}{l}\text { Mean standard deviation for ' } \mathrm{m} \text { ' } \\
\text { experts or "Disagreement" }\end{array}$ & $\sigma_{\mathrm{m}}=\frac{1}{n} \sum_{i=1}^{n} \sqrt{\frac{1}{m} \sum_{k=1}^{m}\left(R_{i-} \overline{r_{l k}}\right)^{2}}$ \\
\hline
\end{tabular}

What is the effect of Disagreement: Disagreement affects the ultimate goal of reaching a final decision and puts the decision maker in a dilemma [266]. The difference in experts' opinion gives rise to uncertainty [265]. The disagreement could arise due to vulnerability at different stages of the research process. Disagreement allows checking if the difference is a natural outcome of expert diversity or ambiguity in questions or representation in data [267]. 
What is the acceptable limit of Disagreement: The acceptable limit of disagreement (Standard Deviation of ' $\mathrm{m}$ ' experts) is 0.10 or less [263].

How to Manage Disagreement: Disagreement could be within a panel group or across different panels. There are several ways to manage disagreement.

- Eliminating the judgment of expert (s) which is in discord to popular views i.e., if $2 / 3$ of the panel members agree on a certain issue.

- Attempt to transform opinion of those who disagree with majority by providing information and/or clarifying understanding of questions and data by the individual expert member.

- Accepting the disagreement and including it in the final report with notes on specific perspective and consideration for such dissension [261].

- In case of a panel that consists of few experts, elimination of judgment of nonconformist would lead to reasonable decision outcome [265].

Disagreement is a probable derivative in pairwise comparison. There are many sources of disagreement. Disagreement may occur due to disparity in personality (expert's ethics, skill and expertise), judgment (insufficient information), structure (expert's views due to position or the organization he/she represents) or semantic (difference in understanding problems due to terminology and words used in questions). While disagreement may pose as a weakness in pairwise comparison, analyzing the source of disagreement may provide useful insight in why the same data has been interpreted differently, the level of difference in opinion as well as the impact of such divergence on the outcome of the research [268]. When disagreement is caused due to more than $30 \%$ of 
the experts in a panel, a cluster analysis is conducted. Disagreement in different clusters is accepted when background of experts in a different cluster is distinct. However, when experts coming from diverge backgrounds have diverging views, a Delphi method is adopted to understand and reach to a verified consensus [269] [75].

Hierarchical clustering is preferred for small data sets. It helps to identify the different groups and also, interpretation of disparity among groups. Dendrogram is a widely used analysis tool that represents the different clusters through a tree diagram. Permutation test can further confirm the validity of number of clusters [270]. There are many different algorithms for finding the number of clusters. To run a cluster analysis in XLSTAT, the dataset is analyzed by Agglomerative Hierarchical Clustering with dissimilarity based on Euclidean distance. The Dendrogram is read from left to right. Figure 25 shows like clusters are grouped the earliest. The vertical lines indicate the grouping and the distance between the clusters [271]. A linkage function uses the dissimilarity to find pairs of clusters. Both dissimilarity and linkage function determine cluster [272].

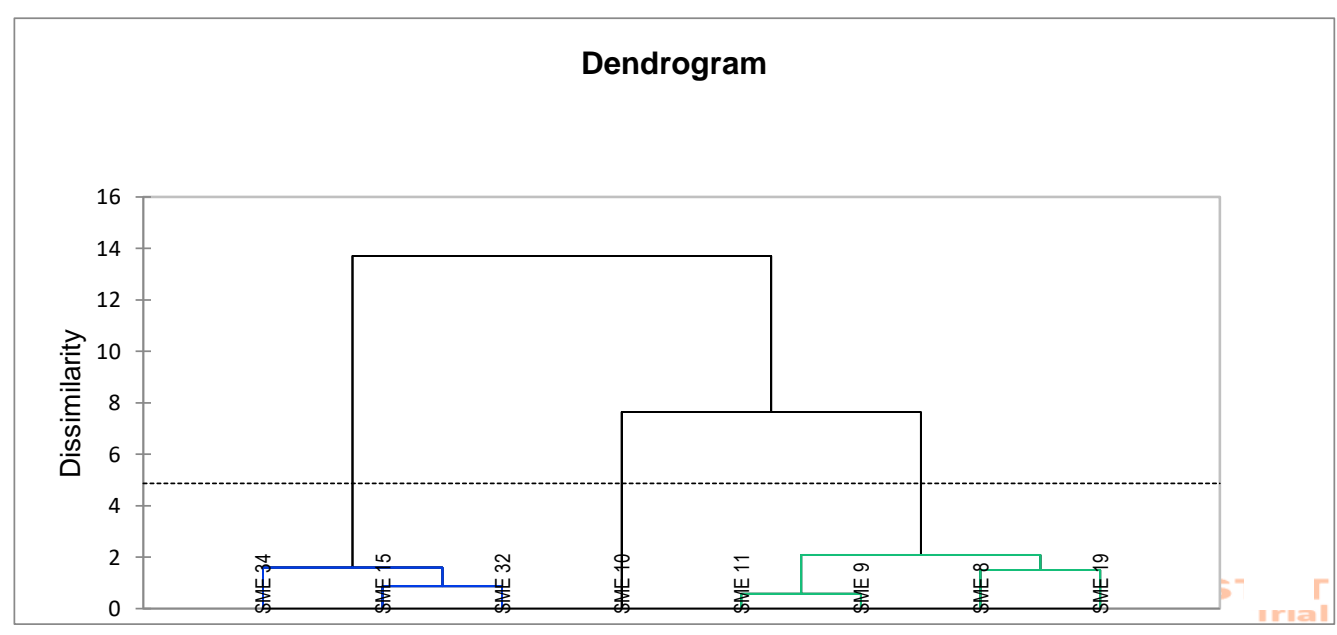

Figure 25: Dendrogram for Cluster Analysis 
To find if there is a significant disagreement among expert panels, a hypotheses testing can be conducted. Intra-class Correlation Coefficient (ICCC) is a measure of correlation within group data set [273]. A null hypotheses $\mathrm{H}_{0}$ : $\mathrm{ICC}=0$ is tested to check disagreement. If there is no correlation, that would conclude that there is complete disagreement between experts. On the contrary, rejection of $\mathrm{H}_{0}$ would lead to the acceptance of alternate hypotheses, $\mathrm{H} 1$ : not $\mathrm{H}_{0}$, which lead to the conclusion that there is no statistically significant disagreement between experts. The steps in testing hypotheses are as follows [274]:

1) Finding F ratio from $F=\frac{M S_{R}}{M S_{E}}$, where MSR is the predicted mean-squared-anomaly and MSE is the mean-squared-error.

2) The calculated $F$ ratio is compared to $F$ critical at a certain degree of freedom and confidence.

Degree of freedom $\mathrm{df}_{1}=\mathrm{df}_{\mathrm{r}}$ and $\mathrm{df}_{2}=\mathrm{df}_{\mathrm{e}}$

For the numerator, $\mathrm{df}_{1}$ is related to mean square regression while for the denominator, $\mathrm{df}_{2}$ is the means square residual. Confidence interval is considered to be $95 \%$ and above.

3) There is no disagreement if the calculated F value is greater than F critical as we can reject $\mathrm{H}_{0}: \mathrm{ICC}=0$.

\subsubsection{Desirability Curves}

Desirability curves or functions are utility or preference curves that helps to evaluate alternatives against different gradation of factors that affect the ultimate objective. It is the process of elicitation to gather experts' view on the of utility or value at different level of the attributes. 
The research study has twenty key elements that impact the five Market Diffusion Potential (MDP) of residential EE technologies in various capacity. Metrics are developed for each of these key elements that would correspond to different levels of MDP or scale of desirability. For example, one of the key elements in the model is safety. The level of safety can be expressed by ordinal scale. The desirability curve for safety is intended to see how increasing level of safety affects MDP. The desirability value of MDP ranges from 0 to 100 . The MDP would be 0 or close to 0 when there is no safety while MDP would be close to 100 with very high safety features of EE technologies [75][269][275][276]. Different types of ordinal and interval scales are used for each of the key elements to create desirability curves from expert's judgment. An example of desirability curve is shown in Figure 26.

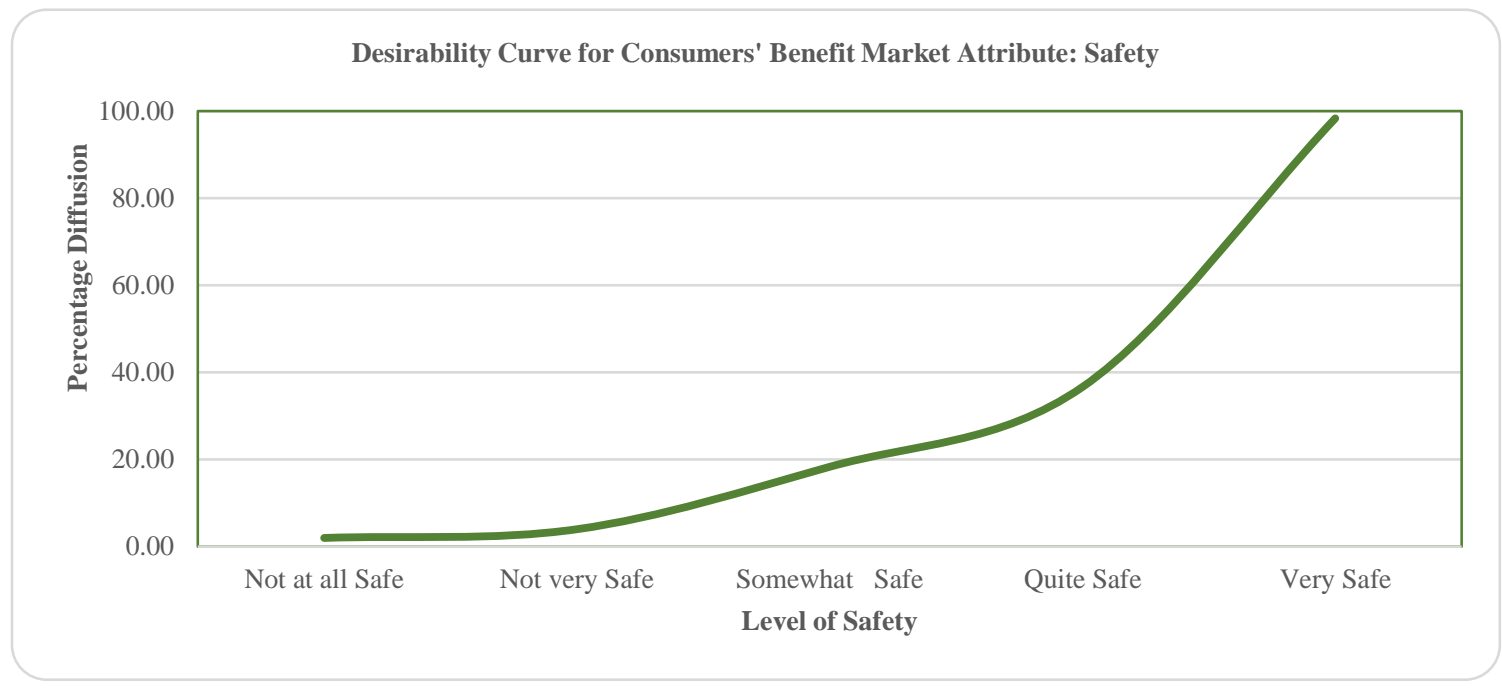

Figure 26: Desirability Curve 


\subsubsection{Evaluating Market Diffusion Potential (MDP)}

The following steps and calculations are used for evaluating MDP of technology cases:

1) Objective: Compare the Market Diffusion Potential (MDP) of EE technology alternatives.

2) Criteria: Market Attributes, $\boldsymbol{A}_{n}$ that impact the MDP of an EE technology. $\boldsymbol{A}_{\boldsymbol{n}}{ }^{M D P}=$ Relative importance of $n_{\text {th }}$ Market Attribute (Criteria) towards MDP for $n=$ Number of Market Attributes (1, ---------, N).

3) Sub-criteria: Key Element, $\mathrm{K}_{j n}$ that contributes in developing Market Attribute.

$\boldsymbol{K}_{\boldsymbol{n} \boldsymbol{j n}}{ }^{M D P}=$ Relative contribution of $\mathrm{j}_{\mathrm{th}}$ Key Element towards $\mathrm{n}_{\mathrm{th}}$ Market Attribute, jn $=$ Number of Key Elements in respective Market Attribute (jn = 1n,-------, jn) $(\mathrm{n}=1,-------, \mathrm{N})$.

Relative Value of $\mathrm{jn}^{\text {th }}{ }^{\mathrm{K}}$ Key Element, $\boldsymbol{V} \boldsymbol{K}_{\boldsymbol{n}_{\boldsymbol{j}} \boldsymbol{n}}^{\boldsymbol{M} \boldsymbol{P}}$ under the $\mathrm{n}^{\text {th }}$ Market Attribute with respect to MDP.

$$
\boldsymbol{V} \boldsymbol{K}_{\boldsymbol{n}_{j} \boldsymbol{n}}^{M \boldsymbol{P} \boldsymbol{P}}=\sum_{n=1}^{N} \sum_{j=1}^{j}\left(\boldsymbol{A}_{\boldsymbol{n}}^{M D P}\right)\left(\boldsymbol{K}_{\boldsymbol{n}_{j} \boldsymbol{n}}^{M D P}\right)
$$

Alternatives: Residential Energy Efficient Technology Alternatives, $T_{i}$.

$\mathrm{D}_{T i}=$ Desirability Value for the product/service feature corresponding to $\mathrm{jn}^{\text {th }}$ Key Element contributing to $\mathrm{n}^{\text {th }}$ Market Attribute.

The Market Diffusion Potential for a Technology Alternative, $T i$,

$$
\operatorname{MDP}_{T i}=\sum_{n=1}^{N} \sum_{j=1}^{j}\left(V K_{n_{j} n}^{M D P}\right)\left(D T i_{n j n}\right)
$$




\section{CHAPTER 5: DEVELOPMENT OF RESEARCH MODEL}

This chapter elaborates the different steps in developing the hierarchical decision model starting from expert panel formulation to finally developing the model before assessing relative weights of different elements and application of the model. The section describes the different criteria (Market Attribute), sub criteria (Key Elements) and alternatives (Technology Cases), background of experts, number of panels, assignment of tasks to each panel, and process of data collection.

\subsection{Expert Panel Formulation}

\subsubsection{Sampling for Expert Identification}

As the purpose of the study is to understand the potential of the market for EE technologies, qualitative research is adopted. Qualitative research has been successfully used for assessing policy [277], understanding social impact of community renewable energy projects [278], evaluating energy practices [279], assessment of wave energy potential [280] and an assessment of many other alternative technologies. Qualitative research is a method of delving into an issue of concern. Hence, in qualitative research sample is selected deliberately to gather most data from "knowledge rich" participants, i.e., experts in this study. Mostly, experts in this sort of 'Purposeful Sampling' are selected based on their education, expertise, and experience on the topic of investigation. Also, experts should be accessible, eager and communicative [281]. There are many kinds of non-probability sampling. In volunteer sampling, researchers let everyone know about their research interest and participants respond. Convenient sampling uses respondents who are 
easy to find. In purposeful sampling, participants are selected depending on their resourcefulness that fits specific objective. Quota sampling selects representative respondents from each of the different groups of participants. Snowball sampling finds respondents when one refers others. Matched sampling is used mostly in experiments where pair samples are required, and Genealogy Based Sampling selects family members wherever they reside [282]. For the present research, a mixed approach of sampling is used as shown in Figure 27:

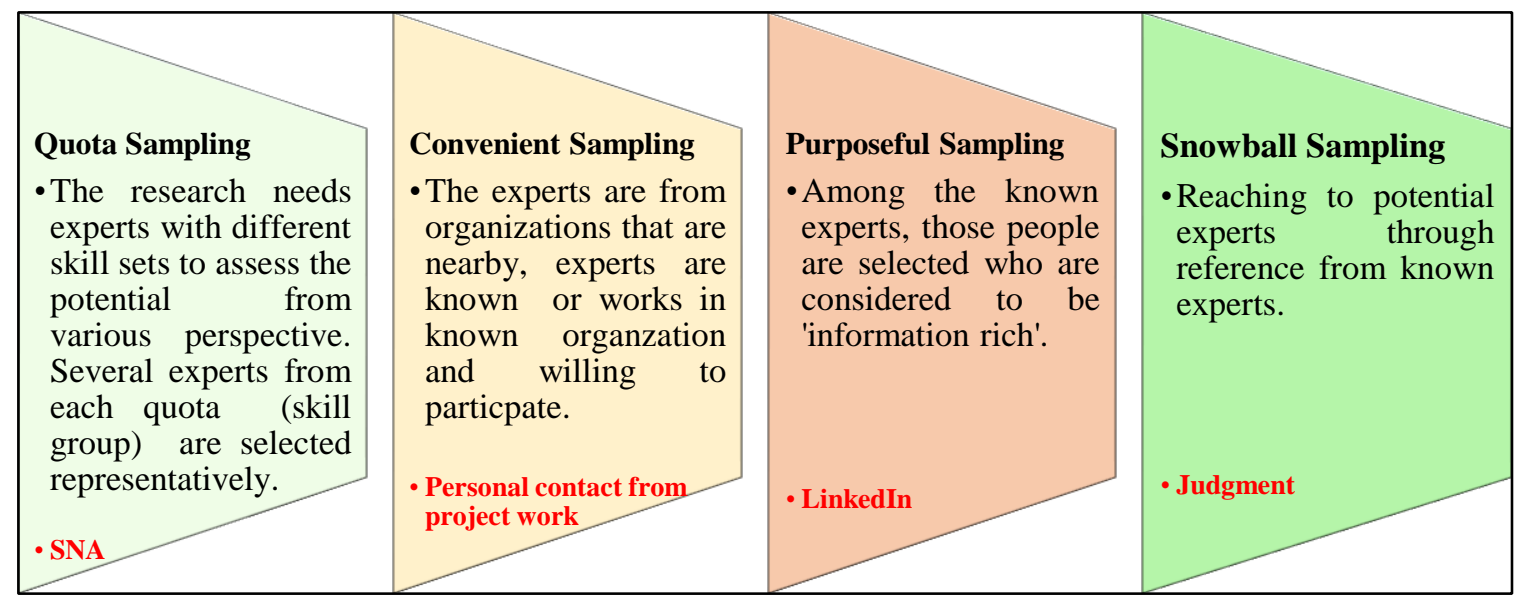

Figure 27: Sampling for Expert Identification

\subsubsection{Identifying Subject Matter Experts}

An abstract for the sequence of steps in finding Subject Matter Experts (SMEs) for the research is shown in Figure 28. The systematic framework is developed based on the literature on a study done by US National Research Council. This is very useful for the research as it guides to the relevant organizations and Subject Matter Experts (SMEs) with the appropriate positions and background methodically based on the criteria identified at the top of the HDM [283]. 


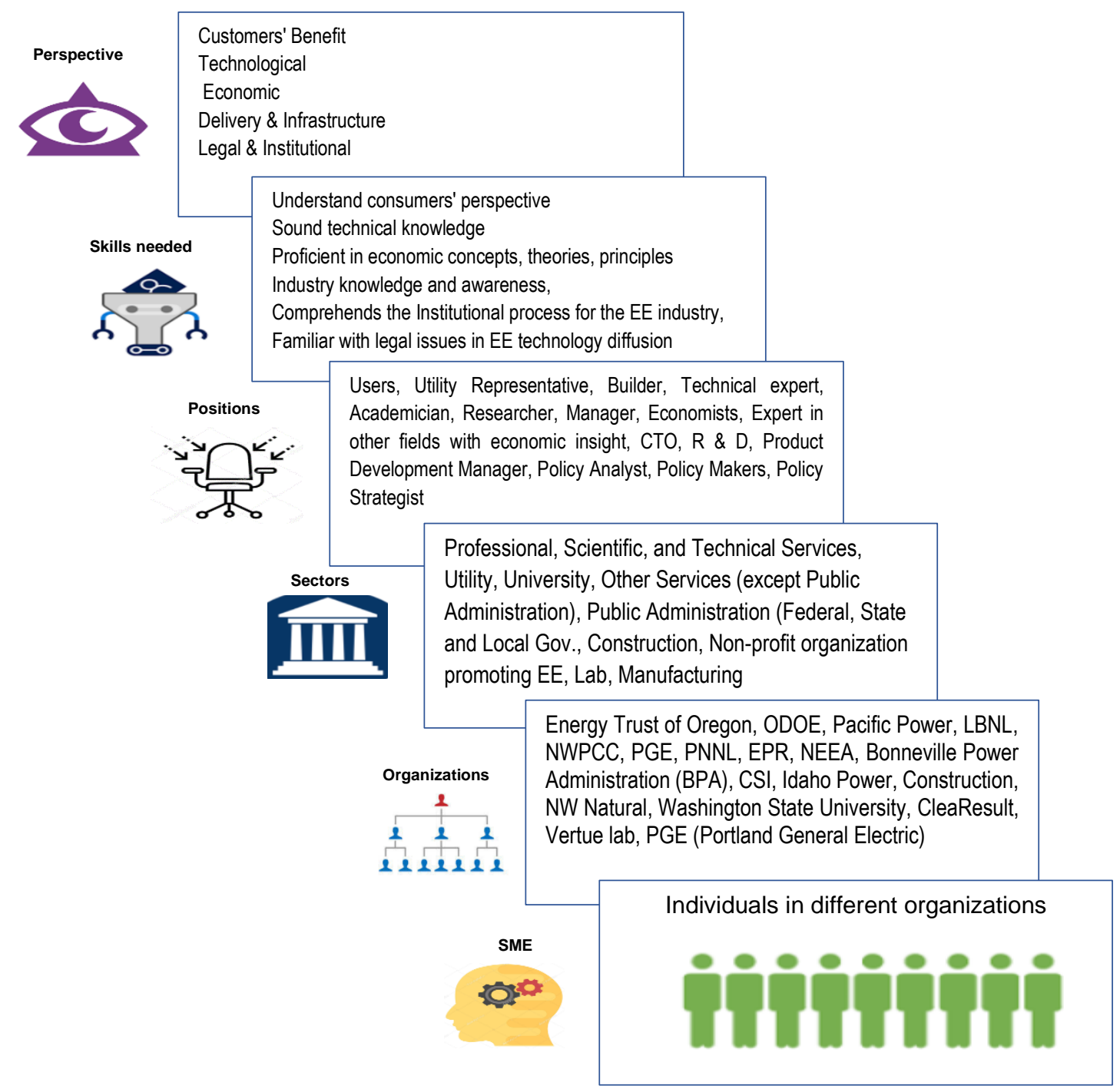

Figure 28: Steps in Identifying Subject Matter Experts (SMEs)

\subsubsection{Bibliometrics and Social Networking Analysis}

What is Bibliometric Analysis: Bibliometrics is also known as "Scientometrics." Bibliometrics is a tool for analyzing publications that include journal articles, proceedings papers, reviews, book chapters, editorial materials, and others. The analysis uses quantitative analysis and statistics [284]. Alfred Lotka and Samuel Bradford are considered 
to be the father of the bibliometric method who set the stage by developing techniques to analyze scholarly publications. Eugene Garfield is credited for further modernizing the tool by citation analysis and systematic processing.

Application of Bibliometrics: The three areas of bibliometric analysis are methodology research, scientific disciplines, and science policy [285].

Methodology research: Intended to improve the bibliometric analysis.

Scientific Disciplines: The primary objective is to analyze scientific publication through different metrics.

Science Policy: The goal is to evaluate productivity. The aim is to make decisions on resource allocation.

Social Networking Analysis (SNA): SNA was invented more than half a century back to reinforce the applicability of bibliometric analysis. SNA identifies the relationship structure of people in communities. SNA uses the data collected through the bibliometric analysis. The outcomes of the study are articles, citations, co-citation networks, collaborating authors or institutions [286]. The key metrics are Size (number of people on the network identified through nodes, their relationships), Cohesiveness (links between nodes, size of network and distance between network) and Centrality (degree shows the importance of a node identified by the number of connections and betweenness identifies the number of unique paths).

Three categories of software are used for SNA [287]:

1. Data collection - e.g., Spreadsheet software (Excel, UCINet)

2. Data analysis - e.g., Social network analysis software (Patek, R) 
3. Data visualization - e.g., Network visualization software (Gephi, Palladio, Cytospace, NodeXL, Social Network Visualizer)

Some widely used scholarly database are Web of Science, Scopus (Basic Research), Compendex (Applied Research), and Sumobrain (Patents).

\subsubsection{Steps and Issues in Expert Panel Formation}

An expert panel is a team of professionals having a different point of view and skill sets [288]. Subject matter experts are an essential component for building models, validation, verification, and quantification. Evaluation by experts is a kind of qualitative research which in many cases prove to be the only option to save the time of lengthy quantitative research or getting an insight of events or issues or generalization confined to limited scope [261]. But there are several critical issues (WHO, WHERE, WHICH, WHAT, HOW) to be considered at different stages of the panel formation process.

Who should be included in the Panel: In many cases, experts are selected based on criteria laid out by superior authority depending on the objective and nature of the research. In academic research, mostly, a panel is chosen by the researcher autonomously with a discussion with supervisor, advisor or through group consensus for the research team. Whoever selects the experts, a panel needs to comprise of people with know-how (Expertise), know-why (Approach), know-what (Experience) and know-where (geography-specific knowledge). Mostly, experts are recognized in the academic or scientific community [289] [290]. It is crucial that there is a balance of experts with broad skill sets depending on the various perspectives identified in the research [291] [149]. 
Where to find experts for panel: Even if the initial search should be from organization whose focus and mission fits the area of research and also those which are widely known and accepted to be at the forefront of EE initiatives, in order to blend different views and experience, expert should be drawn from different pertinent sectors [291].

Which professional role experts should have: People at different levels of the organization practice different skills to achieve organization goal. Top-level executives need to exercise more administrative skill than managers at other levels of the hierarchy. Lower level management or first line supervisors are assumed to possess technical skills, while middle management mostly practices human skills [292]. However, depending on the type of organization, people at different positions may have specific roles and responsibilities [293]. Professional role of experts can be identified based on the issues to be assessed in the research and the related skills required.

The research assumes that the Market Diffusion Potential (MDP) of the Energy Efficient (EE) technologies depend on Consumers' Benefit, Technological, Economic, Delivery and Infrastructure, and Legal and Institutional Market Attribute. Hence, multiple SMEs are needed for validating and quantifying the model. SME are considered to be people who have in-depth knowledge of the subject matter required for certain research and known in the respective community[288] [294]. Expert evaluation is vital for measuring elements that are difficult to quantify in practice. Experts should possess different sets of skill, experience, expertise, and views. They should be willing to employ time and effort and have specialized skill as well as recognized official rank or status [295] 
[296][297]. Knowledge of the state-specific system, codes, climate, and recognition as scientific or professional authority in the respected field is a requirement [298][296].

Moreover, experts should have experience in the assessment process in different projects [299]. Based on the model, the research needs SMEs in Consumers' Benefit, Technological, Economic, Delivery and Infrastructure, and Legal and Institutional Market Attributes. The probable positions, organizations and required capabilities of SMEs are illustrated below:

Consumers' Benefit SMEs: To capture the customers' perception of EE technology, actual user, builder or utility representative are considered as SMEs [300] [149].

Technical SMEs: "Domain-specific knowledge." implies a thorough understanding of a specific field of knowledge. Manufacturers are aware of the advancement and use of technologies and drivers and barriers in the market [297]. Technical experts may be people from industry, academic institutions or national laboratory. Experts from academia can identify enabling technologies needed for emerging or advancement of contemporary technologies (Validation) [149]. Industry and faculty experts each provide invaluable insights with one having specific emphasis while the other has a wider angle of vision. Managers in industries are found to have a broader array of knowledge that people with technical and engineering background [297]. Technical experts may possess very specific technical skill and experience, or a single expert could have expertise in a wide array of technology [301]. Multi-skilled experts may be able to infuse practical, analytical as well as process aspects in the assessment. 
Economic SMEs: An economist or expert who is conversant with economic aspects or assessment process of EE technologies would be able to evaluate the economic feasibility of the technology [300] [149].

Delivery and Infrastructure SMEs: For Delivery and Infrastructure market assessment, a Chief Technology Officer, R \& D Manager, product development manager or experts having industry knowledge and awareness and is familiar with the innovation process of an EE technology would be a much sought after SME [302][300] [149]. Experts should be knowledgeable about industry structure, Key Performance Indicators (KPI), procedure and industry policies [303].

Policy SMEs: Legal and institutional market attribute evaluation needs competent policy analyst, specialists who work in a state, regional or federal organizations with relevant knowledge and contribute in energy, environment, and economic program, policies, regulations, and codes [300].

What would be the size of the expert panel and how many panels should be formed: Usually, the panel formation starts with a long list of potential SMEs [304]. The number of SMEs in a panel mostly depends on the extent of the project complexity. The panel should be well poised concerning experts' skill, experience and expertise considering the different perspectives in this research. However, in the case of multiskilled experts with a broad spectrum of knowledge, the number of experts could be compromised. In most projects, the number of experts in each panel ranges from six to eight [149]. Also, the number of experts in the panel is contingent on the objective and scope of the research, the methodology used, information that may be gathered from each SME and the availability 
and use of secondary data [305]. The number of experts in panels from different Ph.D. dissertation is attached as Appendix D. Expert panels validate and quantify elements in a decision model.

How to avoid bias in selecting experts for a panel: An incorrect inference from research due to intentional or unintentional unfairness in collection, organization, and clarification of data and publication is known as bias [306]. Bias can interfere due to organizational, panel or individual level expert selection. Some common ways to avoid bias are: Selecting more than one expert in a particular field, ensuring a certain level of consensus among experts and choosing an expert with multi-perspective or skill set [307].

A list of expert panels based on SNA is attached as Appendix E.

Moreover, even after finding and selecting the experts with the required skill and experience, it is necessary to ensure that they're willing to participate in the research and also their preferred area of interest in the research.

\subsection{Construction of Hierarchical Decision Model (HDM)}

The HDM for the research consists of four layers. Based on the conceptual and theoretical framework, the key elements are identified from extensive literature review keeping the Customer Value Hierarchy (Figure 6) in perspective. Different key elements are grouped with the help of the strategic planning tool, STEEPLE (Social, Technological, Environmental, Economic, Political, Legal, and Economic) as well as the FAB model. The initial model went through few series of directed evolution. The preliminary model was sent to a small group of selected experts with the recursive process as in Delphi method. 
Several rounds of circulation led to an improved version of initial model with more relevant and contemporary customer value components and market attributes as well as better semantics, improved clarity of terms and most of all a model backed up by practitioners in the field of study. Also, the experts selected the three EE technology cases to test the model. The improved model was validated by expert panels. The final model is framed in Figure 29.

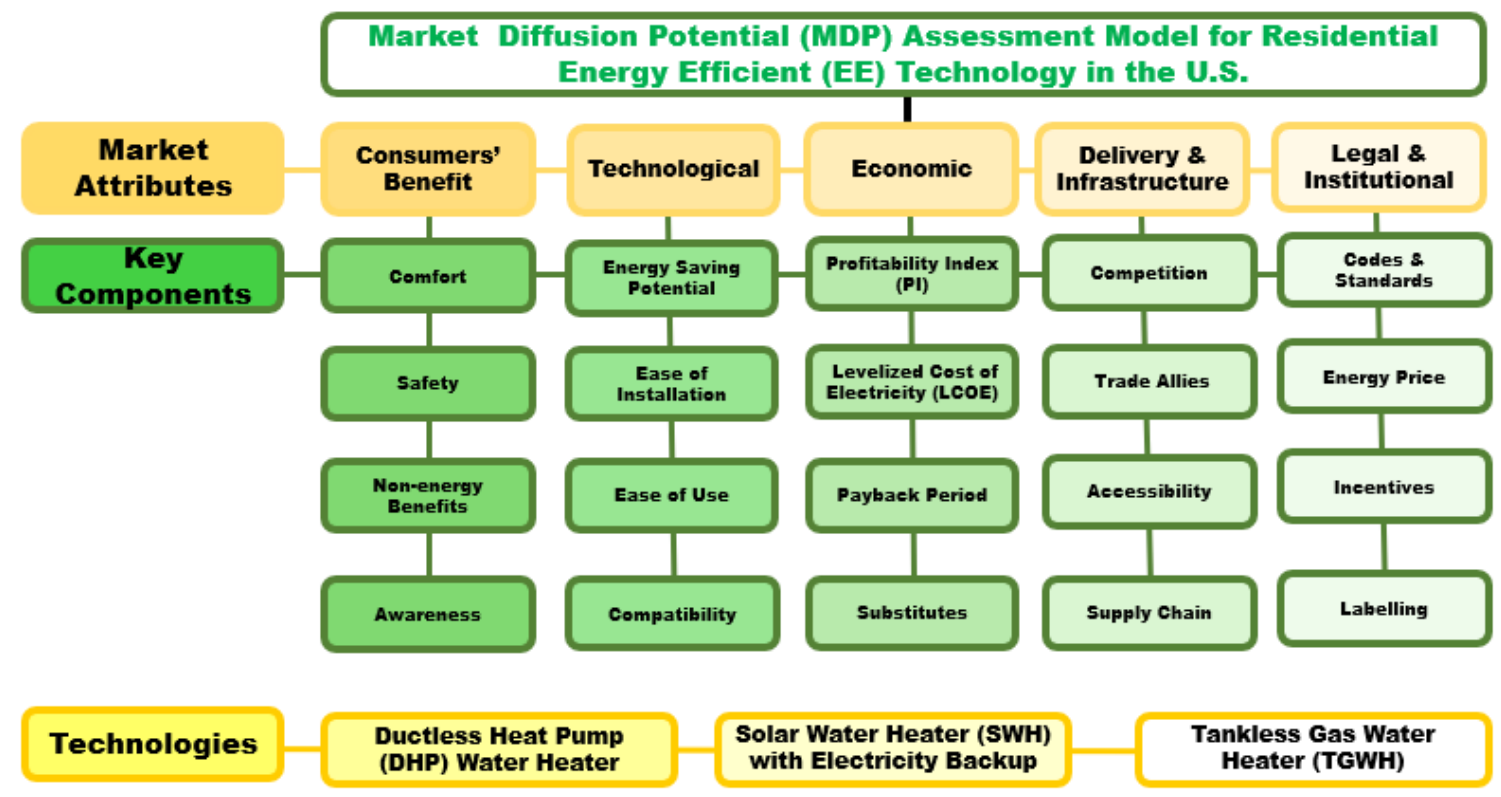

Figure 29: Validated Final HDM

\subsubsection{Objective}

The objective of the research is based on the research motivation and the issues described in Chapter 2. 'Market Diffusion Potential' helps to identify the status quo of a market regarding its capability to satisfy expectations and experiences of customers regarding a technology at a certain point in time. The research project has been initiated to 
develop "A Model to Assess Market Diffusion Potential (MDP) of Residential Energy

Efficient (EE) Technologies in the U.S.”.

\subsubsection{Criteria}

The criteria level of the model consists of Market Attributes that are considered to be the most important that the market should be able to concoct for increased diffusion. The Market Diffusion Potential is assumed to depend on Consumers' Benefit, Technological, Economic, Delivery and Infrastructure, and Legal and Institutional attributes. Table 19 describes the attributes in brief.

\section{Table 19: Market Attributes Definition}

\begin{tabular}{|l|l|}
\hline Market Attributes & \multicolumn{1}{c|}{ Definition } \\
\hline Consumers' Benefit & The aspects that affects personal gain, satisfy consumers and make users \\
\hline Technological & Technological Market Attribute encompasses specific technological factors \\
& Eertaining to hardware and software that determine the adoption decision of \\
\hline Economic & Economic Market Attribute implies the economic viability considering total \\
& expenditure during the life span of an EE technology and depends on initial \\
investment, operation and maintenance as well as disposal cost [311].
\end{tabular}




\subsubsection{Sub-criteria}

The sub-criteria in the model are the key components that consist of product/ service benefits and help to build the respective capability known as market attribute. The key components in the model are illustrated below in Table 20 .

\section{Table 20: Key Component Definition}

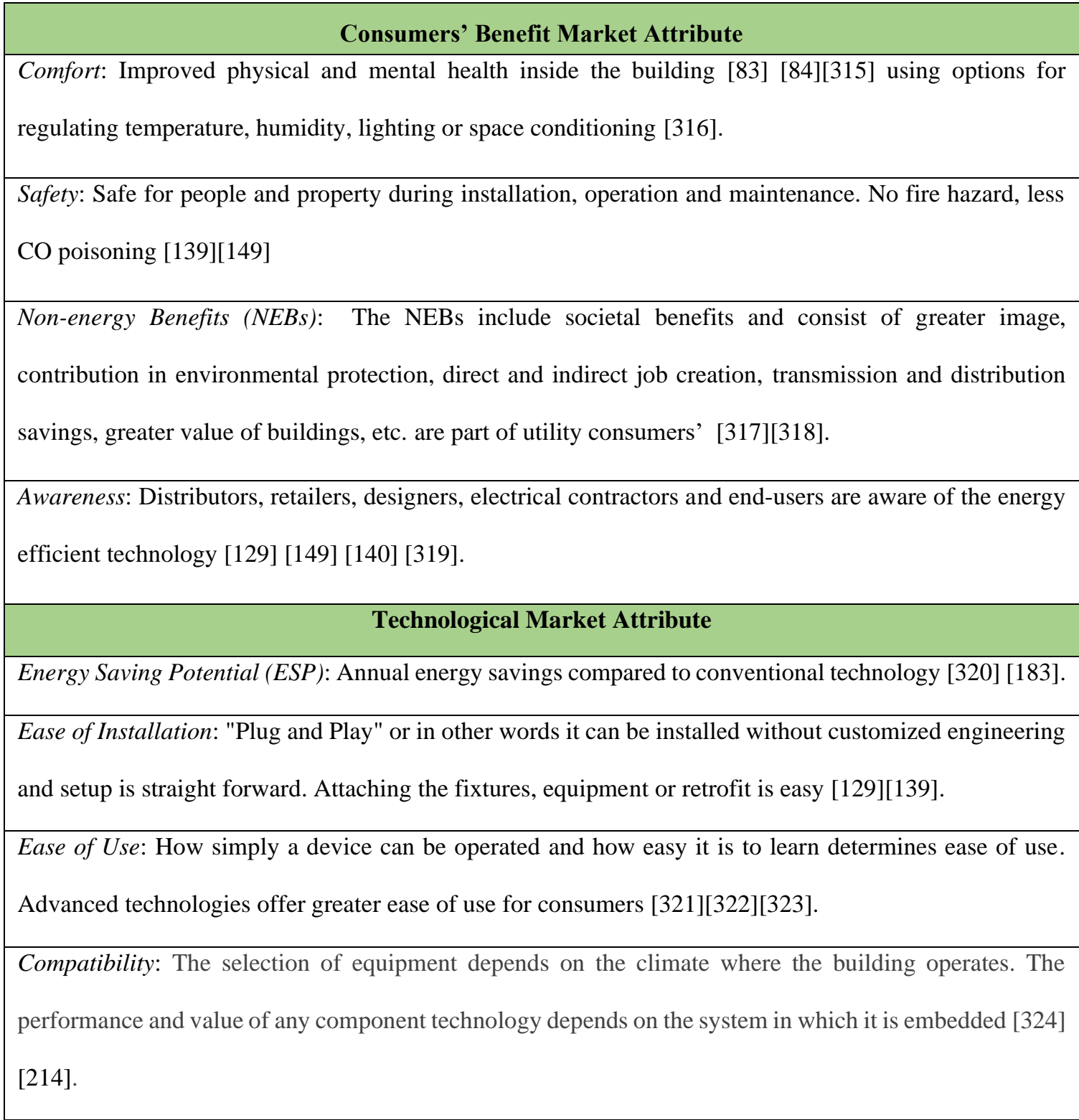




\begin{tabular}{|c|}
\hline Market Attribute \\
\hline $\begin{array}{l}\text { Profitability Index (PI): PI calculates a value for each dollar invested (PI = B/C) [ Where "B" and "C" are } \\
\text { discounted summaries of benefits and costs }[325][326] \text {. }\end{array}$ \\
\hline $\begin{array}{l}\text { Levelized Cost of Electricity }(L C O E) \text { : LCOE is a standardized way of expressing and comparing the } \\
\text { economics of energy efficiency measures. LCOE assumes a certain performance level and economic life. } \\
\text { LCOE is expressed by dollars per kilowatt-hour [327][328]. }\end{array}$ \\
\hline $\begin{array}{l}\text { Payback Period: Payback for an EE technology is the time at which the cumulative savings equal the } \\
\text { cumulative cost[329][330]. }\end{array}$ \\
\hline $\begin{array}{l}\text { Substitutes: Cost of conventional products impacts EE products' diffusion in the market [331]. Cost, } \\
\text { quality and performance of conventional products impacts EE products penetration in the market. } \\
\text { According to Porter's } 5 \text { forces model, the intention to adopt a technology is diminished by availability of } \\
\text { substitutes [332]. }\end{array}$ \\
\hline Delivery and Infrastructure Market Attribute \\
\hline $\begin{array}{l}\text { Competition: Competition in both between EE equipment as well EE and conventional appliance ensure } \\
\text { price competitiveness and supply[138]. }\end{array}$ \\
\hline $\begin{array}{l}\text { Trade Allies: Independent contractors, equipment manufacturers or distributors as trade allies help to } \\
\text { deliver energy efficiency products and expertise directly to residents and businesses. Sales and } \\
\text { marketing training can enhance sales of EE technologies [333][334]. }\end{array}$ \\
\hline $\begin{array}{l}\text { Accessibility: To make the EE technology available, there needs to be easy access to technology } \\
\text { throughout the distribution channel. Accessibility allows the flow of products, technologies, and } \\
\text { information to all participants [335][336]. }\end{array}$ \\
\hline $\begin{array}{l}\text { Supply Chain: There are many players in the market who participate in manufacturing, delivery and } \\
\text { installation of an EE technology. Diffusion of EE technologies depends on shortening supply chain } \\
\text { dealings for cost-effective management of the product supply chain [337]. }\end{array}$ \\
\hline
\end{tabular}




Legal and Institutional Market Attribute
Codes and Standards: Energy-efficiency standards are a set of procedures and regulations that prescribe
the energy performance of manufactured products, sometimes prohibiting the sale of products that are less
efficient than a minimum level [338].
Incentives: Different forms of inducements help in the uptake of EE technologies. Incentives are devised
to ensure sustainable adoption [78][339].
Energy Price: There are many state policies that regulate the energy price through utilities.
The rates change depending on the program and may affect the diffusion of EE technologies [340] [214].
Labelling: Energy labels enable consumers to make an informed choice at the point of purchase, either
by showing the comparative performance of all appliances (rating labels) or by identifying the best-in-
class [341] [277].

\subsubsection{Alternatives}

Three technology cases are considered for comparing MDP. The three reasons for choosing these technologies are, preference by experts in different organizations working in market transformation projects, purpose of use (water heating is the second largest energy consuming appliance in residence), high energy efficiency and diverse fuel source. Ductless Heat Pump (DHP) Water Heater: The DHP is a split system water heater that has two units. The outside unit consists of compressor and condenser. The indoor unit is comprised of air handler with coils that is usually wall mounted. Some of the common brands are, Mayekawa, Panasonic, SanCo [342].

Solar Water Heater with Electricity Backup: The solar water heater absorbs light by means of a collector placed on the roof and converts it into heat. It passes this heat to a water tank 
by means of a circulating pump. A O Smith, and V Guard are two of the popular brands [343].

Tankless Gas Water Heater: The heating element in a gas water heater is a gas fired burner. Water is heated as it flows through the unit. This minimalizes standby heat loss as it does not store water. Some of the common brands are, Rheem, Rinnai[344].

A sample of the HDM developed by software for quantification is attached as Appendix F.

\subsection{Data Collection}

\subsubsection{Steps in Panel Formation}

Experts are identified based on their affiliation, position, knowledge, experience, understanding and willingness to participate. For experts in academia, publication in peer reviewed journal is checked to confirm exceptional domain knowledge required for the study [345]. Working in a particular field gives experts the required testimony for being an expert. Experts are chosen confirming their years of employment in a certain position or in an organization. The information is easily available from websites, google search or LinkedIn profiles. Participation in research in similar field is also an important criterion and the information is collected by searching in web of science (WoS), Compendex, and/or Sumobrain. However, even after choosing and having consent from experts for participating in the research, the experts needed to comply with the time commitment communicate clearly [346]. Also, in case of HDM, occasionally, experts were approached for checking, revision or clarifying their responses to ensure consistency and agreement as inconsistency and disagreement compromise the quality of the research [297]. Due to 
software availability, it was possible to record and analyze expert views through software. The record of the SME who completed a survey was updated immediately for reference as expert were contacted later for purposes mentioned above or for explaining disagreement among experts taking individual expert's background, positional and organization into consideration. Telephone interview, survey through emails as well as through face to face communication using google hangout and zoom made it easier to explain research objective, methodology, process and collect useful insight from experts [261]. A map for expertise and characteristics of experts is shown in Figure 30.
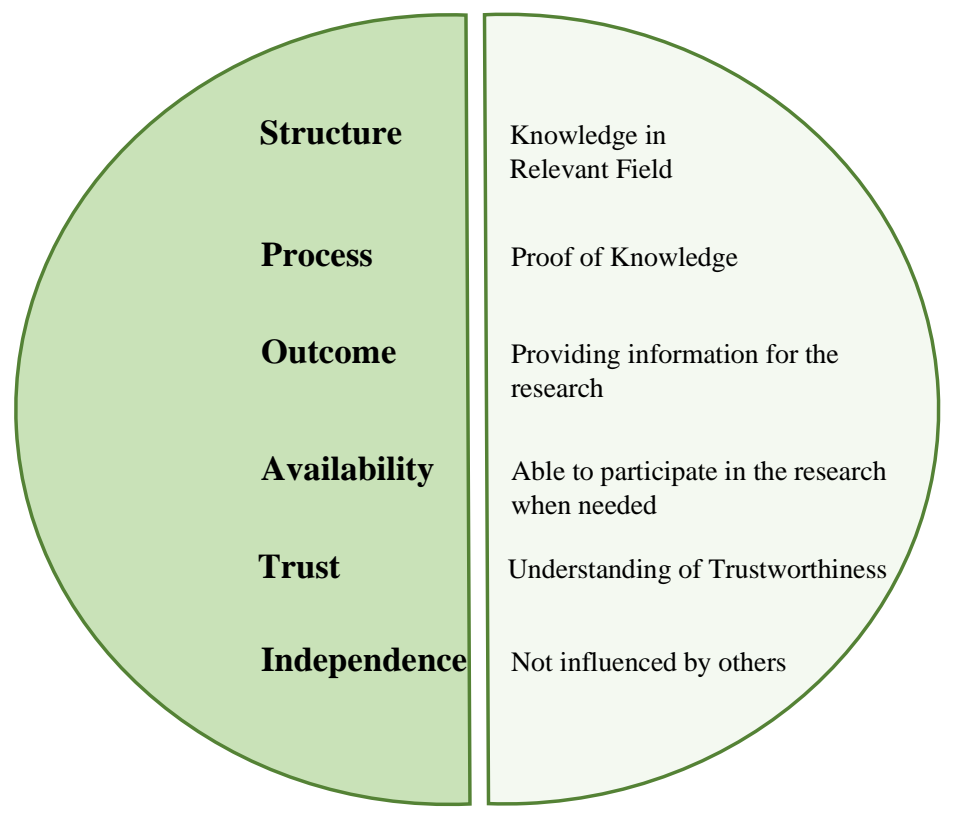

Figure 30: A Map of Expertise and Characteristics for Experts

Different steps in panel formation are illustrated below in the light of Dr Estep's dissertation [275]: 
1) Identifying need of experts (Following steps in Identifying Subject Matter Experts (SMEs) in Chapter 4) according to research model.

2) Finding experts using quantitative (SNA, bibliometric analysis) and qualitative (using nonprobability sampling) tools.

3) Sorting experts based on background, position, experience, publications, contributions, affiliations, award, and other recognitions (as described in Chapter 4).

4) Assigning experts to different panels based on expertise, experience needed for the criteria and sub-criteria and also depending on experts' willingness to participate in specific or all panels.

5) Inviting experts informally.

6) formal invitation and letter of consent after acceptance of informal invitation.

7) Sending survey after receiving consent from experts.

8) Using appropriate communication tool in the form of either email, Qualtrics survey, HDM software survey, phone, and/or face to face interview.

9) After receiving the completed survey, the response is checked for any discrepancy. In case of incomplete survey response, unvalidated data or an element in the model having less than $2 / 3$ majority and/or inconsistency and/or disagreement, the expert is approached for checking and revision.

10) Delivering thank you note to respective experts upon successful recording of data. 


\subsubsection{Expert Panels}

Expert panels are formed for model validation, pairwise quantification, desirability curve formulation, and technology case comparison. A total of 50 (fifty) experts are distributed in 10 (ten) panels who participated in different tasks at different phases of the study as listed in Table 21.

Table 21: Expert Panels for Different Tasks

\begin{tabular}{|c|c|}
\hline Experts & Tasks \\
\hline Panel 1 & Delphi Survey (*) \\
\hline Panel 2 & Validation (*) \\
\hline Panel 3 & Criteria Level Quantification (Market Attributes) (*) \\
\hline Panel 4 & Sub-Criteria Level Quantification (Consumers' Benefit) ( $\nleftarrow$ ) \\
\hline Panel 5 & Sub-Criteria Level Quantification (Technological) ( $\bullet)$ \\
\hline Panel 6 & Sub-Criteria Level Quantification (Economic) $(\bullet)$ \\
\hline Panel 7 & Sub-Criteria Level Quantification (Delivery \& Infrastructure) ( $\bullet$ \\
\hline Panel 8 & Sub-Criteria Level Quantification (Legal \& Institutional) (॰) \\
\hline Panel 9 & Desirability Curve Validation and Quantification (-) \\
\hline Panel 10 & Comparison of Technology Alternatives (•) \\
\hline
\end{tabular}

Table 22 shows the allocation of experts to different panels. Experts are assigned to different panels based on the guideline for choosing experts as laid out in chapter 5, background, position, experience, organization, and willingness to participate within the timeline that is needed to complete the survey on time. 
Table 22: Distribution of Experts in Different Panels

\begin{tabular}{|c|c|c|c|c|c|c|c|c|c|c|c|}
\hline Experts & Background & P1 & P2 & P3 & P4 & P5 & P6 & P7 & P8 & P9 & P10 \\
\hline SME 1 & Director of Planning \& Evaluation & & $*$ & & $\leftarrow$ & $>$ & $\bullet$ & 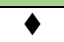 & \& & & \\
\hline SME 2 & President & & * & $\star$ & & & & & & & \\
\hline SME 3 & $\begin{array}{l}\text { Management \& Program Analyst, } \\
\text { Technology Innovation }\end{array}$ & & & * & $\leftarrow$ & & & & & & \\
\hline SME 4 & $\begin{array}{l}\text { Deputy Director \& Director of Impact } \\
\text { Strategy }\end{array}$ & & * & * & $\leftarrow$ & $>$ & $\bullet$ & $\diamond$ & 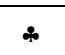 & & \\
\hline SME 5 & CEO & & * & $\star$ & $\leftarrow$ & $\nabla$ & $\bullet$ & & \& & $\boldsymbol{\sigma}$ & \\
\hline SME 6 & $\begin{array}{l}\text { Market Transformation Manager, } \\
\text { Consumer Products }\end{array}$ & & * & $\star$ & & $\nabla$ & $\bullet$ & $\diamond$ & \& & & \\
\hline SME 7 & Senior Energy Analyst & & * & $\star$ & $\leftarrow$ & $>$ & & & & 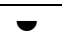 & \\
\hline SME 8 & Energy Engineer & & * & & $\leftarrow$ & $>$ & & & & & \\
\hline SME 9 & Former Power Division Director & & * & * & & & $\bullet$ & 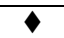 & & $\boldsymbol{\sigma}$ & $\mathbf{\square}$ \\
\hline SME 10 & $\begin{array}{l}\text { Energy \& Sustainability Program } \\
\text { Manager }\end{array}$ & & * & & & $\hat{~}$ & & 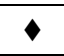 & & & \\
\hline SME 11 & Oregon Department of Energy & & * & & & & & & \& & & \\
\hline SME 12 & Residential Sector Manager & & & & & $>$ & & & \& & 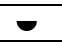 & \\
\hline SME 13 & President & & & & & & & 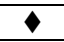 & \& & $\boldsymbol{\sigma}$ & \\
\hline SME 14 & Evaluation Manager & & & & & & $\bullet$ & & & $\boldsymbol{2}$ & \\
\hline SME 15 & Principal & & & & $\leftarrow$ & & & & & & \\
\hline SME 16 & Senior Analyst & & & & & & $\bullet$ & $\nabla$ & & & \\
\hline SME 17 & Building Technology Office, EERE & & & & & & $\bullet$ & & & & \\
\hline SME 18 & Program Manager & & & & & & & $\nabla$ & & & \\
\hline SME 19 & Sustainability Specialist & & & & & & & & \& & & \\
\hline SME 20 & Senior Energy Analyst & & & & & & & & & & $\mathbf{\square}$ \\
\hline SME 21 & Market Policy \& Analytics Manager & & & & & & & & & $\boldsymbol{\sigma}$ & \\
\hline SME 22 & $\begin{array}{l}\text { Manager, Regulatory and Policy } \\
\text { Strategy }\end{array}$ & & & & & & & & & $\boldsymbol{\nabla}$ & \\
\hline SME 23 & Manager, Energy Efficiency & & & & & & & & & $\boldsymbol{\sigma}$ & \\
\hline SME 24 & Senior Director & & & & $\leftarrow$ & & & & & $\nabla$ & \\
\hline SME 25 & Senior Technical Energy Manager & & & & & & & & & $\boldsymbol{0}$ & \\
\hline SME 26 & Senior Vice President Operations & & & & & & & & & $\boldsymbol{0}$ & \\
\hline SME 27 & Director of Program Services & & & & & & & & & $\boldsymbol{\nabla}$ & \\
\hline SME 28 & Senior Program Manager & & & & & & & & & & $\mathbf{\square}$ \\
\hline SME 29 & Director of Sales & & & & & & & & & $\boldsymbol{0}$ & $\mathbf{\square}$ \\
\hline SME 30 & $\begin{array}{l}\text { Global Director of Energy Efficiency } \\
\text { and Renewable Energy }\end{array}$ & & * & & & & & & & & \\
\hline SME 31 & Former CTIO & & * & & & & & & & & \\
\hline SME32 & $\begin{array}{l}\text { Director Retail Technology Strategy/ } \\
\text { Development }\end{array}$ & & $*$ & & & & & & & & \\
\hline SME 33 & $\begin{array}{l}\text { Sr. Scientific/Engineering Associate, } \\
\text { Energy Efficiency Standards Group }\end{array}$ & & * & & & & & & & & \\
\hline SME 34 & Product Strategy Lead & & * & & & & & & & & \\
\hline SME 35 & Program Manager & & $*$ & & & & & & & & \\
\hline SME 36 & Senior Energy Analyst & & $\$$ & & & & & & & & \\
\hline SME 37 & $\begin{array}{l}\text { Policy Strategist \& Industry Foresight } \\
\text { Lead, Enterprise Risk Management }\end{array}$ & & $*$ & & & & & & & & \\
\hline SME 38 & Economist & & * & & & & & & & & \\
\hline SME 39 & Director & & \$ & & & & & & & & \\
\hline SME 40 & $\begin{array}{l}\text { Senior Research Engineer, Energy } \\
\text { Efficiency Engineering Team }\end{array}$ & & * & & & & & & & & \\
\hline SME 41 & Operations Manager & & * & & & & & & & & \\
\hline SME 42 & $\begin{array}{l}\text { Senior Vice President of Research and } \\
\text { Development }\end{array}$ & & * & & & & & & & & \\
\hline SME 43 & Program Manager & & * & & & & & & & & \\
\hline SME 44 & $\begin{array}{l}\text { Senior Manager, Emerging } \\
\text { Technology \& Product Management }\end{array}$ & * & & & & & & & & & \\
\hline SME 45 & Product Portfolio Manager, Buildings & & & & & & & & & & $\mathbf{\square}$ \\
\hline SME 46 & $\begin{array}{l}\text { Leader, Grids and Renewable Energy } \\
\text { Integration }\end{array}$ & & & & & & & & & 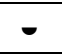 & \\
\hline SME 47 & $\begin{array}{l}\text { Program Manager, Energy Efficiency } \\
\text { Emerging Technologies E3T }\end{array}$ & * & & & & & & & & & \\
\hline SME 48 & $\begin{array}{l}\text { Principal, Testifying Expert and } \\
\text { Energy Economist }\end{array}$ & * & & & & & & & & & \\
\hline SME 49 & $\begin{array}{l}\text { Professor \& Energy Studies Building } \\
\text { Lab (ESBL) Director }\end{array}$ & * & & & & & & & & & \\
\hline SME 50 & Principal & * & & & & & & & & & \\
\hline
\end{tabular}


A Venn diagram is created to show the participation of experts in different tasks as in Figure 31.

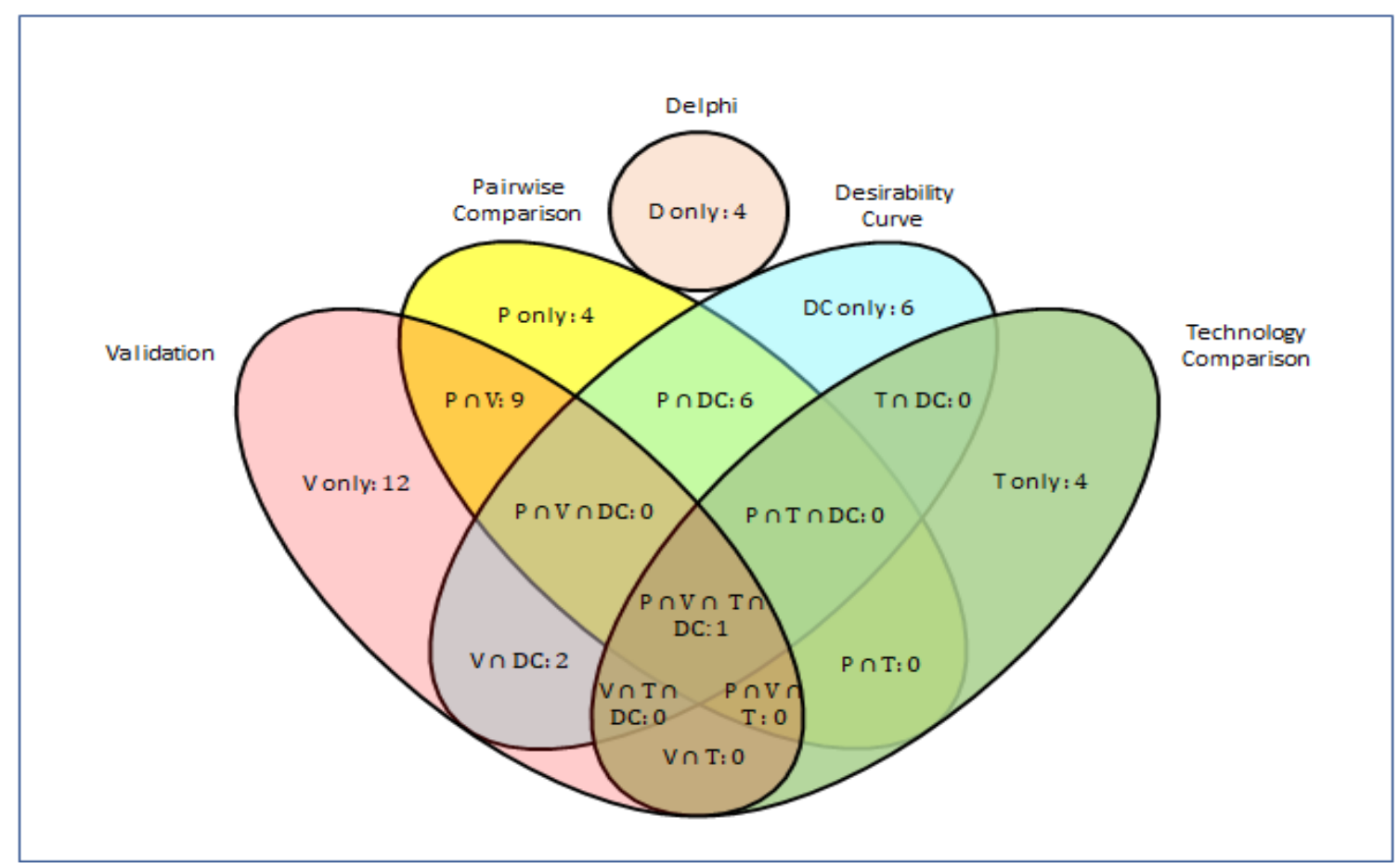

Figure 31: Venn Diagram showing Participation of Experts in Different Tasks 


\section{CHAPTER 6: RESULTS OF MODEL VALIDATION AND QUANTIFICATION}

This chapter shares the results from experts' validation and pairwise comparison of market attributes and key components of market attributes and validation and quantification of desirability curves. All the market attributes and key elements are retained in the final model from the preliminary model as all the elements were accepted by at least $2 / 3^{\text {rd }}$ majority of the experts.

\subsection{Model Validation}

Twenty-four experts from different organizations participated in the validation part of the study. Sustainability experts and strategists not only from leading energy related organizations but also from non-energy related establishments validated elements in the

model. Participation of experts from different organizations give greater confidence to generalize the applicability of the model in different settings for assessing market diffusion potential of energy efficient technologies.

\subsubsection{Criteria: Validation of Market Attributes}

The market attributes are accepted by majority of the experts as modeled in Figure 32. However, experts are cynical about the relative importance of the market attributes and how they interrelate in actual uptake. For example, economic may be less important if technical and customers' benefit are prominent. In fact, the MCDA senses the relative importance of elements from experts' judgmental quantification for individual technology case. 


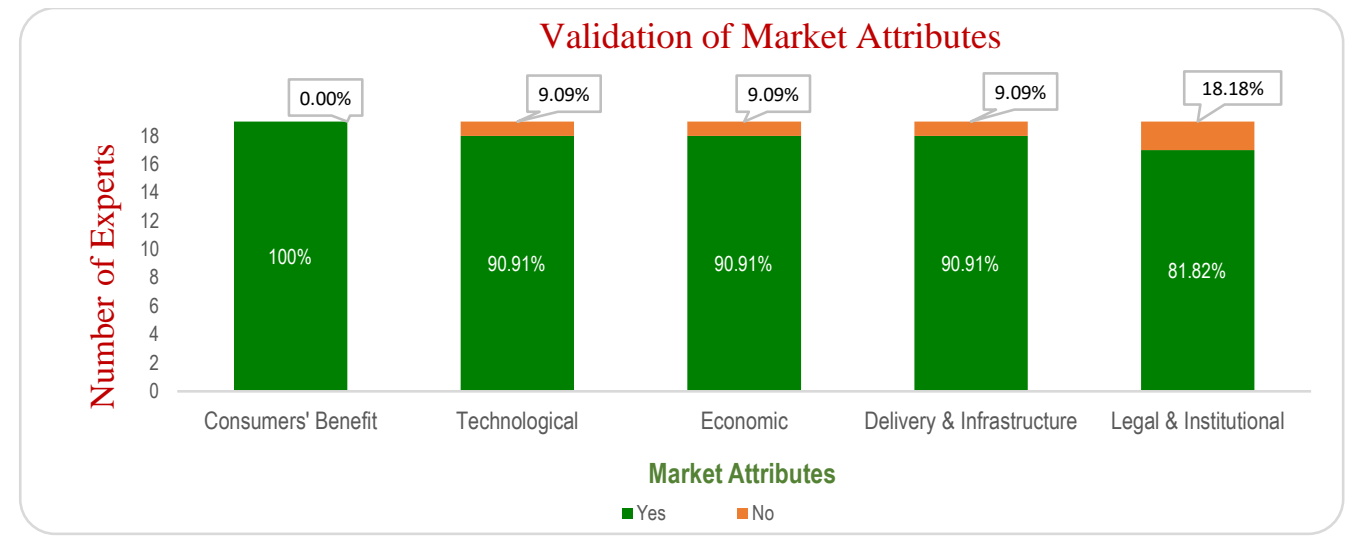

Figure 32: Validation of Market Attributes

\subsubsection{Sub criteria: Validation of Key Components of Market Attributes}

\subsubsection{Validation of Key Components in Consumers' Benefit Market Attribute}

In this key element validation as shown in Figure 33, experts have advised cultural behavioral aspect to be included as a factor in place of NEBs. As the model is based on customer value hierarchy, factors that are the most important in creating value to customers are considered as an element in the model. Also, experts identified safety and comfort to be non-energy benefits. As explained in chapter 5, there are three categories of non-energy benefits. Safety and comfort are utility participant benefits while the non-energy benefit is the societal benefit. Awareness is identified as a key element for delivery and infrastructure. However, value to customers does not only imply the cost but also the time required to obtain the product/service. Awareness provides value to consumers by reducing the time to obtain the technology. 


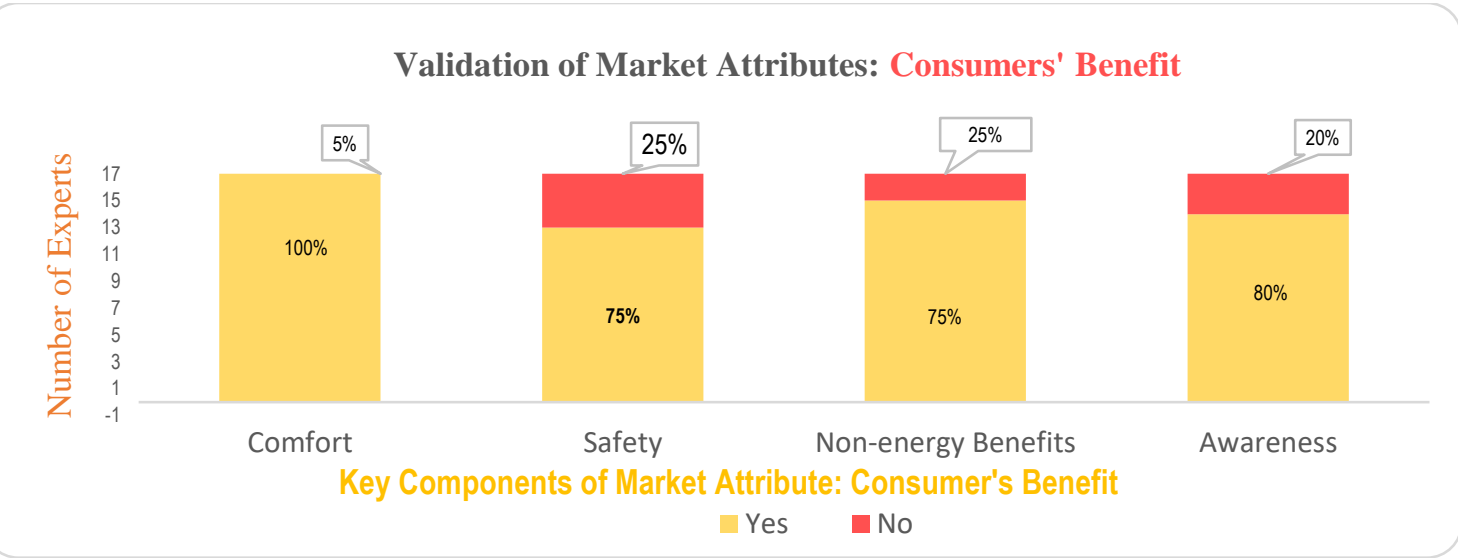

Figure 33: Validation of Key Components of Market Attributes: Consumer's

\section{Benefit}

\subsubsection{Validation of Key Components in Technological Market Attribute}

Most of the experts are in consensus about energy saving potential as a key component of technology market attribute as represented in Figure 34. However, some of the experts have expressed concern about the term compatibility and are in favor of replacing to climate compatibility as compatibility is understood as working well with other technologies (e.g. controls that cause interference with other systems). The term 'compatibility' is further clarified as tentative guideline for metrics to measure compatibility is included for developing desirability curve for compatibility. 


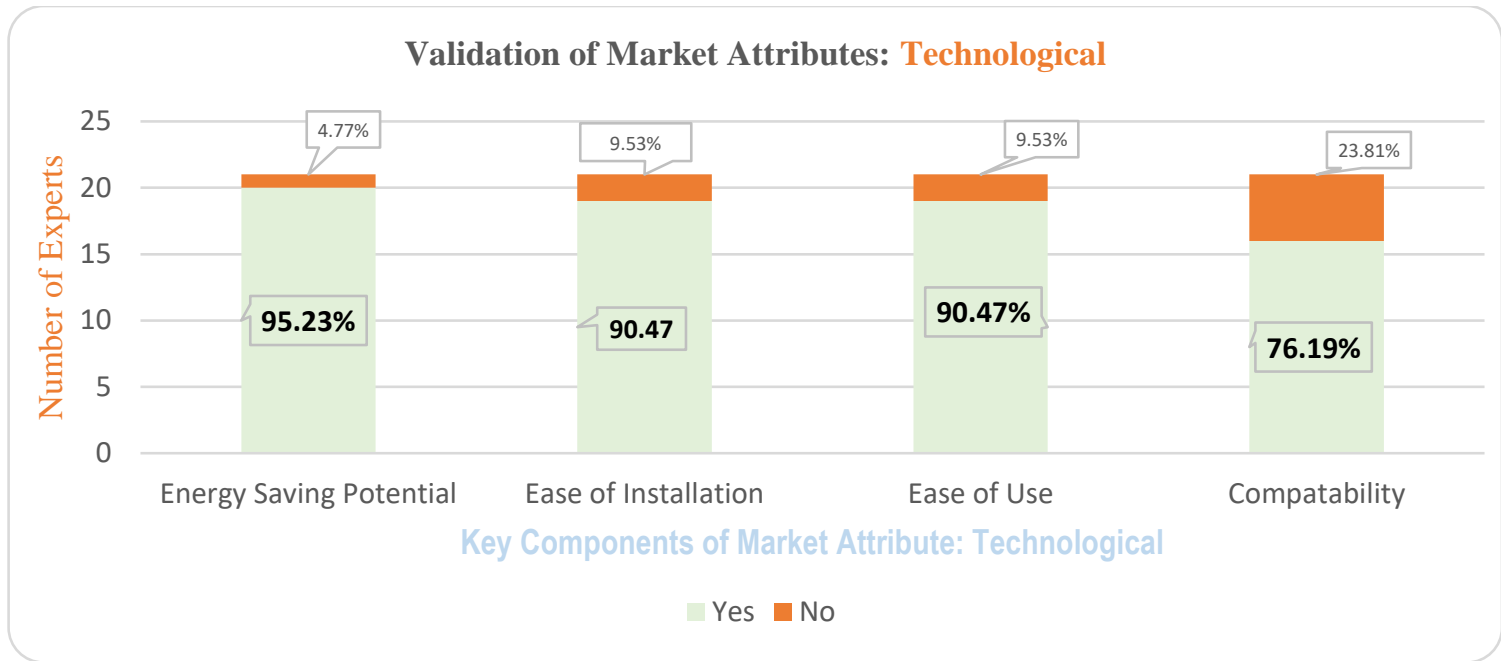

Figure 34: Validation of Key Components of Market Attributes: Technological

\subsubsection{Validation of Key Components in Economic Market Attribute}

In economic market attribute validation as displayed in Figure 35, experts are skeptical about Profitability Index (PI) and Levelized Cost of Electricity (LCOE). The model is from the market's perspective. Hence, to increase the diffusion of residential EE technologies it is not only the ultimate end users who should derive value from the technology. As explained in the theoretical framework, market system for EE technology consists of different actors. The diffusion of the technology is successful when the different market actors at the supply side also gain benefit from adoption of the technology by customers at the demand side. As described in Chapter 1, the success of diffusion of EE technology depend to a large extent on utility adoption of EE programs. Hence, PI and LCOE are important criteria for diffusion of EE technologies as they ensure utility participation as well as investment by other stakeholders in the endeavor. 


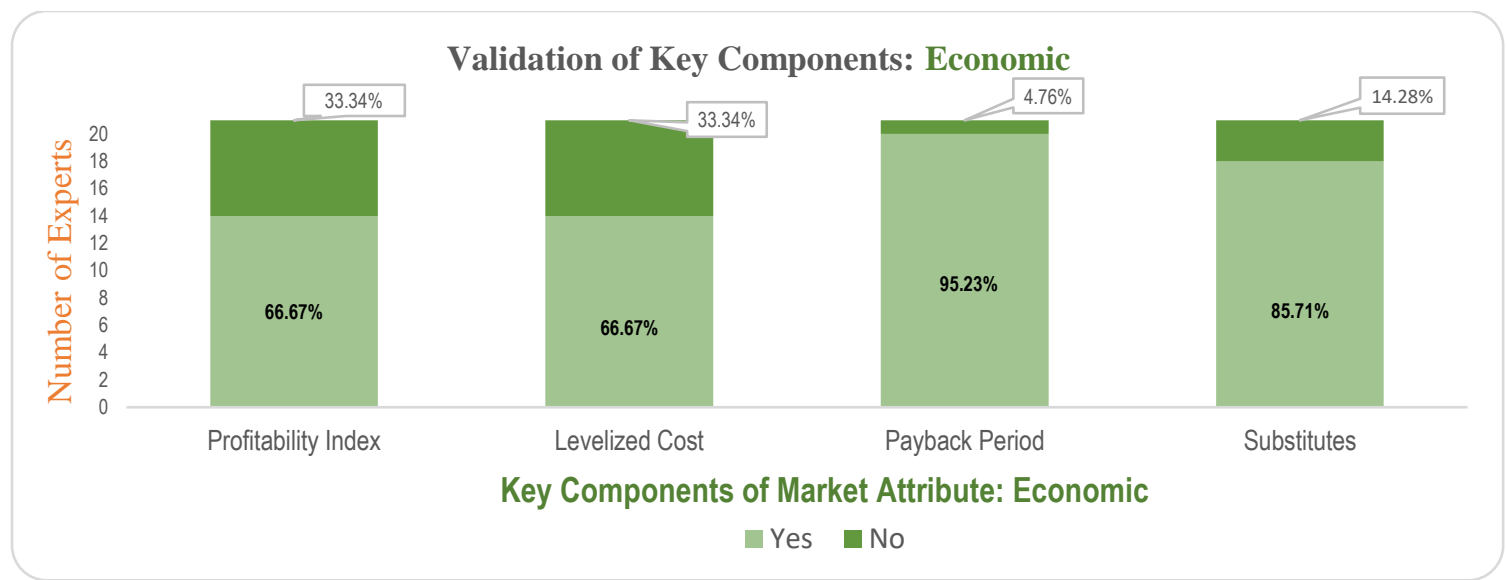

Figure 35: Validation of Key Components of Market Attributes: Economic

6.1.2.4 Validation of Key Components in Delivery and Infrastructure Market Attribute

Validation of this key component as shown in Figure 36, led to clarification of accessibility and supply chain. Accessibility is the ultimate outlet from where the product can be bought. Supply chain involves actors who manufacture, deliver and install EE technologies and the interaction among them. Competition is not only limited between EE technologies, but it has a wider market context that includes competition between EE and non-EE technologies as well. 


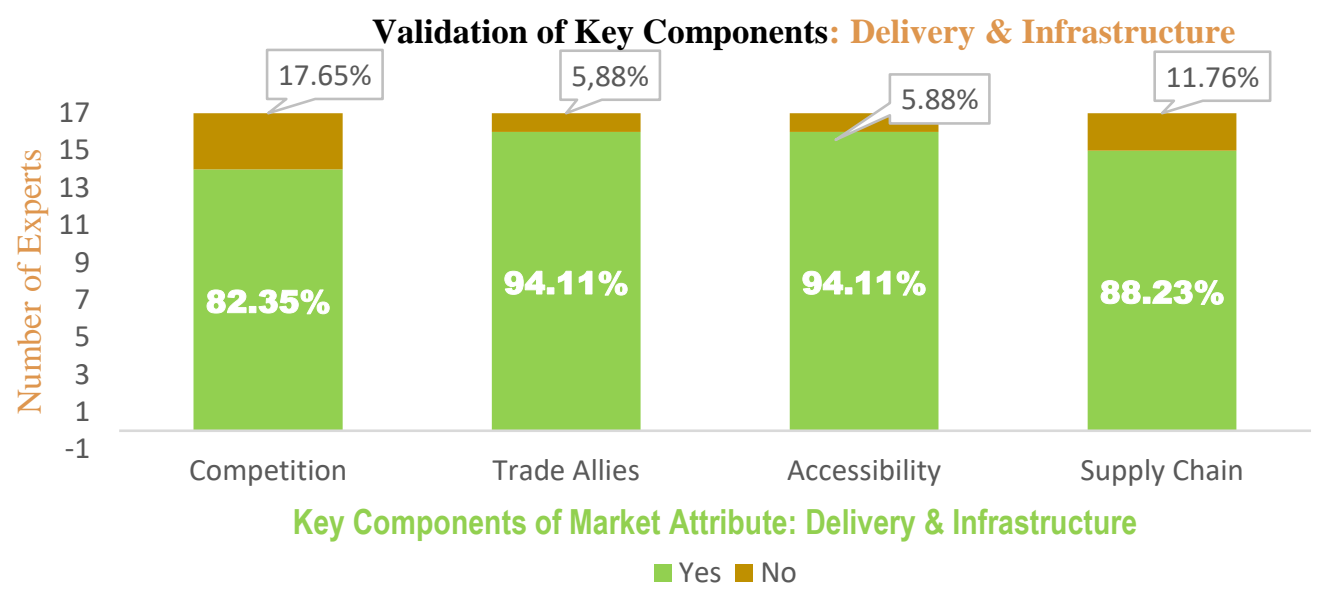

Figure 36: Validation of Key Components of Market Attributes: Delivery and

\section{Infrastructure}

\subsubsection{Validation of Key Components in Legal and Institutional Market Attribute}

In legal and institutional market attribute as represented in Figure 37, experts are divided not on if energy price should be included as a key component but rather if it should be a part of economic or legal and institutional market attribute. Domestic natural gas market is regulated by Federal Energy Regulatory commission. Similarly, there are many state policies that regulate the electricity price through utilities, for example, Real Time Pricing, Time-of-use rates, Critical peak pricing, Flat Energy Rate or Tiered Rates. Those factors are considered as key components under legal and institutional market attribute that need oversight of some regulatory body or institution. Most experts have considered labelling to be an integral part of EE technologies and do not consider it to be an important component of legal and institutional factor. There are many different categories of labels and the labelling needs to be appropriate to convey the correct message 
to the buyers in order to increase the diffusion.

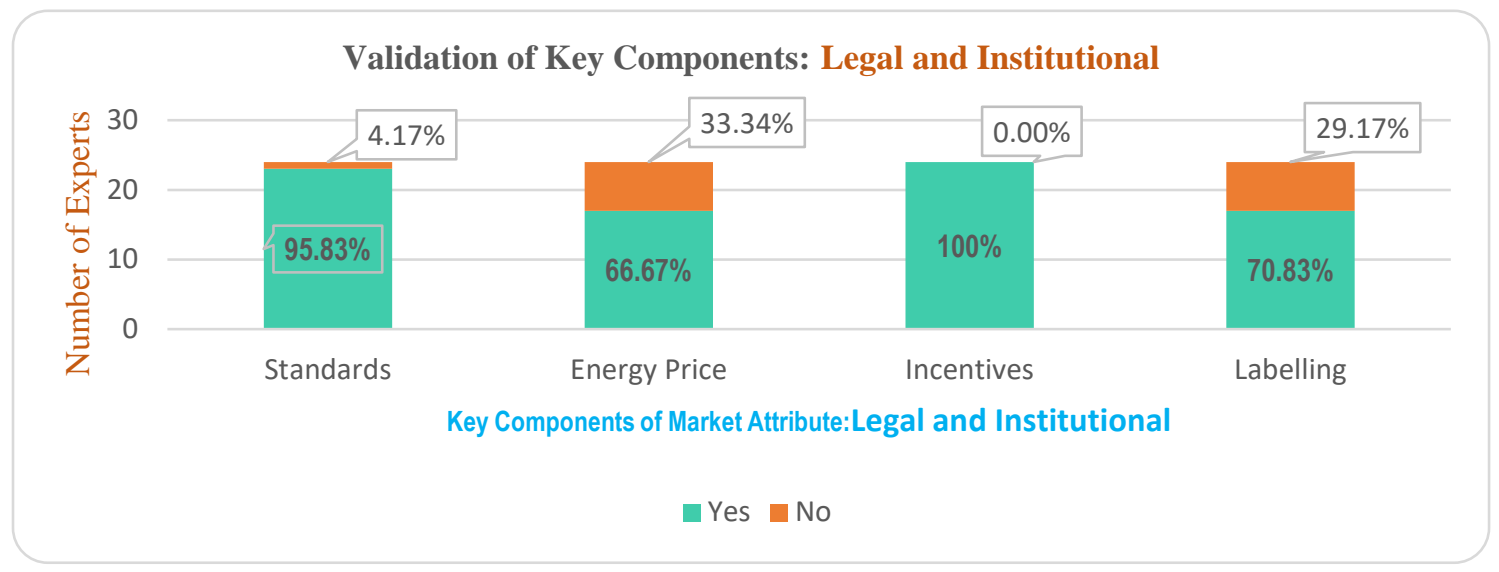

Figure 37: Validation of Key Components of Market Attributes: Legal and Institutional

\subsection{Model Quantification}

\subsubsection{Pairwise Comparison of Market Attributes}

Eight experts consisting of planners, entrepreneurs, program analyst, and impact strategist and market transformation managers are in this panel. Table 23 shows the ranking of different market attributes after pairwise comparison by experts.

Table 23: Pairwise Comparison of Market Attributes

\begin{tabular}{|c|c|c|c|c|c|c|}
\hline (MDP) & $\begin{array}{c}\text { Consumers' } \\
\text { Benefit }\end{array}$ & Technological & Economic & $\begin{array}{c}\text { Delivery } \\
\text { \& Infrastructure }\end{array}$ & $\begin{array}{c}\text { Legal \& } \\
\text { Institutional }\end{array}$ & Inconsistency \\
\hline SME1 & 0.33 & 0.18 & 0.17 & 0.22 & 0.09 & 0.01 \\
\hline SME2 & 0.11 & 0.35 & 0.27 & 0.09 & 0.18 & 0.02 \\
\hline SME3 & 0.36 & 0.12 & 0.26 & 0.17 & 0.09 & 0.04 \\
\hline SME4 & 0.17 & 0.17 & 0.29 & 0.13 & 0.25 & 0.04 \\
\hline SME5 & 0.23 & 0.21 & 0.28 & 0.16 & 0.12 & 0.01 \\
\hline SME6 & 0.27 & 0.09 & 0.2 & 0.12 & 0.32 & 0.08 \\
\hline SME7 & 0.13 & 0.05 & 0.33 & 0.05 & 0.43 & 0.04 \\
\hline SME9 & 0.04 & 0.25 & 0.17 & 0.34 & 0.19 & 0.01 \\
\hline Mean & $\mathbf{0 . 2 1}$ & $\mathbf{0 . 1 8}$ & $\mathbf{0 . 2 5}$ & $\mathbf{0 . 1 6}$ & $\mathbf{0 . 2 1}$ & \\
\hline Minimum & $\mathbf{0 . 0 4}$ & $\mathbf{0 . 0 5}$ & $\mathbf{0 . 1 7}$ & $\mathbf{0 . 0 5}$ & $\mathbf{0 . 0 9}$ & \\
\hline Maximum & $\mathbf{0 . 3 6}$ & $\mathbf{0 . 3 5}$ & $\mathbf{0 . 3 3}$ & $\mathbf{0 . 3 4}$ & $\mathbf{0 . 4 3}$ & $\mathbf{0 . 1 1}$ \\
\hline Std. Deviation & $\mathbf{0 . 1}$ & $\mathbf{0 . 0 9}$ & $\mathbf{0 . 0 6}$ & $\mathbf{0 . 0 8}$ & $\mathbf{0 . 1 1}$ & $\mathbf{0 . 0 8 5}$ \\
\hline Disagreement & & & & & & \\
\hline
\end{tabular}


The inconsistency for each expert and the disagreement among experts are within the acceptable limit $(\leq 0.10)$. Economic market attribute has been ranked as the most important market attribute followed by Consumers' Benefit and Legal and Institutional Market Attribute.

\subsubsection{Pairwise Comparison of Key Components of Market Attributes}

Five different panels with experts from different organizations and different backgrounds participated in pairwise comparison of key components for each of the five market attributes.

\subsubsection{Pairwise Comparison of Key Components in Consumers' Benefit Market Attribute}

Eight experts consisting of program analyst, impact strategist and evaluation managers participated in comparing the four key components of Consumers' Benefit market attribute. Table 24 shows the results from pairwise comparison of key elements in Consumers' Benefit market attribute.

Table 24: Pairwise Comparison of Key Components in Consumers' Benefit Market Attribute

\begin{tabular}{|c|c|c|c|c|c|}
\hline $\begin{array}{c}\text { Consumers' } \\
\text { Benefit } \\
\end{array}$ & Comfort & Safety & $\begin{array}{c}\text { Non-energy } \\
\text { benefit }\end{array}$ & Awareness & Inconsistency \\
\hline SME1 & 0.48 & 0.17 & 0.31 & 0.04 & 0.02 \\
\hline SME8 & 0.31 & 0.42 & 0.14 & 0.14 & 0.03 \\
\hline SME4 & 0.24 & 0.09 & 0.33 & 0.35 & 0 \\
\hline SME5 & 0.19 & 0.29 & 0.22 & 0.31 & 0.01 \\
\hline SME6 & 0.34 & 0.19 & 0.25 & 0.22 & 0.04 \\
\hline SME14 & 0.2 & 0.54 & 0.2 & 0.07 & 0.04 \\
\hline SME15 & 0.25 & 0.56 & 0.06 & 0.14 & 0 \\
\hline SME7 & 0.34 & 0.08 & 0.25 & 0.33 & 0 \\
\hline Mean & 0.29 & 0.29 & 0.22 & 0.2 & \\
\hline Minimum & 0.19 & 0.08 & 0.06 & 0.04 & \\
\hline Maximum & 0.48 & 0.56 & 0.33 & 0.35 & \\
\hline Std. Deviation & 0.09 & 0.18 & 0.08 & 0.11 & \\
\hline Disagreement & & & & & 0.117 \\
\hline
\end{tabular}


The inconsistency for each expert is within acceptable limit $(\leq 0.10)$. However, the disagreement among experts is 0.117 which is above the acceptable limit. Comfort and safety are ranked equally important key components for Consumers' Benefit market attribute.

Hierarchical cluster analysis is used to find the different groups with dissimilar views. The dendrogram in Figure 38 shows clusters in P4 (Panel four).

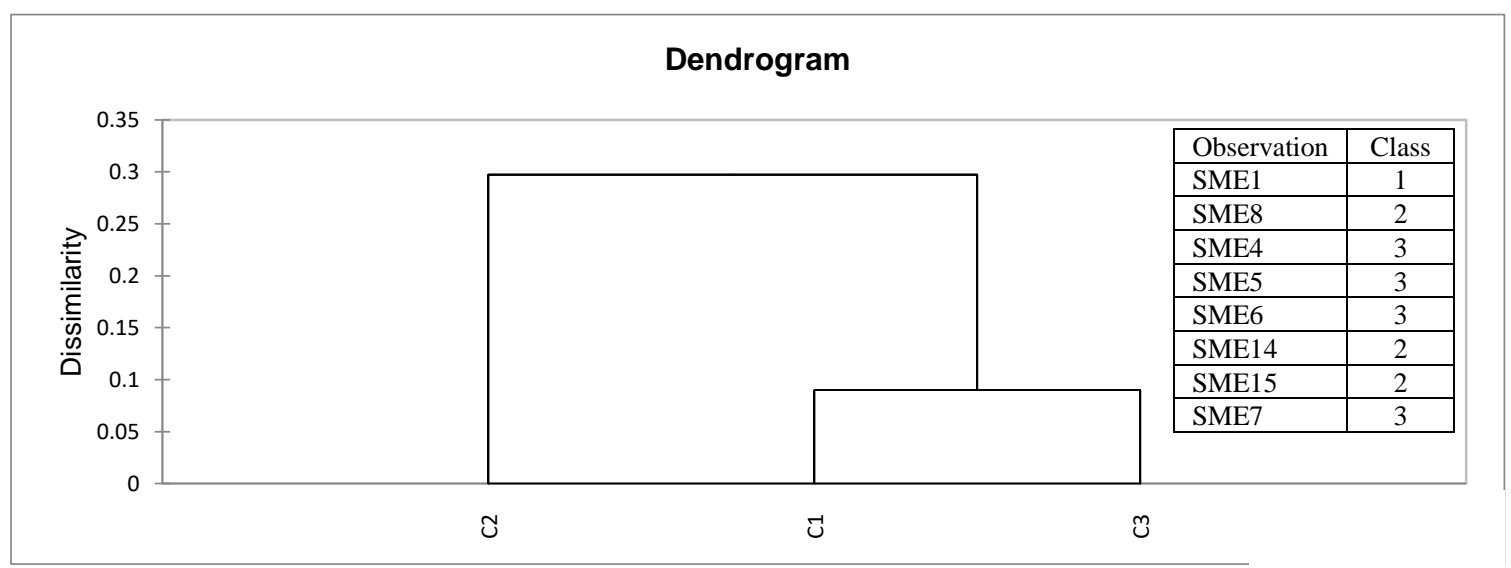

Figure 38: Dendrogram for Consumers' Benefit Market Attribute

The three clusters are analyzed based on experts in each group. Cluster 3 has the most experts and a background check shows that they all come from different organizations but hold senior positions for a long time and mostly energy analysts and strategists. Cluster 2 has experts who also come from different organizations but have years of experience in EE projects. In cluster 1 the only expert has 15 years of experience in energy efficiency program planning and evaluation consulting while another 18 years of experience in planning and evaluation of energy efficiency programs. The disagreement is acceptable as 
in each cluster there is a consensus of opinion and experts are of similar background which is a criterion of acceptance for disagreement as discussed in chapter 4 [269].

6.2.2.2 Pairwise Comparison of Key Components in Technological Market Attribute

Eight experts consisting of analysts, strategists, engineers and sustainability program managers participated in comparing the four key components of Technological market attribute. Table 25 shows the result from pairwise comparison of key elements in Technological market attribute.

Table 25: Pairwise Comparison of Key Components in Technological Market Attribute

\begin{tabular}{|l|c|c|c|c|c|}
\hline Technological & $\begin{array}{c}\text { Energy } \\
\text { Saving } \\
\text { Potential }\end{array}$ & $\begin{array}{c}\text { Ease of } \\
\text { Installation }\end{array}$ & $\begin{array}{c}\text { Ease of } \\
\text { Use }\end{array}$ & Compatibility & Inconsistency \\
\hline SME10 & 0.15 & 0.08 & 0.33 & 0.44 & 0.05 \\
\hline SME1 & 0.32 & 0.19 & 0.22 & 0.27 & 0.01 \\
\hline SME8 & 0.27 & 0.25 & 0.3 & 0.18 & 0 \\
\hline SME4 & 0.31 & 0.24 & 0.14 & 0.31 & 0 \\
\hline SME5 & 0.25 & 0.23 & 0.35 & 0.17 & 0.03 \\
\hline SME12 & 0.31 & 0.16 & 0.36 & 0.17 & 0.05 \\
\hline SME6 & 0.06 & 0.17 & 0.11 & 0.65 & 0.03 \\
\hline SME7 & 0.24 & 0.26 & 0.15 & 0.35 & 0 \\
\hline Mean & $\mathbf{0 . 2 4}$ & $\mathbf{0 . 2}$ & $\mathbf{0 . 2 5}$ & $\mathbf{0 . 3 2}$ & \\
\hline Minimum & $\mathbf{0 . 0 6}$ & $\mathbf{0 . 0 8}$ & $\mathbf{0 . 1 1}$ & $\mathbf{0 . 1 7}$ & \\
\hline Maximum & $\mathbf{0 . 3 2}$ & $\mathbf{0 . 2 6}$ & $\mathbf{0 . 3 6}$ & $\mathbf{0 . 6 5}$ & $\mathbf{0 . 1 5}$ \\
\hline Std. Deviation & $\mathbf{0 . 0 8}$ & $\mathbf{0 . 0 6}$ & $\mathbf{0 . 1}$ & & $\mathbf{0 . 0 9 4}$ \\
\hline Disagreement & & & & & \\
\hline
\end{tabular}

The inconsistency for each expert and the disagreement among experts are within the acceptable limit $(\leq 0.10)$. Compatibility in different climate zone is considered to be the most important component in Technological market attribute followed ease of use and energy saving potential. 
6.2.2.3 Pairwise Comparison of Key Components in Economic Market Attribute

Seven experts consisting of few of the experts in other panels as well as expert in power division and building technology office participated in comparing the four key components of Economic market attribute. Table 26 shows the result from pairwise comparison of key elements in Economic market attribute.

Table 26: Pairwise Comparison of Key Components in Economic Market Attribute

\begin{tabular}{|l|c|c|c|c|c|}
\hline \multicolumn{1}{|c|}{ Economic } & $\begin{array}{c}\text { Profitability } \\
\text { Index }\end{array}$ & $\begin{array}{c}\text { Levelized } \\
\text { Cost }\end{array}$ & $\begin{array}{c}\text { Payback } \\
\text { Period }\end{array}$ & Substitutes & Inconsistency \\
\hline SME1 & 0.21 & 0.14 & 0.32 & 0.32 & 0 \\
\hline SME4 & 0.25 & 0.39 & 0.25 & 0.1 & 0 \\
\hline SME16 & 0.13 & 0.47 & 0.23 & 0.17 & 0 \\
\hline SME5 & 0.16 & 0.29 & 0.35 & 0.2 & 0.01 \\
\hline SME6 & 0.08 & 0.15 & 0.19 & 0.58 & 0.01 \\
\hline SME14 & 0.32 & 0.04 & 0.32 & 0.32 & 0 \\
\hline SME9 & 0.44 & 0.11 & 0.25 & 0.2 & 0.05 \\
\hline Mean & $\mathbf{0 . 2 3}$ & $\mathbf{0 . 2 3}$ & $\mathbf{0 . 2 7}$ & $\mathbf{0 . 2 7}$ & \\
\hline Minimum & $\mathbf{0 . 0 8}$ & $\mathbf{0 . 0 4}$ & $\mathbf{0 . 1 9}$ & $\mathbf{0 . 1}$ & \\
\hline Maximum & $\mathbf{0 . 4 4}$ & $\mathbf{0 . 4 7}$ & $\mathbf{0 . 3 5}$ & $\mathbf{0 . 5 8}$ & \\
\hline Std. Deviation & $\mathbf{0 . 1 1}$ & $\mathbf{0 . 1 5}$ & $\mathbf{0 . 0 5}$ & $\mathbf{0 . 1 5}$ & \\
\hline Disagreement & & & & & $\mathbf{0 . 1 1 5}$ \\
\hline
\end{tabular}

The inconsistency for each expert is within acceptable limit $(\leq 0.10)$. However, the disagreement among experts is 0.115 which is above the acceptable limit. Payback period and substitutes are ranked equally important key components for Economic market attribute.

Hierarchical cluster analysis is used to find the different groups with dissimilar views. The dendrogram in Figure 39 shows the clusters in P6 (Panel six). 


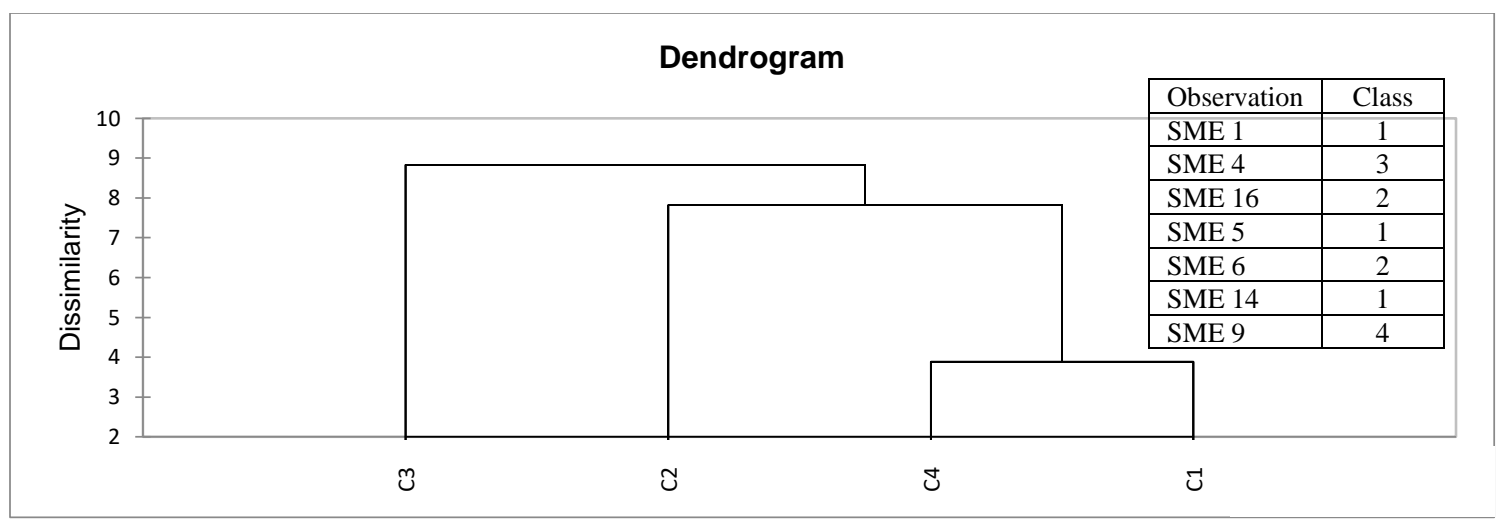

Figure 39: Dendrogram for Economic Market Attribute

There are four clusters in the panel. There are three experts in cluster 1. Experts in cluster 1 are from different organizations but have similar expertise. All of the experts are involved in planning, evaluation and management of EE programs and projects. The two experts in Cluster 2 are analysts who come from different organizations. Cluster 3 and cluster 4 each has only one expert who work in different organizations, different expertise, experience and backgrounds. The disagreement is accepted as experts in each cluster has similar backgrounds [269].

6.2.2.4 Pairwise Comparison of Key Components in Delivery and Infrastructure Market Attribute

Eight experts consisting of few of the experts in other panels and mostly in entrepreneurial position participated in comparing the four key components of delivery and infrastructure market attribute. Table 27 shows the results of pairwise comparison of key elements in Delivery and Infrastructure market attribute. 
Table 27: Pairwise Comparison of Key Components in Delivery \& Infrastructure Market Attribute

\begin{tabular}{|l|c|c|c|c|c|}
\hline $\begin{array}{c}\text { Delivery \& } \\
\text { Infrastructure }\end{array}$ & Competition & $\begin{array}{c}\text { Trade } \\
\text { Allies }\end{array}$ & Accessibility & $\begin{array}{c}\text { Supply } \\
\text { Chain }\end{array}$ & Inconsistency \\
\hline SME13 & 0.19 & 0.46 & 0.19 & 0.16 & 0.02 \\
\hline SME10 & 0.24 & 0.07 & 0.61 & 0.08 & 0.05 \\
\hline SME1 & 0.14 & 0.21 & 0.36 & 0.29 & 0 \\
\hline SME18 & 0.14 & 0.39 & 0.19 & 0.28 & 0.02 \\
\hline SME4 & 0.15 & 0.18 & 0.52 & 0.15 & 0.01 \\
\hline SME16 & 0.34 & 0.38 & 0.11 & 0.16 & 0 \\
\hline SME6 & 0.29 & 0.13 & 0.28 & 0.29 & 0 \\
\hline SME9 & 0.09 & 0.38 & 0.2 & 0.34 & 0.01 \\
\hline Mean & $\mathbf{0 . 2}$ & $\mathbf{0 . 2 8}$ & $\mathbf{0 . 3 1}$ & $\mathbf{0 . 2 2}$ & \\
\hline Minimum & $\mathbf{0 . 0 9}$ & $\mathbf{0 . 0 7}$ & $\mathbf{0 . 1 1}$ & $\mathbf{0 . 0 8}$ & \\
\hline Maximum & $\mathbf{0 . 3 4}$ & $\mathbf{0 . 4 6}$ & $\mathbf{0 . 6 1}$ & $\mathbf{0 . 3 4}$ & \\
\hline Std. Deviation & $\mathbf{0 . 0 8}$ & $\mathbf{0 . 1 4}$ & $\mathbf{0 . 1 7}$ & $\mathbf{0 . 0 9}$ & \\
\hline Disagreement & & & & & $\mathbf{0 . 1 1 6}$ \\
\hline
\end{tabular}

The inconsistency for each expert is within acceptable limit $(<0.10)$. However, the disagreement among experts is 0.116 which is above the acceptable limit. Accessibility and Trade Allies are assessed to be most important key components for Delivery and Infrastructure market attribute.

Hierarchical cluster analysis is used to find the different groups with dissimilar views. The dendrogram in Figure 40 shows the clusters in P7 (Panel seven).

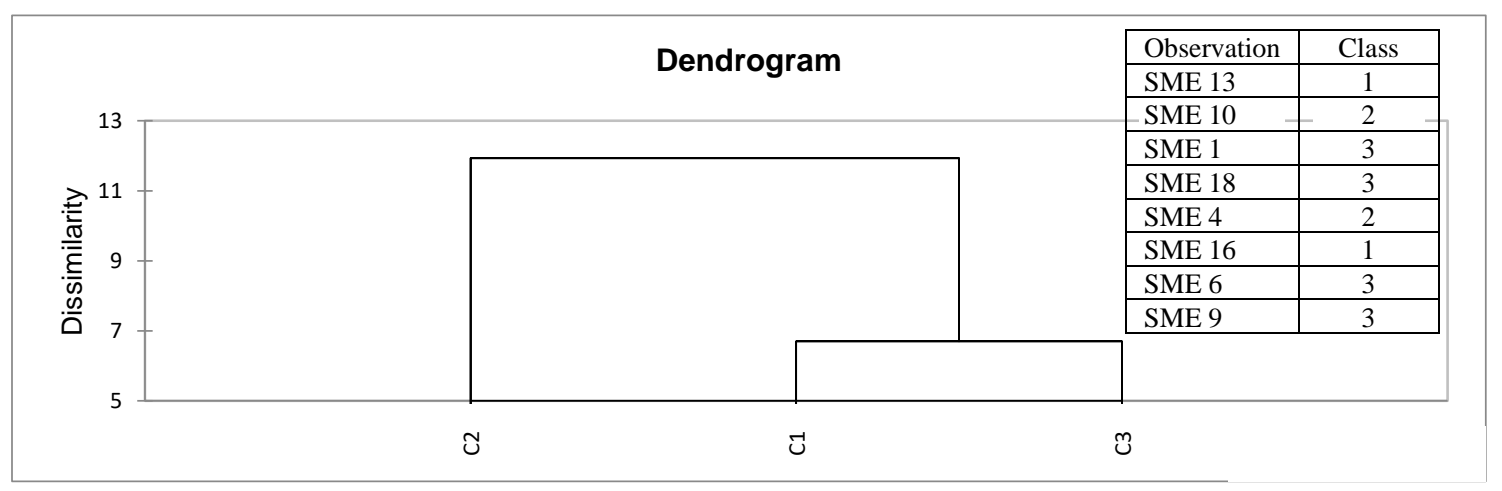

Figure 40: Dendrogram for Delivery \& Infrastructure Market Attribute 
There are three clusters in the panel. There are two experts in each of cluster 1 and 2 . While 4 experts in cluster 3. Experts in cluster 3 have almost same backgrounds while two of the experts are from the same organization. Experts in cluster 1 are from similar organizations that work on market transformation. Experts in cluster 2 are both entrepreneurs. Hence, based on criteria discussed in chapter 4 the disagreement is accepted [269].

6.2.2.5 Pairwise Comparison of Key Components in Legal and Institutional Market Attribute

Seven experts consisting of few of the experts in other panels as well as expert in residential sector energy management as well as energy modelling participated in comparing the four key components of legal and institutional market attribute. Table 28 shows the result from pairwise comparison of key elements in Legal and Institutional market attribute.

Table 28: Pairwise Comparison of Key Components in Legal \& Institutional Market Attribute

\begin{tabular}{|l|c|c|c|c|c|}
\hline $\begin{array}{c}\text { Legal \& } \\
\text { Institutional }\end{array}$ & Standards & $\begin{array}{c}\text { Energy } \\
\text { Price }\end{array}$ & Incentives & Labelling & Inconsistency \\
\hline SME13 & 0.5 & 0.14 & 0.31 & 0.05 & 0.02 \\
\hline SME1 & 0.27 & 0.06 & 0.16 & 0.51 & 0.01 \\
\hline SME4 & 0.52 & 0.1 & 0.32 & 0.06 & 0 \\
\hline SME5 & 0.18 & 0.27 & 0.36 & 0.19 & 0.01 \\
\hline SME12 & 0.29 & 0.21 & 0.36 & 0.15 & 0.07 \\
\hline SME6 & 0.42 & 0.17 & 0.28 & 0.13 & 0.02 \\
\hline SME11 & 0.54 & 0.28 & 0.06 & 0.13 & 0.04 \\
\hline Mean & $\mathbf{0 . 3 9}$ & $\mathbf{0 . 1 8}$ & $\mathbf{0 . 2 6}$ & $\mathbf{0 . 1 7}$ & \\
\hline Minimum & $\mathbf{0 . 1 8}$ & $\mathbf{0 . 0 6}$ & $\mathbf{0 . 0 6}$ & $\mathbf{0 . 0 5}$ & \\
\hline 1Maximum & $\mathbf{0 . 5 4}$ & $\mathbf{0 . 2 8}$ & $\mathbf{0 . 3 6}$ & $\mathbf{0 . 5 1}$ & \\
\hline Std. Deviation & $\mathbf{0 . 1 3}$ & $\mathbf{0 . 0 8}$ & $\mathbf{0 . 1}$ & $\mathbf{0 . 1 4}$ & \\
\hline Disagreement & & & & & $\mathbf{0 . 1 0 6}$ \\
\hline
\end{tabular}


The inconsistency for each expert and the disagreement among experts are within the acceptable limit $(\leq 0.10)$. Codes and Standards and Incentives are considered to be the most important component in Delivery and Infrastructure market attribute.

\subsection{Weights of Elements in HDM Model}

The final relative weights of market attributes and global relative value of key components are shown in Table 29 while Figure 41 captures the final HDM with relative weights. Economic market attribute is considered to be the most important criteria for diffusion of residential EE technologies. Consumers' Benefit and Legal and Institutional are next two attributes that are assessed to be equally important for EE technology diffusion in residential buildings. Codes and Standards have been identified as the most important contributor for diffusion followed by payback period and substitutes. When individual market attributes are analyzed, it shows that Comfort and Safety are the most important key components for Consumers' Benefit market attribute, Compatibility and Ease of Use are the main contributors for Technological Market Attribute, Payback Period and Substitutes are the leading factors for Economic Market Attribute, Accessibility and Trade Allies are the top elements for Delivery and Infrastructure Market Attribute and Codes \& Standards and Incentives are the foremost components of Legal and Institutional Market Attribute. 
Table 29: Final Weights in HDM

\begin{tabular}{|c|c|c|c|c|}
\hline $\begin{array}{c}\text { Market } \\
\text { Attributes }\end{array}$ & $\begin{array}{c}\text { Relative } \\
\text { Value }\end{array}$ & $\begin{array}{l}\text { Key Components of } \\
\text { Market Attributes }\end{array}$ & $\begin{array}{c}\text { Local Value of } \\
\text { Key Components }\end{array}$ & $\begin{array}{l}\text { Global Value of } \\
\text { Key Components }\end{array}$ \\
\hline \multirow{4}{*}{$\begin{array}{l}\text { Consumer's } \\
\text { Benefit }\end{array}$} & \multirow{4}{*}{0.21} & Comfort & 0.29 & 0.061 \\
\hline & & Safety & 0.29 & 0.061 \\
\hline & & Non-energy Benefits & 0.22 & 0.046 \\
\hline & & Awareness & 0.20 & 0.042 \\
\hline \multirow{4}{*}{ Technological } & \multirow{4}{*}{0.18} & Energy Saving Potential & 0.24 & 0.043 \\
\hline & & Ease of Installation & 0.20 & 0.036 \\
\hline & & Ease of Use & 0.25 & 0.045 \\
\hline & & Compatibility & 0.32 & 0.058 \\
\hline \multirow{4}{*}{ Economic } & \multirow{4}{*}{0.25} & Profitability Index (PI) & 0.23 & 0.058 \\
\hline & & Levelized Cost & 0.23 & 0.058 \\
\hline & & Payback Period & 0.27 & 0.068 \\
\hline & & Substitutes & 0.27 & 0.068 \\
\hline \multirow{4}{*}{$\begin{array}{l}\text { Delivery \& } \\
\text { Infrastructure }\end{array}$} & \multirow{4}{*}{0.16} & Competition & 0.20 & 0.032 \\
\hline & & Trade Allies & 0.28 & 0.045 \\
\hline & & Accessibility & 0.31 & 0.050 \\
\hline & & Supply Chain & 0.22 & 0.035 \\
\hline \multirow{4}{*}{$\begin{array}{l}\text { Legal \& } \\
\text { Institutional }\end{array}$} & \multirow{4}{*}{0.21} & Codes \& Standards & 0.39 & 0.082 \\
\hline & & Energy Price & 0.18 & 0.038 \\
\hline & & Incentive & 0.26 & 0.055 \\
\hline & & Labelling & 0.17 & 0.036 \\
\hline
\end{tabular}

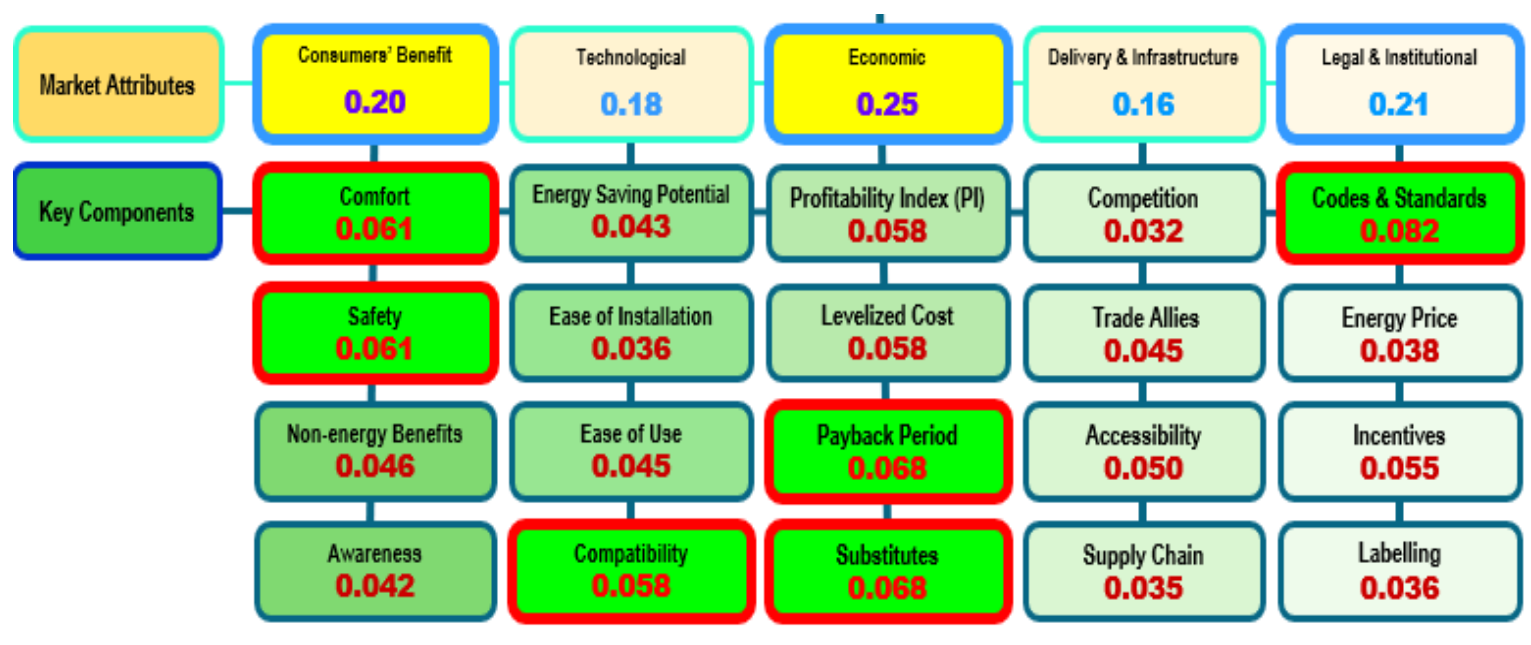

Figure 41: Final Weights in HDM

Triangulation method is used to confirm the results from the study. The method is used to increase confidence in the findings through the confirmation of the result from two 
or more independent sources [347]. As part of the triangulation method, the final result has been shared with experts who find it to be a reflection of reality with economic aspect being the greatest deterrent in diffusion as well as they completely agree that the model correctly captures the influence of Codes and Standards in diffusion of EE technologies.

The result has also been cross checked with findings in different literatures which is consistent.

\subsection{Desirability Curves}

Desirability value for a technology alternative is derived from desirability curves based on expert's judgment of percentage diffusion over the range of units specified for each key element pertaining to a certain market attribute. Desirability values are used to calculate and compare Market Diffusion Potential (MDP) of candidate technologies. Likert scale is used for each key element. Moreover, a guideline on metrics for each key element is provided for applicability and generalizability of the model.

6.4.1 Desirability Curves for Key Components of Consumers' Benefit Market Attribute

Consumers' Benefit market attribute ensures intangible product/service benefits for customers. Four components of Consumer's' Benefit Market Attribute are, Comfort, Safety, Non-energy Benefits (NEBs) and Awareness.

\subsubsection{Desirability Curve for Comfort}

Comfort is an essential element for living as people spend a considerable amount of time inside buildings. Some of the parameters for Indoor Environment Quality (IEA) are 
thermal comfort, visual comfort, indoor air quality and acoustical quality. The level of comfort can be classified based on the physical parameters and human physiology. A tentative guideline on metrics for measuring level of comfort is listed in Table 30 [159].

Figure 42 shows how the level of comfort affects the diffusion of residential EE technologies.

\section{Table 30: A Tentative Guideline on Metrics for Measuring Level of Comfort}

\begin{tabular}{|c|c|c|c|c|}
\hline $\begin{array}{c}\text { Not at all } \\
\text { comfortable }\end{array}$ & $\begin{array}{c}\text { Not very } \\
\text { comfortable }\end{array}$ & $\begin{array}{c}\text { Somewhat } \\
\text { comfortable }\end{array}$ & $\begin{array}{c}\text { Quite } \\
\text { comfortable }\end{array}$ & $\begin{array}{c}\text { Very } \\
\text { comfortable }\end{array}$ \\
\hline Aesthetic & $\begin{array}{c}\text { Aesthetic }+ \\
\text { Visual }\end{array}$ & $\begin{array}{c}\text { Aesthetic + Visual } \\
+ \text { Acoustical }\end{array}$ & $\begin{array}{c}\text { Aesthetic }+ \\
\text { Visual + } \\
\text { Acoustical Air + } \\
\text { Quality }\end{array}$ & $\begin{array}{c}\text { Aesthetic }+ \\
\text { Visual + } \\
\text { Acoustical + Air } \\
\text { Quality + } \\
\text { Temperature }\end{array}$ \\
\hline Aesthetic & Visual & Acoustical & Air Quality & Temperature \\
\hline $\begin{array}{c}\text { Interior design } \\
\text { (Size, layout, } \\
\text { color, greenery) }\end{array}$ & $\begin{array}{c}\text { Aspects such as } \\
\text { view, illuminance, } \\
\text { and reflection }\end{array}$ & $\begin{array}{c}\text { Control of } \\
\text { unwanted noise, } \\
\text { vibrations, and } \\
\text { reverberations }\end{array}$ & $\begin{array}{c}\text { Smells, irritants, } \\
\text { outdoor air, and } \\
\text { ventilation }\end{array}$ & $\begin{array}{c}\text { Air velocity, } \\
\text { humidity, and } \\
\text { temperature }\end{array}$ \\
\hline
\end{tabular}

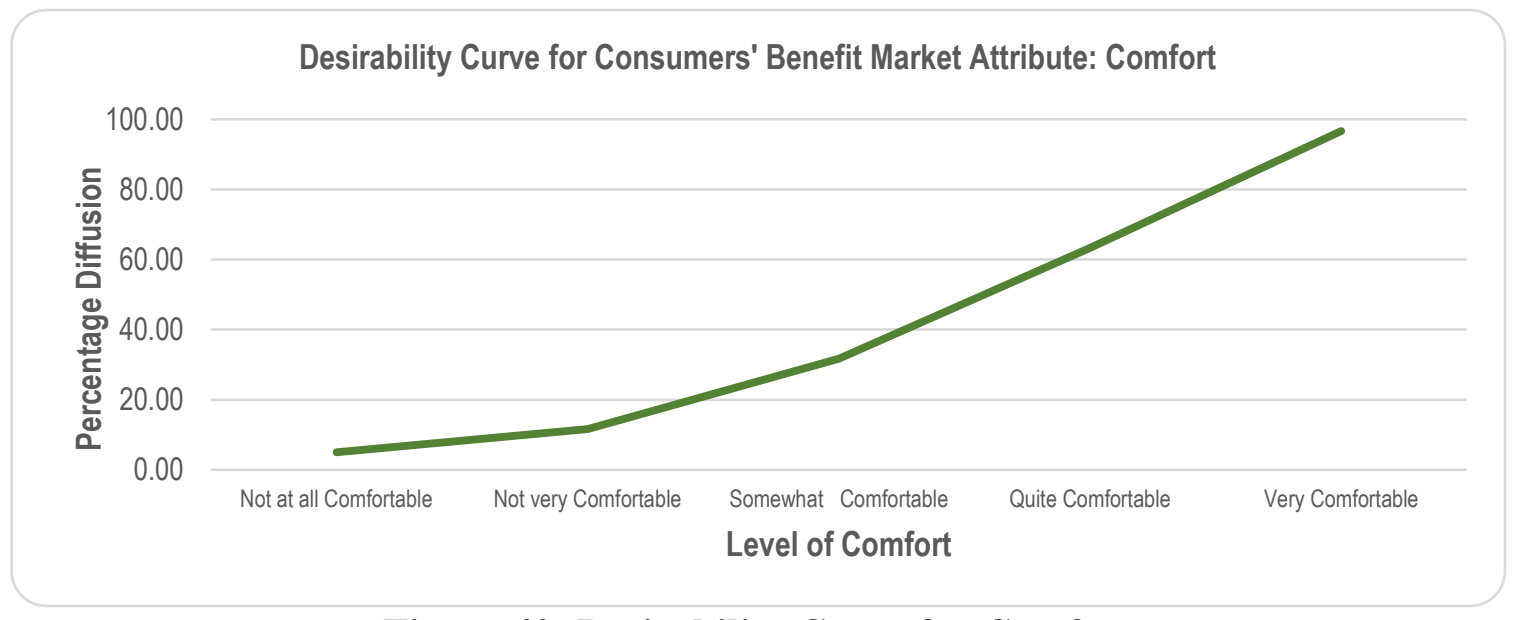

Figure 42: Desirability Curve for Comfort 


\subsubsection{Desirability Curve for Safety}

Safety hazard is an important aspect while choosing household appliances. HUD's Healthy Homes Rating System (HHRS) uses scoring values developed in England. The HHRS is categorized in accordance with the American Academy of Public Health's 1938 publication entitled, "Healthful Principles of a Home." Table 31 provides A tentative guideline on metrics for measuring level of safety using the different categories of health hazards and the levels of safety derived from appliances [348][349]. Figure 43 shows how the level of safety affects the diffusion of residential EE technologies.

\section{Table 31: A Tentative Guideline on Metrics for Measuring Level of Safety}

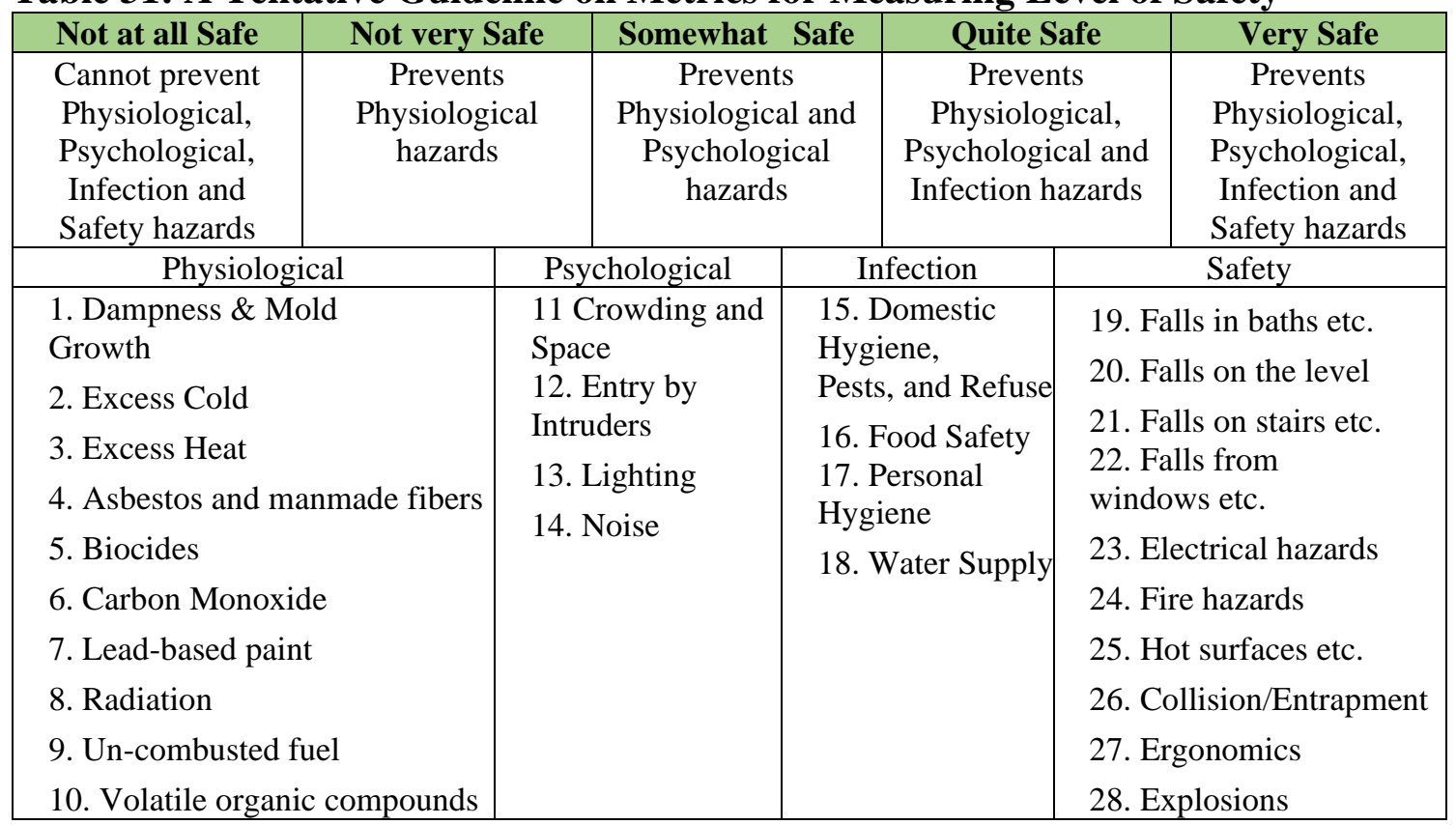




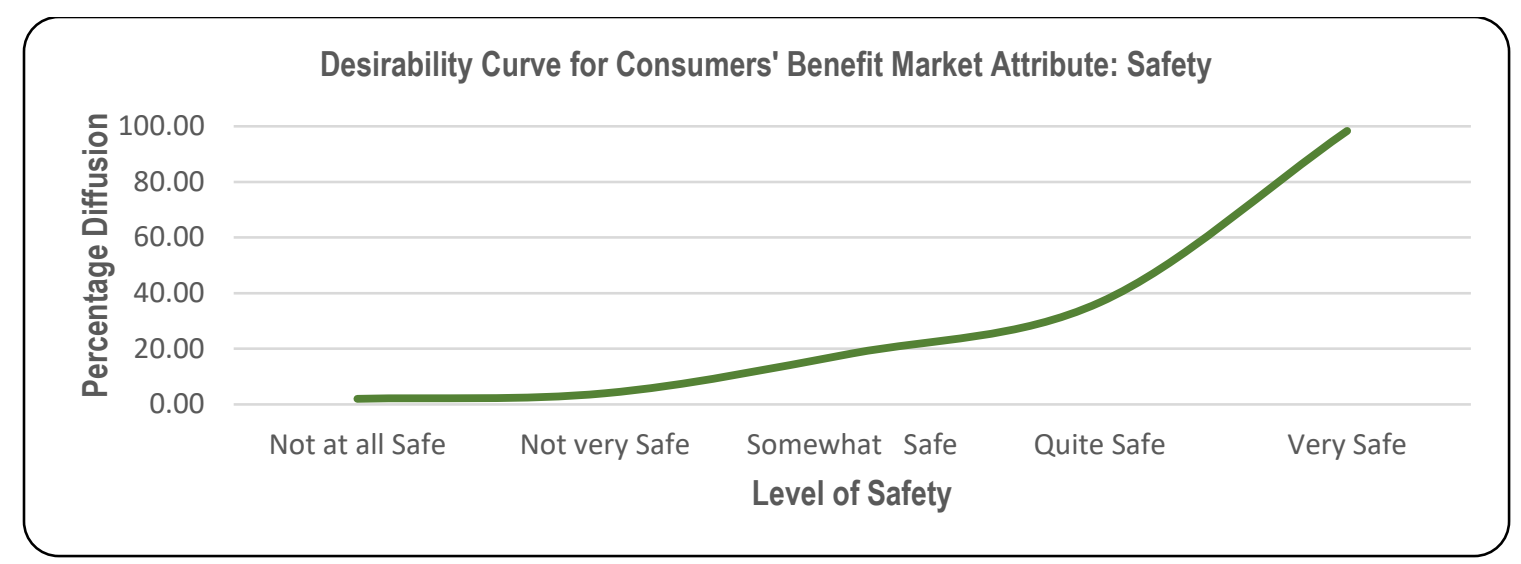

Figure 43: Desirability Curve for Safety

\subsubsection{Desirability Curve for Non-energy Benefits (NEBs)}

There are three categories of NEBs, utility, participant and societal NEBs. Benefits derived by utilities due to diffusion of EE technologies are known as utility NEBs. Participant NEBs are enjoyed by utility customers. Safety and comfort are part of participant NEBs. However, the NEBs in this section consider societal benefit from EE technologies. A tentative guideline on metrics for measuring level of NEBs is described in Table 32. Figure 44 shows how the level of NEBs affect the diffusion of residential EE technologies.

\section{Table 32: A Tentative Guideline on Metrics for Measuring Level of NEBs}

\begin{tabular}{|c|c|c|c|c|}
\hline No Benefits & $\begin{array}{c}\text { Barely } \\
\text { Detectable } \\
\text { Benefits } \\
\end{array}$ & $\begin{array}{c}\text { Moderately } \\
\text { Detectable } \\
\text { Benefits } \\
\end{array}$ & $\begin{array}{c}\text { Strongly } \\
\text { Detectable } \\
\text { Benefits } \\
\end{array}$ & $\begin{array}{c}\text { Very Strongly } \\
\text { Detectable } \\
\text { Benefits } \\
\end{array}$ \\
\hline $\begin{array}{l}\text { No benefits in } \\
\text { Greater image, } \\
\text { increased Property } \\
\text { Values, cost } \\
\text { savings in } \\
\text { Operations and } \\
\text { maintenance or } \\
\text { benefits to low } \\
\text { income customers. }\end{array}$ & Greater Image & $\begin{array}{c}\text { Greater Image + } \\
\text { Increased Property } \\
\text { Value }\end{array}$ & $\begin{array}{c}\text { Greater Image }+ \\
\text { Increased Property } \\
\text { Value + Savings } \\
\text { in Operations and } \\
\text { maintenance }\end{array}$ & $\begin{array}{c}\text { Greater Image }+ \\
\text { Increased Property } \\
\text { Value + Savings } \\
\text { in Operations and } \\
\text { maintenance }+ \\
\text { Benefits for low } \\
\text { income people }\end{array}$ \\
\hline
\end{tabular}




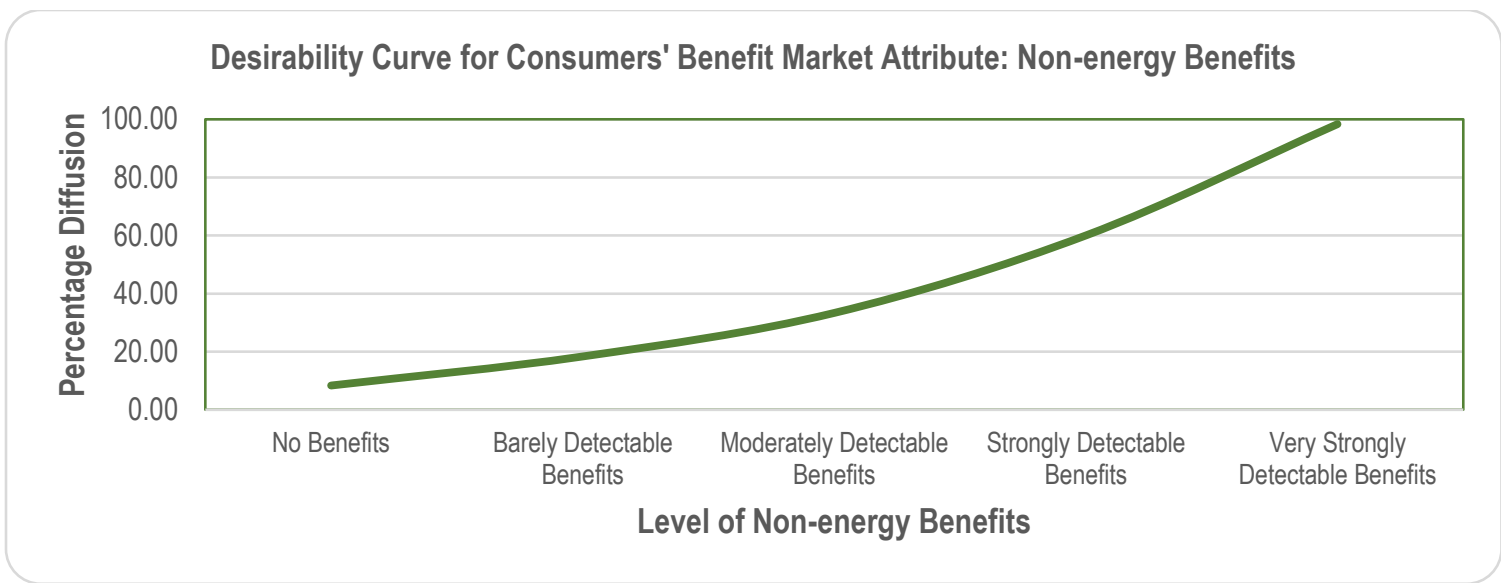

Figure 44: Desirability Curve for Non-energy Benefits

\subsubsection{Desirability Curve for Awareness}

The market players need to be aware about EE technologies. Identifying the level of awareness among different members of the supply chain helps to recognize barriers and take necessary actions. Table 33 highlights a tentative guideline on metrics for measuring level of awareness [336]. Figure 45 shows how the level of awareness affects diffusion of residential EE technologies.

\section{Table 33: A Tentative Guideline on Metrics for Measuring Level of Awareness}

\begin{tabular}{|c|c|c|c|c|}
\hline No Awareness & $\begin{array}{c}\text { Very Low } \\
\text { Awareness }\end{array}$ & Low Awareness & High Awareness & $\begin{array}{l}\text { Very High } \\
\text { Awareness }\end{array}$ \\
\hline $\begin{array}{l}\text { Only Material and } \\
\text { Equipment } \\
\text { Supplier are aware } \\
\text { about EE } \\
\text { Technology }\end{array}$ & $\begin{array}{c}\text { Material and } \\
\text { Equipment } \\
\text { Supplier + Capital } \\
\text { Providers are } \\
\text { aware about EE } \\
\text { Technology }\end{array}$ & $\begin{array}{c}\text { Material and } \\
\text { Equipment } \\
\text { Supplier + Capital } \\
\text { Providers + Local } \\
\text { Authorities are } \\
\text { aware about EE } \\
\text { Technology }\end{array}$ & $\begin{array}{c}\text { Material and } \\
\text { Equipment } \\
\text { Supplier + Capital } \\
\text { Providers + Local } \\
\text { Authorities + } \\
\text { Developers } \\
\text { (Contractors+ } \\
\text { Engineers+ } \\
\text { Designers) }\end{array}$ & $\begin{array}{c}\text { Material and } \\
\text { Equipment } \\
\text { Supplier + Capital } \\
\text { Providers + Local } \\
\text { Authorities + } \\
\text { Developers } \\
\text { (Contractors + } \\
\text { Engineers+ } \\
\text { Designers) are } \\
\text { aware + Owner } \\
\text { and Users are } \\
\text { aware about EE } \\
\text { Technology } \\
\end{array}$ \\
\hline
\end{tabular}




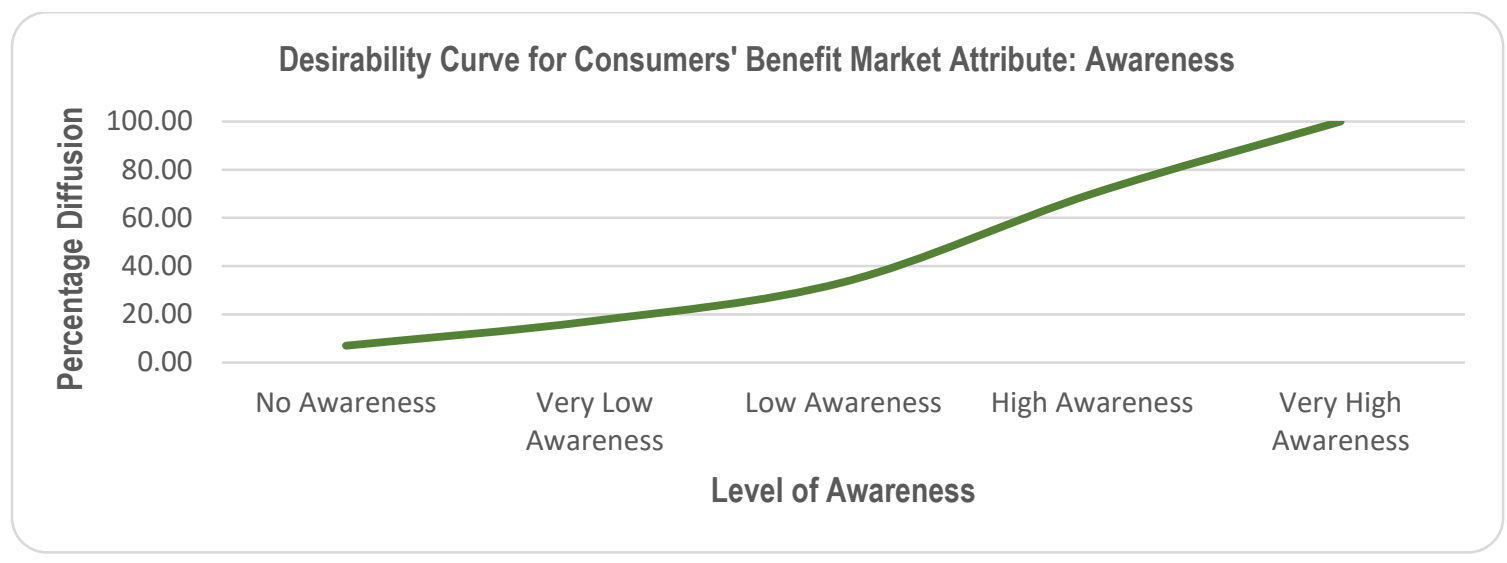

Figure 45: Desirability Curve for Awareness

\subsubsection{Desirability Curves for Key Components of Technological Market Attribute}

Technological market attribute considers hardware and software of the technology and is delivered through the EE technology's Energy Saving Potential, Ease of Installation, Ease of Use and Compatibility.

\subsubsection{Desirability Curve for Energy Saving Potential (ESP)}

Residential EE technologies have different levels of energy saving potential. According to Navigant study, by the year 2033 lighting and water heating have the prospect of saving $58 \%$ electric energy while heating and appliance measures can save $8 \%$ and $9 \%$ energy, cost-effectively. Table 34 lists the technical energy saving potential by different appliances as a tentative guideline on metrics for measuring levels of energy saving potential in quad/yr. (Appendix G) [350] while Figure 46 shows how the energy saving potential affects the diffusion of residential EE technologies. 
Table 34: A Tentative Guideline on Metrics for Measuring Level of Energy Saving Potential

\begin{tabular}{|c|c|c|c|c|}
\hline $\begin{array}{c}\text { Very Low } \\
\text { Energy Saving } \\
\text { Potential }\end{array}$ & $\begin{array}{c}\text { Low Energy } \\
\text { Saving Potential }\end{array}$ & $\begin{array}{c}\text { Moderate } \\
\text { Energy Saving } \\
\text { Potential }\end{array}$ & $\begin{array}{c}\text { High Energy } \\
\text { Saving Potential }\end{array}$ & $\begin{array}{c}\text { Very High } \\
\text { Energy Saving } \\
\text { Potential }\end{array}$ \\
\hline $\mathbf{0 . 1}<$ ESP $\leq \mathbf{0 . 2}$ & $\mathbf{0 . 2}<$ ESP $\leq \mathbf{0 . 3}$ & $\mathbf{0 . 3}<$ ESP $\leq \mathbf{0 . 4}$ & $\mathbf{0 . 4}<$ ESP $\leq \mathbf{0 . 5}$ & ESP $>\mathbf{0 . 5}$ \\
\hline
\end{tabular}

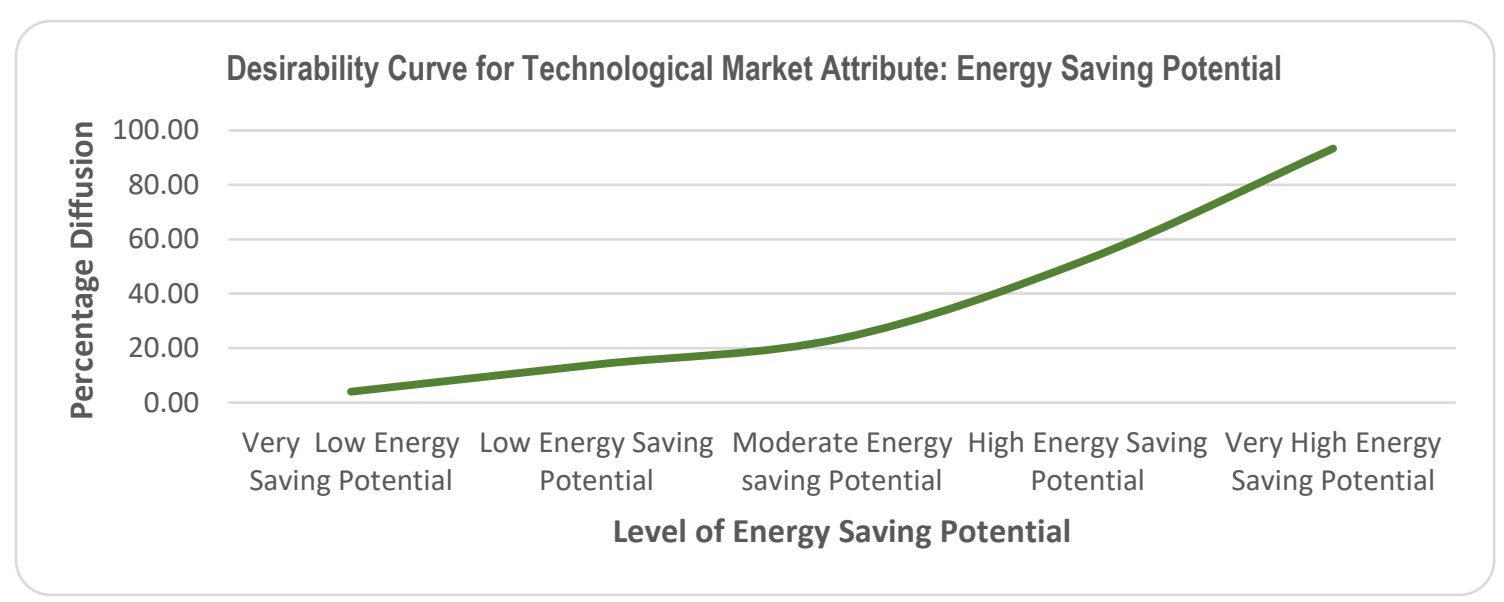

Figure 46: Desirability Curve for Energy Saving Potential

\subsubsection{Desirability Curve for Ease of Installation}

Ease of installation is a compelling factor for the adoption of EE technologies by users. The ease of installation is based on the complexity of work while adapting to different standards, size or shape and time needed [351]. Table 35 provides a tentative guideline on metrics for measuring levels of ease in installation work while Figure 47 shows how the ease of installation affects the diffusion of residential EE technologies. 
Table 35: A Tentative Guideline on Metrics for Measuring Level of Ease of Installation

\begin{tabular}{|c|c|c|c|c|}
\hline $\begin{array}{c}\text { Major work by } \\
\text { Installers }\end{array}$ & $\begin{array}{c}\text { Moderate work } \\
\text { by installers }\end{array}$ & $\begin{array}{l}\text { Minor work by } \\
\text { installers }\end{array}$ & $\begin{array}{l}\text { Minimum work } \\
\text { by installers }\end{array}$ & $\begin{array}{c}\text { Installed by } \\
\text { DIYers }\end{array}$ \\
\hline $\begin{array}{l}\text { Moderate to } \\
\text { extensive } \\
\text { assembly; } \\
\text { Extensive } \\
\text { Installation that } \\
\text { requires technical } \\
\text { expertise. }\end{array}$ & $\begin{array}{l}\text { Minor to } \\
\text { moderate } \\
\text { assembly. } \\
\text { Installation } \\
\text { requires technical } \\
\text { expertise. }\end{array}$ & $\begin{array}{c}\text { Moderate } \\
\text { Difficulty - } \\
\text { Moderate } \\
\text { assembly and } \\
\text { installation. } \\
\text { Extensive } \\
\text { instructions, and } \\
\text { extensive } \\
\text { installation to } \\
\text { existing shelving } \\
\text { or other existing } \\
\text { equipment. }\end{array}$ & $\begin{array}{l}\text { Minor assembly } \\
\text { and minor } \\
\text { installation; } \\
\text { Installations } \\
\text { typically bolt into } \\
\text { existing shelving } \\
\text { or equipment. }\end{array}$ & $\begin{array}{l}\text { Easy to minor } \\
\text { assembly; no } \\
\text { installation } \\
\text { required. }\end{array}$ \\
\hline
\end{tabular}

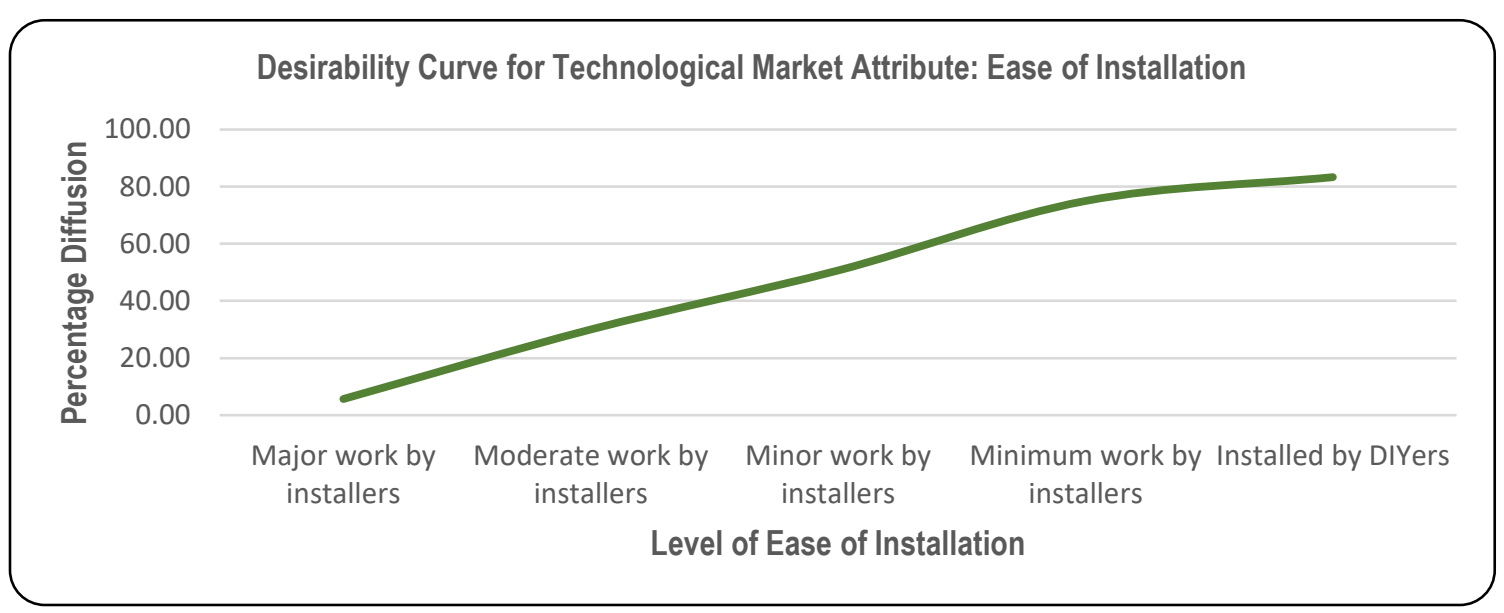

Figure 47: Desirability Curve for Ease of Installation

\subsubsection{Desirability Curve for Ease of Use}

How merely a device can be operated and how easy is to learn determines ease of use [321][322]. A tentative guideline on metrics for measuring level of ease of use based on increasing distance from the device and less use of motor skills is described in Table 36 [352]. Figure 48 shows how the level of ease of use affects the diffusion of residential EE technologies. 
Table 36: A Tentative Guideline on Metrics for Measuring Level of Ease of Use

\begin{tabular}{|c|c|c|c|c|}
\hline $\begin{array}{c}\text { Not at all Easy to } \\
\text { Use }\end{array}$ & $\begin{array}{c}\text { Somewhat Easy } \\
\text { to Use }\end{array}$ & $\begin{array}{c}\text { Quite Easy to } \\
\text { Use }\end{array}$ & Very Easy to Use & $\begin{array}{l}\text { Extremely Easy } \\
\text { to Use }\end{array}$ \\
\hline $\begin{array}{c}\text { Button switch } \\
\text { option }\end{array}$ & Remote control & $\begin{array}{l}\text { Automation via } \\
\text { Bluetooth } 4.0 \\
\text { enabled iPhone, } \\
\text { iPad, iPad mini or } \\
\text { iPod }\end{array}$ & $\begin{array}{l}\text { Devices controlled } \\
\text { by smartphone }\end{array}$ & $\begin{array}{ll}\text { Voice } & \text { activated } \\
\text { device } & \end{array}$ \\
\hline $\begin{array}{l}\text { Devices are } \\
\text { operated manually } \\
\text { by pressing or } \\
\text { pushing buttons. } \\
\text { All the available } \\
\text { options need to be } \\
\text { controlled by } \\
\text { moving close to } \\
\text { the keys near or in } \\
\text { the device } \\
\text { (Fernandes and } \\
\text { Padma 2014). }\end{array}$ & $\begin{array}{l}\text { Remotes are used } \\
\text { that operates } \\
\text { devices from a } \\
\text { distance of up to } \\
30 \text { feet and uses } \\
\text { Infrared with } \\
\text { LEDs (Nejakar } \\
\text { 2014). }\end{array}$ & $\begin{array}{l}\text { Bluetooth can } \\
\text { communicate with } \\
\text { devices from a } \\
\text { distance of } \\
\text { roughly } 10 \text { meters. } \\
\text { A Smartphone, } \\
\text { tablet or a } \\
\text { personal computer } \\
\text { can be } \\
\text { manipulated to } \\
\text { control EE } \\
\text { appliances in } \\
\text { residential } \\
\text { buildings without } \\
\text { the Internet } \\
\text { controllability } \\
\text { (José } \\
\text { 2015)(Rajeev } \\
\text { Piyare 2013). }\end{array}$ & $\begin{array}{l}\text { The smartphone is } \\
\text { used as a remote } \\
\text { control and } \\
\text { devices can be } \\
\text { turned off or on } \\
\text { from outdoor. } \\
\text { Devices can be } \\
\text { controlled when } \\
\text { the consumer is } \\
\text { outside home. } \\
\text { While in the office } \\
\text { or on the way by } \\
\text { car using mobile } \\
\text { cellular networks } \\
\text { such as } 3 \mathrm{G} \text { or } 4 \mathrm{G} \text {, } \\
\text { the device can be } \\
\text { controlled } \\
\text { (Nichols and } \\
\text { Myers } \\
\text { 2006)(Rajeev } \\
\text { Piyare 2013). }\end{array}$ & $\begin{array}{l}\text { The GSM network } \\
\text { can be used to } \\
\text { control devices } \\
\text { from far away. } \\
\text { Voice command is } \\
\text { given through a } \\
\text { mobile } \\
\text { application. The } \\
\text { command is } \\
\text { translated into text } \\
\text { and moves it to the } \\
\text { GSM network. } \\
\text { This option } \\
\text { requires minimum } \\
\text { motor skill, cheap, } \\
\text { suitable for seniors } \\
\text { and no wired } \\
\text { communications } \\
\text { required (Baig, } \\
\text { Beg, and Fahad } \\
\text { Khan 2012). }\end{array}$ \\
\hline
\end{tabular}




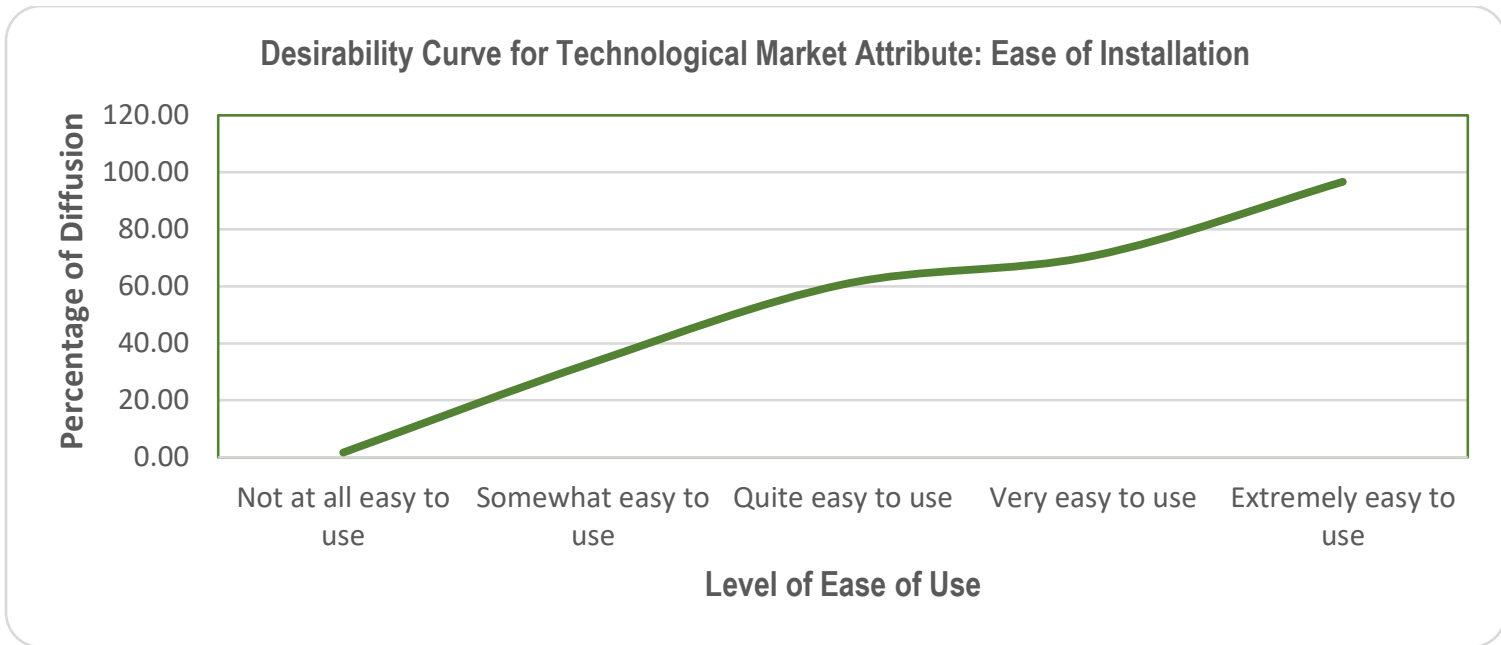

Figure 48: Desirability Curve for Ease of Use

\subsubsection{Desirability Curve for Compatibility}

Climate affects the performance of EE technologies [353]. ASHRAE (American Society of Heating, Refrigerating and Air-Conditioning Engineers) has divided the states into different climate zones based on temperature and moisture. A tentative guideline on metrics for measuring compatibility is highlighted in Table 37 [354] while Figure 49 shows how compatibility affects the diffusion of residential EE technologies.

Table 37: A Tentative Guideline on Metrics for Measuring Level of Compatibility

\begin{tabular}{|c|c|c|c|c|c|c|c|}
\hline \multicolumn{2}{|c|}{$\begin{array}{l}\text { Compatibility in one } \\
\text { climate zone }\end{array}$} & \multicolumn{2}{|c|}{$\begin{array}{l}\text { Compatibility in few } \\
\text { climate zones }\end{array}$} & \multicolumn{2}{|c|}{$\begin{array}{c}\text { Compatibility in some } \\
\text { climate zones }\end{array}$} & \multicolumn{2}{|c|}{$\begin{array}{l}\text { Compatibility in all } \\
\text { climate zones }\end{array}$} \\
\hline & & & & \multirow{2}{*}{\multicolumn{2}{|c|}{$\frac{\text { Zone } 1,2,3}{\text { Climate Zone } 3}$}} & Zone & $2,3,4$ \\
\hline \multicolumn{2}{|c|}{ Climate Zone 1} & \multicolumn{2}{|c|}{ Climate Zone 2} & & & \multicolumn{2}{|c|}{ Climate Zone 4} \\
\hline Very Hot & Hot & Warm & Mixed & Cool & Cold & Very Cold & Subarctic \\
\hline
\end{tabular}




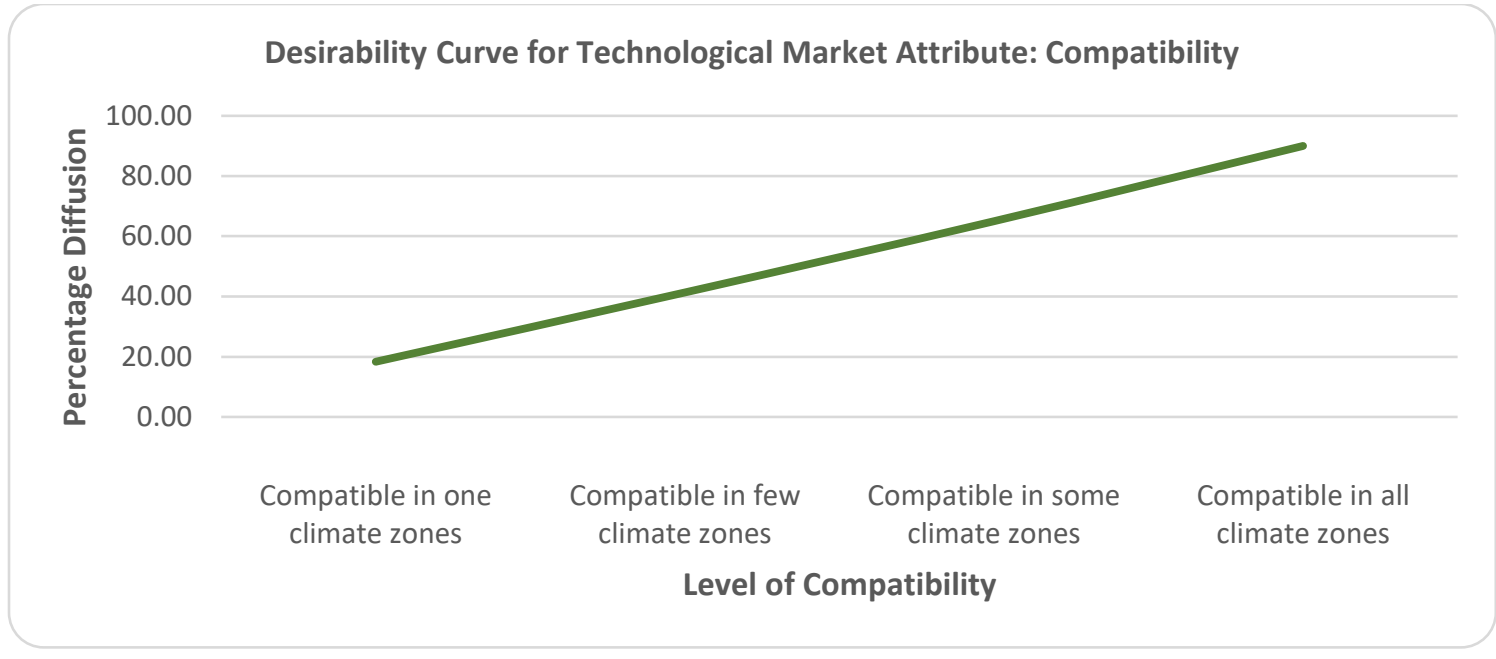

Figure 49: Desirability Curve for Compatibility

6.4.3 Desirability Curves for Key Components of Economic Market Attribute

Economic market attribute is determined by Profitability Index (PI), Levelized Cost of Electricity (LCOE), Payback Period and Substitutes.

\subsubsection{Desirability Curve for Profitability Index (PI)}

Profitability Index (PI) helps to decide investment on attractive residential EE programs. Based on data from literature on energy efficiency projects with Profitability Indices, Table 38 provides a tentative guideline on metrics for measuring level of PI for residential EE projects based on a study (Appendix H) and Figure 50 shows how the values of PI affect the diffusion of residential EE technologies [355].

\section{Table 38: A Tentative Guideline on Metrics for Measuring Level of Profitability Index (PI)}

\begin{tabular}{|c|c|c|c|}
\hline $\begin{array}{c}\text { Very Low or negative } \\
\text { Profitability Index }\end{array}$ & $\begin{array}{c}\text { Low Profitability } \\
\text { Index }\end{array}$ & $\begin{array}{c}\text { High Profitability } \\
\text { Index }\end{array}$ & $\begin{array}{c}\text { Very High } \\
\text { Profitability Index }\end{array}$ \\
\hline $\mathrm{PI}<0$ & $0 \leq \mathrm{PI}<1$ & $1 \leq \mathrm{PI}<2$ & $\mathrm{PI} \geq 2$ \\
\hline
\end{tabular}




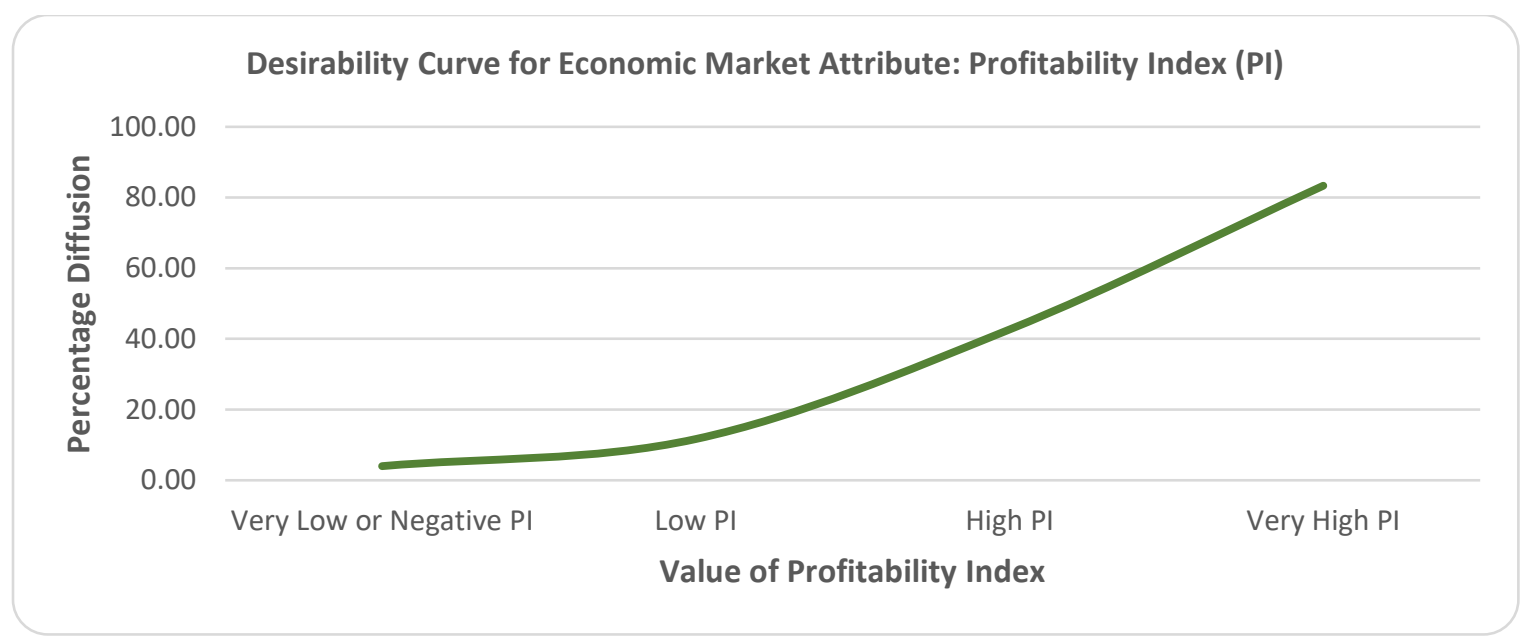

Figure 50: Desirability Curve for Profitability Index (PI)

\subsubsection{Desirability Curve for Levelized Cost of Electricity (LCOE)}

Lazard has confirmed that $\mathrm{EE}$ is the lowest cost investment based on levelized costs of electricity (Appendix I)[356]. Table 39 describes a tentative guideline on metrics for measuring LCOE and Figure 51 shows how LCOE affects the diffusion of residential EE technologies.

Table 39: A Tentative Guideline on Metrics for Measuring Level of LCOE

\begin{tabular}{|c|c|c|c|}
\hline Very Low LCOE & Low LCOE & High LCOE & Very High LCOE \\
\hline $0 \notin / \mathrm{kwhr} \leq \mathrm{LCOE}<$ & $1 \notin / \mathrm{kwhr} \leq \mathrm{LCOE}<$ & $2 \phi / \mathrm{kwhr} \leq \mathrm{LCOE}<$ & $3 \phi / \mathrm{kwhr} \leq \mathrm{LCOE}<$ \\
$1 \notin / \mathrm{kwhh}$ & $2 \notin / \mathrm{kwhr}$ & $3 \notin / \mathrm{kwhr}$ & $4 \phi / \mathrm{kwhr}$ \\
\hline
\end{tabular}




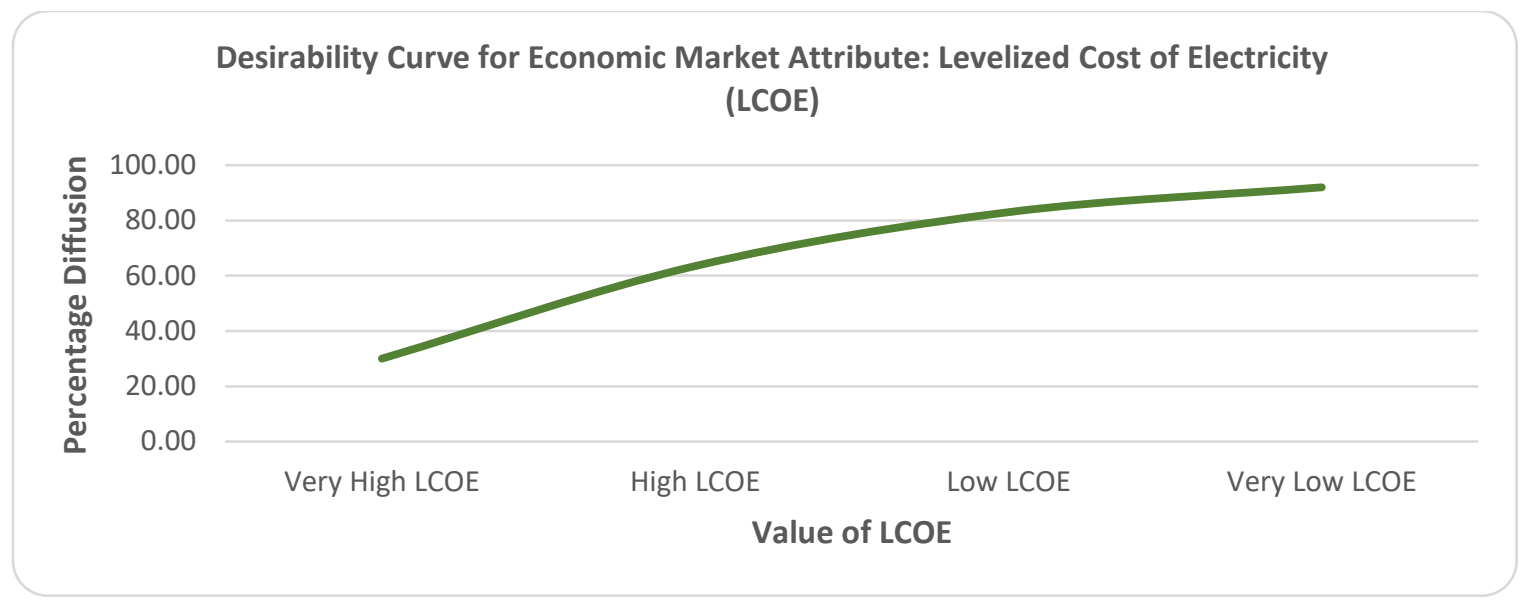

\section{Figure 51: Desirability Curve for Levelized Cost of Electricity (LCOE)}

\subsubsection{Desirability Curve for Payback Period}

Payback period of energy efficient technologies ranges from 0.9 years to 55 years (Appendix J) [357]. A tentative guideline on metrics for measuring payback period is listed in Table 40 and Figure 52 shows how payback period affects the diffusion of residential EE technologies.

Table 40: A Tentative Guideline on Metrics for Measuring Level of Payback Period

\begin{tabular}{|c|c|c|c|}
\hline $\begin{array}{c}\text { Very High Payback } \\
\text { Period }\end{array}$ & High Payback Period & Low Payback Period & $\begin{array}{c}\text { Very Low Payback } \\
\text { Period }\end{array}$ \\
\hline Payback Period $>12$ & $8 \leq \mathrm{PI} \leq 12$ & $4 \leq \mathrm{PI}<8$ & $1 \leq$ Payback Period $<4$ \\
\hline
\end{tabular}




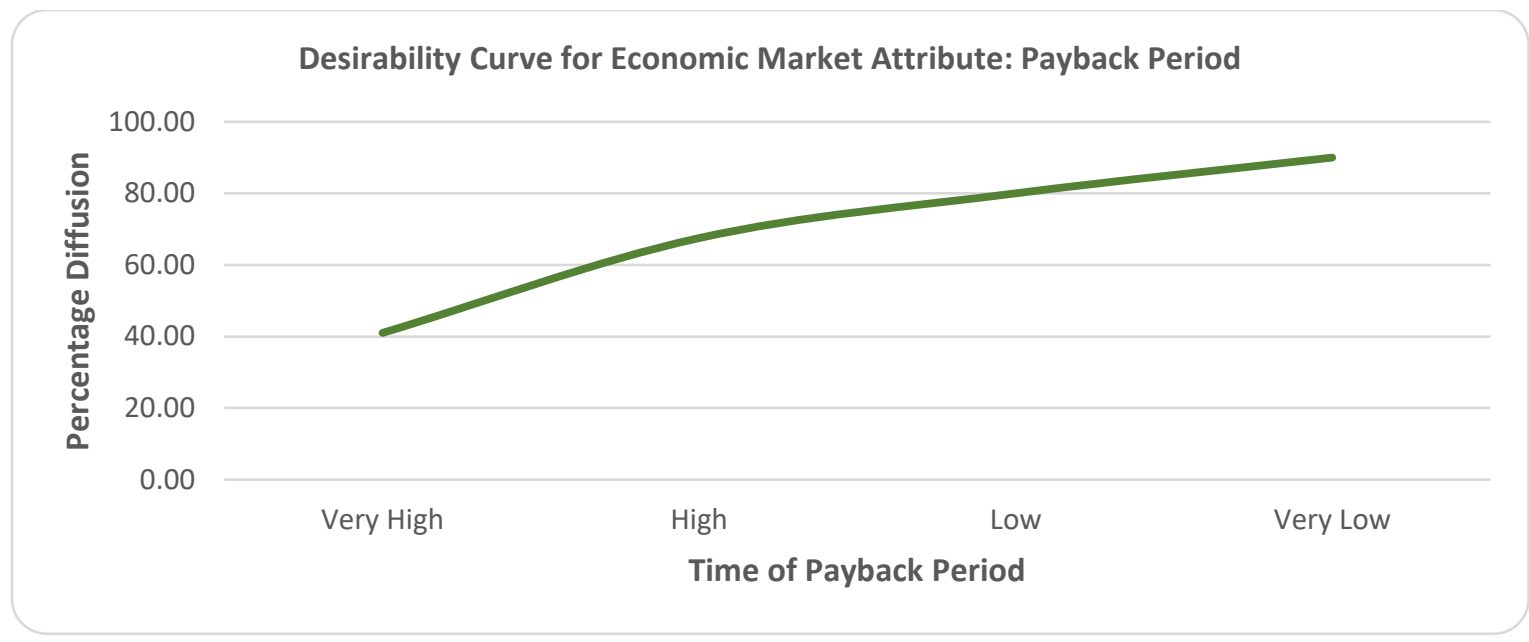

Figure 52: Desirability Curve for Payback Period

\subsubsection{Desirability Curve for Substitutes}

Substitute is recognized as a powerful barrier in Porter's five forces for adoption of technologies [358][359]. Table 41 highlights a tentative guideline on metrics for measuring the impact of substitutes and Figure 53 shows how impact of substitutes affects the diffusion of residential EE technologies.

\section{Table 41: A Tentative Guideline on Metrics for Measuring Level of Impact of Substitutes}

\begin{tabular}{|l|l|l|l|}
\hline \multicolumn{1}{|c|}{$\begin{array}{c}\text { Very Low Impact of } \\
\text { Substitute }\end{array}$} & \multicolumn{1}{c|}{$\begin{array}{c}\text { Low Impact of } \\
\text { Substitute }\end{array}$} & \multicolumn{1}{c|}{$\begin{array}{c}\text { High Impact of } \\
\text { Substitute }\end{array}$} & $\begin{array}{c}\text { Very High Impact of } \\
\text { Substitute }\end{array}$ \\
\hline High Cost and Low & High Cost and High & Low Cost and Low & Low Cost and High \\
Quality of Substitute & Quality of Substitute & Quality of Substitute & Quality of Substitute \\
immensely facilitates EE & somewhat facilitates EE & somewhat hinders & immensely hinders \\
technology diffusion & technology diffusion & diffusion of EE & diffusion of EE \\
& & technologies & technologies \\
\hline
\end{tabular}




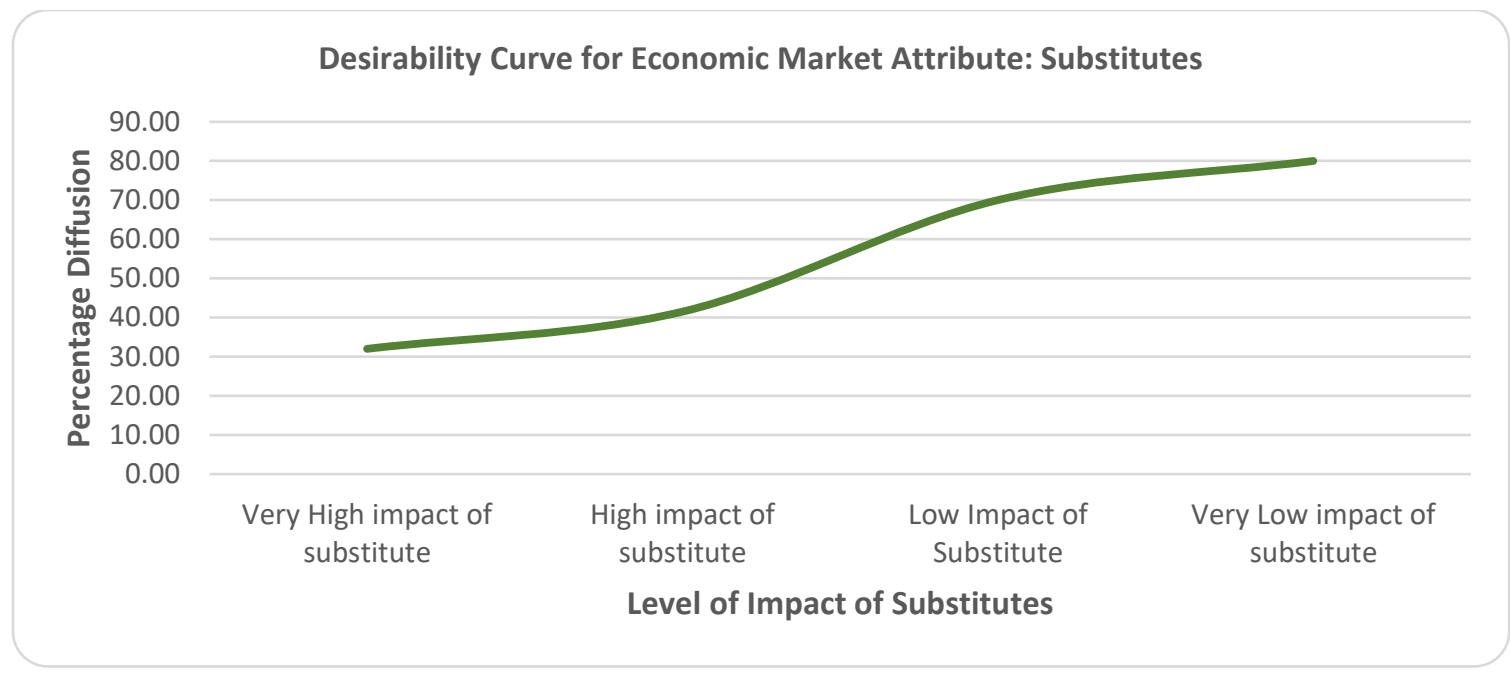

Figure 53: Desirability Curve for Substitutes

6.4.4 Desirability Curves for Key Components of Delivery and Infrastructure Market Attribute

Components of the Delivery and Infrastructure market attribute are Competition, Trade Allies, Accessibility and Supply Chain.

\subsubsection{Desirability Curve for Competition}

Competition in the market ensures supply and product variety and keeps cost in check. Based on the number of sellers and respective power on regulating price there could be several structures [360][361]. Table 42 categorizes the level of competition as a tentative guideline on metrics for measuring level of competition while Figure 54 shows how the level of competition affects the diffusion of residential EE. 
Table 42: A Tentative Guideline on Metrics for Measuring Level of Competition

\begin{tabular}{|c|c|c|c|c|}
\hline No Competition & $\begin{array}{c}\text { Low } \\
\text { Competition }\end{array}$ & $\begin{array}{c}\text { Moderate } \\
\text { Competition }\end{array}$ & $\begin{array}{c}\text { High } \\
\text { Competition }\end{array}$ & $\begin{array}{c}\text { Very High } \\
\text { Competition }\end{array}$ \\
\hline $\begin{array}{c}\text { Pure Monopoly } \\
\text { (one seller) }\end{array}$ & $\begin{array}{c}\text { Duopoly (two } \\
\text { sellers) }\end{array}$ & $\begin{array}{c}\text { Oligopoly (few } \\
\text { sellers) }\end{array}$ & $\begin{array}{c}\text { Monopolistic } \\
\text { competition } \\
\text { (many sellers) }\end{array}$ & $\begin{array}{c}\text { Perfect } \\
\text { Competition } \\
\text { (Numerous } \\
\text { sellers) }\end{array}$ \\
\hline
\end{tabular}

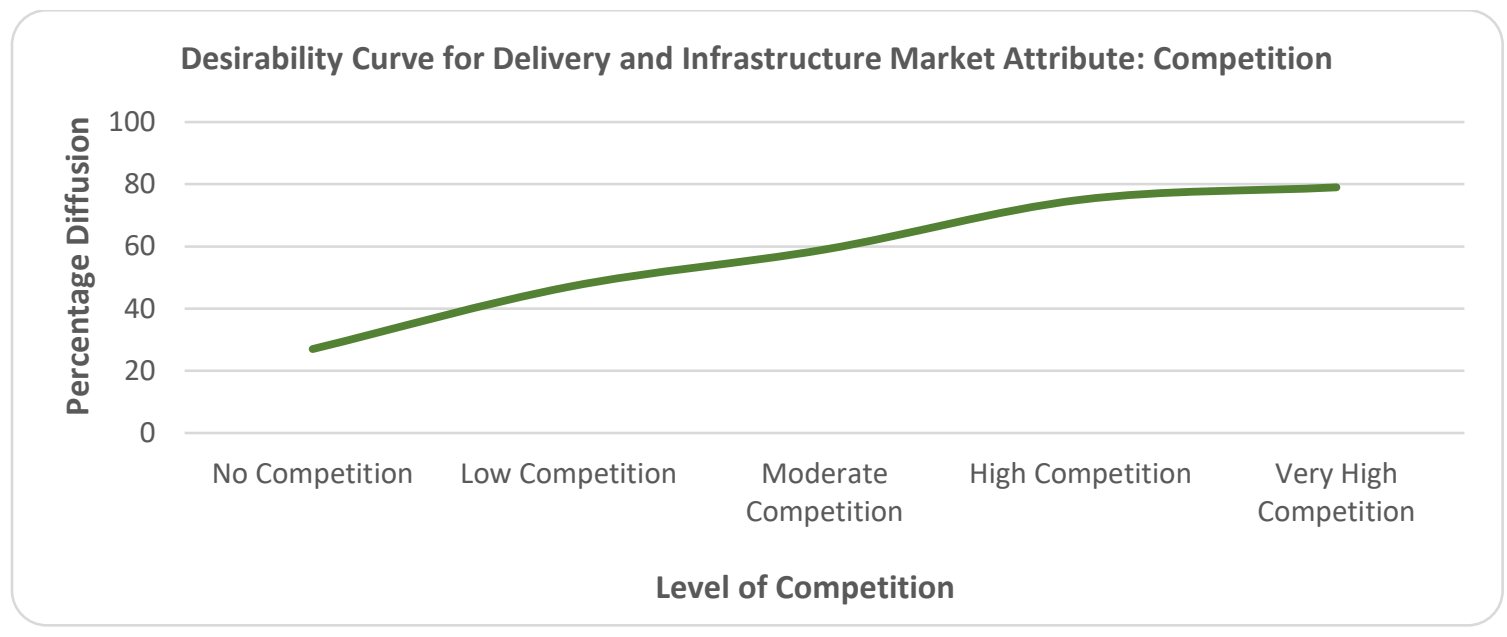

\section{Figure 54: Desirability Curve for Competition}

\subsubsection{Desirability Curve for Trade Allies}

Being at the frontline in delivering EE technologies to customers, the diffusion of EE technologies depends to a large extent on the effectiveness of trade allies. Table 43 describes the various factors that are important in deriving trade ally support for increasing the diffusion of EE technologies as a tentative guideline on metrics for measuring impact of trade allies [333] while Figure 55 shows how the impact of trade allies affects diffusion of residential EE technologies. 
Table 43: A Tentative Guideline on Metrics for Measuring Level of Impact of Trade Allies

\begin{tabular}{|c|c|c|c|c|}
\hline $\begin{array}{c}\text { Very Low Impact } \\
\text { of Trade Allies }\end{array}$ & $\begin{array}{l}\text { Low Impact of } \\
\text { Trade Allies }\end{array}$ & $\begin{array}{c}\text { Moderate Impact } \\
\text { of Trade Allies }\end{array}$ & $\begin{array}{l}\text { High Impact of } \\
\text { Trade Allies }\end{array}$ & $\begin{array}{c}\text { Very High } \\
\text { Impact of Trade } \\
\text { Allies }\end{array}$ \\
\hline $\begin{array}{c}\text { Unengaged + } \\
\text { Unaware + } \\
\text { Unequipped + } \\
\text { Without } \\
\text { Incentives }\end{array}$ & $\begin{array}{c}\text { Engaged + } \\
\text { Unaware + } \\
\text { Unequipped + } \\
\text { Without } \\
\text { Incentives }\end{array}$ & $\begin{array}{c}\text { Engaged + } \\
\text { Aware + } \\
\text { Unequipped + } \\
\text { Without } \\
\text { Incentives }\end{array}$ & $\begin{array}{c}\text { Engaged + } \\
\text { Aware + } \\
\text { Equipped + } \\
\text { Without } \\
\text { Incentives }\end{array}$ & $\begin{array}{l}\text { Engaged + } \\
\text { Aware + } \\
\text { Equipped + Get } \\
\text { Incentives }\end{array}$ \\
\hline Unengaged & Engaged & Aware & Equipped & Incentives \\
\hline $\begin{array}{l}\text { Trade Allies who } \\
\text { have not signed up } \\
\text { for a particular } \\
\text { Utility Program }\end{array}$ & $\begin{array}{l}\text { Trade Allies who } \\
\text { sign up for a } \\
\text { particular Utility } \\
\text { Program }\end{array}$ & $\begin{array}{l}\text { Thrade Ally } \\
\text { knows about the } \\
\text { objective oof the } \\
\text { utility program }\end{array}$ & $\begin{array}{l}\text { Providing program } \\
\text { support, sales } \\
\text { coaching, and } \\
\text { technical coaching } \\
\text { through regular } \\
\text { contact with an } \\
\text { outreach } \\
\text { professional can } \\
\text { give trade allies } \\
\text { the tools to be } \\
\text { effective for } \\
\text { ambassadors for } \\
\text { DSM programs. in } \\
\text { terms of business } \\
\text { skills, sales skills, } \\
\text { and technical } \\
\text { content. }\end{array}$ & $\begin{array}{lr}\text { Recognized } & \text { and } \\
\text { Rewarding } & \text { for } \\
\text { actions by } & \text { Trade } \\
\text { Allies } & \end{array}$ \\
\hline
\end{tabular}




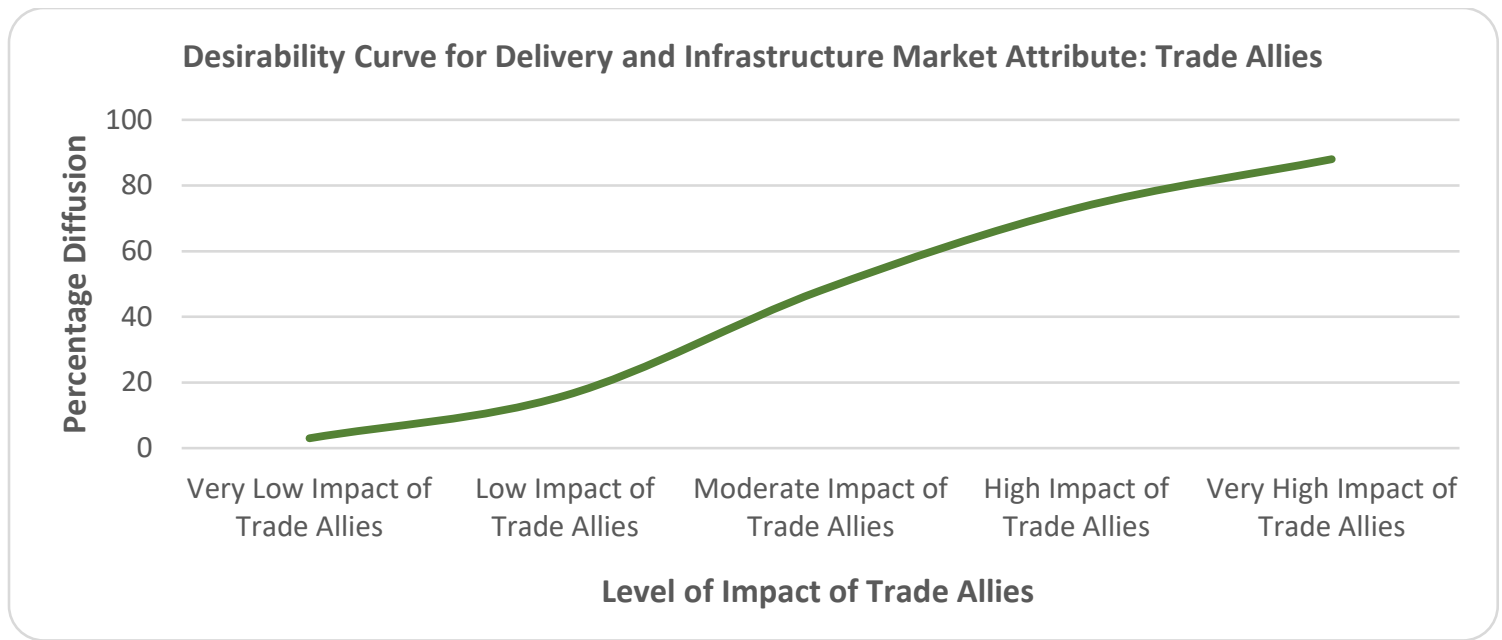

Figure 55: Desirability Curve for Trade Allies

\subsubsection{Desirability Curve for Accessibility}

Distribution channel is a strategic decision as easy availability of an EE technology product affects its diffusion. Table 44 lists the intermediaries with increasing accessibility as a tentative guideline on metrics for measuring level of accessibility and Figure 56 shows the how increased accessibility affect the diffusion of residential EE technologies [362].

Table 44: A Tentative Guideline on Metrics for Measuring Level of Accessibility

\begin{tabular}{|c|c|c|c|c|}
\hline $\begin{array}{c}\text { Very Low } \\
\text { Accessibility }\end{array}$ & Low Accessibility & $\begin{array}{c}\text { Moderate } \\
\text { Accessibility }\end{array}$ & $\begin{array}{c}\text { High } \\
\text { Accessibility }\end{array}$ & $\begin{array}{c}\text { Very High } \\
\text { Accessibility }\end{array}$ \\
\hline $\begin{array}{c}\text { Highly selective, } \\
\text { or direct sale to } \\
\text { customers (only } \\
\text { one wholesaler, } \\
\text { retailer or } \\
\text { distributor) }\end{array}$ & $\begin{array}{c}\text { Considerable } \\
\text { selectivity (more } \\
\text { than only one } \\
\text { wholesaler, } \\
\text { retailer or } \\
\text { distributor) }\end{array}$ & $\begin{array}{c}\text { Some selectivity } \\
\text { (products sold few } \\
\text { number of outlets) }\end{array}$ & $\begin{array}{c}\text { Moderately } \\
\text { intensive } \\
\text { (products are sold } \\
\text { in different } \\
\text { outlets, within } \\
\text { certain categories) }\end{array}$ & $\begin{array}{c}\text { Intensive } \\
\text { (consumers } \\
\text { encounter the } \\
\text { product } \\
\text { everywhere) }\end{array}$ \\
\hline
\end{tabular}




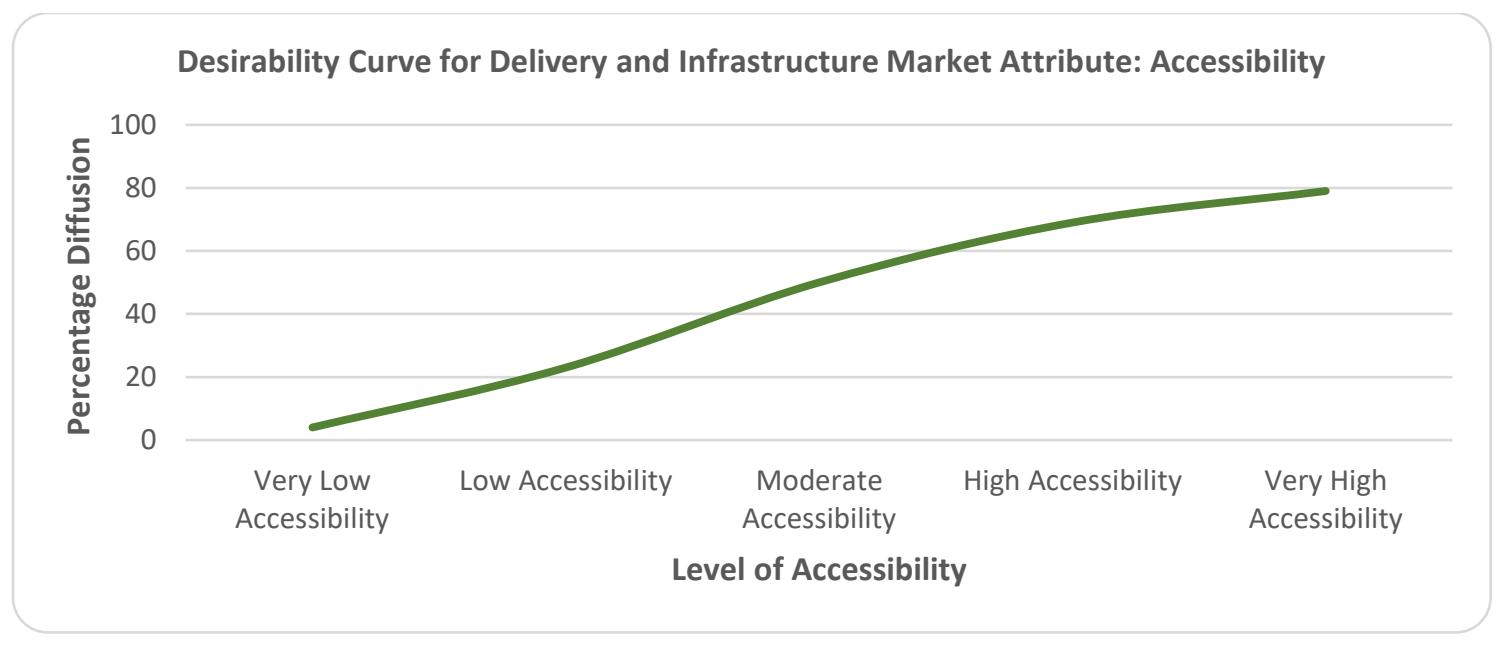

Figure 56: Desirability Curve for Accessibility

\subsubsection{Desirability Curve for Supply Chain}

Supply Chain for EE technologies depends on diffusion of tangible and intangible resources in the form of information, finance and materials. Managing the supply chain for diffusion of EE technology depends on reducing the cost. Table 45 shows the range of supply chain cost effectiveness based on total cost as a percentage of annual sales as a tentative guideline on metrics for measuring level of supply chain effectiveness [363] [364] [365] and Figure 57 shows how the impact of supply chain affects the diffusion of residential EE technologies.

Table 45: A Tentative Guideline on Metrics for Measuring Level of Supply Chain Effectiveness

\begin{tabular}{|c|c|c|c|}
\hline $\begin{array}{c}\text { Supply Chain is not } \\
\text { at all Cost Effective }\end{array}$ & Low Accessibility & Moderate Accessibility & $\begin{array}{c}\text { Supply Chain Very } \\
\text { Cost Effective }\end{array}$ \\
\hline Cost of SC $\geq 20 \%$ & $\begin{array}{c}15 \% \leq \text { Cost of SC }< \\
20 \%\end{array}$ & $10 \% \leq$ Cost of SC $<15 \%$ & $5 \% \leq$ Cost of SC < 10\% \\
\hline
\end{tabular}




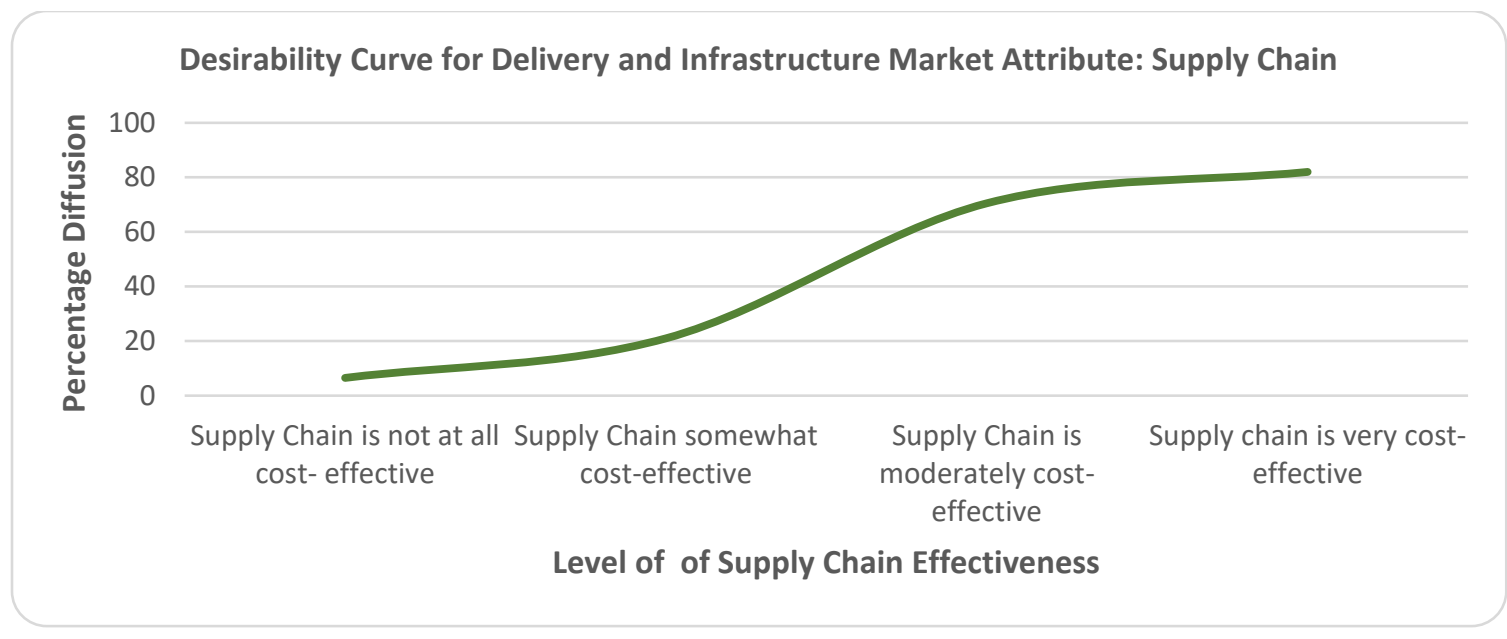

Figure 57: Desirability Curve for Supply Chain

6.4.5 Desirability Curves for Key Components of Legal and Institutional Market Attribute

Legal and Institutional market attribute is composed of Standards, Energy Price, Incentives and Labelling.

\subsubsection{Desirability Curve for Standards and Codes}

There are many different standards in various states to encourage the use of EE technologies. The impact of standards depends on if it is binding or non-binding or a standalone or combination of standards. Table 46 lists the different standards adopted in different states for increasing diffusion of EE technology as a tentative guideline on metrics for measuring level of impact of codes and standards and Figure 58 shows how different codes and standards affect the diffusion of residential EE technologies [313]. 
Table 46: A Tentative Guideline on Metrics for Measuring Level of Impact of Codes and Standards

\begin{tabular}{|c|c|c|c|c|}
\hline $\begin{array}{c}\text { Very Low Impact } \\
\text { of Codes and } \\
\text { Standards }\end{array}$ & $\begin{array}{c}\text { Low Impact of } \\
\text { Codes and } \\
\text { Standards }\end{array}$ & $\begin{array}{c}\text { Moderate Impact } \\
\text { of Codes and } \\
\text { Standards }\end{array}$ & $\begin{array}{c}\text { High Impact of } \\
\text { Codes and } \\
\text { Standards }\end{array}$ & $\begin{array}{c}\text { Very High } \\
\text { Impact of Codes } \\
\text { and Standards }\end{array}$ \\
\hline $\begin{array}{c}\text { Efficiency does } \\
\text { not comply with } \\
\text { Codes and } \\
\text { Standards at all }\end{array}$ & $\begin{array}{c}\text { Efficiency is } \\
\text { somewhat close to } \\
\text { Compliance with } \\
\text { Codes and } \\
\text { Standards }\end{array}$ & $\begin{array}{c}\text { Efficiency close to } \\
\text { Complies with } \\
\text { Codes and } \\
\text { Standards }\end{array}$ & $\begin{array}{c}\text { Efficiency } \\
\text { Complies with } \\
\text { Codes and } \\
\text { Standards }\end{array}$ & $\begin{array}{c}\text { Efficiency } \\
\text { Exceeds Codes } \\
\text { and Standards }\end{array}$ \\
\hline
\end{tabular}

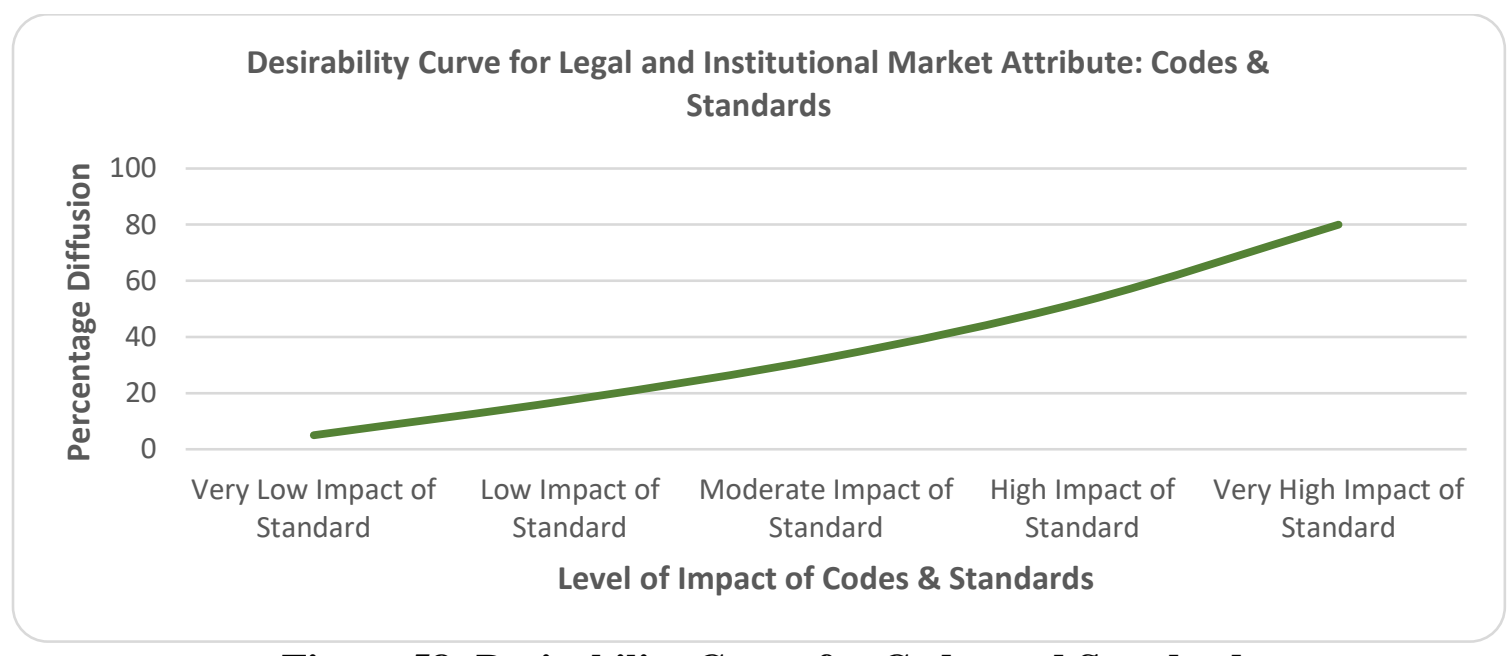

Figure 58: Desirability Curve for Codes and Standard

\subsubsection{Desirability Curve for Energy Price}

The impact of energy price depends on type of fuel used for residential EE technologies. Fuel prices impact in different ways. Cost of electricity generation or the energy cost in households may increase due to increase in real energy prices for consumers [19]. Hence, if real energy price for an EE technology is low, that would likely make it more preferable to customers and would be considered to have high impact on diffusion of EE technologies. Table 47 shows the different fuel types as a tentative guideline on metrics 
for measuring level of impact of energy price and Figure 59 shows how energy price affects the diffusion of residential EE technologies.

Table 47: A Tentative Guideline on Metrics for Measuring Level of Impact of Energy Price

\begin{tabular}{|c|c|c|c|c|}
\hline $\begin{array}{c}\text { Very High } \\
\text { Impact of Energy } \\
\text { Price }\end{array}$ & $\begin{array}{c}\text { High Impact of } \\
\text { Energy Price }\end{array}$ & $\begin{array}{c}\text { Moderate Impact } \\
\text { of Energy Price }\end{array}$ & $\begin{array}{c}\text { Low Impact of } \\
\text { Energy Price }\end{array}$ & $\begin{array}{c}\text { Very Low Impact } \\
\text { of Energy Price }\end{array}$ \\
\hline Electricity & Propane & Oil & Natural Gas & Solar \\
\hline
\end{tabular}

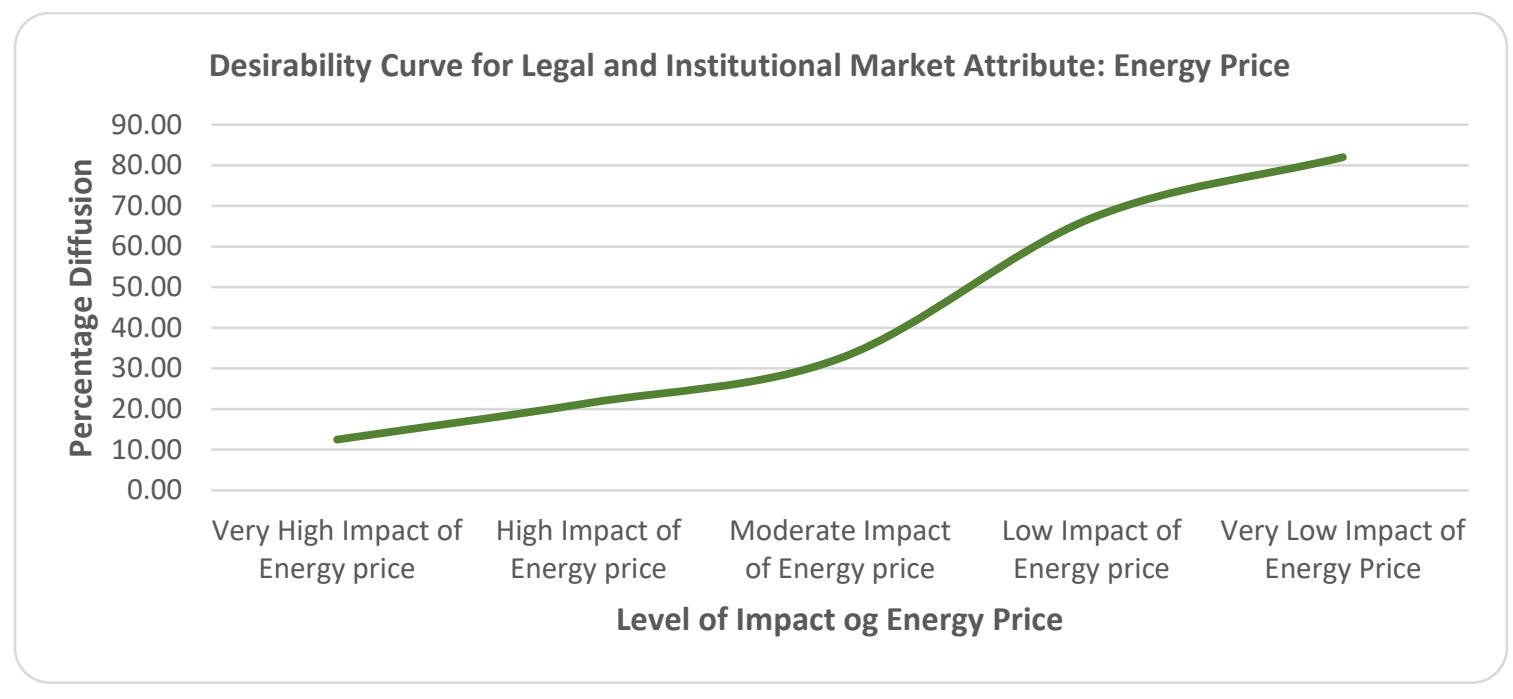

Figure 59: Desirability Curve for Energy Price

\subsubsection{Desirability Curve for Incentives}

Incentives are offered to different supply chain members at different times during the life cycle of an EE technology [366]. Table 48 provides a tentative guideline on metrics for measuring level of impact of incentives and Figure 60 shows how the impact of incentives affects the diffusion of residential EE technologies. 
Table 48: A Tentative Guideline on Metrics for Measuring Level of Impact of Incentives

\begin{tabular}{|l|l|l|l|}
\hline \multicolumn{1}{|c|}{$\begin{array}{c}\text { Very Low Impact of } \\
\text { Incentives }\end{array}$} & \multicolumn{1}{|c|}{$\begin{array}{c}\text { Low Impact of } \\
\text { Incentives }\end{array}$} & $\begin{array}{c}\text { Moderate Impact of } \\
\text { Incentives }\end{array}$ & \multicolumn{1}{|c|}{$\begin{array}{c}\text { High Impact of } \\
\text { Incentives }\end{array}$} \\
\hline $\begin{array}{l}\text { Neither the program } \\
\text { nor the supply chain } \\
\text { members are } \\
\text { appropriate }\end{array}$ & $\begin{array}{l}\text { Right Supply Chain } \\
\text { member but not the } \\
\text { Appropriate program }\end{array}$ & $\begin{array}{l}\text { Appropriate program } \\
\text { but not the right Supply } \\
\text { Chain member }\end{array}$ & $\begin{array}{l}\text { Appropriate program for } \\
\text { the correct Supply Chain } \\
\text { member }\end{array}$ \\
\hline
\end{tabular}

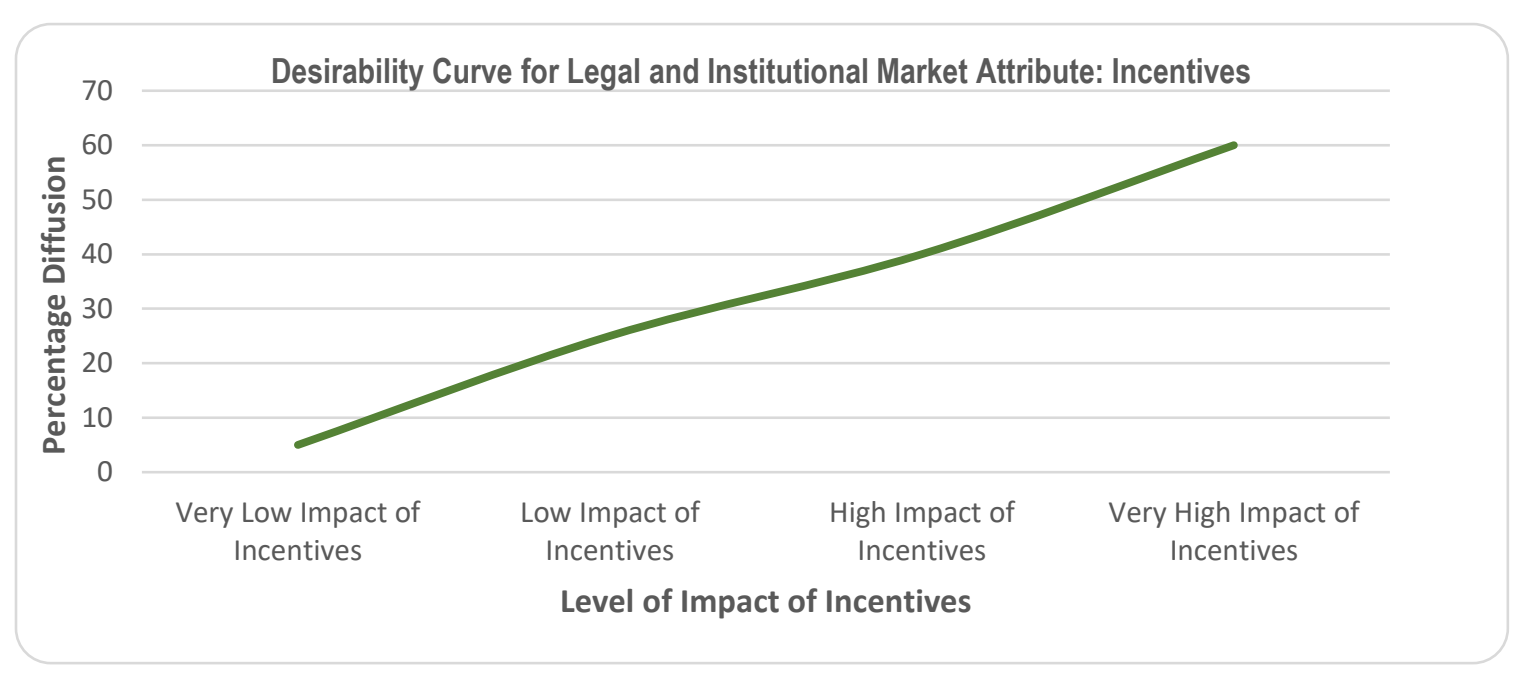

Figure 60: Desirability Curve for Incentives

\subsubsection{Desirability Curve for Labelling}

There are different types of labelling that provide different categories of information and also how they are presented. Table 49 provides a tentative guideline of metrics for measuring impact of labelling on residential EE technologies and Figure 61 shows the impact of labelling on diffusion [341]. 
Table 49: A Tentative Guideline on Metrics for Measuring Level of Impact of Labelling

\begin{tabular}{|c|c|c|c|c|c|}
\hline $\begin{array}{l}\text { Very Low Impact of } \\
\text { Labelling }\end{array}$ & \multicolumn{2}{|c|}{$\begin{array}{l}\text { Low Impact of } \\
\text { Labelling }\end{array}$} & \multicolumn{2}{|l|}{$\begin{array}{l}\text { High Impact of } \\
\text { Labelling }\end{array}$} & $\begin{array}{l}\text { Very High Impact of } \\
\text { Labelling }\end{array}$ \\
\hline $\begin{array}{l}\text { Labelling not } \\
\text { appropriate to product } \\
\text { or adopters }\end{array}$ & \multicolumn{2}{|c|}{$\begin{array}{l}\text { Labelling appropriate to } \\
\text { product not adopters }\end{array}$} & \multicolumn{2}{|c|}{$\begin{array}{l}\text { Labelling appropriate to } \\
\text { adopters but not to } \\
\text { products }\end{array}$} & $\begin{array}{l}\text { Labelling appropriate to } \\
\text { product and adopters. }\end{array}$ \\
\hline \multicolumn{2}{|c|}{ Intended Information } & \multicolumn{2}{|c|}{ Appropriate Product } & & levant Adopter Category \\
\hline \multicolumn{2}{|c|}{$\begin{array}{l}\text { Energy efficiency, operating cost, } \\
\text { Annual electricity consumption, } \\
\text { key performance attributes relevant } \\
\text { to their location }\end{array}$} & \multicolumn{2}{|c|}{$\begin{array}{l}\text { Each refrigerator Does not provide } \\
\text { the exact same performance in the } \\
\text { home as in the laboratory }\end{array}$} & \multicolumn{2}{|c|}{$\begin{array}{l}\text { Endorsement labels while } \\
\text { establishing new } \\
\text { technologies in the market. } \\
\text { Comparative labels for } \\
\text { spreading good practice, } \\
\text { reduce barriers }\end{array}$} \\
\hline
\end{tabular}

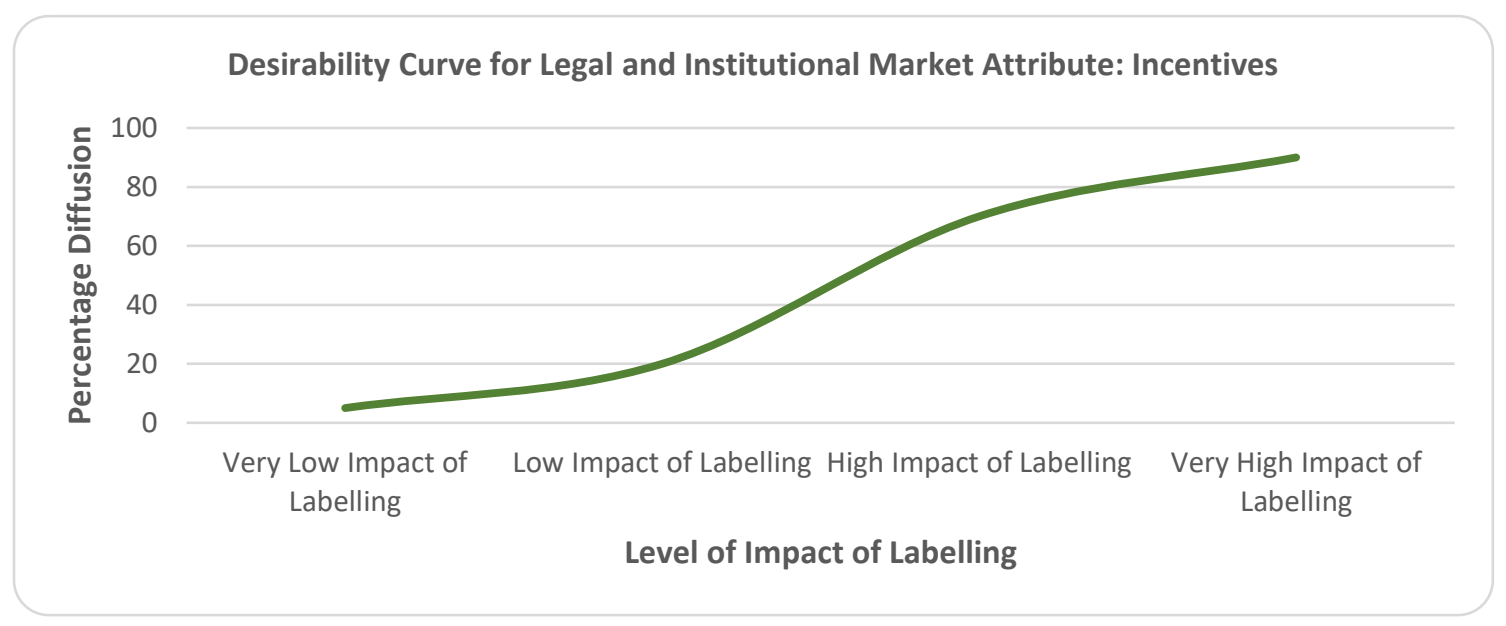

Figure 61: Desirability Curve for Labelling 


\section{CHAPTER 7: MARKET DIFFUSION POTENTIAL OF TECHNOLOGY CASES AND ANALYSIS}

This chapter analyzes the results from application of the MDP model for comparing the relative diffusion potential of the three technology cases. The low rating attributes for each technology case are identified and different actions are discussed for improving the MDP by refining the ratings of different key components in the model. A scenario analysis captures the importance of different market attributes in MDP model relevant to the different technology cases.

\subsection{Technology Cases}

The Market Diffusion Potential is applied to three technology cases to compare their relative diffusion potential.

Water heaters are the second most energy-consuming appliance in U.S. homes. Like the HVACs, there are several options to make the residential water heaters more energy efficient. Most of the design considerations focus on insulation, electronic ignition, and power vent (Lekov et al. 2011). Some of the highly efficient WHs are tankless water heaters, condensing storage water heaters, heat pump water heaters (HPWHs), and solar water heaters [367]

Tankless Water Heaters: Condensing tankless water heaters use two heat exchangers that make it more energy efficient than conventional non-condensing tankless water heaters. The residual heat from the flue gases is extracted in this technology that enables to preheat the groundwater and allows to use less energy to heat the water to its desired temperature [344]. 
Condensing Storage Water Heaters: These are storage tank heaters. Condensing storage tank heaters are more efficient than tankless heaters. A fan directs air and fuel to a combustion unit. The exhaust gas is channeled to another heat exchanger that helps to recirculate the waste heat from the combustion to heat the water, and achieve higher efficiency, thereby (ACEEE 2012)

Solar Water Heaters: Solar water heaters save the most energy as the heating source is solar energy. The operating cost is low, and the only cost involved is the initial purchasing cost [368].

Heat Pump Water Heaters: Heat pump water heaters use heat extracted from air from inside or outside the house and transforms it to a higher temperature to heat the storage tank water. A compressor is used to transfer heat from lower temperature air or ground source to the water. The efficiency is derived from the heat source which is environment rather than from any fuel source [368]. Table 50 shows the comparative advantages of different energy efficient water heaters.

Table 50: Technology Cases

\begin{tabular}{|l|c|c|c|}
\hline \multicolumn{1}{|c|}{ Water Heaters } & $\begin{array}{c}\text { Energy Savings Compared to } \\
\text { Minimum Standard }\end{array}$ & $\begin{array}{c}\text { Appropriate } \\
\text { Climate }\end{array}$ & $\begin{array}{c}\text { Expected Lifetime } \\
\text { (yrs.) }\end{array}$ \\
\hline $\begin{array}{l}\text { High Efficiency Storage } \\
\text { Tank WH (Oil, Gas, } \\
\text { Electric) }\end{array}$ & $10 \%-20 \%$ & Any & $8-10$ \\
\hline $\begin{array}{l}\text { Demand Tankless WH } \\
\text { (Gas or electric) }\end{array}$ & $45 \%-60 \%$ & Any & 20 \\
\hline $\begin{array}{l}\text { Ductless Heat Pump } \\
\text { (DHP) WH }\end{array}$ & $\begin{array}{c}65 \% \text { compared to electric } \\
\text { resistance WH }\end{array}$ & Mid-Hot & 10 \\
\hline $\begin{array}{l}\text { Solar WH with electric } \\
\text { backup }\end{array}$ & $70 \%-90 \%$ & Mid-Hot & 20 \\
\hline
\end{tabular}




\subsection{Application of the MDP Assessment Model to Technology Cases}

The three technologies are used as test cases to achieve the following objectives:

- Which technology has the highest MDP

- How to improve the low rating components to increase the MDP of the technologies

- Scenario analysis to create a future based scenario for the technologies and check what might facilitate higher diffusion of the candidate technologies

\subsubsection{MDP of Technology Cases}

The MDP of the technology cases are calculated using the following steps:

- Links were sent to experts for completing the comparison through qualtrics survey.

- Expert grouped the different technologies using the metrics in desirability curves for each key component.

- The desirability value for each key component is multiplied by the global weight for the key component and the relative weight of the corresponding market attribute.

- Summation of all the values gives the MDP for a certain technology case.

The results are shown in Table 51. 
Table 51: Market Diffusion Potential (MDP) of Technology Cases

\begin{tabular}{|c|c|c|c|c|c|c|c|c|c|}
\hline $\begin{array}{c}\text { Market } \\
\text { Attributes }\end{array}$ & Value & $\begin{array}{c}\text { Key } \\
\text { Components } \\
\text { of Market } \\
\text { Attributes }\end{array}$ & $\begin{array}{l}\text { Local } \\
\text { Value }\end{array}$ & $\begin{array}{c}\text { Ductless } \\
\text { Heat Pump } \\
\text { (DHP) }\end{array}$ & $\begin{array}{l}\text { Global } \\
\text { Value for } \\
\text { DHP }\end{array}$ & $\begin{array}{c}\text { Solar } \\
\text { Water } \\
\text { Heater } \\
\text { (SWH) }\end{array}$ & $\begin{array}{c}\text { Global } \\
\text { Value } \\
\text { for } \\
\text { SWH }\end{array}$ & $\begin{array}{c}\text { Tankless } \\
\text { Gas Water } \\
\text { Heater } \\
\text { (TGWH) }\end{array}$ & $\begin{array}{c}\text { Global } \\
\text { Value for } \\
\text { TGWH }\end{array}$ \\
\hline \multirow{4}{*}{$\begin{array}{l}\text { Consumer's } \\
\text { Benefit }\end{array}$} & \multirow{4}{*}{0.21} & Comfort & 0.061 & 96.67 & 1.24 & 63.33 & 0.81 & 63.33 & 0.81 \\
\hline & & Safety & 0.061 & 98.33 & 1.26 & 36.67 & 0.47 & 36.67 & 0.47 \\
\hline & & $\begin{array}{l}\text { Non-energy } \\
\text { Benefits }\end{array}$ & 0.046 & 98.33 & 0.95 & 60.00 & 0.58 & 33.33 & 0.32 \\
\hline & & Awareness & 0.042 & 100 & 0.88 & 17.33 & 0.15 & 100 & 0.88 \\
\hline \multicolumn{4}{|c|}{ Total for Consumers' Benefit } & \multicolumn{2}{|c|}{4.33} & \multicolumn{2}{|c|}{2.02} & \multicolumn{2}{|c|}{2.48} \\
\hline \multirow{4}{*}{ Technological } & \multirow{4}{*}{0.18} & $\begin{array}{c}\text { Energy Saving } \\
\text { Potential }\end{array}$ & 0.043 & 52.67 & 0.41 & 93.33 & 0.72 & 23.67 & 0.18 \\
\hline & & $\begin{array}{c}\text { Ease of } \\
\text { Installation }\end{array}$ & 0.036 & 75 & 0.49 & 30 & 0.19 & 30 & 0.19 \\
\hline & & Ease of Use & 0.045 & 96.67 & 0.78 & 96.67 & 0.78 & 96.67 & 0.78 \\
\hline & & Compatibility & 0.058 & 90 & 0.94 & 41.33 & 0.44 & 90 & 0.94 \\
\hline \multicolumn{4}{|c|}{ Total for Technological } & \multicolumn{2}{|c|}{2.62} & \multicolumn{2}{|c|}{2.13} & \multicolumn{2}{|c|}{2.10} \\
\hline \multirow{4}{*}{ Economic } & \multirow{4}{*}{0.25} & $\begin{array}{l}\text { Profitability } \\
\text { Index (PI) }\end{array}$ & 0.058 & 83 & 1.20 & 12 & 0.17 & 12 & 0.17 \\
\hline & & Levelized Cost & 0.058 & 30 & 0.44 & 92 & 1.34 & 83 & 1.20 \\
\hline & & $\begin{array}{c}\text { Payback } \\
\text { Period }\end{array}$ & 0.068 & 90 & 1.53 & 67 & 1.14 & 41 & 0.70 \\
\hline & & Substitutes & 0.068 & 41 & 0.70 & 32 & 0.54 & 41 & 0.70 \\
\hline \multicolumn{4}{|c|}{ Total for Economic } & \multicolumn{2}{|c|}{3.87} & \multicolumn{2}{|c|}{3.19} & \multicolumn{2}{|c|}{2.77} \\
\hline \multirow{4}{*}{$\begin{array}{c}\text { Delivery \& } \\
\text { Infrastructure }\end{array}$} & \multirow{4}{*}{0.16} & Competition & 0.032 & 59 & 0.30 & 47 & 0.24 & 59 & 0.30 \\
\hline & & Trade Allies & 0.045 & 73 & 0.53 & 88 & 0.63 & 48 & 0.35 \\
\hline & & Accessibility & 0.050 & 50 & 0.40 & 23 & 0.18 & 50 & 0.40 \\
\hline & & Supply Chain & 0.035 & 70.5 & 0.39 & 6.5 & 0.05 & 21 & 0.12 \\
\hline \multicolumn{4}{|c|}{ Total for Delivery \& Infrastructure } & \multicolumn{2}{|c|}{1.62} & \multicolumn{2}{|c|}{1.10} & \multicolumn{2}{|c|}{1.17} \\
\hline \multirow{4}{*}{$\begin{array}{c}\text { Legal \& } \\
\text { Institutional }\end{array}$} & \multirow{4}{*}{0.21} & $\begin{array}{c}\text { Codes \& } \\
\text { Standards }\end{array}$ & 0.082 & 52.5 & 0.90 & 80 & 1.38 & 32.5 & 0.56 \\
\hline & & Energy Pricing & 0.038 & 21.50 & 0.17 & 67 & 0.53 & 67 & 0.53 \\
\hline & & Incentive & 0.055 & 60 & 0.69 & 60 & 0.69 & 60 & 0.69 \\
\hline & & Labelling & 0.036 & 90 & 0.68 & 90 & 0.25 & 20 & 0.15 \\
\hline \multicolumn{4}{|c|}{ Total for Legal \& Institutional } & \multicolumn{2}{|c|}{2.45} & \multicolumn{2}{|c|}{2.85} & \multicolumn{2}{|c|}{1.94} \\
\hline Mar & t Diffusi & Potential (MDP & & & & & & & \\
\hline & & & & & & & & & \\
\hline
\end{tabular}


The result shows that Ductless Heat Pump (DHP) Water Heater has the highest Market Diffusion Potential (MDP) followed by Solar Water Heater (SWH) with Electric Backup and Tankless Gas Water Heater (TGWH).

Table 29 lists the highest and lowest rating key components of the three technology cases with corresponding desirability values.

\subsubsection{Improving MDP of Technology Cases}

From the calculation of MDP of the technology cases it is possible to identify the Highest Rating and Lowest Rating key components for each of the technology cases as listed in Table 52. This helps to identify areas for improvement in order to increase the MDP of the specific technology case. 
Table 52: Highest and Lowest Rating Key Components for Technology Cases

\begin{tabular}{|c|c|c|c|}
\hline $\begin{array}{c}\text { Ratings of Key } \\
\text { Components } \\
\end{array}$ & Key Components & Desirability Value Metrics & $\begin{array}{c}\text { Desirability } \\
\text { Value }\end{array}$ \\
\hline \multicolumn{4}{|c|}{ Ductless Heat Pump (DHP) Water Heater } \\
\hline \multirow[t]{5}{*}{ Highest Rating } & Awareness & Very High Awareness & 100 \\
\hline & Ease of Use & Extremely Easy to Use & 96.67 \\
\hline & Payback Period & Very Low Payback Period & 90 \\
\hline & Supply Chain & Supply Chain Very Cost Effective & 82 \\
\hline & Labelling & Very High Impact of Labelling & 90 \\
\hline \multirow[t]{3}{*}{ Lowest Rating } & Levelized Cost of Electricity & LCOE greater than $3 \phi$ & 30 \\
\hline & Accessibility & Moderate Accessibility & 50 \\
\hline & Energy Price & High impact of Energy Price & 21.50 \\
\hline \multicolumn{4}{|c|}{ Solar Water Heater (SWH) with Electric Backup } \\
\hline \multirow[t]{5}{*}{ Highest Rating } & Energy saving Potential & $\begin{array}{l}\text { Very High Energy Saving } \\
\text { Potential }\end{array}$ & 93.33 \\
\hline & Ease of Use & Extremely Easy to Use & 96.67 \\
\hline & $\begin{array}{l}\text { Levelized Cost of Electricity } \\
\text { (LCOE) }\end{array}$ & LCOE greater than $1 \phi$ or less & 92 \\
\hline & Trade Allies & Very High Impact of Trade Allies & 88 \\
\hline & Labelling & Very High Impact Labelling & 90 \\
\hline \multirow{6}{*}{ Lowest Rating } & Awareness & Very Low Awareness & 17.33 \\
\hline & Profitability Index (PI) & $\mathrm{PI}<1$ & 12 \\
\hline & Compatibility & Low Compatibility & 41,33 \\
\hline & Accessibility & Low Accessibility & 23 \\
\hline & Supply Chain & $\begin{array}{l}\text { Supply Chain is not at all Cost } \\
\text { Effective }\end{array}$ & 6.5 \\
\hline & Ease of Installation & Moderate Work by Installers & 30 \\
\hline \multicolumn{4}{|c|}{ Tankless Gas Water Heater (TGWH) } \\
\hline \multirow{4}{*}{ Highest Rating } & Awareness & Very High Awareness & 100 \\
\hline & Ease of Use & Extremely Easy to Use & 96.67 \\
\hline & Compatibility & Very High Compatibility & 90 \\
\hline & Incentives & Very High Impact of Incentives & 60 \\
\hline \multirow{5}{*}{ Lowest Rating } & Non-energy Benefits (NEBs) & $\begin{array}{l}\text { Moderate Detectable Non-energy } \\
\text { Benefits }\end{array}$ & 33.33 \\
\hline & Payback Period & High Payback Period & 41 \\
\hline & Labelling & Low Impact of Labelling & 20 \\
\hline & Energy Saving Potential & $\begin{array}{l}\text { Moderate Energy Saving } \\
\text { Potential }\end{array}$ & 23.67 \\
\hline & Ease of Installation & Moderate Work by Installers & 30 \\
\hline
\end{tabular}

The next section analyzes the low rating components in the model for each of the technology cases and prescribes probable actions to increase Market Diffusion Potential (MDP).

\subsubsection{Improving MDP of Ductless Heat Pump (DHP) Water Heater}

The Levelized Cost of Electricity (LCOE) depends on electric rates and Coefficient of Performance (COP). The LCOE increases with increase in electricity rates and also with 
decreasing COP [369]. COP is a performance measure for Heat Pump Water Heater (HPWH) which is expressed as a ratio of energy content in delivered hot water divided by electrical energy spent in driving the system [370]. To increase the diffusion of DHP, the utility's decoupling strategy can satisfy the interest of both the utility and the customers and encourage the diffusion of DHP water heater. Decoupling of utility rates mean disentangling profit of utilities from sales. Rather than selling more power, utilities increase their customer base by promoting EE technologies [371].

The COP of HPWH can be improved by Isolated System Energy Charging (ISEC) which is based on the philosophy of reinvention of a technology. In ISEC system a couple of heat pumps are used in series to increase the COP. ISEC has proved to be an effective method of increasing the COP of a heat pump by $25 \%$ [372]. Also, a review of different water heater technologies found that hybrid water system consisting of several heating technologies can increase COP and reduce cost of using DHP WH for both water and space heating [373].

The next low rating attribute is accessibility. The distribution of DHP mostly depends on availability of rebates to downstream members according to Northwest Heat Pump Water Heater Initiative Market Progress Evaluation Report \#1[342]. Several studies have proved midstream programs to be an effective approach in enticing different outlets in piling and selling DHPs [374]. The midstream program is devised in a way so that contractors get rebates from distributors once they sell the product and provide proof of installation. Market Intelligence is developing the correct strategy that adapts to the market 
in perspective based on market information is important for successful midstream program to increase accessibility of DHP[375]. Most midstream programs involve utility, implementers, manufacturers, distributors, contractors and customers as shown in Figure 62 [374].Utility may form strategic alliance with manufacturer and contractors to reduce the link of actors and increase diffusion more effective and efficiently.

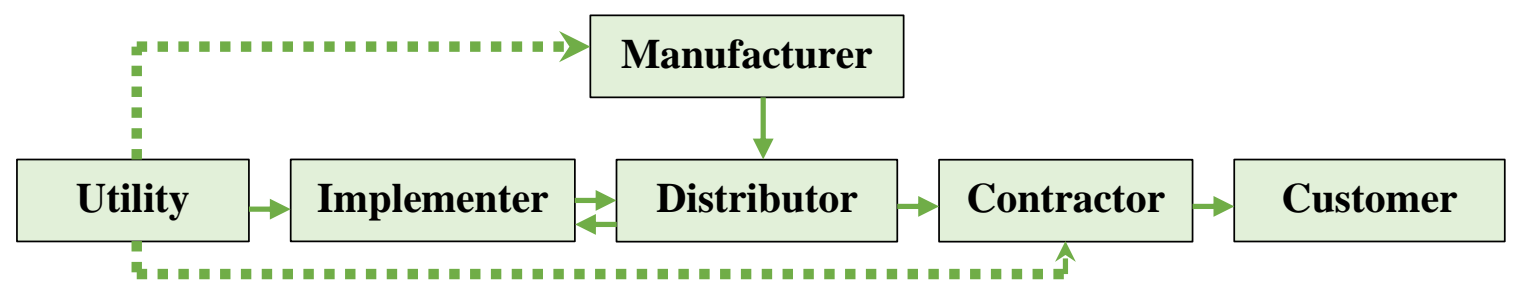

$\| n+n=n n=n$ Strategic Alliance

Figure 62: Actors in Midstream Programs

The third low rating attribute for DHP is energy price. Natural Gas Heat Pump Water Heater (NGHPWH) can reduce the reliance on electricity and increase the efficiency of HPWH. NEEA has recently initiated a program on market transformation for GHPWH [376]. Geothermal HPWH can be another option when some of the disadvantages like space, installation and cost of installation are competitive [377].

\subsubsection{Improving MDP of Solar Water Heater with Electricity Backup}

Among all the water heaters, solar water heater has the least awareness despite being the most energy efficient technology for water heating. The high initial cost discourages distributors and contractors to promote solar water heater. For increasing awareness of solar water heater, utility can capitalize the existing distributor-contractor-customer 
channel for residential solar panels and promote SWH similar to Tesla' battery technology and EV car business [378].

PI of SWH is low. In order to make the investment in SWH programs more attractive careful program planning is needed that should ensure how to minimize the payback period and also reliability of the technology [379].

Solar water heater cannot be used in all climates as in freezing temperature the collector may get damaged. Also, larger tanks are required to store water because of possible fluctuation in sunlight. Therefore, an electric back up is used to get uninterrupted service. However, this increases the cost. One way to reduce the effect of climate is to use cost effective battery storage [380].

SWH is distributed in two steps as shown in Figure 63.

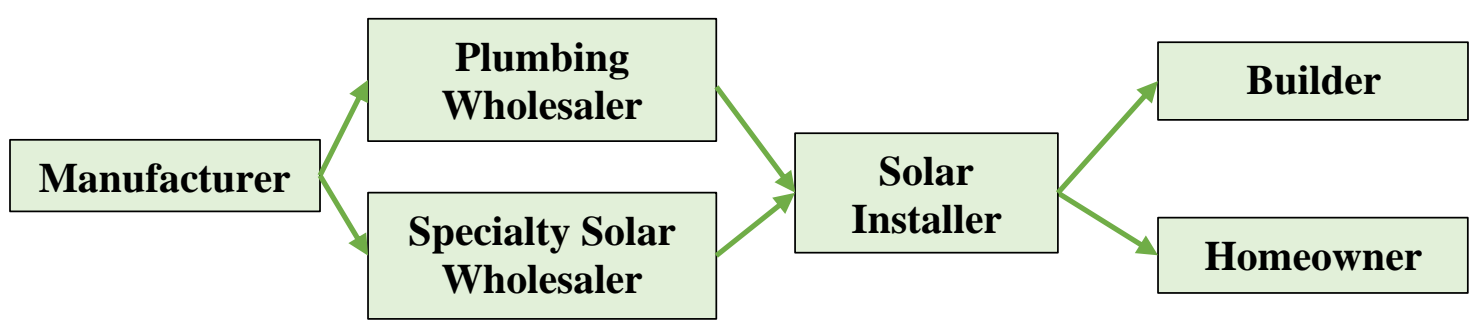

Figure 63: Distribution Channel for SWH

For availability of SWH, direct selling is found to be an effective strategy rather than several intermediaries to reach to ultimate customers. Building network with homeowners and builders create more opportunity for diffusion of SWH.

There are many barriers in the supply chain for SWH which leads to increased cost of the supply chain. As explained by Soni and Shrivastava, supply chain cost can be reduced 
in various ways. Some of the strategies are, minimizing the cost of raw material by effective sourcing, appropriate make or buy decision for component manufacturing and integration, finding ways to reduce transportation and distribution cost by direct sales, increased reliability in onsite integration and installation through highly trained professionals to avoid cost of rework, maintenance for greater longevity, and finally, careful disposal and recovery [381].

Installation of solar water heater needs considerable installation work. However, DIY solar water heaters are available but with sacrifice in efficiency. With increased efficiency in component parts and enabling technology as well as system architecture it is possible to achieve high efficiency solar water heater with less complex installation work [382].

\subsubsection{Improving MDP of Tankless Gas Water Heater (TGWH)}

Tankless Gas Water Heaters (TGWH) have large payback periods, however, due to the high efficiency and low initial investment cost, TGWH are the most widely used water heaters. In most cases, utility rebates or incentives depend on a minimum efficiency of the TGWH. Increased efficiency of TGWH can be derived when it serves the purpose of water heating as well as space heating [383].

High flow rates of tankless gas water heater can lead to heat loss and reduce its energy saving potential. Innovation in advanced Intermittent Ignition Device (IID) or standing pilot light can help to minimize heat loss and increase energy saving potential. Increased energy saving potential can also be achieved by remote bathrooms or hot tubs, booster for appliances, such as dishwashers or clothes washers, booster for a solar water heater [384]. 
Installing TGWH by DIY needs advanced skill. Without proper training and expertise DIY always runs the risk of safety hazards. However, manufacturers and distributors can organize workshops to train owners in installing TGWHs with minimum support from contractors.

A few TGWH are Energy Star certified. However, TGWH should have zonal energy rating label that would ensure its adaptability in all climate zone and help customers in their buying decisions.

Findings from the above analysis are:

- MDP of Ductless Heat Pump (DHP) Water Heaters can be increased by using alternate fuel source instead of electricity, increasing COP by technology improvement or dual use of the devise and finally, to create increased awareness about DHP, middle stream programs can be implemented.

- $\quad$ MDP of Solar Water Heater (SWH) can also be increased by greater awareness through capitalizing solar panel distributors and marketing channels. PI ensures investment in energy efficiency projects and utility participation. To make the SWH program feasible the payback period needs to be reduced through careful program planning. Supply chain cost effectiveness depends on appropriate action at each stage of the supply chain tasks.

- MDP of TGWH can be increased by compensating the long payback period by dual application. For labelling, TGWH should have zoned energy rating label to promote its compatibility in all climate zones. 
Table 53 shows the percentage increase in MDP value of Technology Cases with increase in desirability values due to appropriate actions adopted to increase the desirability values of low rating components. 
Table 53: Increased MDP of Technology Cases with Change in Desirability Values

\begin{tabular}{|c|c|c|c|c|c|}
\hline $\begin{array}{l}\text { Technology } \\
\text { Cases }\end{array}$ & $\begin{array}{c}\text { Key } \\
\text { Components }\end{array}$ & $\begin{array}{c}\text { Original } \\
\text { Metric of Key } \\
\text { Components }\end{array}$ & $\begin{array}{c}\text { Original } \\
\text { Desirability } \\
\text { Value }\end{array}$ & $\begin{array}{c}\text { Improved } \\
\text { Metric of Key } \\
\text { Components }\end{array}$ & $\begin{array}{c}\text { Improved } \\
\text { Desirability } \\
\text { Values }\end{array}$ \\
\hline \multirow{3}{*}{ 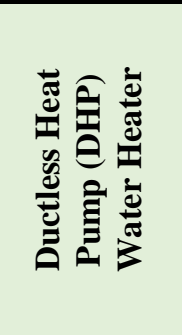 } & $\begin{array}{l}\text { Levelized Cost } \\
\text { of Electricity } \\
\text { (LCOE) }\end{array}$ & $\mathrm{LCOE}>3 \phi$ & 30 & $\begin{array}{l}1 \mathrm{1} \leq \mathrm{LCOE} \\
<2 \mathrm{c} / \mathrm{kwhr}\end{array}$ & 83 \\
\hline & Accessibility & $\begin{array}{c}\text { Moderate } \\
\text { Accessibility }\end{array}$ & 50 & $\begin{array}{c}\text { High } \\
\text { Accessibility }\end{array}$ & 69 \\
\hline & Energy Price & $\begin{array}{l}\text { High impact of } \\
\text { Energy Price }\end{array}$ & 21.50 & $\begin{array}{c}\text { Moderate } \\
\text { Impact of } \\
\text { Energy Price }\end{array}$ & 67 \\
\hline \multicolumn{5}{|c|}{ Original MDP of Ductless Heat Pump (DHP) Water Heater } & 14.88 \\
\hline \multicolumn{5}{|c|}{ Improved MDP of Ductless Heat Pump (DHP) Water Heater } & 16.17 \\
\hline \multicolumn{5}{|c|}{ Percentage Increase in MDP of Ductless Heat Pump (DHP) Water Heater } & $8.7 \%$ \\
\hline $\begin{array}{l}\text { Technology } \\
\text { Cases }\end{array}$ & $\begin{array}{c}\text { Key } \\
\text { Components }\end{array}$ & $\begin{array}{c}\text { Original } \\
\text { Metric of Key } \\
\text { Components }\end{array}$ & $\begin{array}{c}\text { Original } \\
\text { Desirability } \\
\text { Value }\end{array}$ & $\begin{array}{c}\text { Improved } \\
\text { Metrics of Key } \\
\text { Components }\end{array}$ & $\begin{array}{c}\text { Improved } \\
\text { Desirability } \\
\text { Values }\end{array}$ \\
\hline \multirow{5}{*}{ 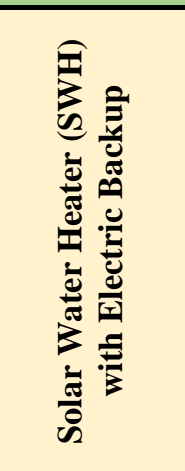 } & $\begin{array}{l}\text { Profitability } \\
\text { Index (PI) }\end{array}$ & PI $<1$ & 12 & $\mathrm{PI}>2$ & 83 \\
\hline & Compatibility & $\begin{array}{c}\text { Low } \\
\text { Compatibility }\end{array}$ & 41.33 & $\begin{array}{c}\text { High } \\
\text { Compatibility }\end{array}$ & 65 \\
\hline & Accessibility & $\begin{array}{c}\text { Low } \\
\text { Accessibility }\end{array}$ & 23 & $\begin{array}{c}\text { High } \\
\text { Accessibility }\end{array}$ & 69 \\
\hline & Supply Chain & $\begin{array}{c}\text { Supply Chain is } \\
\text { not at all Cost } \\
\text { Effective }\end{array}$ & 6.5 & $\begin{array}{l}\text { Supply Chain } \\
\text { Moderately } \\
\text { Cost Effective }\end{array}$ & 70.5 \\
\hline & $\begin{array}{c}\text { Ease of } \\
\text { Installation }\end{array}$ & $\begin{array}{l}\text { Moderate Work } \\
\text { by Installers }\end{array}$ & 30 & $\begin{array}{l}\text { Minimum Work } \\
\text { by Installers }\end{array}$ & 75 \\
\hline \multicolumn{5}{|c|}{ Original MDP of Solar Water Heater (SWH) with Electric Backup } & 11.28 \\
\hline \multicolumn{5}{|c|}{ Improved MDP of Solar Water Heater (SWH) with Electric Backup } & 13.58 \\
\hline \multicolumn{5}{|c|}{ Percentage Increase in MDP of Solar Water Heater (SWH) with Electric Backup } & $20.39 \%$ \\
\hline $\begin{array}{l}\text { Technology } \\
\text { Cases }\end{array}$ & $\begin{array}{c}\text { Key } \\
\text { Components }\end{array}$ & $\begin{array}{c}\text { Original } \\
\text { Metric of Key } \\
\text { Components }\end{array}$ & $\begin{array}{c}\text { Original } \\
\text { Desirability } \\
\text { Value }\end{array}$ & $\begin{array}{c}\text { Improved } \\
\text { Metric of key } \\
\text { Components }\end{array}$ & $\begin{array}{c}\text { Improved } \\
\text { Desirability } \\
\text { Values }\end{array}$ \\
\hline \multirow{4}{*}{ 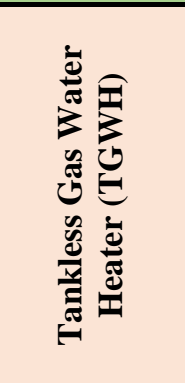 } & $\begin{array}{l}\text { Payback } \\
\text { Period }\end{array}$ & $\begin{array}{c}\text { Very High } \\
\text { Payback Period }\end{array}$ & 41 & $\begin{array}{l}\text { High Payback } \\
\text { Period }\end{array}$ & 67 \\
\hline & Labelling & $\begin{array}{l}\text { Low Impact of } \\
\text { Labelling }\end{array}$ & 20 & $\begin{array}{l}\text { High Impact of } \\
\text { Labelling }\end{array}$ & 70 \\
\hline & $\begin{array}{c}\text { Energy Saving } \\
\text { Potential }\end{array}$ & $\begin{array}{c}\text { Moderate } \\
\text { Energy Saving } \\
\text { Potential }\end{array}$ & 23.67 & $\begin{array}{c}\text { High energy } \\
\text { saving Potential }\end{array}$ & 52.67 \\
\hline & $\begin{array}{c}\text { Ease of } \\
\text { Installation }\end{array}$ & $\begin{array}{l}\text { Moderate Ease } \\
\text { of Installation }\end{array}$ & 30 & $\begin{array}{l}\text { Minor Work by } \\
\text { Installers }\end{array}$ & 50.67 \\
\hline \multicolumn{5}{|c|}{ Original MDP of Tankless Gas Water Heater (TGWH) } & 10.46 \\
\hline \multicolumn{5}{|c|}{ Improved MDP of Tankless Gas Water Heater (TGWH) } & 11.6 \\
\hline \multicolumn{5}{|c|}{ Percentage Increase in MDP of Tankless Gas Water Heater (TGWH) } & $10.89 \%$ \\
\hline
\end{tabular}




\subsubsection{Scenario Analysis}

The scenario analysis is performed to visualize how change in relative strength of the market attributes created by product/service values offered through key components can impact the ranking of Technology Cases. Five different scenarios are developed by assigning maximum weight to a certain market attribute and assigning a weight of 0.1 to the other market attributes.

The next section shows the choice of technology cases based on different scenarios. DHP has the most MDP based on experts' judgment as shown in Figure 64.

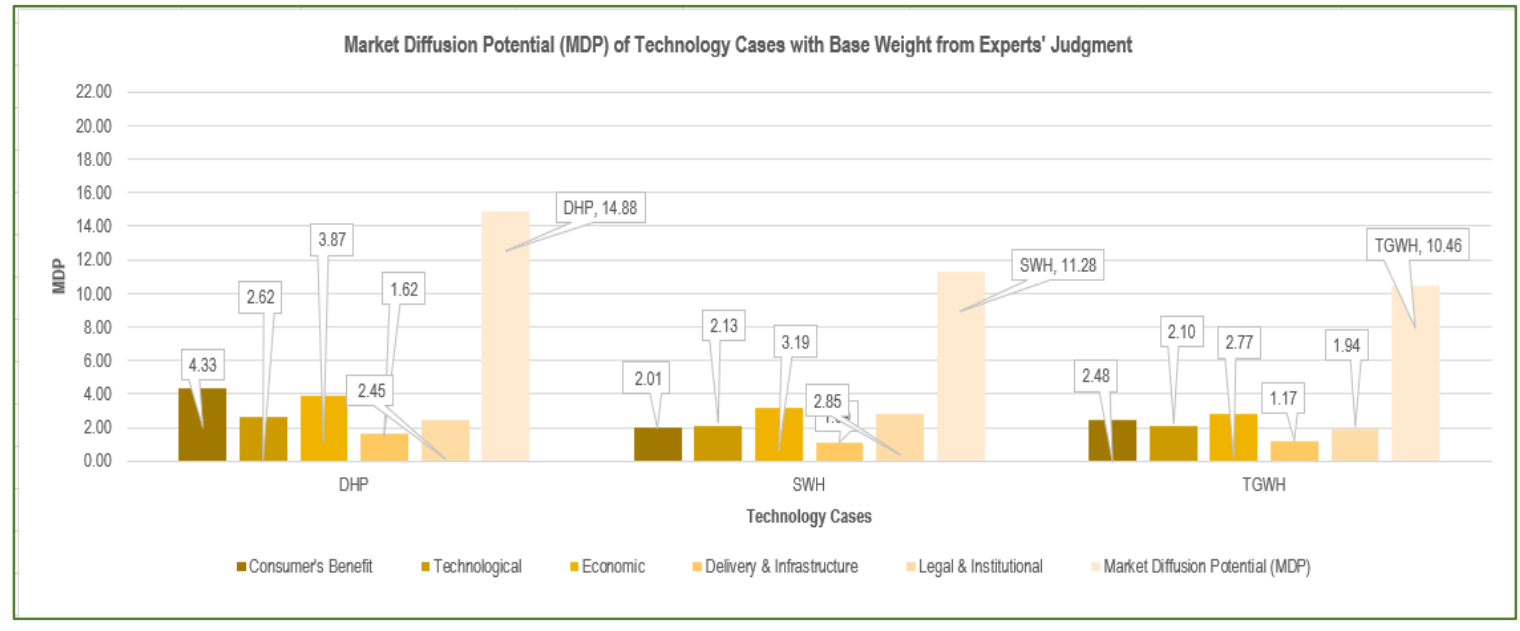

Figure 64: Ranking of Technology Cases with the Base Weights of Market Attributes

In a Customers' Benefit centric market approach, the MDP of DHP increases by $36 \%$ while the MDP of SWH decreases by $14.4 .5 \%$ and the MDP for TGWH increases by $11.8 \%$ as shown in Figure 65. This proves the importance of Customers' Benefit Market Attribute for DHP and TGWH, however, for SWH, it is not the most important attribute to prefer. 


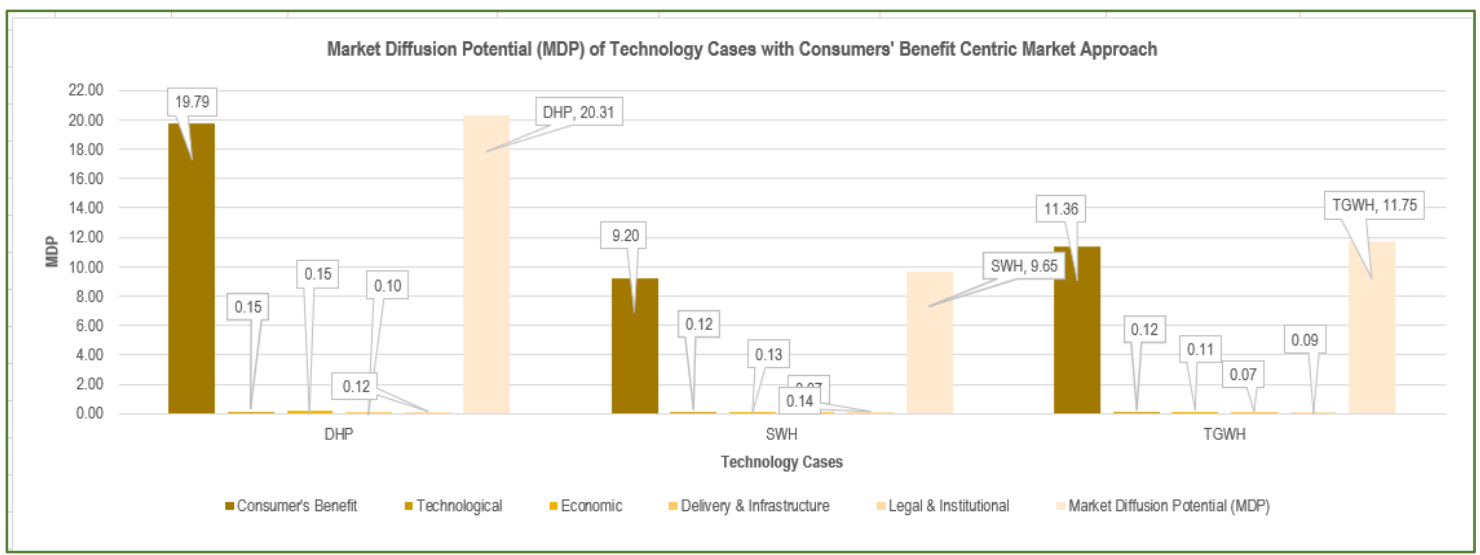

Figure 65: Ranking of Technology Cases with the Consumers' Benefit Centric Market Approach

As expected, Technological Excellence centric market approach does not increase the MDP for all three technology cases commendably as it is not the most important market attribute for increasing the diffusion of residential EE technologies as shown in Figure 66.

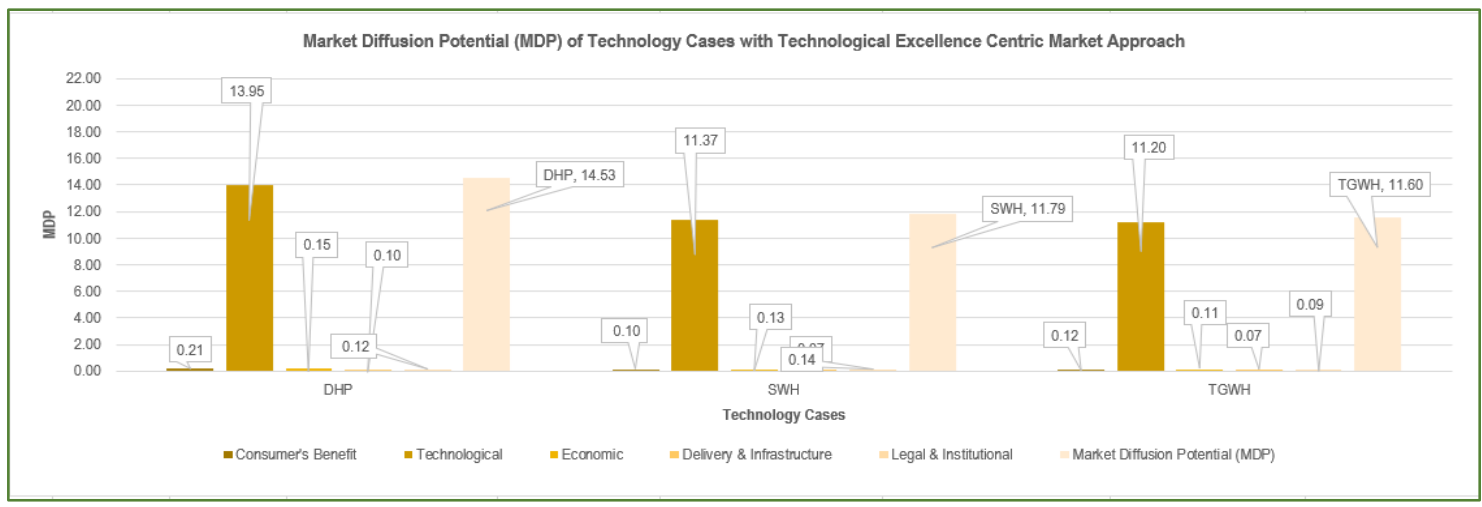

Figure 66: Ranking of Technology Cases with Technological Excellence Centric Market Approach

Economic Advantage centric market approach increases the diffusion of all the technology cases as it is identified as the most important contributing market attribute for diffusion of residential EE technologies. However, the MDP increases the most for SWH 
by $12 \%$ while for DHP and TGWH the increases in MDP are 3.5\% and 5.55\% respectively as shown in Figure 67.

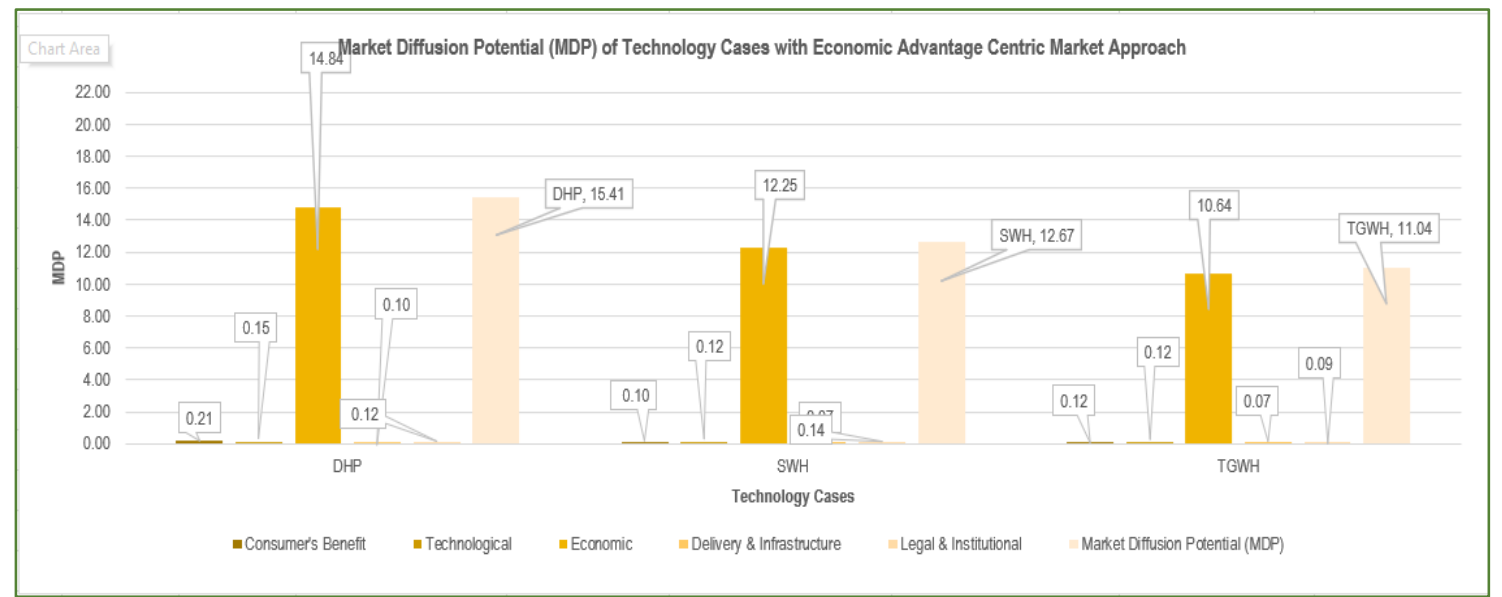

Figure 67: Ranking of Technology Cases with Economic Advantage Centric Market Approach

Delivery \& Infrastructure superiority centric market approach is the least impactful as it has the least effect in the diffusion of residential EE technologies as shown in Figure 68. The MDPs of all the technology cases decreases with this approach. This helps to identify where to allocate resources for increasing MDP.

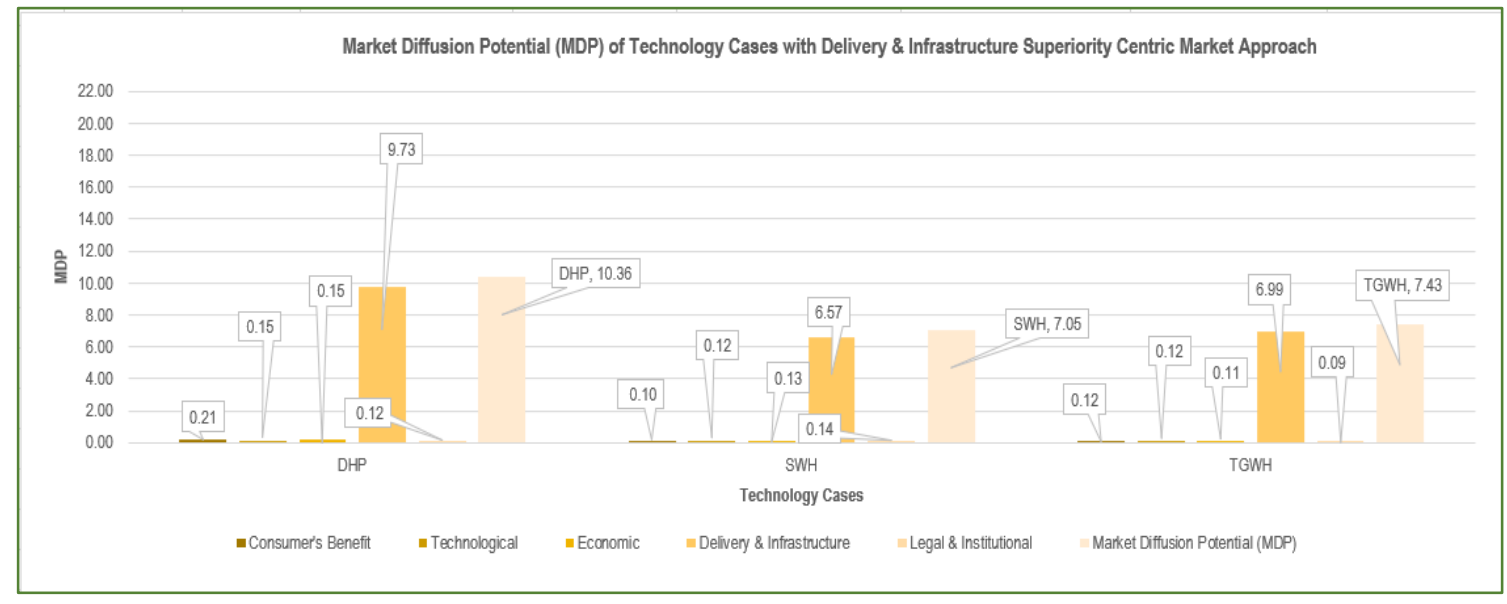

Figure 68: Ranking of Technology Cases with Delivery \& Infrastructure Superiority Centric Market Approach 
Legal and Institutional strength centric market approach does not change the MDP of DHP and TGWH, however, it shows an increase in MDP of SWH as modeled in Figure 69. Codes \& Standard has been identified as the most important key component for increasing the diffusion of residential EE technologies. The efficiency of SWH far exceeds that which is required by Standards which means it complies fully with the requirement of standards. On the contrary, for DHP and TGWH there are rooms for improvement in efficiency, hence, strength in Legal \& Market attribute does not increase their MDPs.

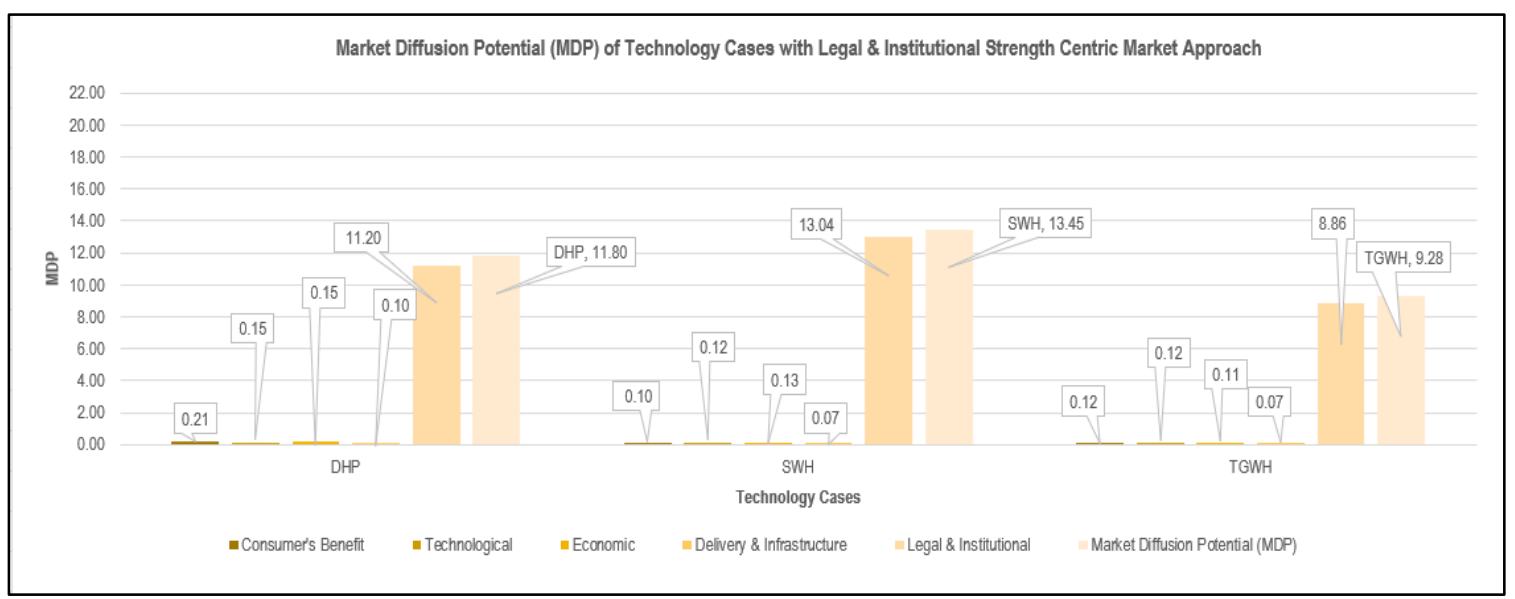

Figure 69: Ranking of Technology Cases with Legal \& Institutional Strength Centric Market Approach

The ranking of the three technology cases with respective to different scenario is shown in Table 54. 
Table 54:Ranking of Technology Cases in Different Scenarios

\begin{tabular}{|l|c|c|c|c|c|c|}
\hline & \multicolumn{6}{|c|}{ Scenarios } \\
\cline { 2 - 7 } & $\begin{array}{c}\text { Status } \\
\text { quo } \\
\text { Technology }\end{array}$ & $\begin{array}{c}\text { Consumers } \\
\text { Benefit } \\
\text { Centric } \\
\text { Market } \\
\text { Approach }\end{array}$ & $\begin{array}{c}\text { Technological } \\
\text { Excellence } \\
\text { Centric } \\
\text { Market } \\
\text { Approach }\end{array}$ & $\begin{array}{c}\text { Economic } \\
\text { Advantage } \\
\text { Centric } \\
\text { Market } \\
\text { Approach }\end{array}$ & $\begin{array}{c}\text { Delivery \& } \\
\text { Infrastructure } \\
\text { Superiority } \\
\text { Centric } \\
\text { Market } \\
\text { Approach }\end{array}$ & $\begin{array}{c}\text { Legal \& } \\
\text { Institutional } \\
\text { Strength } \\
\text { Centric } \\
\text { Market } \\
\text { Approach }\end{array}$ \\
\hline $\begin{array}{l}\text { Ductless Heat } \\
\text { Pump (DHP) } \\
\text { Water Heater }\end{array}$ & $\begin{array}{c}13.02 \\
(1)\end{array}$ & $\begin{array}{c}\mathbf{2 1 . 1 5} \\
(1)\end{array}$ & $\begin{array}{c}14.84 \\
(1)\end{array}$ & $\begin{array}{c}11.55 \\
(1)\end{array}$ & $\begin{array}{c}\mathbf{4 . 1 3} \\
(1)\end{array}$ & $\begin{array}{c}11.20 \\
(2)\end{array}$ \\
\hline $\begin{array}{l}\text { Solar Water Heater } \\
\text { (SWH) with }\end{array}$ & $\mathbf{9 . 0 6}$ & $\mathbf{8 . 0 5}$ & $\mathbf{1 1 . 4 9}$ & $\mathbf{1 0 . 5 0}$ & $\mathbf{2 . 6 0}$ & $\mathbf{1 1 . 2 9}$ \\
Electric Backup & $(2)$ & $(3)$ & $(3)$ & $(2)$ & $\mathbf{( 3 )}$ & $(1)$ \\
\hline $\begin{array}{l}\text { Tankless Gas } \\
\text { Water Heater } \\
\text { (TGWH) }\end{array}$ & $\mathbf{8 . 7 3}$ & $\mathbf{1 0 . 2 8}$ & $\mathbf{1 1 . 9 4}$ & $\mathbf{9 . 0 9}$ & $\mathbf{2 . 9 7}$ & $\mathbf{8 . 2 8}$ \\
\hline
\end{tabular}

The scenario analysis gives interesting insights to changes in the operational level with respect to change in the strategy level. It identifies the critical product/service values that needs to be revamped in order to increase the diffusion of EE technologies. Also, scenario analysis assists in formulating plans for specific technology endeavor. Some of the key findings from this analysis are:

- Identifying the Market Attribute where the technology is not performing well. For example, the DHP stood the test of scenario analysis till delivery \& infrastructure but when the relative weight of Legal and Institutional is increased the total MDP decreased which implies that there is room for improvement.

- Similarly, when a technology case goes up in rank with respect to MDP it means that it is performing well in that market attribute. For example, Solar water heater goes up by a rank when the weight of Legal and Institutional market attribute is increased. Codes and Standards have been identified as having the highest weight in the model 
among key components. Solar water heater exceeds performance efficiency and which is the reason for a relatively higher ranking from other technology cases.

- The other important finding from the scenario analysis is, even when the relative weight of a market attribute is increased the relative MDP decreases from status quo or reference case. For example, in case of Delivery and Infrastructure, MDP for all the technology cases decreased even when the relative weight of Delivery and Infrastructure is increased as it has the lowest relative weight among all the market attributes in the model.

\subsection{Generalizability of the Model}

The Market Diffusion Potential Model is developed to assess the diffusion potential of residential EE technologies and is applied to water heaters as technology cases. The model can be generalized in three frontiers.

Generalizability in different organizations: Twenty - four experts from different public, and private entities which include both energy and non-energy related organizations from across the U.S. participated in validating the model. This allows greater acceptance and applicability of the model in various organizational settings.

Generalizability for different EE technologies: The model can be applied to a variety of EE technologies used in residential as well as in commercial and industrial sectors as the tentative guideline on metrics for each key component for developing desirability curves gives the model greater flexibility and applicability to evaluate MDP. 
Generalizability in different states: The Model can be used in different states as experts from different states participated in validating, developing the desirability curves and evaluating the technology cases. Each desirability curve is based on metrics that provides the option for evaluating technology cases in different states irrespective of level of awareness, different climate zone, supply chain cost effectiveness, level of impact of trade allies, status of codes and standards, and pattern of incentive programs as well as for other key elements in the model. 


\section{CHAPTER 8: CONCUSION AND CONTRIBUTION}

This section of the report describes the conclusion of the study, and also, the theoretical and practical contribution from the study.

\subsection{Conclusion}

The research developed the MDP model to assess MDP of residential EE technologies. Five market attributes and twenty key components have been identified as the most important elements in assessing MDP of EE technologies. The relative weights of the market attributes and the key components are identified from experts' quantification. The model allows to identify low rating attributes in the model and helps to improve MDP by taking appropriate actions. Also, scenario analysis provides a snapshot of hypothetical situations that helps decision makers to realize what to expect in case of extreme market inclination to improve MDP of residential EE technologies.

\subsection{Contribution}

The research contributes in several ways to the knowledge bank on diffusion of residential EE technologies. Firstly, it provides the definition of different product/service values that can create market attributes through literature review. Secondly, the conceptual framework shows how the diffusion, customer satisfaction, fulfilled expectations and experience, product/service value and Market Diffusion Potential (MDP) are connected and one affects the other. Thirdly, it helps to assess the diffusion from market's perspective. Finally, it develops a generalized framework that can be used for assessing MDP of a wide variety of EE technologies and helps to identify areas for further research and insights. 


\subsubsection{Theoretical Contribution}

Theoretical contribution of the research is discussed in terms of originality of the study. Originality is supported by incremental contribution and revelatory contribution. Incremental contribution is how the research improves the existing theory about increasing diffusion of residential EE technologies while the revelatory contribution is improvement of the existing knowledge [385]. Table 55 shows the research gaps and contributions.

\section{Table 55: Research Gaps and Contributions}

\begin{tabular}{|c|c|}
\hline GAPS & Research Contributions \\
\hline $\begin{array}{l}\text { GAP 1: Residential EE technology adoption has } \\
\text { been analyzed from users' viewpoint but not from } \\
\text { the perspective of market that affects the potential of } \\
\text { diffusion. }\end{array}$ & $\begin{array}{l}\text { The model shows how the different market } \\
\text { attributes and key components affect diffusion and } \\
\text { can be used to measure diffusion potential of } \\
\text { residential EE technologies. }\end{array}$ \\
\hline $\begin{array}{l}\text { GAP 2: Different models analyze the effect of } \\
\text { drivers and barriers on adoption but do not quantify } \\
\text { the impact in the diffusion of residential EE } \\
\text { technologies. }\end{array}$ & $\begin{array}{l}\text { The desirability curves and quantified model } \\
\text { allows to consider both the impact of drivers and } \\
\text { barriers holistically by showing relative impacts or } \\
\text { weights. }\end{array}$ \\
\hline $\begin{array}{l}\text { GAP 3: Possible incentives, policy interventions, } \\
\text { and behavioral modifications are mostly based on the } \\
\text { subjective judgment of existing barriers and drivers } \\
\text { rather than objectively measuring the impact of these } \\
\text { actions on increasing diffusion. }\end{array}$ & $\begin{array}{l}\text { Identifying low rating attributes appropriate } \\
\text { actions are formulated to increase the market } \\
\text { diffusion potential that is measurable. Scenario } \\
\text { analysis shows the impact of different market } \\
\text { approach on diffusion potential of residential EE } \\
\text { technologies. }\end{array}$ \\
\hline
\end{tabular}




\subsubsection{Practical Contribution}

The results of the model can help in Programmatic Savings, Market Transformation as well as Non-Programmatic savings initiatives. The evaluation of MDP for EE technologies would be useful for program development, market transformation initiatives as well as feed invaluable information to a wide array of organizations with diversified interests in energy savings, climate change and sustainability.

\section{Programmatic Savings by Utility Programs}

The research found Market Diffusion Potential as one the most critical input for assessing emerging energy efficiency programs [167].

The different stages of a utility program to achieve energy saving target are shown in Figure

70.

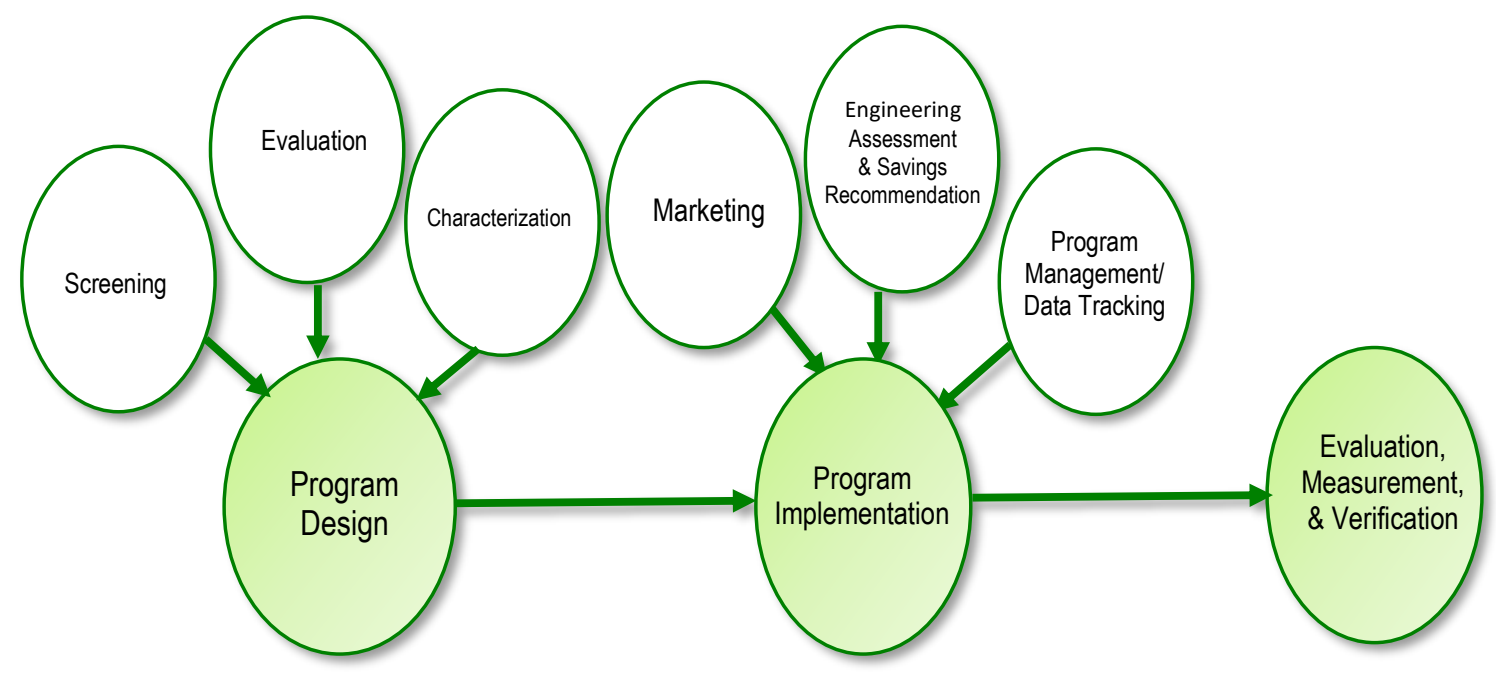

Figure 70: Different Activities in Utility Program Adoption 


\section{Program Design}

An initial plan that considers all important aspects needed for successful deployment of the program. The three steps in product design phase are:

Screening: Selection of EE technology based on technological potential.

Evaluation: Selection of EE technology based on technological, economic, environmental potential.

Characterization: Field tests are carried out for measure development.

Program Implementation

Implementation of program is intended to achieve desired energy savings within planned time and budget. The three phases in program implementation are:

Marketing: This phase involves promotion of the measure through awareness using various approaches.

Engineering Assessment \& Savings Recommendation: Based on energy audit, customized EE initiatives are prescribed at this phase.

Program Management/ Data Tracking: This phase involves smooth implementation of the program through disbursement of incentives, documenting savings and customer relation. Evaluation, Measurement, \& Verification

A thorough and concrete evidence of energy savings is needed to check on-going program as well as planning for future improvement. Energy audit to record kilowatts per hour or terms of saving ensures success of the program.

The present Market Diffusion Potential (MDP) model would help in selecting program alternative, program design and Implementation phase by identifying promising $\mathrm{EE}$ 
technologies in terms of consumers' utility, technological, economic, industry and legal potential. This would also help in taking appropriate actions for deployment.

\section{Programmatic Savings by Market Transformation}

Market transformation is a deliberate attempt to change the behavior of market that would accelerate the adoption of an EE technology. Market behavior is regulated by customers' perception and awareness, technological features, economic feasibility, competition and existing law and regulations. Market transformation helps to steer the desired diffusion of new technologies as well as technologies going through ordeal in penetrating the market [386]. The different tasks in a market transformation project is shown in Figure 71.

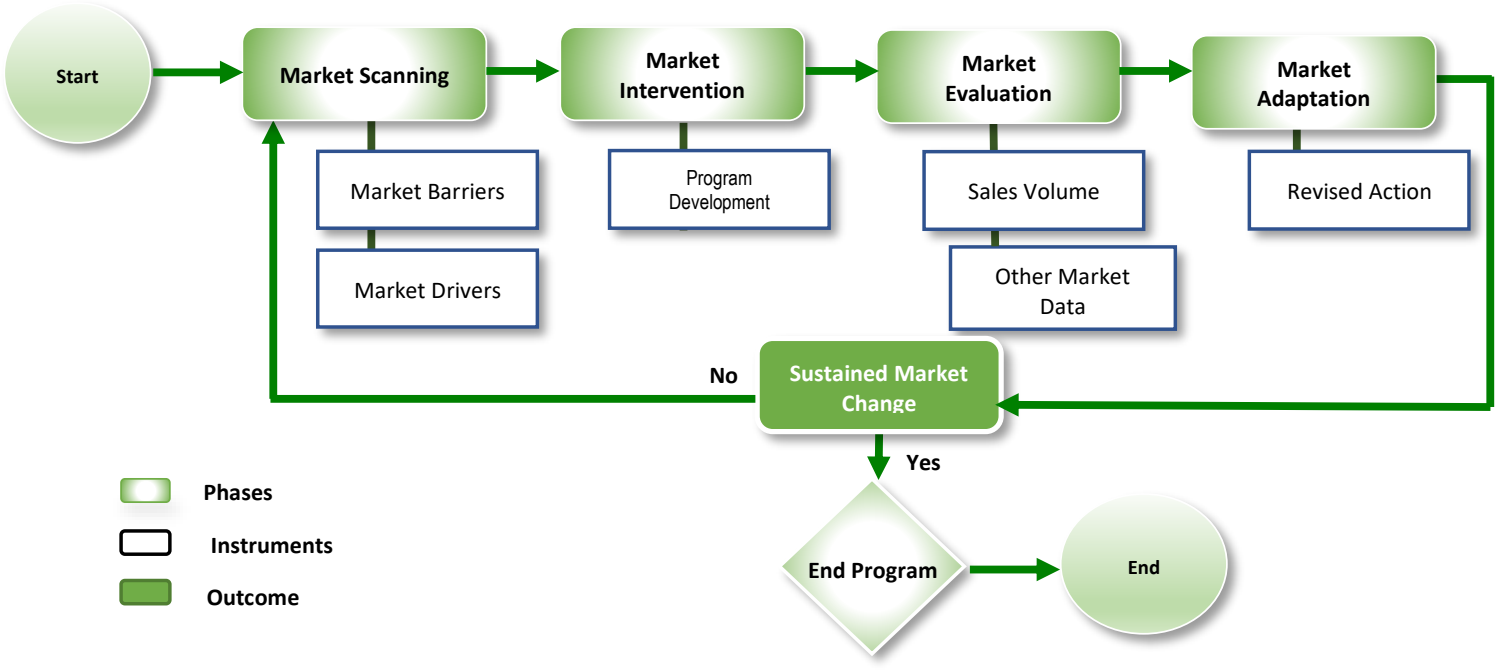

Figure 71: Market Transformation Cycle

Market Diffusion Potential Model would identify the barriers and drivers in terms of customers' benefit, technological, economic, delivery, and legal and institutional aspects. It would help to formulate appropriate programs to remove barriers and leverage existing 
drivers for new technologies. For existing technologies, it would allow to fine tune ongoing market intervention programs [171].

\section{Non-Programmatic Savings}

The "Technical energy saving potential" is the maximum savings achievable considering all technical constraints but ignoring cost consideration and market barriers. "Economic potential" is a subset of technical potential that considers cost effectiveness criteria. A more feasible saving potential is "Achievable economic potential" that considers the practicality and calculates potential that is achievable today or possible within the 20 years' time horizon [387]. According to Navigant study, by the year 2033 lighting and water heating has the prospect of saving $58 \%$ electric energy while heating and appliance measures can save $8 \%$ and $9 \%$ energy, cost effectively [388]. The Cost-Effective Achievable Potential (End Use) metric in the MDP model would enable to predict the potential savings by an EE technology.

The MDP model would also clarify the existing Codes and Standards. Institute of Electrical Efficiency (IECC) white paper predicts the potential savings by EE appliances [389][390]. The different categories of codes with percentage savings for residential sector would help to identify the potential savings by a technology or room for further efficiency improvement.

Based on the status quo of an EE technology, it would be possible to plan tax credits and other incentives. 


\section{R \& D Projects}

The results of evaluation of EE technologies by MDP model can also help as an input to BPA's Road mapping projects by identifying market drivers and R \& D scopes. It would help to understand the gaps in capability [391]. Results of consumers' utility, technological and industry potential would also unveil the opportunity of new innovations in component, equipment, enabling technology and system architecture [392]. R \& D aids in rescuing struggling EE technologies in the market. Electric Power Research Institute (EPRI) and Gas Technology Institute (GTI) and organization alike could use the results for individual or collaborative research in EE technologies.

Hence, to summarize, the results of the model would aid in determining energy performance standards, target setting, information diffusion, capacity building, public awareness, R \& D, financial assistance as well as investment decisions [115]. 


\section{CHAPTER 9: LIMITATION}

A major part of the current study uses experts' knowledge, expertise, experience and individuality to assess the elements that cannot be otherwise quantified. Despite careful planning, execution, monitoring and precision, the research is susceptible to the impact of inconsistency, disagreement, reliability, validity and bias. Steps are taken at different stages of the research process to minimize these effects and improve the quality of the research.

The preliminary model is developed through a small-scale Delphi survey that identifies market attributes and key components relevant to the diffusion of residential EE technologies. However, the number of market attributes and key components are screened due to the limitation of the number of criteria, sub criteria and alternatives that can be handled by MCDA.

The validation of the model is done with the decision rule of $2 / 3^{\text {rd }}$ majority of experts' acceptance. As knowledge is subjective, without consensus among experts there is always the doubt of leaving out or including elements in the model that may affect the validity and reliability of the model.

At the preliminary phase of expert identification, experts are identified using SNA and Bibliometric analysis. However, the identified experts are mostly in the academic field. To find practitioners in the field of EE, nonprobability sampling methods are used to find the knowledge rich person for the study. The limitation of this approach is the risk of including experts leaving out absolutist (only one expert can have the correct answer) or multiplist (it is not possible to ascertain which expert has the correct knowledge). To gather objective opinion from experts, strict selection criteria are set that includes but are not limited to 
Research profile, publication, professional affiliation, experience only, other appropriate qualitative and quantitative tools are also used to select experts.

Inconsistency and disagreement are checked and when the acceptable limit of 0.1 is exceeded, appropriate actions are taken.

Disagreement is managed by cluster analysis and recognizing different groups with diverging views. However, with HDM, we intend to accept final outcome based on consensus. Hence, it is not effective for situations where preference of different groups is important.

Debiasing approaches ae adopted as described in chapter 4 to minimize the effect of bias.

Also, the model may need to be adapted at different times depending on environmental uncertainties. In the event of the current Covid- 19 pandemic, the relative weights of the model could change due to unprecedented change in daily life. Consumers would be thinking about installing an EE appliance only in case of emergency replacement. There will not be many cases of installation of EE appliance in new buildings. Also, due to financial stress, it is expected that EE appliance would not be somewhere at the top of consumers priority list of expenditure. Presumably, the economic market attribute in the model could become more important from the existing model in the pandemic market situation. Codes and standards and incentives would be of lesser importance for institutions. However, because of social distancing consumers would prefer to buy appliances online rather than in-person. Delivery and installation would be challenging as people would not be very welcoming to allow installers work inside their homes. Hence, 
the weight of delivery and infrastructure could be more than legal and institutional market attribute. To summarize, the model is vulnerable to changes in the environment as explained through the example of the current pandemic situation. 


\section{CHAPTER 10: FUTURE RESEARCH}

This chapter provides few thoughts on possible research ideas based on the current research.

The future research recommendations are directed towards eliminating some of the limitations and also application of the model to different areas and fields.

As mentioned in the limitation part, selecting attributes in the model depends on the subjective judgment of experts. Criteria, sub criteria, desirability curves and alternatives for the HDM model can be generated by organizing workshops as it is done in identifying market drivers in technology road mapping. This provides the opportunity of sharing knowledge among experts, refining and reaching to a consensus that leads to a model more acceptable by different actors in the market.

The scenario analysis is performed by changing relative weights at the criteria level or market attributes. It would be interesting to use the scenario analysis at the performance level or key components for the research, to identify the scenario of the product/service value towards Market Diffusion Potential (MDP).

Each key component is tenable for further research and hence, HDM can be developed to get greater insight in these key components in the model for example, non-energy benefits, awareness, incentives and others.

Data Envelop Analysis (DEA) can be performed using the performance weights to analyze how dominated alternative can be moved to the efficient frontier. 
To summarize, there are ample opportunities of further research in residential EE technology diffusion by adapting, extending and modifying the MDP assessment model developed in this research. 


\section{REFERENCES}

[1] S. Bhattacharjee and A. P. Mccoy, "Energy Efficient Technology Diffusion Factors: A Systematic Review," Int. J. Sci. Eng. Res., vol. 3, no. 11, pp. 1-7, 2012.

[2] J. Darmstadter, "Recalling the Oil Shock of 40 Years Ago," Resour. Futur. Resour., no. December, p. 9, 2013.

[3] F. Bösch and R. Graf, "Reacting to anticipations: Energy crises and energy policy in the 1970s. An introduction," Hist. Soc. Res., vol. 39, no. 4, pp. 7-21, 2014.

[4] V. Schwarz and M. Alers, "Promoting Energy Efficiency in Buildings : Lessons Learned from InternationaL Experience," United Nations Dev. Program., vol. New York, 2009.

[5] R. Fouquet, "Lessons from energy history for climate policy," 2015.

[6] J. Li and R. E. Just, "Modeling household energy consumption and adoption of energy efficient technology," Energy Econ., vol. 72, pp. 404-415, 2018.

[7] M. Pierce, "Energy Efficiency," New Sci., vol. 175, no. 2362, p. 11, 2002.

[8] M. Lackner, Energy Efficiency: Comparison of Different Systems and Technologies, no. October. 2017.

[9] S. Pelin, "The Role and Importance of Energy Efficiency for Sustainable Development of the Countries The Role and Importance of Energy Ef fi ciency for Sustainable Development of the Countries," Researcgate, no. July, 2018.

[10] K. Engelund and K. B. Wittchen, "Cost-optimal levels," Concert. Action Energy Perform. Build., no. April, 2012.

[11] U.S. Energy Information Administration, "Today in Energy," 2020.

[12] AEE, "Advanced Energy Technology for GHG Reduction," Adv. Energy Econ., 2014.

[13] S. Nadel and G. Herndon, "The Future of the Utility Industry and the Role of Energy Efficiency," 2014 ACEEE Summer Study Energy Effic. Build., pp. 270-285, 2014.

[14] T. U. Daim, I. Iskin, T. Oliver, and J. Kim, "Chapter 5: Technology Roadmapping, An Efficient Tool for Driving Regional Technological Changes: Case of Energy Efficiency in the NorthWest US," in Sustainable Systems and Energy Management at the Regional Level: Comparative Approaches, 2012, pp. 348-364.

[15] H. Allcott and M. Greenstone, "Is There an Energy Efficiency Gap ?," J. Econ. Perspect., vol. 26, no. July, p. 38, 2012.

[16] Center for Sustainable Systems University of Michigan, "U . S . Energy System," 2019.

[17] EIA, "Buildings," U.S. Energy Inf. Adm., no. AEO2020, p. 20, 2019.

[18] J. A. S. Laitner, S. Nadel, R. N. Elliott, H. Sachs, and A. S. Khan, "The Long-Term Energy Efficiency Potential : What the Evidence Suggests," no. January, 2012.

[19] S. Nadel, N. Elliott, and T. Langer, "Energy Efficiency in the United States: 35 Years and Counting," Am. Counc. an Energy-Efficient Econ., no. June, 2015.

[20] IEA, “U.S. Energy-Related Carbon Dioxide Emissions, 2018," 2019.

[21] T. Houser and H. Pitt, "Preliminary US Emissions Estimates for 2019," Rhodium Group, 2020. .

[22] IRENA, Global energy transformation: A roadmap to 2050 (2019 edition). 2019.

[23] U.S. EIA, "Annual Energy Outlook 2019 with projections to 2050," Annu. Energy Outlook 2019 with Proj. to 2050, vol. 44, no. 8, pp. 1-64, 2019.

[24] World Business Council for Sustainable Development, "Transforming the Market," World 
Bus. Counc. Sustain. Dev., 2009.

[25] L. Ettenson, N. Long, N. Resources, and D. Council, "Market Transformation and Resource Acquisition : Challenges and Opportunities in California' s Residential Efficiency Lighting Programs What Is Market Transformation ?," ACEEE, pp. 51-63, 2010.

[26] C. Nelson and I. Smith, "Transforming the market for energy efficiency in Minneapolis: Recommendations for residential energy efficiency rating and disclosure," no. September, 2018.

[27] J. Jennings, N. Energy, E. Alliance, and M. Montgomery, "Collaborating with Architecture Firms to Influence Design of High Performance Buildings Overview of Firm Focus Strategy," pp. 113-124, 2010.

[28] K. Kieckhäfer, K. Wachter, and T. S. Spengler, "Analyzing manufacturers' impact on green products' market diffusion - the case of electric vehicles," J. Clean. Prod., vol. 162, pp. S11S25, 2017.

[29] A. L. Klingler, "Self-consumption with PV + Battery systems: A market diffusion model considering individual consumer behaviour and preferences," Appl. Energy, vol. 205, no. August, pp. 1560-1570, 2017.

[30] M. Moglia, S. Cook, and J. McGregor, "A review of Agent-Based Modelling of technology diffusion with special reference to residential energy efficiency," Sustain. Cities Soc., no. 31, pp. 173-182, 2017.

[31] J. Mills, Bradford \& Schleich, "Residential Energy-Efficient Technology Adoption, Energy Conservation, Knowledge, and Attitudes: An Analysis of European Countries," Energy Policy, vol. 49, pp. 616-628, 2012.

[32] K. F. Kee, "Adoption and Diffusion," in The International Encyclopedia of Organizational Communication, The Intern., file:///C:/Users/Momtaj/Desktop/EE Literature from SCOPUS/Product Value.pdf, Ed. JohnWiley \& Sons, Inc. Published 2017 by JohnWiley \& Sons, Inc., 2017, p. 15.

[33] E. M. Rogers, Diffusion of Innovations Third Edition. 1983.

[34] V. Carr Jr., "Technology adoption and diffusion," The Learning Center for Interactive Technology, 1999. [Online]. Available: icyte.com.

[35] C. A. Antonopoulos, "Diffusion of Energy Efficient Technology in Commercial Buildings: An Analysis of the Commercial Building Partnerships Program," PDXScholar, 2013.

[36] P. Lund, "Market penetration rates of new energy technologies," Energy Policy, vol. 34, no. 17, pp. 3317-3326, 2006.

[37] K. U. Rao and V. V. N. Kishore, "A review of technology diffusion models with special reference to renewable energy technologies," Renew. Sustain. Energy Rev., vol. 14, no. 3, pp. 1070-1078, 2010.

[38] International Federation of Red Cross and Red Crescent Societies, "Rapid assessment for markets: Guidelines for an inital emergency market assessment," 2014.

[39] R. Becqué et al., "Accelerating Building Efficiency: Eight Actions for Urban Leaders," pp. 1160, 2015.

[40] International Energy Agency, "Energy Efficiency Market Report 2013," ENERGY Effic. 2013 Mark. Trends Mediu. Prospect. Mark. Rep., 2013.

[41] Department of Economic and Social Affairs, "Case Studies of Market Transformation Energy Efficiency and Renewable Energy Case Studies of Market Transformation Energy Efficiency and," United Nations, Dep. Econ. Soc. Aff., 2007. 
[42] D. Ürge-Vorsatz and J. Hauff, "Drivers of market trasformation towards energy efficiency: Analysis of a case study," Proc. ACEEE Summer Study Energy Effic. Build., vol. 6, pp. 6403$6415,2000$.

[43] M. I. Shioka and W. T. Ana, "Management Concept of Product and Service Value," Innov. Supply Chain Manag., vol. 9, no. 1, pp. 11-16, 2015.

[44] K. J. Mach, M. D. Mastrandrea, P. T. Freeman, and C. B. Field, "Unleashing expert judgment in assessment," Glob. Environ. Chang., vol. 44, pp. 1-14, 2017.

[45] D. Huitt, W., Hummel, J., \& Kaeck, "Assessment, Measurement, Evaluation \& Research," Educational Psychology Interactive. Valdosta, GA, 2001. [Online]. Available: http://www.edpsycinteractive.org/.

[46] Ponto Julie, "Understanding and Evaluating Survey Research," J. Adv. Pract. Oncol., vol. 6, no. 2, pp. 168-71, 2015.

[47] Arevik Avedian, "Survey Design," Harvard Law Sch., 2014.

[48] B. H. Hall, "Innovation and Diffusion," no. October, pp. 1-47, 2003.

[49] P. Balachandra, B. S. Reddy, and P. Balachandra, "Commercialisation of Sustainable Energy Technologies," no. November, 2007.

[50] R. P. DeGroot, Features - Advantages - Benefits: The Persuasive Language of Selling. 2012.

[51] G. Saward, V. Ambrosiadou, and S. Polovina, "A FAB Approach to E-Commerce Knowledge Accessibility Requirements," ResearchGate, no. April, 2014.

[52] Team Coaching International, "Features, Advantages and Benefits ( FAB ) Exercise," 2016.

[53] B. M. Muradovich, "Conceptual aspects of Marketing Readiness Level assessment model," Glob. J. Eng. Sci. Res. Manag., vol. 4, no. 10, pp. 34-44, 2017.

[54] N. Bogdan, "Consumers products and services value perception," no. May, 2014.

[55] P. Kotler and K. L. Keller, Marketing Management, Global. Pearson Education Limited, 2010.

[56] K. Lorette, "Marketing Plan for a New Product Launch," OAMK, pp. 5-66, 2012.

[57] M. M. Lele and U. Karmarkar, "Good Product Support Is Smart Marketing," Harv. Bus. Rev., no. November, p. 2, 1983.

[58] P. Kotler and G. Armstrong, "Principles of Marketing," World Wide Web Internet Web Inf. Syst., p. 785, 2010.

[59] Su-Mei Lin, "Marketing mix (7P) and performance assessment of Western fast food industry in Taiwan: An application by associating DEMATEL (Decision making Trial and Evaluation Laboratory) and ANP (Analytic Network Process)," African J. Bus. Manag., vol. 5, no. 26, pp. 10634-10644, 2011.

[60] M. Rafiq and P. K. Ahmed, "Using the 7Ps as a generic marketing mix," Mark. Intell. Plan., vol. 13, no. 9, pp. 4-15, 1995.

[61] A. Dickson, E. K. Hussain, and A.-A. Joe, "Theoretical and conceptual framework: Mandatory ingredients of a quality research," Int. J. Sci. Res., vol. 7, no. 1, pp. 438-441, 2018.

[62] B. H. Hall and B. Khan, "Adoption of New Technology," New Econ. Handb., no. May, pp. 138, 2003.

[63] S. A. Aulia, I. Sukati, and Z. Sulaiman, "A Review: Customer Perceived Value and its Dimension," Asian J. Soc. Sci. Manag. Stud., vol. 3, no. 2, pp. 150-162, 2016.

[64] J. T. Gourville, "Note on Innovation Diffusion: Rogers' Five Factors.," Harvard Bus. Sch. Cases, no. 502, pp. 1-6, 2006. 
[65] L. V. Wood, "Engaging the New Energy Consumer," Electr. Perspect., pp. 1-39, 2010.

[66] PwC, "Customer engagement in an era of energy transformation," 2016.

[67] G. E. Okudan, M.-C. Chiu, and T.-H. Kim, "Perceived feature utility-based product family design: a mobile phone case study," J. Intell. Manuf., vol. 24, no. 5, pp. 935-949, 2013.

[68] D. D. Morar, "An overview of the consumer value literature - perceived value, desired value," Int. Conf. "Marketing - from Inf. to Decis. 6th Ed., no. November 2013, pp. 169186, 2013.

[69] J. K. Turner, "Building a Successful Sales Story Business-to-Business Sales Use FAB ( Features , Advantages , Benefits )," 2012.

[70] X. Wei, A. Kusiak, M. Li, F. Tang, and Y. Zeng, "Multi-objective optimization of the HVAC (heating, ventilation, and air conditioning) system performance," Energy, vol. 83, pp. 294306, 2015.

[71] N. Kok, M. McGraw, and J. M. Quigley, "The diffusion of energy efficiency in building," Am. Econ. Rev., vol. 101, no. 3, pp. 77-82, 2011.

[72] I. Navigant Consulting, "Updated Buildings Sector Appliance and Equipment Costs and Efficiency," 2016.

[73] G. T. B. Lasseur, "The Rate of Diffusion of Innovations," no. July, 2011.

[74] Moore A. Geoffrey, Crossing The Chasm [Revised Edition]. 2001.

[75] I. \& Iskin and T. Daim, "Adoption of Energy Efficient Technologies from a Demand Side Management Barriers and Policy tools," 2014.

[76] I. M. Hoffman et al., "The Total Cost of Saving Electricity through Utility Customer-Funded Energy Efficiency Programs: Estimates at the National , State , Sector and Program Level," 2015.

[77] R. Gold, C. Waters, and D. York, "Leveraging Advanced Metering Infrastructure to Save Energy | ACEEE," Energise 2020 Energy Innov. a Sustain. Econ. Pap. Proceedings. New Delhi 2020 Alliance an Energy Effic. Econ., no. 202, pp. 349-356, 2020.

[78] S. De la Rue du Can, G. Leventis, A. Phadke, and A. Gopal, "Design of incentive programs for accelerating penetration of energy-efficient appliances," Energy Policy, vol. 72, pp. 5666, 2014.

[79] M. L. T. Cossio et al., "Lighting the way: Perspectives on the global lighting market," Mc Kinsey Co., 2011.

[80] U.S. Department of Energy, "Energy Efficiency Trends in Residential and Commercial Buildings," Energy, no. October, pp. 1-32, 2008.

[81] C. J. Andrews and U. Krogmann, "Technology diffusion and energy intensity in US commercial buildings," Energy Policy, vol. 37, no. 2, pp. 541-553, 2009.

[82] B. S. Reddy, "Barriers and drivers to energy efficiency - A new taxonomical approach," Energy Convers. Manag., vol. 74, pp. 403-416, 2013.

[83] W. J. Fisk, "Health and Productivity G Ains From B Etter Indoor E Nvironments and Their Relationship With Building Energy E Fficiency," Annu. Rev. Energy Environ., vol. 25, pp. 537-66, 2000.

[84] L. Edwards and P. Torcellini, "A Literature Review of the Effects of Natural Light on Building Occupants," Nrel/Tp-550-30769, no. July, p. 58, 2002.

[85] M. Younger, H. R. Morrow-Almeida, S. M. Vindigni, and A. L. Dannenberg, "The Built Environment, Climate Change, and Health. Opportunities for Co-Benefits," Am. J. Prev. Med., vol. 35, no. 5, pp. 517-526, 2008. 
[86] US dept of Energy, "Energy Efficiency Makes Homes More Affordable," Energy Tech. Bull., pp. 1-4, 1998.

[87] E. M. Trisko, "Energy Expenditures by American Families Energy Expenditures as Percentage of Household Executive Summary," Electr. ACCCE(American Coalitionfor Clean Coal, no. April 2016, 2016.

[88] L. Ryan and N. Campbell, "Spreading the net: the multiple benefits of energy efficiency improvements," Int. Energy Agency, no. May, 2012.

[89] International Energy Agency, "Capturing the Multiple Benefits of Energy Efficiency: Executive Summary," IEA, pp. 18-25, 2014.

[90] G. Heffner and N. Campbell, "Evaluating the co-benefits of low-income energy-efficiency programmes," Environment, no. January, pp. 27-28, 2011.

[91] J. Freire-González, D. Font Vivanco, and I. Puig-Ventosa, "Economic structure and energy savings from energy efficiency in households," Ecol. Econ., vol. 131, pp. 12-20, 2017.

[92] W. Steinhurst and V. Sabodash, "The Jevons Paradox and Energy Efficiency," Energy, vol. 5, no. 1, pp. 69-79, 2011.

[93] A. Leiserowitz et al., "Saving Energy at Home and on the Road: A Survey of Americans' Energy Saving Behaviors, Intentions, Motivations, and Barriers," Yale Proj. Clim. Chang., no. 703, pp. 1-47, 2009.

[94] M. H. Smith, "Doubling Energy \& Resource Productivity by 2030 -," pp. 1-33, 2015.

[95] ACEEE, "How Does Energy Efficiency Create Jobs? Fact Sheet," pp. 1-2, 2011.

[96] S. Shrestha, Comparison of Energy Efficient and Green Buildings: Technological and Policy Aspects with Case Studies from Europe, the USA, India and Nepal. Universitätsverlag der TU, 2016.

[97] IEA, "Insight into energy labels," 2017.

[98] E. Alexandri et al., "The Macroeconomic and Other Benefits of Energy Efficiency," 2016.

[99] OECD/IEA, "Energy efficiency market report 2016," 2016.

[100] C. Taylor, B. Hedman, A. Goldberg, and S. Glatt, "Price Effects of Energy Efficiency: Does More Industrial EE Equal Lower Energy Prices for All?," ACEEE Summer Study Energy Effic. Ind., pp. 1-12, 2015.

[101] European Policy Centre, "Access to clean and efficient energy in developing countries: The need for EU action to implement SDG7," 2017.

[102] OECD, "Research Co-operation between Developed and Developing Countries in the Area of Climate Change Adaptation and Biodiversity," 2014.

[103] T. D. Gerarden, R. G. Newell, and R. N. Stavins, "Assessing the Energy-Efficiency Gap," Natl. Bur. Econ. Res. Work. Pap. Ser., no. January, pp. 1-74, 2015.

[104] J. Palm and K. Reindl, "Understanding barriers to energy-efficiency renovations of multifamily dwellings," Energy Effic., 2017.

[105] O. Jridi, M. Jridi, S. A. Barguaoui, and F. Z. Nouri, "Energy paradox and political intervention: A stochastic model for the case of electrical equipments," Energy Policy, vol. 93, no. September, pp. 59-69, 2016.

[106] M. Arens, E. Worrell, and W. Eichhammer, "Drivers and barriers to the diffusion of energyefficient technologies - a plant-level analysis of the German steel industry," Energy Effic., vol. 10, no. 2, pp. 441-457, 2017.

[107] K. Gillingham, D. Rapson, and G. Wagner, "The rebound effect and energy efficiency policy," Rev. Environ. Econ. Policy, vol. 10, no. 1, pp. 68-88, 2016. 
[108] M. Croucher, "Potential problems and limitations of energy conservation and energy efficiency," Energy Policy, vol. 39, no. 10, pp. 5795-5799, Oct. 2011.

[109] I. Hengstenberg, "D 2.3 : List of most effective energy saving measures in office buildings," pp. 1-20, 2016.

[110] C. E. Anthony and D. Del Bueno, "A performance-based development system," Nurs. Manage., vol. 24, no. 6, pp. 32-34, 1993.

[111] S. Radas, "Diffusion Models in Marketing: How to Incorporate the Effect of External Influence?," Econ. Trends Econ. Policy, vol. 15, no. 105, pp. 30, 30-51, 51, 2006.

[112] D. Chandrasekarn and G. Tellis, "A Critical Review of Marketing Research on Diffusion of New Products," Rev. Mark. Res., vol. 3, no. 1, pp. 39-80, 2007.

[113] J. McWhorter, "A study of early adopters of innovation," Univ. Alabama Birmingham, ProQuest Diss. Publ., p. 24, 2012.

[114] S. Detrow, "Energy-Efficiency Efforts May Not Pay Off," Scientific America, 2015.

[115] K.-H. Lee, "Drivers and Barriers to Energy Efficiency Management for Sustainable Development," Sustain. Dev., vol. 23, no. 1, pp. 16-25, 2015.

[116] E. Cagno and A. Trianni, "Exploring drivers for energy efficiency within small- and mediumsized enterprises: First evidences from Italian manufacturing enterprises," Appl. Energy, vol. 104, pp. 276-285, 2013.

[117] G. Hochman and G. R. Timilsina, "Energy efficiency barriers in commercial and industrial firms in Ukraine : An empirical analysis," vol. 63, pp. 22-30, 2017.

[118] B. S. Reddy, "Overcoming the energy efficiency gap in India's household sector," Energy Policy, vol. 31, no. 11, pp. 1117-1127, 2003.

[119] E. Ó Broin, É. Mata, J. Nässén, and F. Johnsson, "Quantification of the energy efficiency gap in the Swedish residential sector," Energy Effic., vol. 8, no. 5, pp. 975-993, 2015.

[120] M. DeGusta, "Business Report Are Smart Phones Spreading Faster than Any Technology in Human History?," 2012.

[121] R. Gross, R. Hanna, A. Gambhir, P. Heptonstall, and J. Speirs, "How long does innovation and commercialisation in the energy sectors take ? Historical case studies of the timescale from invention to widespread commercialisation in energy supply and end use technology," Energy Policy, vol. 123, no. October, pp. 682-699, 2018.

[122] D. Comin and B. Hobijn, "Lobbis and Technology Diffusion," Rev. Econ. Stat., vol. 91, no. 2, pp. 229-244, 2009.

[123] N. Kok, M. McGraw, and J. M. Quigley, "The diffusion over time and space of energy efficiency in building," Ann. Reg. Sci., vol. 48, no. 2, pp. 541-564, 2012.

[124] L. X. W. Hesselink, "Adoption of Residential Energy Efficient Technologies: a Review on Agent Based Modeling Studies," 2017.

[125] J. A. Moya, "A Natural Analogy to the Diffusion of Energy-Efficient Technologies," Energies, vol. 9, no. 6, p. 471, 2016.

[126] N. Ã. Nagesha and P. Balachandra, "Barriers to energy efficiency in small industry clusters : Multi-criteria-based prioritization using the analytic hierarchy process," vol. 31, pp. 19691983, 2006.

[127] B. B. Sergio and J. G. Vanegas, "Rank of barriers to energy efficiency: The case of microenterprises from Medellín, Colombia," Annu. Int. Conf. Am. Soc. Eng. Manag. 2012, ASEM 2012 - Agil. Manag. Embrac. Chang. Uncertain. Eng. Manag., no. October 2012, pp. 116-122, 2012. 
[128] A. Soepardi and P. Thollander, "Analysis of relationships among organizational barriers to energy efficiency improvement: A case study in Indonesia's steel industry," Sustain., vol. 10, no. 1, 2018.

[129] P. Gupta, S. Anand, and H. Gupta, "Developing a Roadmap to Overcome Barriers to Energy Efficiency in Buildings Using Best Worst Method," Sustain. Cities Soc., vol. 31, pp. 244-259, 2017.

[130] C. Van Aerschot, "Barriers to Greater Energy Efficiency within the Building Industry," 2008 ACEEE Summer Study Energy Effic. Build., pp. 342-353, 2008.

[131] T. Häkkinen and K. Belloni, "Barriers and drivers for sustainable building," Build. Res. Inf., vol. 39, no. 3, pp. 239-255, 2011.

[132] G. R. Timilsina, G. Hochman, and I. Fedets, "Understanding energy efficiency barriers in Ukraine: Insights from a survey of commercial and industrial firms," Energy, vol. 106, no. July, pp. 203-211, 2016.

[133] T. L. Saaty and M. Ozdemir, "Negative priorities in the analytic hierarchy process," Math. Comput. Model., vol. 37, no. 9-10, pp. 1063-1075, 2003.

[134] A. H. I. Lee, "A fuzzy supplier selection model with the consideration of benefits, opportunities, costs and risks," Expert Syst. Appl., vol. 36, no. 2 PART 2, pp. 2879-2893, 2009.

[135] J. Anund, P. Lundqvist, and J. Arias, "Categorizing barriers to energy efficiency in buildings," Energy Procedia, vol. 75, no. 0, pp. 2839-2845, 2015.

[136] V. Beillan, E. Battaglini, A. Goater, and A. Huber, "Barriers and drivers to energy-efficient renovation in the residential sector: Empirical findings from five European countries," ECEEE Rep., pp. 1083-1093, 2011.

[137] ACNEEP, "The History of Energy Efficiency," 2013.

[138] ACEEE, "Overcoming Market Barriers And Using Market Forces to Advance Energy Efficiency," 2013.

[139] T. Wang, X. Li, P.-C. Liao, and D. Fang, "Building energy efficiency for public hospitals and healthcare facilities in China: Barriers and drivers," Energy, no. 103, pp. 588-597, 2016.

[140] Y. Qiu, G. Colson, and C. Grebitus, "Risk preferences and purchase of energy-efficient technologies in the residential sector," Ecol. Econ., vol. 107, pp. 216-229, 2014.

[141] K. R. Cowan and T. U. Daim, "Understanding Adoption of Energy Efficiency Technologies: Applying Behavioral Theories of Technology Acceptance \& Use to Understand the Case of LED Lighting for Commercial, Residential, and Industrial End-Users," in 2011 Proceedings of PICMET '11: Technology Management in the Energy Smart World (PICMET), 2011, pp. 1-9.

[142] A. Barbu, N. Griffiths, and G. Morton, Achieving energy efficiency through behaviour change: what does it take?, no. 5. 2013.

[143] S. Nižetić, "Realisation barriers in energy efficiency projects in Croatian public buildings: a critic overview and proposals," Int. J. Sustain. Energy, pp. 1-13, 2016.

[144] C. I. Goodier and K. Chmutina, "Non-technical barriers for decentralised energy and energy efficient buildings," Int. J. Energy Sect. Manag., vol. 8, no. 4, pp. 544-561, 2014.

[145] Y. Zhang and Y. Wang, "Barriers' and Policies' Analysis of China's Building Energy Efficiency," Energy Policy, no. 62, pp. 768-773, 2013.

[146] K. H. Chai and C. Yeo, "Overcoming energy efficiency barriers through systems approachA conceptual framework," Energy Policy, vol. 46, pp. 460-472, 2012. 
[147] Y. Asayama and B. Limmeechokchai, "Policies and Measures to Remove Energy Efficiency Barriers in Thai Buildings toward NAMAs," no. March, pp. 19-21, 2014.

[148] L. D. Anadon, "Increasing Residential Building Energy Efficiency in China An Evaluation of Policy Instruments," 2016.

[149] National Academy of Sciences; National Academy of Engineering, Real Prospects for Energy Efficiency in the United States. 2008.

[150] R. D. Van Buskirk, "Estimating Energy Efficiency Technology Adoption Curve Elasticity with Respect to Government and Utility ...," no. April 2014, 2015.

[151] V. Costantini, F. Crespi, G. Orsatti, and A. Palma, "Policy Inducement Effects in Energy Efficiency Technologies. An Empirical Analysis of the Residential Sector," Green Energy Technol., vol. 164, pp. 201-232, 2015.

[152] A. Palmer, "Customer experience management: A critical review of an emerging idea," J. Serv. Mark., vol. 24, no. 3, pp. 196-208, 2010.

[153] M. J. Rotheram-Borus and N. Duan, "Next generation of utility customers," J. Am. Acad. Child Adolesc. Psychiatry, vol. 42, no. 5, 2003.

[154] B. Mills and J. Schleich, "What's Driving Energy Efficient Appliance Label Awareness and Purchase Propensity?," Energy Policy, no. 38, pp. 814-825, 2010.

[155] N. Kostora, "Awareness, versatility driving hydronics market," Airconditioning, heating and refrigeration news, pp. 14-15, 2015.

[156] C.-S. Tan, H.-Y. Ooi, and Y.-N. Goh, "A moral extension of the theory of planned behavior to predict consumers' purchase intention for energy-efficient household appliances in Malaysia," Energy Policy, no. 107, pp. 459-471, 2017.

[157] by Bryan Urban, K. Roth, and C. Harbor, "Energy Savings from Five Home Automation Technologies: A Scoping Study of Technical Potential Final Report to the Consumer Technology Association," no. April, 2016.

[158] N. Economides, "Notes for microecomics," 2015.

[159] P. Šujanová, M. Rychtáriková, T. S. Mayor, and A. Hyder, "A Healthy, Energy-Efficient and Comfortable Indoor Environment, a Review," Energies, pp. 1-37, 2019.

[160] W. Salmon, C. Turner, S. Analyst, and B. Owens, "Energy Performance of LEED ${ }^{\circledR}$ for New Construction Buildings," 2008.

[161] Å. L. Hauge, J. Thomsen, and T. Berker, "User evaluations of energy efficient buildings: Literature review and further research," Adv. Build. Energy Res., vol. 5, no. 1, pp. 109-127, 2011.

[162] Sandy Bond, "Californian Realtors' Perceptions towards Energy-Efficient 'Green' Housing," J. Sustain. Real Estate, vol. 7, no. 1, pp. 134-159, 2015.

[163] R. Kamasak, "The contribution of tangible and intangible resources, and capabilities to a firm's profitability and market performance," Eur. J. Manag. Bus. Econ., vol. 26, no. 2, pp. 252-275, 2017.

[164] R. Othman, R. Arshad, N. A. Aris, and S. M. M. Arif, "Organizational Resources and Sustained Competitive Advantage of Cooperative Organizations in Malaysia," Procedia Soc. Behav. Sci., vol. 170, pp. 120-127, 2015.

[165] A. Rasheed and I. A. Manarvi, "A Framework of Technology Diffusion in Aircraft Manufacturing Industry Environment," Proc. Int. MultiConference Eng. Comput. Sci., vol. II, pp. 19-21, 2008.

[166] R. Caiazza and T. Volpe, "Innovation and its diffusion: process, actors and actions," Technol. 
Anal. Strateg. Manag., vol. 29, no. 2, pp. 181-189, 2017.

[167] I. Iskin and T. U. Daim, "An assessment model for energy efficiency program planning in electric utilities: Case of Northwest U.S.," Sustain. Energy Technol. Assessments, vol. 15, pp. 42-59, 2016.

[168] ACEEE, "Evaluation, Measurement \& Verification," 2017.

[169] BPA (Bonneville Power Administration), "Energy Efficiency Asset Management Strategy," 2014.

[170] Bonneville Power Administration, "Overview of Momentum Savings," 2015.

[171] NEEA, "NEEA's Definition of Market Transformation," 2017.

[172] L. Berkeley, E. Reliability-, E. Policy, T. Assistance, and U. S. E. P. Agency, "Setting Baselines for Planning and Evaluation of Efficiency Programs," 2016.

[173] C. Cobb and L. Gage, "Non-programmatic Savings," 2014.

[174] D. M. Violette and P. Rathbun, "Estimating Net Savings - Common Practices," 2017.

[175] BPA, "Methodology for Quantifying Market- Induced , Non-Programmatic Savings," 2011.

[176] M. T. Johansson and P. Thollander, "A review of barriers to and driving forces for improved energy efficiency in Swedish industry- Recommendations for successful in-house energy management," Renew. Sustain. Energy Rev., vol. 82, no. September 2017, pp. 618-628, 2018.

[177] X. et al. Cole, J.C., McDonald, J.B., Wen, "Marketing energy efficiency: perceived benefits and barriers to home energy efficiency," Energy Effic., vol. 11, no. 7, pp. 1811-1824, 2018.

[178] N. Shah, A. Phadke, E. Energy, and T. Division, "Country Review of Energy- Efficiency Financial Incentives in the Residential Sector," no. May, pp. 583-594, 2011.

[179] M. A. Cahn, S. Kamieniecki, D. McCain-Tharnstrom, and D. Fiack, "Bureaucracy and Politics of Energy and Environmental Policy in the Western States," in Environmental Politics and Policy in the West, Third Edition, 2017, p. 224.

[180] D. M. Gromet, H. Kunreuther, and R. P. Larrick, "Political ideology affects energy-efficiency attitudes and choices," PNAS, vol. 110, no. 23, pp. 9314-9319, 2013.

[181] T. Dietz, C. Leshko, and A. M. Mccright, "Politics shapes individual choices about energy efficiency," PNAS, vol. 110, no. 23, pp. 9191-9192, 2013.

[182] R. Bartlett et al., "Affordable Energy-Efficient New Housing Solutions," no. May, 2012.

[183] W. Goetzler, R. Zogg, J. Young, and J. Schmidt, "Energy Savings Potential and Research, Development, \& Demonstration Opportunities for Residential Building Heating, Ventilation , and Air Conditioning Systems," no. October, pp. 1-265, 2012.

[184] S. Dunn, "Cold Climate Air-Source Heat Pumps: An Innovative Technology to Stay Warm in Winter and Cool in Summer," Office of Energy Efficiency \& Renewable Energy, 2016. .

[185] D. Austin, "Addressing Market Barriers to Energy Efficiency in Buildings," no. February 2010, 2012.

[186] The National Academy Press, Real Prospects for Energy Efficiency in the United States. 2010.

[187] P. Szuppinger and É. Csobod, "Principles of Energy Efficient Planning," 2011.

[188] California Energy Commission, "Existing Buildings Energy Efficiency Action Plan California's Existing Buildings Energy Efficiency Action Plan," 2015.

[189] I. Yüksek and T. T. Karadayi, "Building Life Cycle Energy-Efficient Building Design in the Context of Building Life Cycle," in INTECHOPEN, 2017, p. 33.

[190] International Energy Agency, "Technology Roadmap for energy-efficient buildings," 2011. 
[191] V. Vakiloroaya, B. Samali, A. Fakhar, and K. Pishghadam, "A review of different strategies for HVAC energy saving," Energy Convers. Manag., vol. 77, pp. 738-754, 2014.

[192] F. Belic, Z. Hocenski, and D. Sliskovic, "HVAC control methods - A review," 2015 19th Int. Conf. Syst. Theory, Control Comput. ICSTCC 2015 - Jt. Conf. SINTES 19, SACCS 15, SIMSIS 19, pp. 679-686, 2015.

[193] R. Hart, "Introduction to Commercial Building HVAC Systems and Energy Code Requirements," Pacific Northwest Natl. Lab., p. 63, 2016.

[194] R. Ahmad, S. P. Srivastava, R. Maurya, S. M. Rajendran, K. R. Arya, and A. K. Srivastava, "Complex HVAC," Int. Code Counc., vol. 1, no. 5, pp. 1-6, 2008.

[195] J. Heller and D. Auer, "HVAC Technologies in Multifamily Buildings," 2016.

[196] S. N. Teli and V. Majali, "Review Paper on Energy Efficiency Technologies for Heating, Ventilation and Air Conditioning (HVAC)," Int. J. Sci. Eng. Res., no. June 2017, 2015.

[197] Pacific Northwest Energy Star, "Residential Ducted Heat Pump Program Information," 2017.

[198] S. Kärkkäinen and E. Oy, "Heat pumps for cooling and heating," Int. Energy Agency DemandSide Manag. Program., p. 66, 2011.

[199] Public Service Department, "Heat Pump Report," 2015.

[200] GIACOMINI, "Radiant Ceiling Systems," 2015.

[201] UNEP, "Accelerating the Global Adoption of Energy-Efficient Lighting," 2017.

[202] Energy Star, "The Light Bulb Revolution," 2017.

[203] S. H. Jones and E. Efficiency, "Research and Development for water heating technologies," no. January, pp. 61-71, 2004.

[204] N. R. C. Navigant Consulting Inc.cademy of Sciences, National Academy of Engineering, "EIA- Technology Forecast Updates - Residential and Commercial Building Technologies Reference Case," 2008.

[205] C. E. Roy, "Heating systems heating systems," ASHRAE J., vol. 51, no. 9, pp. 54-70, 2009.

[206] Energy Star, "Three System Types To Meet Your Needs," 2007.

[207] K. Brozyna and A. Rapport, "Measure Guideline: Transitioning to a Tankless Water Heater," NREL, no. September, 2012.

[208] J. Gagliano and P. Systems, "Residential Water Heaters," NREL, p. 44, 2011.

[209] SuperEffiicient.org, "Heat Pump Water Heaters :Summary and Comparison of International Test Standards," no. June 2013, 2013.

[210] W. Berg et al., "The 2019 State Energy Efficiency Scorecard," ACEEE, no. October, 2019.

[211] Massachusetts Department of Energy Resources, "Massachusetts Comprehensive Energy Plan," 2018.

[212] R. Bain, "Driving Energy Efficiency in the Public Sector - A Model for Success," ACEEE, pp. 1-12, 2016.

[213] A. Webb and H. Lee, "Northwest Ductless Heat Pump Initiative: Market Progress Evaluation \# 8 Prepared For NEEA : Prepared by :," 2019.

[214] J. Lorentzen, H. Rogers, and S. Zhang, "An Examination of the US Residential Heating Market," 2018.

[215] R. Kumar, Research Methodology, 3rd ed. SAGE Publications Ltd., 2011.

[216] S. Goundar, "Chapter 3 - Research Methodology and Research Method," Researcgate, no. May, p. 43, 2019.

[217] A. Kumar et al., "A review of multi criteria decision making (MCDM) towards sustainable 
renewable energy development," Renew. Sustain. Energy Rev., vol. 69, no. June 2016, pp. 596-609, 2017.

[218] M. Moglia, D. Kinsman, and S. Maheepala, "Multi-Criteria Decision Assessment Methods to Identify Total Water Cycle Management Strategies," 2012.

[219] E. K. Zavadskas, K. Govindan, J. Antucheviciene, and Z. Turskis, "Hybrid multiple criteria decision-making methods: A review of applications for sustainability issues," Econ. Res. Istraz., vol. 29, no. 1, pp. 857-887, 2016.

[220] R. J. Clarke, "Research models and methodologies," HDR Semin. Ser. Fac. Commer. Univ. Wollongong, pp. 1-65, 2005.

[221] A. Mardani, A. Jusoh, K. Nor, Z. Khalifah, and A. Valipour, "Multiple criteria decision-making techniques and their applications - a review of the literature from 2000 to 2014," Econ. Res. Istraživanja, vol. 28, no. 1, pp. 516-571, 2015.

[222] L. M. D. V. Terrientes, "Hierarchical outranking methods for multi-criteria decision aiding," no. May, p. 164, 2015.

[223] Ermatita, Sri Hartati, R. Wardoyo, and A. Harjoko, "Electre Methods in Solving Group Decision Support System Bioinformatics on Gene Mutation Detection Simulation," Int. J. Comput. Sci. Inf. Technol., vol. 3, no. 1, pp. 40-52, 2011.

[224] M. G. Yücel and A. Görener, "Decision Making for Company Acquisition by ELECTRE Method," Int. J. Supply Chain Manag., vol. 5, no. 1, pp. 75-83, 2016.

[225] F. Tscheikner-Gratl, P. Egger, W. Rauch, and M. Kleidorfer, "Comparison of multi-criteria decision support methods for integrated rehabilitation prioritization," Water (Switzerland), vol. 9, no. 2, 2017.

[226] A. Kolios, V. Mytilinou, E. Lozano-Minguez, and K. Salonitis, "A comparative study of multiple-criteria decision-making methods under stochastic inputs," Energies, vol. 9, no. 7, pp. 1-21, 2016.

[227] T. Ding, L. Liang, M. Yang, and H. Wu, "Multiple Attribute Decision Making Based on CrossEvaluation with Uncertain Decision Parameters," Math. Probl. Eng., vol. 2016, 2016.

[228] A. R. Fallahpour and A. R. Moghassem, "Evaluating applicability of VIKOR method of multicriteria decision making for parameters selection problem in rotor spinning," Fibers Polym., vol. 13, no. 6, pp. 802-808, 2012.

[229] A. Mardani, E. K. Zavadskas, K. Govindan, A. A. Senin, and A. Jusoh, "VIKOR technique: A systematic review of the state of the art literature on methodologies and applications," Sustain., vol. 8, no. 1, pp. 1-38, 2016.

[230] E. K. Zavadskas and Zenonas Turskis, "Multiple criteria decision making (MCDM) methods in economics: An overview," Technol. Econ. Dev. Econ., vol. 17, no. 2, pp. 397-427, 2011.

[231] M. Velasquez and P. T. Hester, "An Analysis of Multi-Criteria Decision Making Methods," Int. J. Oper. Res., vol. 10, no. 2, pp. 56-66, 2013.

[232] W. J. Hahn, S. L. Seaman, and R. Bikel, "Making Decisions with Multiple Attributes: A Case in Sustainability Planning," Graziadio Bus. Rev., vol. 15, no. 2, p. 11, 2012.

[233] N. Kadoić, N. B. Ređep, and B. D. Divjak, "Decision making with the analytic network process," 2013.

[234] A. M. Dytczak and G. Ginda, "DEMATEL-based Ranking Approaches," WSB Univ. Wroclaw Res. J., vol. 16, no. 3, p. 12, 2016.

[235] M. Amiri, J. Salehi Sadaghiyani, N. Payani, and M. Shafieezadeh, "Developing a DEMATEL method to prioritize distribution centers in supply chain," Manag. Sci. Lett., vol. 1, no. 3, 
pp. 279-288, 2011.

[236] S.-L. Si, X.-Y. You, H.-C. Liu, and P. Zhang, "DEMATEL Technique: A Systematic Review of the State-of-the-Art Literature on Methodologies and Applications," Math. Probl. Eng., vol. 2018, no. 1, pp. 1-33, 2018.

[237] M. DAĞDEVIREN and i. YÜKSEL, "Personnel selection using analytic network process," Mistanbul Ticaret Üniversitesi Fen Bilim. Derg. Yıl, vol. 6, no. 1, pp. 99-118, 2007.

[238] J. Rezaei, "Best-worst multi-criteria decision-making method," Omega (United Kingdom), vol. 53, no. June 2015, pp. 49-57, 2015.

[239] W. Ho, "Integrated analytic hierarchy process and its applications - A literature review," Eur. J. Oper. Res., vol. 186, no. 1, pp. 211-228, 2008.

[240] C. Zalengera, R. E. Blanchard, P. C. Eames, A. M. Juma, M. L. Chitawo, and K. T. Gondwe, "Overview of the Malawi energy situation and A PESTLE analysis for sustainable development of renewable energy," Renew. Sustain. Energy Rev., vol. 38, pp. 335-347, 2014.

[241] Dundar Kocaoglu, "A participative approach to program evaluation," IEEE Trans. Eng. Manag., vol. EM-30, no. 3, pp. 112-118, 1983.

[242] P. Gerdsri and D. F. Kocaoglu, "Technology Policy Instrument ( TPI ): A Decision Model for Evaluating Emerging Technologies for National Technology Policy Research Framework," in PICMET 2007 Proceedings, 5-9 August, Portland, Oregon, 2007, pp. 5-9.

[243] J. Estep, "Development of a technology transfer score to inform the selection of a research proposal," in Conference: 2015 Portland International Conference on Management of Engineering and Technology (PICMET), 2015.

[244] S. V. \& Katherine Tucker, David Tucker, James Eastham, Elizabeth Gibson and T. Daim, "Network Based Technology Roadmapping for Future Markets: Case of 3D Printing," Technol. Invest., pp. 137-156, 2014.

[245] C. Gennings, D. Heuman, O. Fulton, and A. J. Sanyal, "Use of desirability functions to evaluate health status in patients with cirrhosis," J. Hepatol., vol. 52, no. 5, pp. 665-671, 2010.

[246] I. O. Irhoma and C. Sansom, "CSP Assessment in Comparison to other Electricity Generation Options Using Multicriteria Decison Analysis (The Libyan Case)," vol. 6, no. 7, pp. 14-27, 2017.

[247] H. Chen and D. F. Kocaoglu, "A sensitivity analysis algorithm for hierarchical decision models," Eur. J. Oper. Res., vol. 185, no. 1, pp. 266-288, 2008.

[248] S. S. James J. Park, Albert Y. Zomaya, Sang-Soo Yeo, "Network and Parallel Computing," in 9th IFIP International Conference, NPC 2012, Gwangju, Korea, September 6-8, 2012, Proceedings, 2012, p. 647.

[249] T. Daim, J. Kim, and K. Phan, Research and Development Management: Technology Journey Through Analysis. Forecasting and decisionmaling. Springer International Publishing, 2017.

[250] R. Heale and A. Twycross, "Validity and reliability in quantitative studies," vol. 18, no. 3, pp. 66-67, 2015.

[251] H. Taherdoost and H. Group, "Validity and Reliability of the Research Instrument; How to Test the Validation of a Questionnaire / Survey in a Research," Int. J. Acad. Res. Manag., vol. 5, no. January 2016, p. 36, 2017.

[252] N. Golfashni, "Validity and Reliability in Social Science Research," Educ. Res. Perspect., vol. 38, no. 1, pp. 105-123, 2011. 
[253] Ro. A. Bolarinwa, "Principles and Methods of Validity and Reliability Testing of Questionnaires Used in Social and Health Science Researches," Soc. Heal. Sci. Res., pp. 195-201, 2015.

[254] K. Bannigan and R. Watson, "Reliability and validity in a nutshell," J. Clin. Nurs., vol. 18, no. 23, pp. 3237-3243, 2009.

[255] G. M. Sullivan, "A Primer on the Validity of Assessment Instruments," J. Grad. Med. Educ., vol. 3, no. 2, pp. 119-120, 2011.

[256] K. L. Marquardt, D. Pemstein, B. Seim, and Y. T. Wang, "What makes experts reliable? Expert reliability and the estimation of latent traits," Res. Polit., vol. 6, no. 4, 2019.

[257] K. Roulston and S. A. Shelton, "Reconceptualizing Bias in Teaching Qualitative Research Methods," Qual. Inq., vol. 21, no. 4, pp. 332-342, 2015.

[258] G. Montibeller and D. von Winterfeldt, "Biases and Debiasing in Multi-Criteria Decision Analysis," in 2015 48th Hawaii International Conference on System Sciences, 2015, pp. $1218-1226$.

[259] G. Kou, D. Ergu, and J. Shang, "Enhancing data consistency in decision matrix: Adapting Hadamard model to mitigate judgment contradiction," Eur. J. Oper. Res., vol. 236, no. 1, pp. 261-271, 2014.

[260] J. Szybowski, "The Cycle Inconsistency Index in Pairwise Comparisons Matrices," Procedia Comput. Sci., vol. 96, pp. 879-886, 2016.

[261] L. Langfeldt, Expert panels evaluating research: Decision-making and sources of bias, vol. 13, no. 1. 2004.

[262] H. L. Li and L. C. Ma, "Detecting and adjusting ordinal and cardinal inconsistencies through a graphical and optimal approach in AHP models," Comput. Oper. Res., vol. 34, no. 3, pp. 780-798, 2007.

[263] D. F. Kocaoglu, "A participative approach to program evaluation," Eng. Manag. IEEE Trans., no. 3, pp. 112-118, 1983.

[264] M. S. Abbas, "Consistency Thresholds for Hierarchical Decision Model," 2013 Portl. Int. Conf. Manag. Eng. Technol., vol. San Jose, pp. 411-425, 2013.

[265] S. Lin and M. Lu, "Characterizing disagreement and inconsistency in experts' judgments in the analytic hierarchy process," IManagement Decis., vol. 50, no. 7, pp. 1252-1265, 2012.

[266] E. Lalumera, "Overcoming Expert Disagreement In A Delphi Process . An Exercise In Reverse Epistemology," Humanamente., vol. 28, pp. 87-103, 2015.

[267] A. P. Benini, N. Chataigner, N. Noumri, J. Parham, J. Sweeney, and L. Tax, "The Use of Expert Judgment in Humanitarian Analysis - Theory, Methods and Applications," ACAPS, no. August, pp. 1-218, 2017.

[268] M. Schaekermann, G. Beaton, M. Habib, A. Lim, K. Larson, and E. Law, "Understanding Expert Disagreement in Medical Data Analysis through Structured Adjudication," vol. 3, no. November, 2019.

[269] H. Barham, "Development of a Readiness Assessment Model for Evaluating Big Data Projects : Case Study of Smart City in Oregon , USA," ResearchGate, no. August, 2019.

[270] G. Restrepo, U. Valle, and E. J. Llanos, "Three Dissimilarity Measures to Contrast Dendrograms," J. Chem. Inf. Model., vol. 47, pp. 761-770, 2007.

[271] O. Yim and K. T. Ramdeen, "Hierarchical Cluster Analysis: Comparison of Three Linkage Measures and Application to Psychological Data," Quant. Methods Psychol., vol. 11, no. 1, pp. 8-21, 2015. 
[272] P. K. Kimes, J. S. Marron, Y. Liu, and N. Hayes, "Statistical Significance for Hierarchical Clustering," 2014.

[273] D. Liljequist, B. Elfving, and K. S. Roaldsen, Intraclass correlation - A discussion and demonstration of basic features. 2019.

[274] T. U. Daim, M. B. Dabić, J. R. N., Lavoie, and B. J. Galli, R\&D Management in the Knowledge Era. Springer International Publishing, 2019.

[275] J. Estep, "Development of a Technology Transfer Score for Evaluating Research Proposals: Case Study of Demand Response Technologies in the Pacific Northwest," ProQuest Diss. Theses, p. 253, 2017.

[276] R. Lavoie, "A Scoring Model to Assess Organizations ' Technology Transfer Capabilities : the Case of a Power Utility in the Northwest USA," PDXScholar, 2019.

[277] C. Schelly, "Understanding Energy Practices: A Case for Qualitative Research," Soc. Nat. Resour., vol. 29, no. 6, pp. 744-749, 2016.

[278] J. C. Rogers, E. A. Simmons, I. Convery, and A. Weatherall, "Social impacts of community renewable energy projects: findings from a woodfuel case study," Energy Policy, vol. 42, pp. 239-247, 2012.

[279] R. J. Geerts, "Towards a Qualitative Assessment of Energy Practices: Illich and Borgmann on Energy in Society," Philos. Technol., vol. 30, no. 4, pp. 521-540, 2017.

[280] F. Lucero, P. A. Catalán, Á. Ossandón, J. Beyá, A. Puelma, and L. Zamorano, "Wave energy assessment in the central-south coast of Chile," Renew. Energy, vol. 114, pp. 120-131, 2017.

[281] L. A. Palinkas, S. M. Horwitz, C. A. Green, J. P. Wisdom, N. Duan, and K. Hoagwood, "Purposeful Sampling for Qualitative Data Collection and Analysis in Mixed Method Implementation Research," Adm. Policy Ment. Heal., vol. 42, no. 5, pp. 2-4, 2015.

[282] Mohsin Alvi, "A Manual for Selecting Sampling Techniques in Research," 2016.

[283] Executive office of the President, "North American Industry Classification System," Census.gov/naics, p. 963, 2017.

[284] Thomson Reuters, "Whitepaper Using Bibliometrics," 2008.

[285] D. F. Thompson and C. K. Walker, "A descriptive and historical review of bibliometrics with applications to medical sciences," Pharmacotherapy, vol. 35, no. 6, pp. 551-559, 2015.

[286] A. Umut, Z. Taşkın, and G. Düzyol, "Use of Social Network Analysis in Bibliometric Researches," 2012.

[287] Home Office, "Social Network Analysis: 'How to guide," 2016.

[288] K. Teferra, M. D. Shields, A. Hapij, and R. P. Daddazio, "Mapping model validation metrics to subject matter expert scores for model adequacy assessment," Reliab. Eng. Syst. Saf., vol. 132, pp. 9-19, 2014.

[289] Maxime Bernaert and Geert Poels, "The Quest for Know-How, Know-Why, Know-What and Know-Who: Using KAOS for Enterprise Modelling," in International Conference on Advanced Information Systems Engineering, 2011, pp. 29-40.

[290] K. W. Middleton, "Personalizing Entrepreneurial Learning: a pedagogy for facilitating the Know Why," Entrep. Res. Journa, vol. 4, no. 2, pp. 167-204, 2013.

[291] S. Rowe et al., "How experts are chosen to inform public policy: Can the process be improved?," Health Policy (New. York)., vol. 112, no. 3, pp. 172-178, 2013.

[292] S. Tonidandel, P. W. Braddy, and J. W. Fleenor, "Relative importance of managerial skills for predicting effectiveness," J. Manag. Psychol., vol. 27, no. 6, pp. 636-655, 2012. 
[293] P. Kumar, "An Analytical study on Mintzberg' s Framework : Managerial Roles," Int. J. Res. Manag. Bus. Stud., vol. 2, no. 3, 2015.

[294] K. D. Balt, "A Methodology for Implementing the Analytical Hierarchy Process to Decision Making in Mining," 2015.

[295] A. R. Colson and R. M. Cooke, "Expert elicitation: Using the classical model to validate experts' judgments," Rev. Environ. Econ. Policy, vol. 12, no. 1, pp. 113-132, 2018.

[296] G. H. Aas et al., Assessing educational quality: Knowledge production and the role of experts. 2009.

[297] J. S. Mattoon and J. S. Mattoon, "Designing and Developing Technical Curriculum : Finding the Right Subject Matter Expert," J. STEM Teach. Educ., vol. 42, no. 2, 2005.

[298] ECA(European Consortium for Accreditation), "ECA Principles for the Selection of Experts," 2005.

[299] J. Dijkstra et al., "Expert validation of fit-for-purpose guidelines for designing programmes of assessment," BMC Med. Educ., vol. 12, no. 1, 2012.

[300] U.S. National Research Council, Prospective Evaluation of Applied Energy Research and Development at DOE (Phase Two). 2007.

[301] R. J. Budnitz et al., "Use of technical expert panels: Applications to Probabilistic Seismic Hazard Analysis," Risk Anal., vol. 18, no. 4, pp. 463-469, 1998.

[302] Advance CTE, "The state of career technical education: Increasing access to industry experts in high schools," State Career Tech. Educ., 2016.

[303] Muzeview, "Are Your Industry Experts 'Competent'?," Muzeview Research LLC, 2018. [Online]. Available: http://muzeview.com/are-your-industry-experts-competent/.

[304] The Royal Society of Canada, "Expert panels: Manual of procedural guidelines," 2010.

[305] S. L. Dworkin, "Sample size policy for qualitative studies using in-depth interviews," Arch. Sex. Behav., vol. 41, no. 6, pp. 1319-1320, 2012.

[306] S. Milosrdnice, "Bias in research," Biochem. Medica, vol. 23, no. 1, pp. 12-15, 2013.

[307] B. Hlavka and C. Scullion, "Bias, guess and expert judgement in actuarial work A report by the Getting Better Judgement Working Party," no. November, 2015.

[308] D. Salvatore, "Consumer Preferences and Choice," Microeconomics, pp. 57-86, 2008.

[309] S. Ghugh, "Chapter 1 Microeconomics of Consumer Theory," pp. 17-26, 2014.

[310] E. Malone, "Driving Efficiency with Non-Energy Benefits Recent Synapse Research on NEBs," pp. 1-19, 2014.

[311] M. Chiesa, "The Economic Evaluation of Energy Efficiency in Industry: An Innovative Methodology," ACEEE Summer Study Energy Effic. Ind., no. June 2014, pp. 1-11, 2015.

[312] NEEP, "Northeast and Mid-Atlantic Heat Pump Water Heater Market Strategies Report," 2012.

[313] E. Doris, J. Cochran, and M. Vorum, "Energy Efficiency Policy in the United States: Overview of Trends at Different Levels of Government Energy Efficiency Policy in the United States: Overview of Trends at Different Levels of Government," Natl. Renew. Energy Lab., vol. December, no. December, p. 63, 2009.

[314] F. Liu, "Improving Energy Efficiency in Buildings," Energy Sect. Manag. Assist. Progr., no. August, pp. 1-22, 2014.

[315] U.S. DOE, "Quadrennial Technology Review: An Assessment of Energy Technologies and Research Opportunities," no. September, 2015.

[316] L. Earle, B. Sparn, A. Rutter, and D. Briggs, "Residential Energy Efficiency Demonstration 
Hawaii and Guam Energy Demonstration Project Residential Energy Efficiency Demonstration Hawaii and Guam Energy," NREL, no. March 2014, 2014.

[317] E. Mills and A. Rosenfeld, "Consumer non-energy benefits as a motivation for making energy-efficiency improvements," Energy, vol. 21, no. 7-8, pp. 707-720, 1996.

[318] L. a Skumatz and J. Gardner, "Methods and Results for Measuring Non-Energy Benefits in the Commercial and Industrial Sectors," ACEEE Summer Study Energy Effic. Ind., no. 1, pp. 163-176, 2005.

[319] E. Cagno, A. Trianni, G. Spallina, and F. Marchesani, "Drivers for energy efficiency and their effect on barriers: empirical evidence from Italian manufacturing enterprises," Energy Effic., vol. 10, no. 4, pp. 855-869, 2017.

[320] M. C. Dubois and A.. Blomsterberg, "Energy saving potential and strategies for electric lighting in future north european, low energy office buildings: A literature review," Energy Build., vol. 43, no. 10, pp. 2572-2582, 2011.

[321] A. J. Hester, "A Comparison of the Influence of Social Factors and Technological Factors on Adoption and Usage of Knowledge Management Systems," pp. 1-10, 2010.

[322] A. Parasuraman, "Index ( TRI ) A Multiple-Item Scale to Embrace New Technologies," J. Serv. Res., vol. 2, no. 4, pp. 307-320, 2000.

[323] M. Ferreira and M. Almeida, "Benefits from energy related building renovation beyond costs, energy and emissions," Energy Procedia, vol. 78, pp. 2397-2402, 2015.

[324] H. Staller and A. Tisch, "Energy efficient building design. State of the Art Report," Sustain. Constr. Innov., 2010.

[325] M. A. Gurau, "The use of Profitability Index in Economic Evaluation of Industrial Investment Projects," Proc. Manuf. Syst., vol. 7, no. 1, pp. 55-58, 2012.

[326] H. Doukas, "On the appraisal of 'Triple-A' energy efficiency investments," Energy Sources, Part B Econ. Planning, Policy, vol. 13, no. 7, pp. 320-327, 2018.

[327] EIA, "Levelized Cost and Levelized Avoided Cost of New Generation Resources in the Annual Energy Outlook 2016 Levelized Cost of Electricity ( LCOE ) and its limitations," 2016.

[328] Dyesol, "What is Levelised Cost of Energy ( LCOE )?," 2011.

[329] G. S. B. Ganandran, T. M. I. Mahlia, H. C. Ong, B. Rismanchi, and W. T. Chong, "Cost-benefit analysis and emission reduction of energy efficient lighting at the universiti tenaga nasional," Sci. World J., vol. 2014, 2014.

[330] J. J. Kim, "Economic analysis on energy saving technologies for complex manufacturing building," Resour. Conserv. Recycl., vol. 123, pp. 249-254, 2017.

[331] J. A. Parnell, "Industry Competition," Strateg. Manag. Theory Pract., pp. 27-52, 2013.

[332] D. Gomez-Mejia, Luis and Balkin, "Mapping supply chain strategy: an industry analysis," J. Manag. Dev., vol. 23, no. 7, pp. 635-648, 2007.

[333] Energy Trust of Oregon, "Trade Ally Benefits and Enrollment," 2016.

[334] E. Schmidt and M. C. R. P. Solutions, "Leveraging Trade Allies to Build, Maintain and Advance Market Transformation Programs," 2016.

[335] R. B. Hoag, "Market Research and Developing a marketing plan," Hudson Val. Bus. J., p. 48, 2008.

[336] K. N. Delve, A. Wilkins, F. Garcia-Lopez, and M. J. Scholand, "Five A's: Barrier classification and market transformation program design for energy efficient technologies," ACEEE Summer Study Energy Effic. Build., pp. 105-116, 2004.

[337] Bluegreen Alliance Foundation, "The Supply Chain for Energy Efficient Product 
Manufacturing," 2017.

[338] R. Bartlett, M. A. Halverson, and D. L. Shankle, "Understanding Building Energy Codes and Standards," Energy, no. March, 2003.

[339] T. Frappé-sénéclauze and J. Macnab, "Evolution of Energy Efficiency Requirements in the BC Building Code," no. July, 2015.

[340] B. Baatz, "Rate Design Matters: The Intersection of Residential Rate Design and Energy Efficiency," ACEEE, no. March, 2017.

[341] IEA, "Achievements of appliance energy efficiency standards and labelling programs: A Global Assessment," 2015.

[342] NEEA, "Northwest Heat Pump Water Heater Initiative Market Progress Evaluation Report \# 1," 2015.

[343] Z. Wang, W. Yang, F. Qiu, X. Zhang, and X. Zhao, "Solar water heating: From theory, application, marketing and research," Renew. Sustain. Energy Rev., vol. 41, pp. 68-84, 2015.

[344] AHRI, "Advances in Water Heating Technology," 2011.

[345] D. K. Pace and P. P. Staff, "Subject Matter Expert ( SME )/ Peer Use in M \& S V \& V," Proc. Work. Found. Model. Simul. Verif. Valid. 21st Century, vol. SCS, pp. 22-24, 2002.

[346] R. P. Lavin, L. A. Slepski-nash, U. States, P. Health, U. States, and C. E. Kasper, "Said Another Way," ResearchGate, no. May 2019, 2007.

[347] R. Heale, D. Forbes, and R. Heale, "Understanding triangulation in research," vol. 16, no. 4, p. 101494, 2013.

[348] K. Burkart and J. Martinez, "Findings from the Initial Use of the Healthy Homes Rating System ( HHRS ) in Three American Cities," J Urban Heal., vol. 94, pp. 450-456, 2017.

[349] HUD.GOV, "Overview of the Healthy Home Rating System ( HHRS )," 2020.

[350] W. Goetzler, K. Foley, J. Young, and G. Chung, "Energy Savings Potential and RD \& D Opportunities for Commercial Building Appliances ( 2015 Update )," 2016.

[351] USDOE, "Builders Challenge Quality Criteria Support Document," 2010.

[352] CRAIG, "Electronic Aids for Daily Living," 2017. [Online]. Available: https://craighospital.org/services/assistive-technology/assistive-tech-electronic-aids.

[353] Z. Tian and J. A. Love, "Application of radiant cooling in different climates: Assessment of office buildings through simulation," IBPSA 2009 - Int. Build. Perform. Simul. Assoc. 2009, no. January 2009, pp. 2220-2227, 2009.

[354] M. A. Billingsley, I. M. Hoffman, E. Stuart, S. R. Schiller, C. A. Goldman, and K. Lacommare, "The Program Administrator Cost of Saved Energy for Utility Customer-Funded Energy Efficiency Programs," 2014.

[355] H. Doukas, "On the appraisal of 'Triple-A' energy efficiency investments," Energy Sources, Part B Econ. Plan. Policy, vol. 13, no. 7, pp. 320-327, 2018.

[356] U S. EIA, "Levelized Cost and Levelized Avoided Cost of New Generation Resources in the Annual Energy Outlook 2020," 2020.

[357] A. Staniszewski, A. Denysenko, M. Evans, L. Parker, and S. Yu, "Best Available Technologies in the U . S . Buildings Sector," Pacific Northwest Natl. Lab., no. May, 2018.

[358] G. Bruijl, "Business Environment The RelevancThe Relevance of Porter's Five Forces in Today 's Innovative and Changinge Of Porter 's Five Forces In Today ' s Innovative And Changing Business Environment," Researcgate, no. January, p. 21, 2018.

[359] Y. Kalyuzhnova and R. Pomfre, Sustainable Energy in Kazakhstan: Moving to Cleaner 
Energy in a Resource-ric Country. Routledge, 2018.

[360] S. Bernell, "Perfect Competition and Pure Monopoly," in Health Economics: Core Concepts and Essential Tools, 2016, pp. 85-104.

[361] K. Zelga, "The importance of competition and enterprise competitiveness," Woeld Sci. News, vol. 72, no. 72, pp. 301-306, 2017.

[362] A. Maniçoba, "Distribution channel structure: An overview of determinants," Periódico Divulg. Científica da FALS, no. May, 2015.

[363] A. Pettersson, "Measurement of Excellence a n d Cost in a Supply Chain," 2015.

[364] D. J. Bjornstad and M. V Lapsa, Heat Pump Water Heater Technology: Experiences of Residential Consumers and Utilities, no. June. 2004.

[365] A. I. Pettersson and A. Segerstedt, "Measuring supply chain cost," Int . J . Prod. Econ., vol. 143, pp. 357-363, 2013.

[366] McKinsey, "Unlocking Energy Efficiency in the U . S . Economy," Outlook, 2009.

[367] J. Maguire, X. Fang, and E. Wilson, "Comparison of Advanced Residential Water Heating Technologies in the United States," Nrel/Tp-5500-55475, no. May, 2013.

[368] ACEEE, "Water heating," 2012.

[369] C. Pike, E. Whitney, C. Pike, and E. Whitney, "Heat pump technology: An Alaska case study," J. Renew. Sustain. ENERGY, no. 9, p. 10, 2017.

[370] A. Pollard, "The Energy Performance of Heat Pump Water Heaters," ResearchGate, no. August, 2019.

[371] D. Defined, "Clean Energy Policies in States and Communities Decoupling," Clean Energy Policies in States and Communities Decoupling, p. 8, 2009.

[372] B. Wiebke, F. Martin, and $\varnothing$. Marie, "High efficient heat pump system using storage tanks to increase COP by means of the ISEC concept - Part I : Model," DTU, p. 9, 2015.

[373] P. A. Hohne, K. Kusakana, and B. P. Numbi, "A review of water heating technologies : An application to the South African context," vol. 5, pp. 1-19, 2019.

[374] T. Galvin, "Mid-stream programs: Overview DTE activities : Commercialization pathway," Navig. Consult. Inc., pp. 1-19, 2018.

[375] D. Vida and D. R. International, "Swimming to Midstream : New Residential HVAC Program Models and Tools," pp. 1-12, 2016.

[376] NEEA, "Advanced Water Heating Specification for Gas-Fueled Residential Storage Water Heaters," 2019.

[377] A. Morris and A. Sheets, "Geothermal systems -System Types, Applicability and Environmental Impacts," 2011.

[378] E. Hettich and G. M.- Gallen, Tesla Motors Business Model Configuration, vol. 44, no. 0. 2014, pp. 1-21.

[379] M. Cambell, "The Drivers of the Levelized Cost of Electricity for Utility-Scale Photovoltaics," 2008.

[380] Z. Wang and X. Zhao, "Solar Water-Heating Systems," Sci. Direct, 2018.

[381] V. K. Soni, R. Shrivastava, and S. P. Untawale, "Supply Chain Management in Solar Water Heater Industry for Global Supply Chain Management in Solar Water Heater Industry for Global Competitiveness," Researcgate, p. 15, 2015.

[382] UNDP, "Solar Water Heating System," 2014.

[383] D. Bohac, M. S. Lobenstein, and T. Butcher, "Actual Savings and Performance of Natural Gas Tankless Water Heaters Prepared for Minnesota Office of Energy Security," Cent. 
Energy Environ., 2010.

[384] Energy.Gov, "Tankless or Demand Type Water Heater," 2019. .

[385] A. A. B. Ruíz, "What is theoretical contribution? A narrative review," Sarhad J. Manag. Sci., vol. 3, no. 2, pp. 54-67, 2015.

[386] Energy and Mines Ministers' Conference, Market transformation strategies for energyusing equipment in the building sector, no. August. 2017.

[387] Conservation Seattle City Light 2016 IRP, "Conservation Potential Assessment," 2016.

[388] A. Lee, "Energy Efficiency Resource Assessment Report," 2014.

[389] U.S. Energy Information Administration, "Residential and Commercial Sector Energy Code Adoption and Compliance Rates," 2017.

[390] I. Rohmund, A. Duer, S. Yoshida, J. Borstein, L. Wood, and A. Cooper, "Assessment of Electricity Savings in the U.S. Achievable through New Appliance/Equipment Efficiency Standards and Building Efficiency Codes (2010 - 2025)," Edison Found., no. May, 2011.

[391] J. V. Hillegas-Elting, T. Oliver, J. Binus, T. Daim, J. Estep, and J. Kim, "Opening the door to breakthroughs that address strategic organizational needs: Applying technology roadmapping tools and techniques at an electric utility," Portl. Int. Conf. Manag. Eng. Technol., vol. 2015-Septe, pp. 2564-2573, 2015.

[392] W. Goetzler, M. Guernsey, and J. Young, "Research and Development Roadmap for Emerging HVAC Technologies," no. October, p. 121, 2014. 


\section{APPENDIX}

\section{APPENDIX A: Electricity Consumption by End-Use Sector (Quadrillion Btu)}

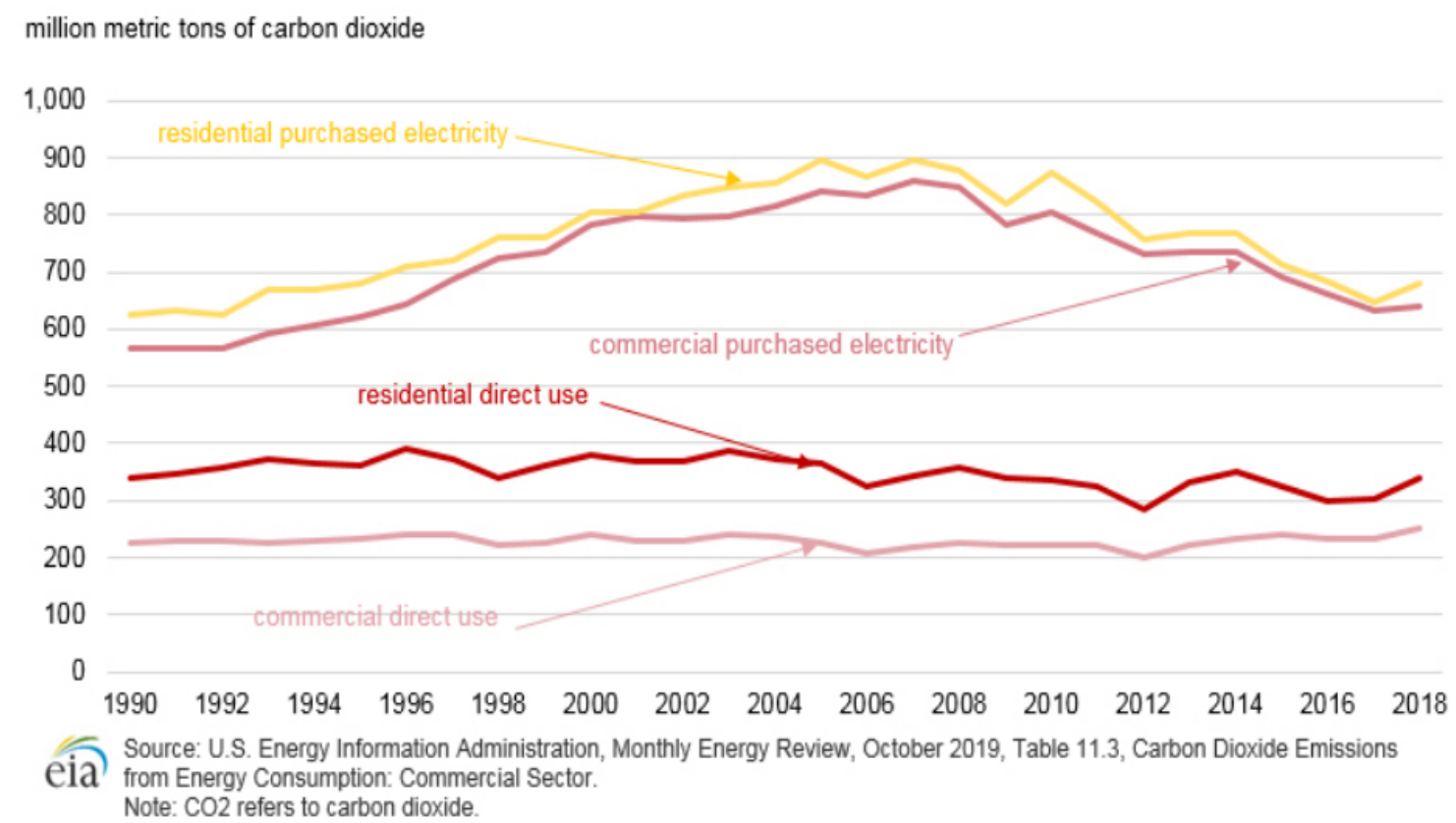


APPENDIX B: The Proportion of All Electric Homes is Rising in the U.S

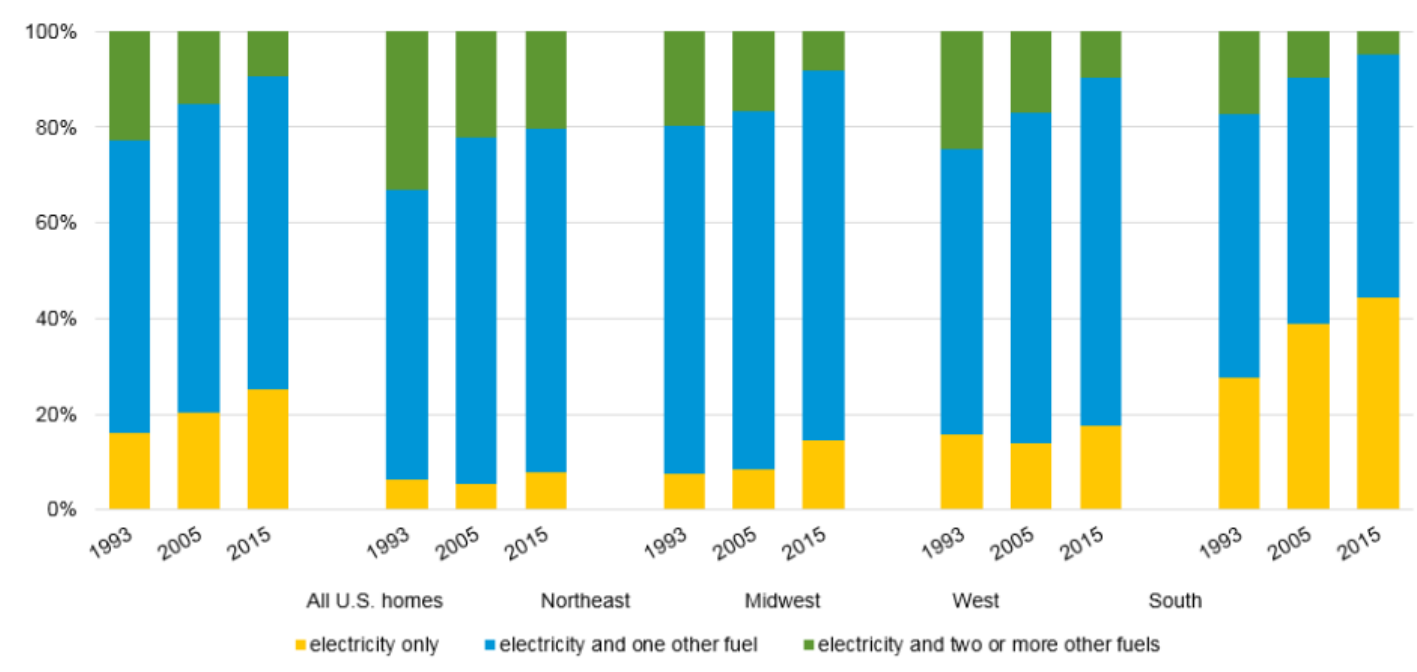


APPENDIX C: State Scores in the 2019 State Scorecard

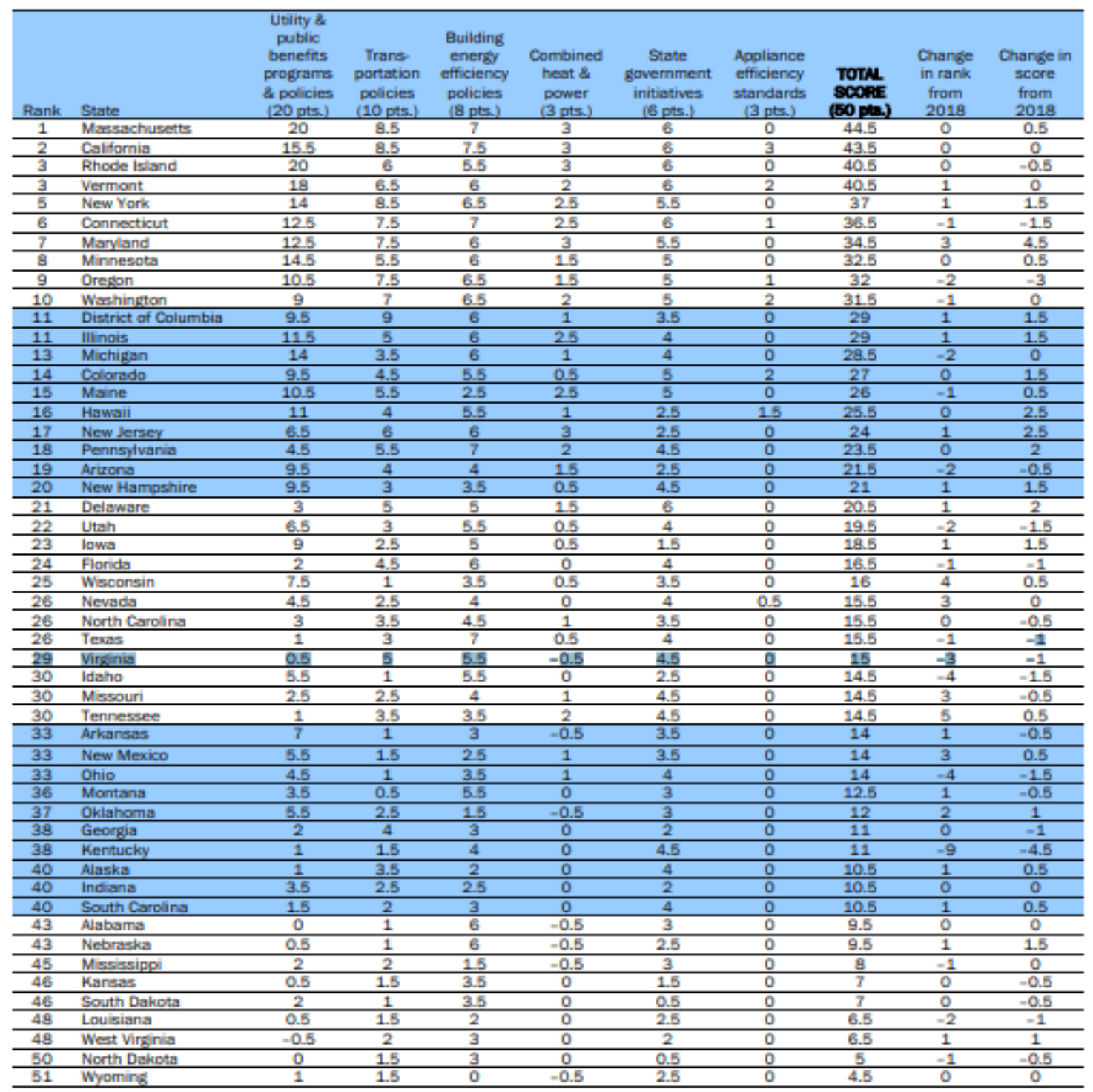


APPENDIX D: Number of Experts in Expert Panels from different Ph.D Dissertations

\begin{tabular}{|c|c|c|c|c|c|}
\hline Research Focus & $\begin{array}{c}\text { Experts Position } \\
\text { WHICH }\end{array}$ & Organizations WHERE & $\begin{array}{l}\text { No. of Panels (No. of } \\
\text { Experts in each pane } \\
\text { I) WHAT }\end{array}$ & Expertise WHO & Reference \\
\hline $\begin{array}{l}\text { HDM Judgment Quantification of } \\
\text { Criteria for Utility Program } \\
\text { Alternative Assessment. } \\
>\text { Energy efficiency program } \\
>\text { management considerations } \\
>\text { Energy savings potential } \\
>\text { Ancillary benefits potential } \\
>\text { Program development \& } \\
\text { implementation potential } \\
>\text { Market dissemination } \\
\text { potential } \\
>\text { Alternatives }\end{array}$ & $\begin{array}{ll}> & \text { Emerging Technology } \\
& \text { Program Manager } \\
> & \text { Director of Planning and } \\
\text { Evaluation } \\
>\text { Senior Emerging Technology } \\
\text { \& Product Management } \\
>\quad \text { Manager, Conservation } \\
\text { Resources } \\
>\text { Chief Technology Innovation } \\
\text { Officer } \\
>\text { Senior Economist, Economic } \\
\text { Annalysis } \\
>\text { Policy Analyst }\end{array}$ & $\begin{array}{ll}> & \text { Non-profit organizations } \\
\text { Utility } \\
>\text { Research Lab } \\
>\text { University } \\
>\text { Consulting Company }\end{array}$ & $\begin{array}{l}\text { Six Panels: Five panels } \\
\text { for criteria and one } \\
\text { panel for the } \\
\text { alternatives. 26 subject } \\
\text { matter experts with } \\
\text { experience in the areas } \\
\text { of management, } \\
\text { planning, engineering, } \\
\text { and economics. The } \\
\text { number of experts on } \\
\text { panels ranges from } 3 \text { - } \\
\text { 18. Some experts are } \\
\text { part of more than one } \\
\text { panel. }\end{array}$ & 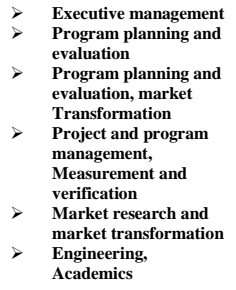 & $\begin{array}{l}\text { (Iskin and } \\
\text { Daim 2016) }\end{array}$ \\
\hline $\begin{array}{l}\text { HDM Judgment Quantification of } \\
\text { Criteria for Evaluating research } \\
\text { proposals for demand response } \\
\text { technologies by Technology } \\
\text { Transfer Score. } \\
>\text { Organizational } \\
>\text { Technological } \\
\text { Social } \\
>\text { Market Readiness }\end{array}$ & $\begin{array}{ll}\text { Program Director } \\
>\text { R\&D Chief Officer } \\
>\text { Vice President } \\
>\text { Sr. Vice President } \\
>\text { Executive VP } \\
>\text { Sr. Research Scientist } \\
>\text { R\&D Executive } \\
>\text { Sr. Technology Transfer } \\
\text { Manager } \\
>\text { Technology to Market Advisor } \\
>\text { Vice President Technology } \\
\text { Management } \\
\text { Mr. Analyst } \\
>\text { Policy Strategist } \\
>\text { Public Utilities Specialist } \\
>\text { Director of Retail Programs } \\
>\text { Project Manager } \\
>\text { Professor } \\
\text { Dr. Instructor } \\
\end{array}$ & $\begin{array}{ll}\text { National labs } \\
>\text { Universities } \\
\text { Utilities, } \\
>\text { non-profit research } \\
\text { Organizations } \\
>\text { R\&D Cooperative } \\
>\text { DOE } \\
>\text { NW Power Council } \\
>\text { Industry } \\
>\text { Consulting Services }\end{array}$ & $\begin{array}{l}\text { Seven Panels: One } \\
\text { panel validated the } \\
\text { model. Five panels } \\
\text { worked on judgment } \\
\text { quantification of } \\
\text { criteria. One panel is } \\
\text { employedr for } \\
\text { desirability curve } \\
\text { validation. Fifty-four } \\
\text { (54) subject matter } \\
\text { experts are selected. } \\
\text { The number of experts } \\
\text { on panels ranges from } \\
4-12 \text {. Some experts } \\
\text { are part of more than } \\
\text { one panel. }\end{array}$ & $\begin{array}{ll}> & \text { Technology transfer } \\
& \text { Research investigators } \\
& \text { Policy strategists } \\
& \text { Research Management } \\
& \text { Project management }\end{array}$ & (Estep 2017) \\
\hline $\begin{array}{l}\text { HDM Judgment Quantification of } \\
\text { criteria for evaluating Nuclear } \\
\text { Power Plant alternative siting } \\
\text { technologies. } \\
>\text { Social } \\
>\text { Technical } \\
>\text { Economic } \\
>\text { Environmental } \\
>\text { Political }\end{array}$ & $\begin{array}{ll}> & \text { Professors } \\
& \text { Project Managers } \\
\text { St. Executives } \\
>\text { Policy Strategists }\end{array}$ & $\begin{array}{ll}> & \text { Nuclear Energy Institute } \\
\text { International Nuclear } \\
\text { Energy Academy } \\
>\text { U.S. Nuclear Engineering } \\
\text { Schools } \\
>\text { Universities } \\
>\text { Energy Consultation } \\
\text { National Labs } \\
>\text { Nuclear Power \& } \\
\text { Renewable Energy } \\
\text { Company } \\
> & \text { Nuclear Energy } \\
\text { Technology Company } \\
> & \text { International Nuclear } \\
& \text { Academy Saf Safty } \\
> & \text { Nuclear Commission Consultant } \\
& \text { Com }\end{array}$ & $\begin{array}{l}\text { Six Panels: One panel } \\
\text { for each of the five } \\
\text { perspectives validation } \\
\text { and quantification. } \\
\text { The sixth panel } \\
\text { worked as principal } \\
\text { panel performing } \\
\text { several major tasks } \\
\text { and to fulfilling the } \\
\text { shortages on other } \\
\text { panels. Fifty-three } \\
\text { (53) subject matter } \\
\text { experts are selected. } \\
\text { The number of experts } \\
\text { on panels ranges from } \\
6 \text { - 15. Some experts } \\
\text { are part of more than } \\
\text { one panel. }\end{array}$ & $\begin{array}{ll} & \begin{array}{l}\text { Nuclear energy } \\
\text { technologies }\end{array} \\
\text { Engineering } \& \\
\text { technology, } \\
\text { Economics } \\
\text { Financing } \\
> \\
\text { Environment and } \\
\text { climate change, } \\
\text { economic and social } \\
\text { development } \\
\text { Market development } \\
\text { Policy analyst } \\
\text { Regulatory experts }\end{array}$ & (Lingga 2016) \\
\hline 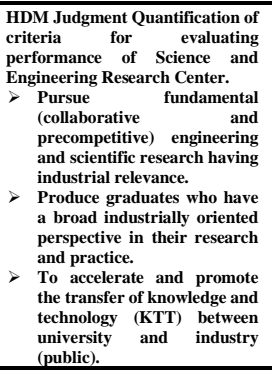 & $\begin{array}{ll} & \text { Directors } \\
\text { Leading Researchers } \\
\text { Center Directors } \\
>\text { Center Co-directors } \\
>\text { Evaluators } \\
>\text { Leading Authors } \\
>\text { Students } \\
>\text { Project Directors }\end{array}$ & 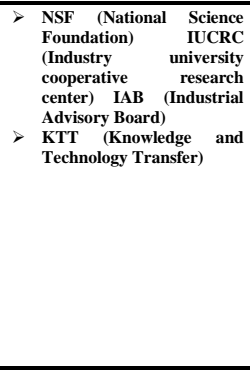 & $\begin{array}{l}\text { Five set of panels: A set } \\
\text { of Two panels with } \\
\text { different experts are } \\
\text { dedicated for each of } \\
\text { the five perspectives } \\
\text { validation and } \\
\text { quantification. The } \\
\text { sixth panel validates } \\
\text { and quantifies the } \\
\text { desirability curve. } \\
\text { Thirty-seven (37) } \\
\text { subject matter experts } \\
\text { are selected. The } \\
\text { number of experts on } \\
\text { panels ranges from 1 - } \\
\text { 15. Some experts are } \\
\text { part of more than one } \\
\text { panel. }\end{array}$ & 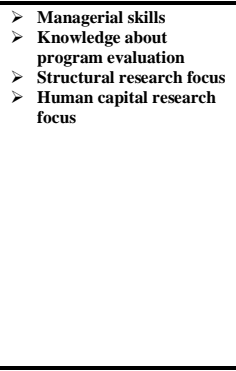 & $\begin{array}{l}\text { (Gibson and } \\
\text { Daim 2016) }\end{array}$ \\
\hline $\begin{array}{l}\text { HDM Judgment Quantification of } \\
\text { criteria for of Energy Policy } \\
\text { Instruments for the Adoption of } \\
\text { Renewable Energy: Case of Wind } \\
\text { Energy in the Pacific Northwest } \\
\text { U.S. } \\
\text { Economic } \\
\text { Social } \\
>\text { Political } \\
>\text { Environmental } \\
\text { Technical }\end{array}$ & $\begin{array}{ll}> & \text { Senior Utility Analyst } \\
> & \text { Policy Analyst } \\
> & \text { Senior Analyst } \\
> & \text { President } \\
> & \text { Oregon Representative } \\
> & \text { Senior Manager of Planning } \\
> & \text { Director of Planning \& } \\
> & \text { Evaluation } \\
> & \text { Evaluation Manager } \\
> & \text { Analyst } \\
> & \text { Project Manager } \\
> & \text { Energy and Environment } \\
& \text { Directorate } \\
> & \text { Revenue Analyst } \\
> & \text { Power Planning Manager } \\
> & \text { NEPA and Policy Planning } \\
& \text { Supervisor } \\
> & \text { Customer Service Engineering } \\
> & \text { Smart Grid Program Manager }\end{array}$ & 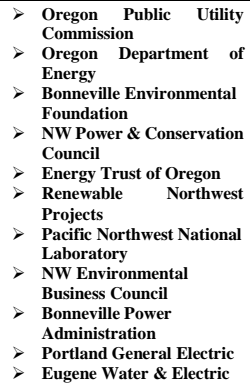 & $\begin{array}{l}\text { Six panels: One panel } \\
\text { assesses the relative } \\
\text { importance of } \\
\text { perspective with } \\
\text { respect to mission. Five } \\
\text { panels are for } \\
\text { assessing each of the } \\
\text { five perspectives with } \\
\text { respect to policy } \\
\text { target. Twenty-Five } \\
\text { (25) subject matter } \\
\text { experts are selected. } \\
\text { The number of experts } \\
\text { on panels ranges from } \\
6 \text { - 16. Some experts } \\
\text { are part of more than } \\
\text { one panel. }\end{array}$ & $\begin{array}{ll}> & \text { Policy planning } \\
> & \text { Policy evaluation } \\
& \text { Renewable energy } \\
& \text { projects } \\
> & \text { Power generation } \\
> & \text { Environmentalists } \\
> & \text { Socio-economic studies }\end{array}$ & 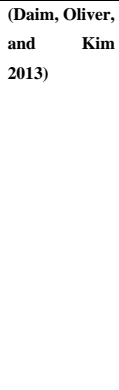 \\
\hline
\end{tabular}




\section{APPENDIX E: List of Experts from SNA}

\begin{tabular}{|c|c|c|c|c|c|c|}
\hline \multicolumn{7}{|c|}{ Expert Identification by SNA } \\
\hline Name & $\begin{array}{c}\text { Publicatio } \\
n\end{array}$ & Degree & Betweenness & Affiliation & Position & email \\
\hline KRARTI,M & 8 & 8 & 23 & $\begin{array}{l}\text { University of Colorado } \\
\text { at Boulder, CO, USA }\end{array}$ & $\begin{array}{c}\text { professor and } \\
\text { coordinator of the } \\
\text { Building Systems } \\
\text { Program }\end{array}$ & $\begin{array}{l}\text { krarti@color } \\
\text { ado.edu }\end{array}$ \\
\hline MEYERS,S & 5 & 13 & 103.857 & $\begin{array}{c}\text { Environmental and } \\
\text { Energy Technologies } \\
\text { DivisionLawrence } \\
\text { Berkeley National } \\
\text { Laboratory }\end{array}$ & $\begin{array}{l}\text { Senior Scientific } \\
\text { Engineering } \\
\text { Associate }\end{array}$ & $\begin{array}{l}\text { SPMeyers@1 } \\
\text { bl.gov }\end{array}$ \\
\hline FENG,W & 4 & 14 & 243 & $\begin{array}{l}\text { Lawrence Berkeley } \\
\text { National Laboratory }\end{array}$ & $\begin{array}{c}\text { Principal Scientific } \\
\text { Engineering } \\
\text { Associate }\end{array}$ & $\begin{array}{l}\text { WeiFeng@1b } \\
\text { 1.gov }\end{array}$ \\
\hline MCNEIL,M & 4 & 13 & 200.375 & $\begin{array}{c}\text { Environmental Energy } \\
\text { Technologies Division, } \\
\text { Lawrence Berkeley } \\
\text { National Laboratory }\end{array}$ & $\begin{array}{l}\text { Energy/Environmen } \\
\text { tal Policy Research } \\
\text { Scientist/Engineer }\end{array}$ & $\begin{array}{l}\text { MAMcNeil } \\
\text { @1bl.gov }\end{array}$ \\
\hline LEKOV,A & 4 & 10 & 109.125 & $\begin{array}{c}\text { Energy Technologies } \\
\text { Area, Lawrence } \\
\text { Berkeley National } \\
\text { Laboratory }\end{array}$ & $\begin{array}{l}\text { Energy/Environmen } \\
\text { tal Policy Research } \\
\text { Scientist/Engineer }\end{array}$ & $\begin{array}{l}\text { ABLekov@1 } \\
\text { bl.gov }\end{array}$ \\
\hline TAYLOR,JE & 4 & 9 & 33 & $\begin{array}{l}\text { Charles E. Via, Jr. } \\
\text { Department of Civil } \\
\text { and Environmental } \\
\text { Engineering, Virginia } \\
\text { Tech } \\
\end{array}$ & $\begin{array}{l}\text { associate professor } \\
\text { of civil and } \\
\text { environmental } \\
\text { engineering }\end{array}$ & jet@vt.edu \\
\hline SCOTT,MJ & 3 & 14 & 91.5 & $\begin{array}{l}\text { Pacific Northwest } \\
\text { National Laboratory }\end{array}$ & $\begin{array}{l}\text { Senior Staff } \\
\text { Economist }\end{array}$ & $\begin{array}{l}\text { michael.scott } \\
@ \text { pnl.gov }\end{array}$ \\
\hline ZHOU,N & 3 & 11 & 355.393 & $\begin{array}{l}\text { Lawrence Berkeley } \\
\text { National Laboratory, }\end{array}$ & $\begin{array}{c}\text { Energy/Environmen } \\
\text { tal Policy Staff } \\
\text { Scientist/Engineer } \\
\end{array}$ & $\begin{array}{l}\text { NZhou@ @lbl. } \\
\text { gov }\end{array}$ \\
\hline YANG,Z & 3 & 11 & 18 & Stanford University & $\begin{array}{l}\text { Staff Researcher at } \\
\text { Stanford University }\end{array}$ & $\begin{array}{c}\text { zhengyan@ } \\
\text { usc.edu }\end{array}$ \\
\hline CHOI,JK & 3 & 9 & 57 & $\begin{array}{c}\text { Department of } \\
\text { Mechanical } \\
\text { Engineering, } \\
\text { Renewable and Clean } \\
\text { Energy Program, } \\
\text { University of Dayton } \\
\end{array}$ & $\begin{array}{l}\text { Assistant Professor; } \\
\text { Assistant Director, } \\
\text { Industrial } \\
\text { Assessment Center } \\
\text { (UD-IAC) }\end{array}$ & $\begin{array}{l}\text { jchoi1@uday } \\
\text { ton.edu }\end{array}$ \\
\hline BRECHA,RJ & 3 & 8 & 47 & $\begin{array}{l}\text { Physics Dept., } \\
\text { University of Dayton, } \\
\text { Dayton, } \mathrm{OH}\end{array}$ & Full-Time Faculty & $\begin{array}{c}\text { rjbrecha@g } \\
\text { mail.com,rbr } \\
\text { echa1@uday } \\
\text { ton.edu } \\
\end{array}$ \\
\hline SCHLEICH,J & 3 & 5 & 5 & $\begin{array}{c}\text { Virginia Polytechnic } \\
\text { Institute and State } \\
\text { University, }\end{array}$ & Professor & $\begin{array}{l}\text { joachim.schl } \\
\text { eich@isi }\end{array}$ \\
\hline ALBERINI,A & 3 & 4 & 5 & $\begin{array}{c}\text { University of } \\
\text { Maryland - } \\
\text { Department of } \\
\text { Agricultural \& } \\
\text { Resource Economics; } \\
\text { Fondazione Eni Enrico } \\
\text { Mattei (FEEM) } \\
\end{array}$ & $\begin{array}{c}\text { Professor } \\
\text { Department of } \\
\text { Agricultural and } \\
\text { Resource } \\
\text { Economics }\end{array}$ & $\begin{array}{c}\text { anna.alberini } \\
\text { @ feem.it }\end{array}$ \\
\hline PATEL,PL & 2 & 14 & 126.111 & $\begin{array}{l}\text { Joint Global Change } \\
\text { Research Institute, } \\
\text { Pacific Northwest } \\
\text { National Laboratory, }\end{array}$ & $\begin{array}{l}\text { Integrated Human- } \\
\text { Earth SS Team } \\
\text { cientists }\end{array}$ & $\begin{array}{c}\text { pralit.patel@ } \\
\text { pnnl.gov }\end{array}$ \\
\hline
\end{tabular}




\begin{tabular}{|c|c|c|c|c|c|c|}
\hline LETSCHERT,V & 2 & 10 & 223.421 & $\begin{array}{l}\text { Energy Analysis } \\
\text { Department, } \\
\text { Environmental Energy } \\
\text { Technologies Division, } \\
\text { Lawrence Berkeley } \\
\text { National Laboratory }\end{array}$ & $\begin{array}{l}\text { Senior Scientific } \\
\text { Engineering } \\
\text { Associate }\end{array}$ & $\begin{array}{c}\text { VLetschert@ } \\
\text { lbl.gov }\end{array}$ \\
\hline EVANS,M & 2 & 9 & 36 & $\begin{array}{l}\text { Joint Global Change } \\
\text { Research Institute, } \\
\text { Pacific Northwest } \\
\text { National Laboratory }\end{array}$ & $\begin{array}{c}\text { Integrat Analys \& } \\
\text { Dec Sci Team } \\
\text { Scientist }\end{array}$ & $\begin{array}{c}\text { m.evans@pn } \\
\text { nl.gov }\end{array}$ \\
\hline YU,S & 2 & 9 & 36 & $\begin{array}{l}\text { Joint Global Change } \\
\text { Research Institute, } \\
\text { Pacific Northwest } \\
\text { National Laboratory, }\end{array}$ & $\begin{array}{l}\text { Integrat Analys \& } \\
\text { Dec Sci Team } \\
\text { Scientist }\end{array}$ & $\begin{array}{l}\text { Sha.Yu@pnn } \\
\text { l.gov }\end{array}$ \\
\hline MCMAHON,J & 2 & 8 & 24.071 & $\begin{array}{l}\text { Environmental Energy } \\
\text { Technologies Division, } \\
\text { Lawrence Berkeley } \\
\text { National Laboratory }\end{array}$ & Guest Management & $\begin{array}{l}\text { JEMcMahon } \\
\text { @lbl.gov }\end{array}$ \\
\hline LIU,X & 2 & 7 & 140.31 & $\begin{array}{c}\text { College of Information } \\
\text { Sciences and } \\
\text { Technology, The } \\
\text { Pennsylvania State } \\
\text { University } \\
\end{array}$ & Ph. D Student & $\begin{array}{l}\text { xv15190.@ist } \\
\text {.psu.edu }\end{array}$ \\
\hline ZHIVOV,A & 2 & 7 & 12 & $\begin{array}{l}\text { U.S. Army ERDC- } \\
\text { CERL Champaign, } \\
\text { Illinois, USA }\end{array}$ & Member ASHRAE & $\begin{array}{l}\text { alexander.m. } \\
\text { zhivov@usa } \\
\text { ce.army.mil }\end{array}$ \\
\hline ASADI,S & 2 & 6 & 12 & $\begin{array}{c}\text { Pennsylvania State } \\
\text { University }\end{array}$ & $\underline{\text { Assistant Professor }}$ & $\begin{array}{c}\text { sxa51@psu.e } \\
\text { du }\end{array}$ \\
\hline
\end{tabular}


APPENDIX F: HDM Generated by Software

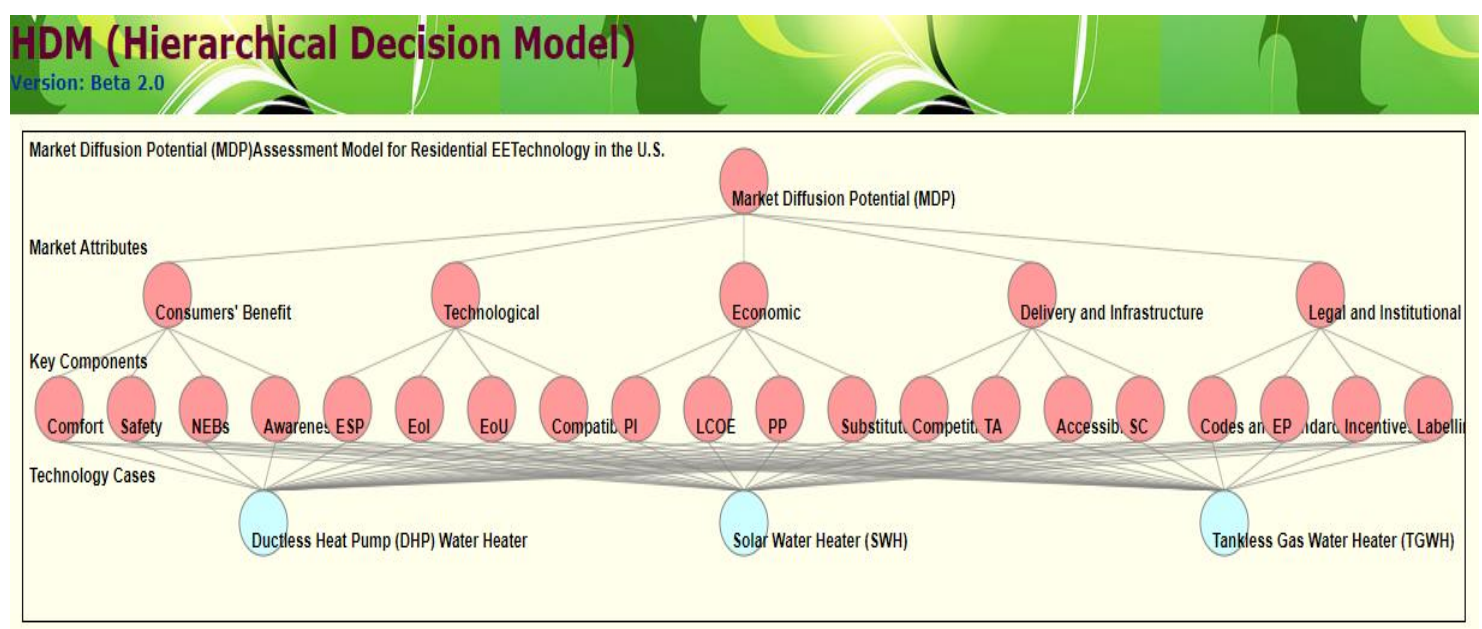

\begin{tabular}{|l|l|}
\hline NEBs (Non-energy Benefits) & PI (Profitability Index) \\
\hline ESP (Energy Saving Potential) & LCOE (Levelized Cost of Electricity) \\
\hline EoI (Ease of Installation) & TA (Trade Allies) \\
\hline EoU (Ease of Use) & SC (Supply Chain) \\
\hline PP (Payback Period) & EP( Energy Price) \\
\hline
\end{tabular}


APPENDIX G: Technical Energy Saving Potential

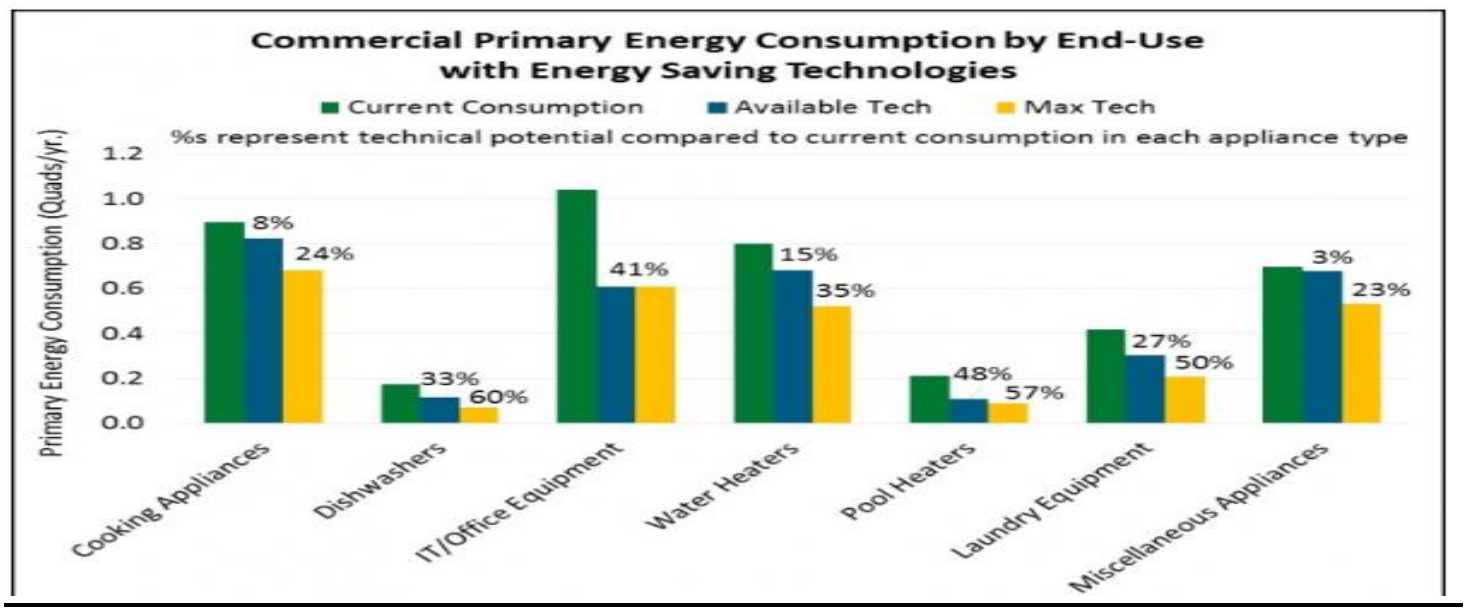


APPENDIX H: ProfitabilityIndex (PI) of EE projects

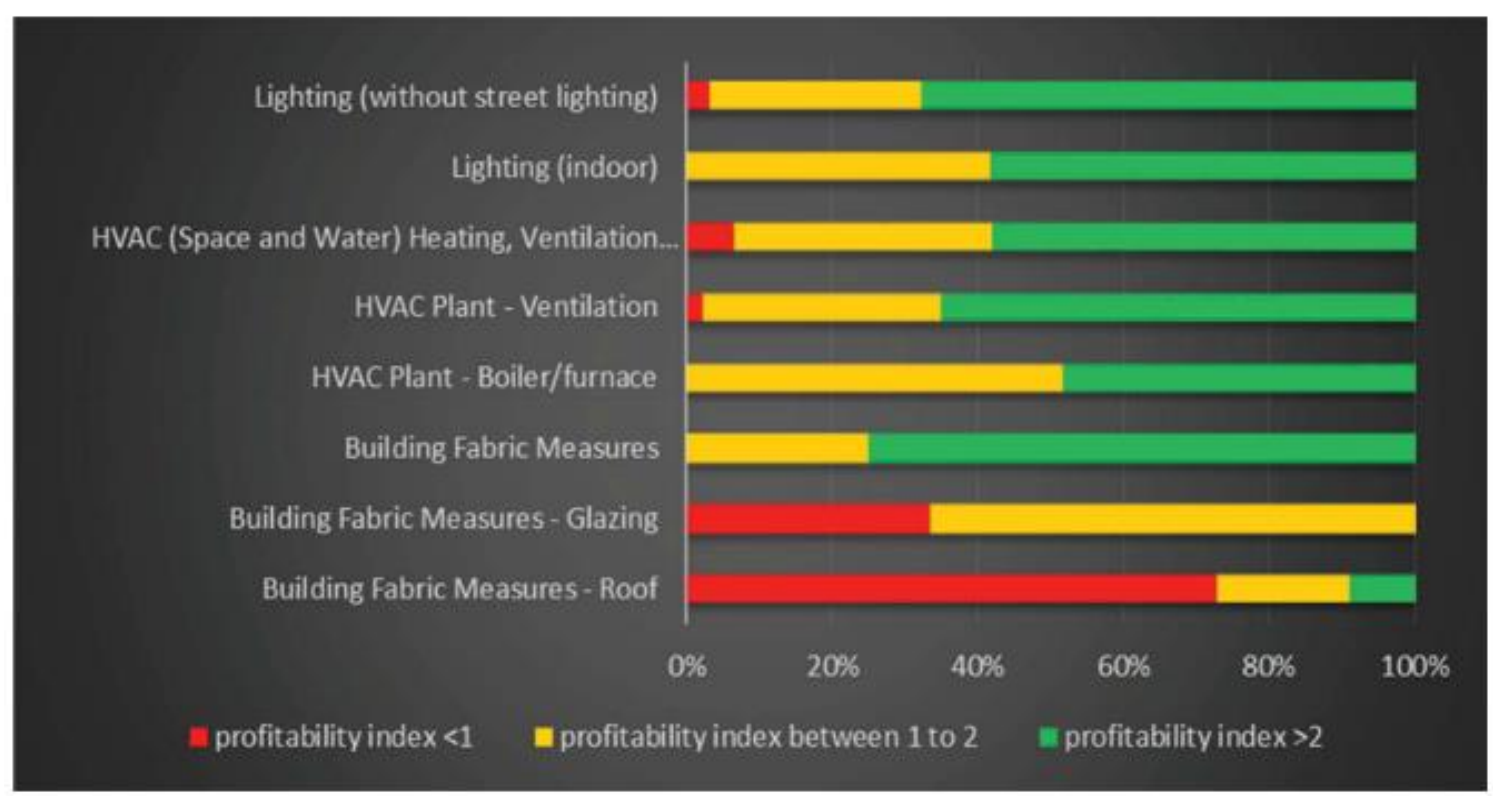


APPENDIX I: Levelized Cost of Electricity Resources

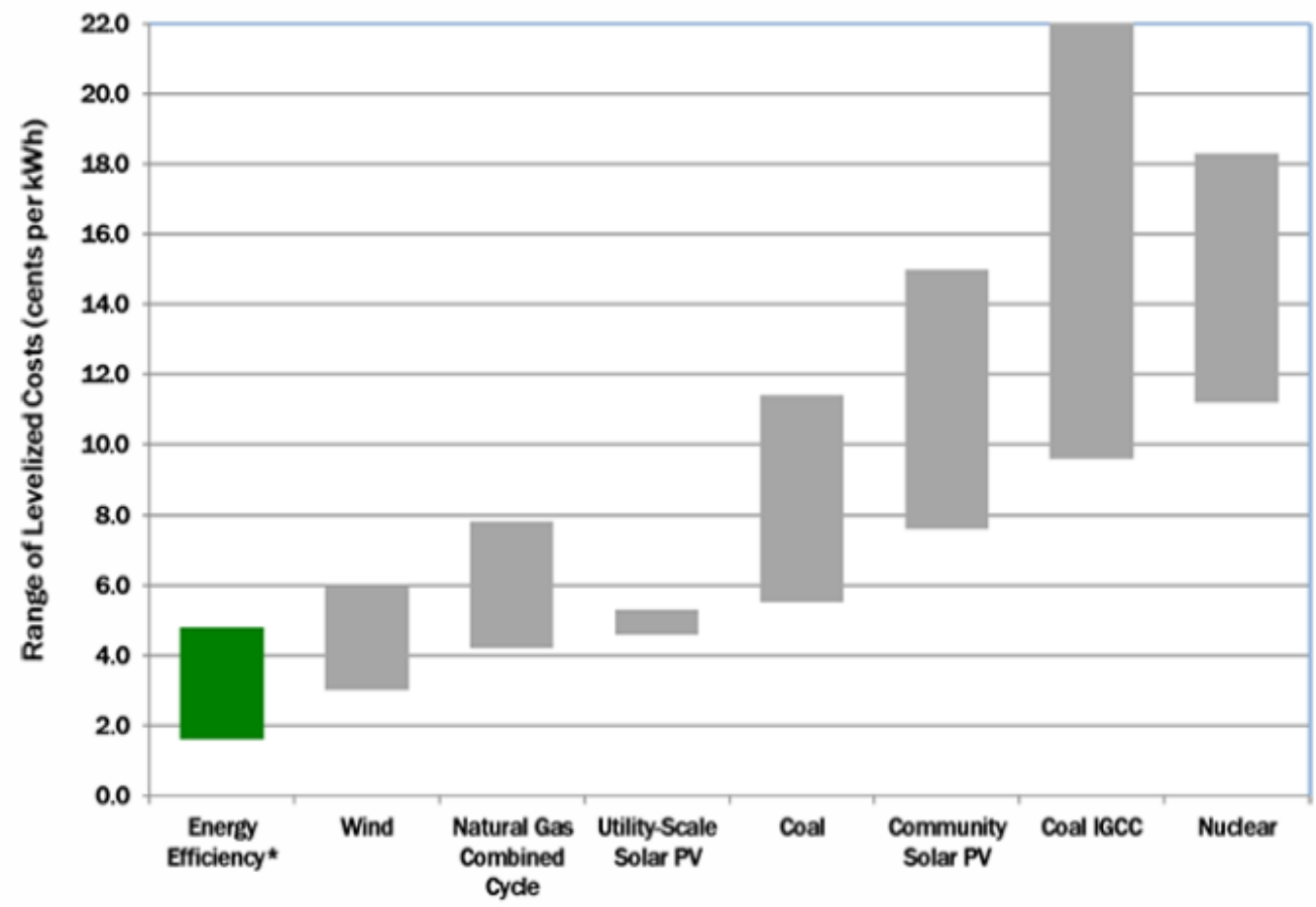

* Notes: Energy efficiency program portfolio data from Molina 2014; All other data from Lazard 2017. High-end range of coal includes $90 \%$ carbon capture and compression. 


\section{APPENDIX J: Payback Period of EE Technologies}

\begin{tabular}{|l|c|}
\hline \multicolumn{1}{|c|}{ Technology } & Payback Period \\
\hline Condensing gas tankless water heaters & 0.9 years \\
\hline Occupant responsive lighting & 8.5 years \\
\hline Heat Pump Water Heaters & 4.1 years \\
\hline LED Downlight Luminaries & 3.7 years \\
\hline Building energy management and information systems & 3.7 years \\
\hline Fixed window attachments & 37 years \\
\hline Advanced rooftop unit controls & 12 years \\
\hline Plug load control devices & 8.9 years \\
\hline Comprehensive attic update & 6.4 years \\
\hline Dynamic solar control systems & 55 years \\
\hline
\end{tabular}

Best Available Technologies in the U.S. Buildings Sector May 2018. Pacific Northwest National Laboratory U.S.

Department of Energy 